\title{
NBSIR 76-1070
}

\section{Evaluation of Backflow Prevention Devices: A State-of-the-Art Report}

Grover C. Sherlin

Robert W. Beausoliel

Center for Building Technology Institute for Applied Technology National Bureau of Standards

Washington, D. C. 20234

June 1976

Final Report

Prepared for

Water Supply Division Environmental Protection Agency

Washington, D. C. 20460 

NBSIR 76-1070

EVALUATION OF BACKFLOW

PREVENTION DEVICES:

A STATE-OF-THE-ART REPORT

Grover C. Sherlin

Robert W. Beausoliel

Center for Building Technology Institute for Applied Technology National Bureau of Standards

Washington, D. C. 20234

June 1976

Final Report

Prepared for

Water Supply Division

Environmental Protection Agency

Washington, D. C. 20460

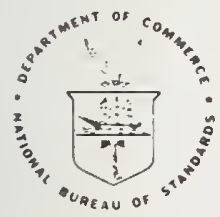

U.S. DEPARTMENT OF COMMERCE, Elliot L. Richardson, Secretary

Edward O. Vetter, Under Secretary

Dr. Betsy Ancker-Johnson, Assistant Secretary for Science and Technology

NATIONAL BUREAU OF STANDARDS, Ernest Ambler, Acting Director 



\section{CONTENTS}

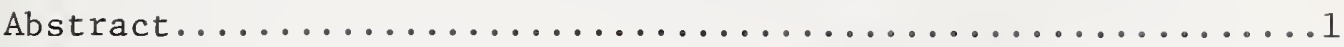

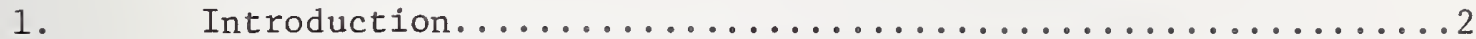

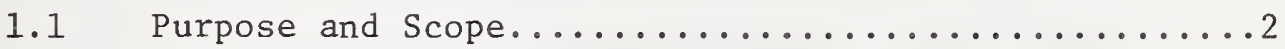

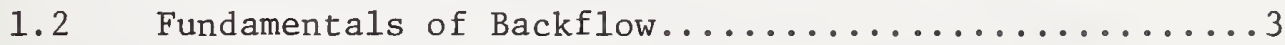

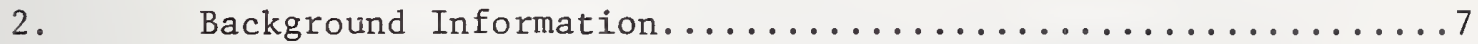

2.1 Historical Background and Recorded Incidents of Backflow through Backflow Connection and

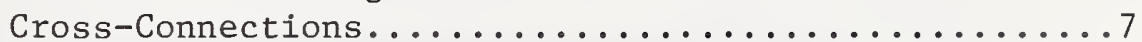

2.2 Navy Study of FCCCR Certification Procedures........9

2.3 A.S.S.E. Concern for Backflow Problems............10

2.4 Backflow Prevention Devices and Piping

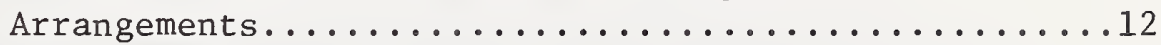

3. Elements in the Evaluation of Backflow Prevention Devices...18

3.1 The Product Standards.......................

3.2 The Plumbing Codes........................ 19

3.3 The Manufacturers of Backflow Prevention Devices.....23

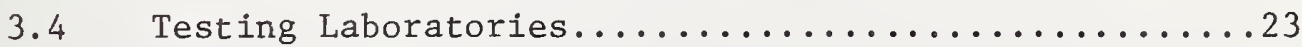

3.5 A Conceptual Model Cross-Connection Contro1

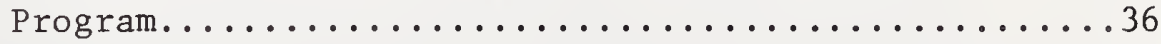

4. Evaluation of Devices........................... 39

4.1 Design Considerations that Affect Reliability.......39

4.2 Methods that Test Appropriate Attributes..........45

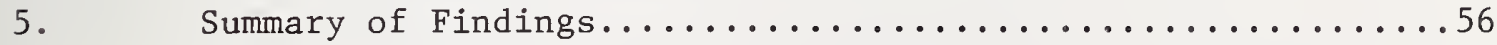

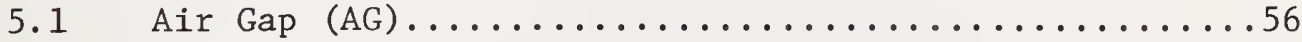

5.2 The Reduced Pressure Backflow Device (RPBD)........56

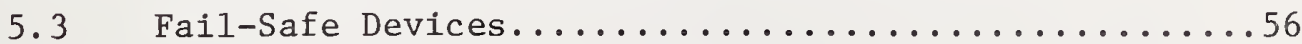

5.4 Realistic and Useable Test Methods................ 57 
6. Conclusion and Recommendations........................

$6.1 \quad$ Conclusions..................................

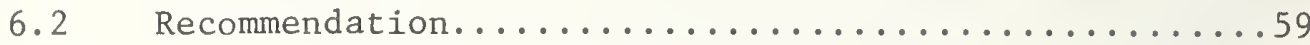

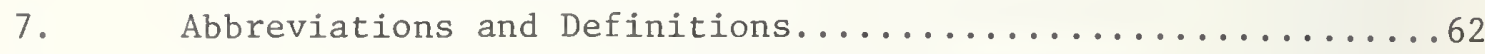

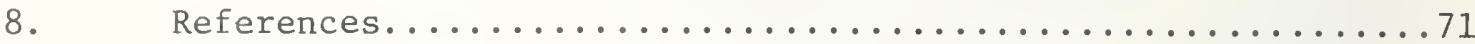

9. Acknowledgement.............................

10. Appendix.................................

10.1 Vacuum Dissipation Calculations................ 76

10.2 Navy Survey Form.........................

10.3 Procedures for a National Voluntary Laboratory

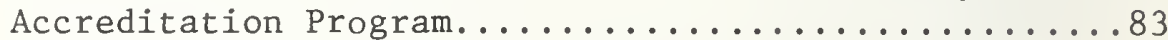

10.4 Hose Connection Vacuum Breaker Test..............100

10.5 Reduced-Pressure Backflow Prevention Device Test.....104

10.6 Analysis of Test Methods in A.S.S.E. Standards

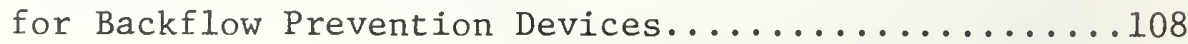

10.7 Units of Measure and S.I. Conversion Factors........137 


\section{EVALUATION OF BACKFLOW PREVENTION DEVICES:}

\section{A STATE-OF-THE-ART REPORT}

by

Grover C. Sherlin and Robert W. Beausoliel

\section{ABSTRACT}

A significant potential for potable water supply contamination exists within all water supply systems due to backflow and crossconnections. Surveillance of the water supplies to protect from such hazards requires continuing vigilance by the administrators of crossconnection control programs, and continuing upgrading of technical criteria and methods of evaluation.

The Environmental Protection Agency assists local (usually municipal) authorities, through the State water supply agency, in establishing and operating cross-connection control programs. Essential to these programs are (1) information on the suitability of commercially available devices for use in potentially high-hazard locations, and (2) practical and effective standardized test methods for evaluation of devices. The National Bureau of Standards investigation reported herein addresses the two needs identified.

This study includes a systematic review of the literature, together with consultations and visits with water purveyors, plumbing officials, laboratory officials and researchers in this field. Emphasis has been placed on those devices, test methods, and laboratory practices considered most essential to an effective assessment of the state-of-the-art. Also, test development needs were identified in a few areas of greatest concern.

Key Words: Backflow; backflow preventers; back pressure; backsiphonage; cross-connections; health hazard; potable water; vacuum breaker; water supply. 


\subsection{Purpose and Scope}

As approved Dec. 16, 1974, Public Law 93-523 (called the "Safe Drinking Water Act") marks the first time a national commitment has been made to safeguard public drinking water supplies. It provides that the Federal Government - U.S. Environmental Protection Agency (EPA) - set national standards, and that the states enforce those standards and otherwise supervise public water supply systems and sources of drinking water. The Act gives EPA responsibility for setting minimum national drinking water standards for all public water systems throughout the United States having at least 15 service connections or regularly serving at least 25 people. EPA is also authorized to help States

15 improve their drinking water programs by providing technical assistance, employee training and financial support.

Although the Safe Drinking Water Act is primarily concerned with the contaminants 1 that must be processed out of the raw water by those

20 persons who own and operate a public water supply system, EPA has long been concerned with contaminants that may enter a potable water system by backflow from a consumer's pipeline through a cross-connection.

In this particular concern, EPA assists local (usually municipal) 25 authorities, through the State water supply agency, in establishing and operating cross-connection control programs. Essential to these programs are (1) up-to-date information on the suitability of various types of commercially available protective devices for use in potentially highhazard locations, and (2) practical and effective standardized test

30 methods for use in evaluating such devices. The collective experience of EPA, other federal agencies, and state agencies has shown that a significant potential for potable water supply contamination exists within al1 water supply systems, and that minimization of such hazards requires continuing vigilance by the administrators of cross-connection control

35 programs, and continuing upgrading of the state-of-the-art in matters of technical criteria and methods of evaluation. EPA has requested the National Bureau of Standards (NBS) to provide assistance in meeting the needs identified above.

NBS has undertaken to perform the tasks of (1) producing a state40 of-the-art survey and report, drawing upon available NBS laboratory findings to evaluate existing or modified test procedures, and (2) of developing guide criteria for the laboratory evaluation of backflow protection devices and examining protocols required for evaluation purposes.

This report assesses the state-of-the-art for the evaluation of devices used to protect potable water supplies against backflow contamination. Backflow contamination of a water supply can arise in

I/ A number of terms and abbreviations have been defined in section 7 . 
either of two plumbing system configurations. In the first configuration, a so-called "direct cross-connection" exists where the potable water supply piping is mechanically joined to piping or pressurized devices which may contain potential contaminants. Examples of direct cross-connections are inter-connections between dual-purpose water distributing systems (potable system and a protection system, laboratory water system, etc); completely submerged inlets from water supply lines to closed plumbing fixtures, tanks or vats; and continuous water connections between supply and drain systems, pump priming lines, etc.

10 In the second configuration, an "indirect cross-connection" or a "potential cross-connection" exists. This is one in which the interconnection is not continuous and the completion of the cross-connection depends upon certain possible occurrences. Examples: water closets with

15 direct flush valve supply, bathtubs or lavatories with faucet openings that may become submerged, etc. $[1,2], \underline{2 /}$

In either case, i.e., direct or indirect cross-connection, backflow results from an adverse pressure differential across the cross-connection.

20 Thus, the necessary conditions for potable water contamination by backflow are the simultaneous occurrence of events which produce (a) a crossconnection, (b) an adverse pressure differential across the connection, and (c) the presence of a contaminant on the normal downstream side of the cross-connection. If prevention of conditions (b) and (c) above

25 could be assured, special backflow prevention devices would not be necessary. However, many of the types of events which give rise to either the presence of a contaminant or an adverse pressure differential or both appear unexpectedly beyond human control; therefore, there are many design situations where adequate backflow protection devices must

30 be used.

This study has involved collection of information from a number of sources. These include a systematic review of the literature, together with consultations and visits with water purveyors, plumbing officials,

35 laboratory officials and researchers in this field. To the extent that the scope of these investigations was restricted by the resources available for this study, emphasis has been placed on those devices, test methods, and laboratory practices considered most essential to an effective assessment of the state-of-the-art. Also, test development

40 needs were identified in a few areas of greatest concern.

\subsection{Fundamentals of Backflow}

Backflow can result when either a direct or an indirect cross45 connection to a potable water supply experiences an adverse pressure differential. In other words, backflow can occur when the pressure in the potable water system is, or momentarily becomes, less than that in

2/ Numbers in brackets refer to sequential listing of references in section 8 . 
the system to which it is connected. For example, consider the hypothetical and typical illustration of a backflow situation depicted on figure 1. Here an upfeed water supply riser serves a number of fixtures in a tall building. Assuming that all fixtures are closed and the 5 line supplying water to the building is broken in the street, the column of water in the riser will fall to a level of approximately 33 feet to balance the atmospheric pressure on the broken end of the pipe thus creating a vacuum in the upper levels of the riser. Then if, as shown on this figure, the water supply faucet of fixture "A" (with hose sub10 merged in laboratory sink) were opened, the contents of the sink would, under the atmospheric pressure, be "sucked" or back-siphoned into the riser. This volume of non-potable liquid would be distributed to other water outlets in the building after the water service was restored; consequently, a health hazard for occupants of the building served by

15 that riser would result. It is conceivable that this slug of non-potable liquid could travel through the riser and the service piping to the street main where it would subsequently be transferred to the service piping of other premises and thereby create a widespread health hazard.

20 Dawson and Kalinske have demonstrated that a column of water in a closed riser as shown in figure 1 would fall to its final position shown. in about seven seconds [3]. The falling column of water would first accelerate, then decelerate to zero velocity at the 33-foot level shown. Therefore, it is seen that the potential back-siphonage hazard can occur

25 quite rapidly. It is interesting to note that a subatmospheric condition would exist temporarily inside the riser as the water column fell even if the riser were completely open at the top. This condition would occur because the atmospheric air flowing into the riser would experience a loss of pressure due to the entrance loss (frictional loss) and also a loss of pressure in the direction of flow due to pipe friction and

30 velocity head. Therefore, even if means were developed to completely vent a riser, some degree of back-siphonage potential would exist during the transient period when the water column was falling. Of course, if the riser were vented, all of the water in the riser would flow into the 35 excavation shown and no potential back-siphonage hazard would exist after flow ceased.

If, as indicated by figure 1 , a faucet " $B$ " were open at the instant the water main were broken, air would immediately begin entering the 40 riser as the water fell from the riser. This, of course, would greatly reduce the peak magnitude of the vacuum in the riser as well as its duration. Assuming that the volume of vacuum was initially about $71 / 3$ gallons (internal volume of the pipe), the method of Dawson and Kalinske [3] indicated that the time to dissipate the vacuum from 29 inches of 45 mercury to atmospheric pressure would be 4.6 seconds through a $3 / 8$-inch diameter opening at the faucet. See Appendix Section 10.1 for details concerning the sample calculation and applicable equation.

Referring again to figure 1 , we may assume that faucets " $A$ " and "B" were closed and the interconnection "C", a check valve between the heating system and the water system, was leaking.

Then chemically treated heating 


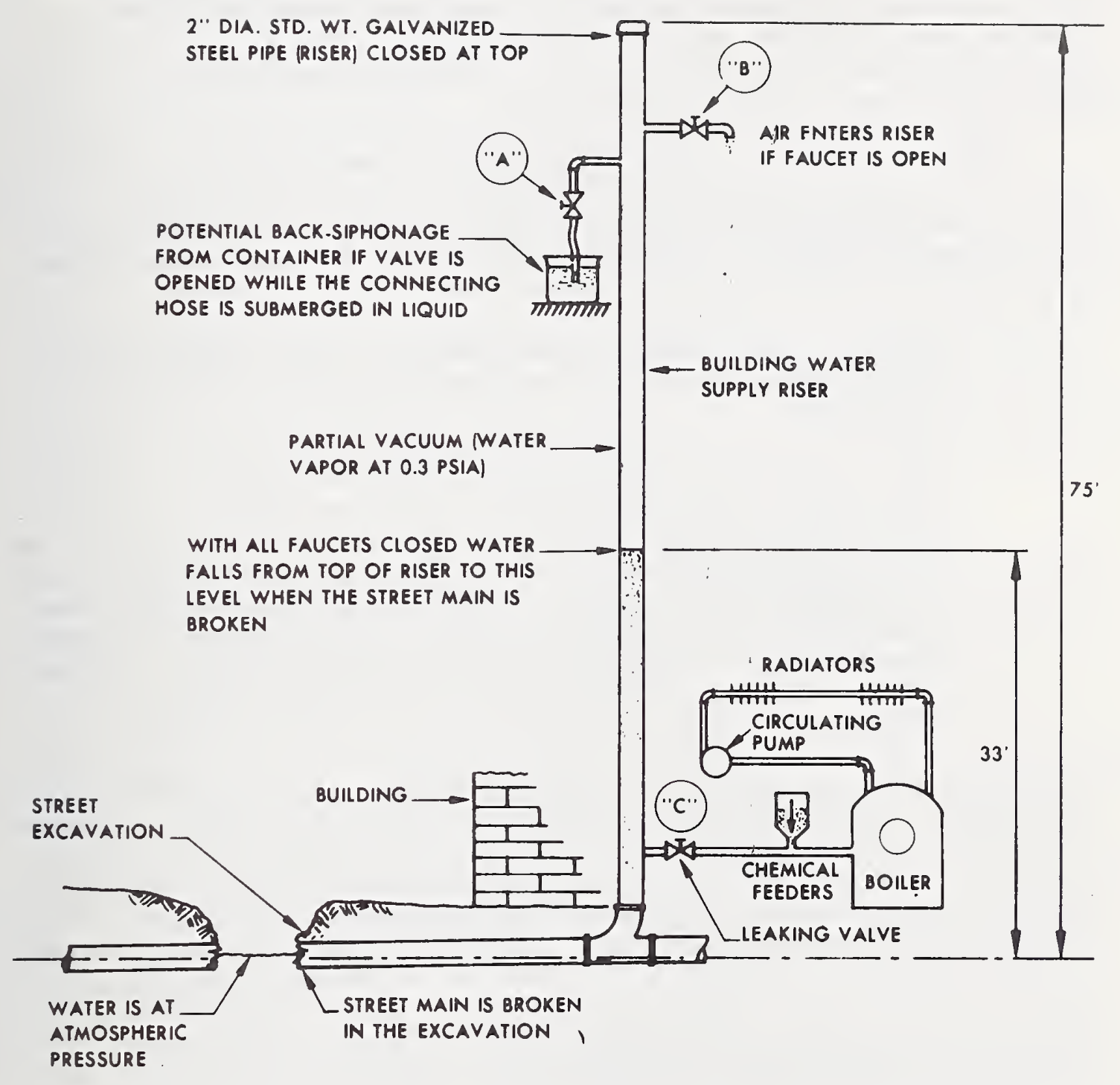

Figure 1. Illustrating Two Examples of Backflow: (A) by Backsiphonage and (C) by Back Pressure 
system water would backflow into the riser from the back pressure caused by the circulating pump and/or boiler. When the break in the street main was subsequently repaired and service restored, the slug of chemically treated water could be distributed through all potable water outlets within the riser and perhaps to other premises connected to the street main.

There are, of course, many other more common situations which can give rise to adverse pressure differentials of the types shown on figure

10 1. For example, back-siphonage in cross-connections can occur by way of a vacuum generated in the potable water piping of any building as follows :

a. Draining of hot water heaters and/or a water supply system without venting air into the system can create vacuums within the system.

b. "Imperfections of workmanship at tee connections or couplings may produce restrictions which would cause high water velocities with consequent reduction in pressure. The pressure may be reduced sufficiently so as to produce a negative pressure at the side outlet of the tee and consequent siphonage from the submerged inlet fixture to which the side of the tee is connected." [3] Excessive water demand can result in equally high velocities in the main line and excessive reduction in pressure in branch piping with similar back-siphonage.

This section has indicated that the possibility of backflow depends on a number of factors usually unique to a particular cross-connection situation. Unfortunately, very little data are known to exist on the frequency-of-occurrence of adverse pressure differentials, contaminant presence, or both, with or without backflow prevention devices installed. Therefore, no means exist presently to predict backflow hazard potential or hazard reduction through use of backflow prevention devices. If such data were available, analyses of this type would be straightforward and quite useful not only in identifying high risk cross-connection situations, but also in predicting the relative effectiveness of alternative methods of backflow protection. 


\section{BACKGROUND INFORMATION}

2.1 Historical Background and Recorded Incidents of Backflow Through Backflow Connections and Cross-Connections

The previous section has given an overview of the mechanisms of the cross-connection problem. This section presents some actual backflow incidents chronologically and gives indication of what is being done presently to prevent such incidents.

A highly publicized and investigated incident involving backflow resulted in an outbreak of amoebic dysentery in a hotel during the World's Fair in Chicago in 1933. This epidemic brought world-wide attention to Chicago and stands as a landmark in the development of cross-connection 15 control efforts. The most important outcome from the Chicago incident was the recommendation that air-gap separation be used for preventing contamination of the potable water supply [4]. Vacuum breakers were not available during the Chicago epidemic era, but by 1945 vacuum breakers had been developed and approved for use [4].

"Craun and McCabe [5] conducted a review of the causes of water borne-disease outbreaks occurring in the U.S. during 1946-70. During this 25 year period, there were 358 recognized outbreaks of disease or chemical poisoning attributed to contaminated drinking water. These 25 outbreaks affected 72,358 individuals and resulted in 36 deaths....

The majority of the outbreaks (71 percent) resulted from contamination of private, individual water systems; but most of the illnesses (83 percent) occurrred as the result of outbreaks in community water 30 systems. The major cause of outbreaks in community water systems was contamination of the distribution system, primarily through crossconnections and back siphonage; however, few illnesses resulted from this source because the contamination was confined to rather small areas." [6] Table 1 lists some of the more sensational, recently recorded, 35 incidents of backflow.

The U.S. Environmental Protection Agency publication, "CrossConnection Control Manual," cites a number of interesting incidents including the following concerning the sill faucet or hose bibb [7].

"A California laborer had been using an aspirator, attached to a garden hose, to spray a driveway with weed killer containing arsenic. Sometime while he was at the job, the water pressure reversed. Taking no notice of the incident, the man disconnected the hose and, feeling thirsty, drank from the bibb of the hose connection at the house. Arsenic in the waterline killed him." 


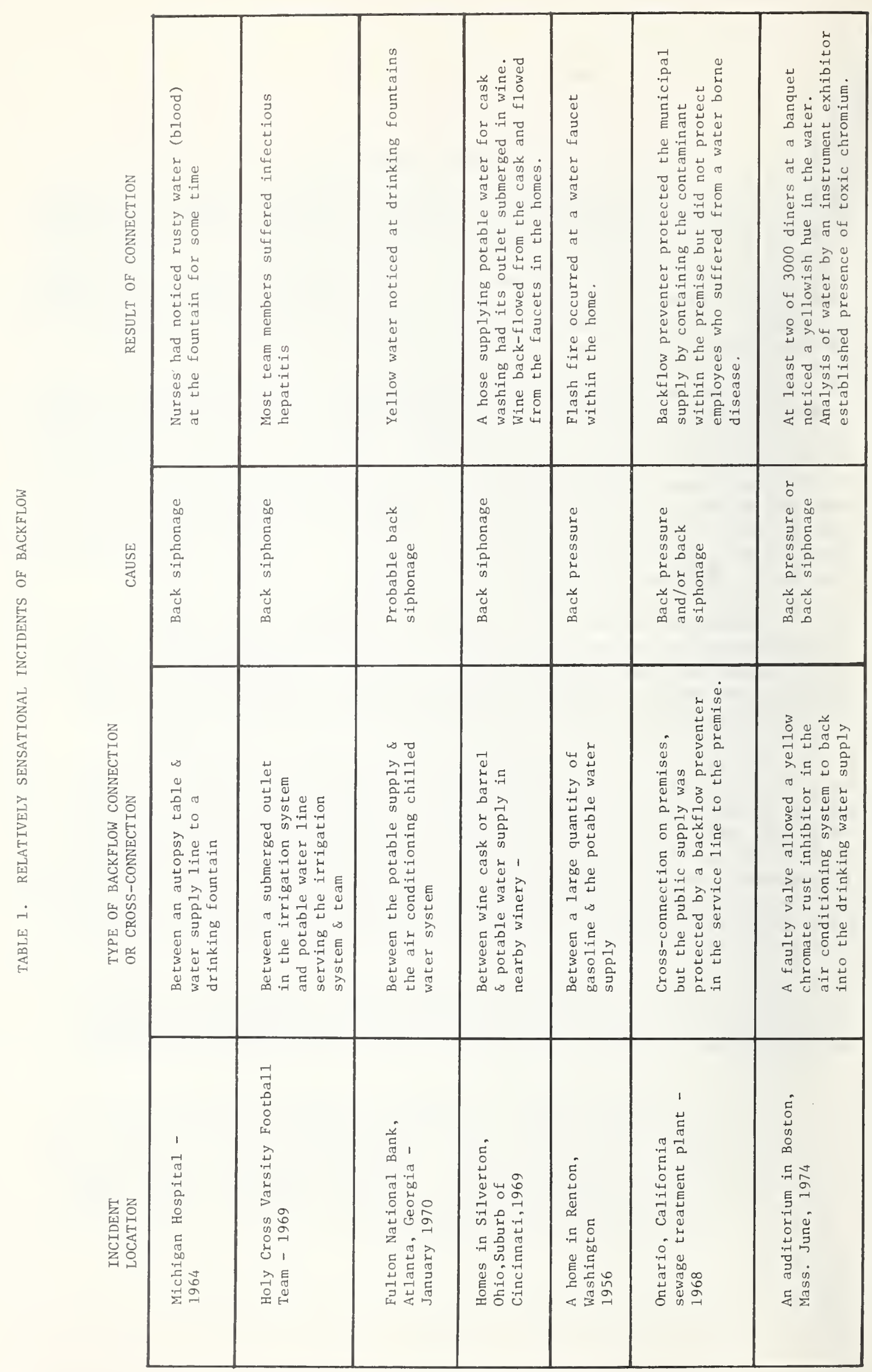


Hutchinson, speaking to the American Water Works Association [8] and earlier to the American Society of Sanitary Engineering [9], stated that there is no organized cross-connection incident reporting system. It is conceivable that if some mechanism for reporting such incidents

5 existed, it would be found that the number of backflow and crossconnection incidents is actually many times larger than current knowledge indicates. If practical, a reporting system would be invaluable in setting priorities for device usage and for pinpointing and correcting causes. Such a system might include records of low water pressure and

10 vacuum in the water piping to hazardous premises such as sewage treatment plants and industrial plants. Recurring low pressure would indicate system deficiencies requiring correction.

During a cross-connection survey in Calhoun County, Michigan, [10] 15 pressure-vacuum recording gages were installed in some 45 different locations. A total of ninety (90) charts were obtained during the survey and sixteen of these showed low or negative pressure. The existence of low pressure in the potable water supply indicates potential for backflow.

During world II,according to Navy Technical Note N-1169 [11] there were numerous backflow occurrences caused by docked Naval and and merchant vessels accidentally pumping harbor water through on-shore water lines. Sanitary protection of the water supply was frequently neglected due to the urgency of wartime schedules. As a result,a group of individuals concerned with backflow prevention proposed in 1944 to establish a foundation $3 /$ at the University of Southern California to study the problem. On $1 \overline{4}$ September 1944, the Board of Trustees of the 30 University established the FCCCR as a formal arm of the University.

The FCCCR adopted definitions and specifications for backflow prevention devices as early as 1948 when Paper Number 5 [12] was published. In 1959, an expanded set of definitions and specifications was 35 published as USCEC Report 48-101. [13] Shortly thereafter, a joint committee representing numerous Southern California water utilities expanded USCEC Report 48-101 into what became known as the Manual for Cross-Connection Control - Recommended Practice. [14] This manual, which contains additional information on the application of backflow pre40 venters, was first published in 1960. The 2nd and 3rd Editions were published in 1965 and 1966, respectively, with minor revisions. During 1967 and 1968, the manual (particularly section 10 covering specifications) was thoroughly reviewed by a committee representing water utilities, local health authorities, manufacturers, and the Foundation.

3/ At the time of the Navy report the name was Foundation for CrossConnection Control Research (FCCCR). 
The major changes which resulted were incorporated in the 4 th Edition of the Manual, [15] published in 1969.

Navy Technical Note $\mathrm{N}-1169$ [1]] resulted from the need to understand better the impact of a change in certification procedure by FCCCR. The Naval Civil Engineering Laboratory at Port Hueneme, California conducted a survey of authorities concerned with backflow prevention, including persons in city, county, state and federal governments. Responses from 62 localities are summarized in Table 2. The column headings in the

10 table are of necessity cryptic, but by following the arrangement of the survey questions (reproduced here as Appendix 10.2) possible confusion of meanings is minimized. Nearly half of those responding indicated that the reduced pressure principle backflow preventer was the minimum protection required for a health hazard to the potable water supply.

15 Although the Navy has relied heavily on certification procedures to assure that the very best protection would be provided at its bases and docks, it may find that periodic field testing of devices is more certain assurance of best protection.

\subsection{The A.S.S.E. Concern for Backflow Problems}

The American Society of Sanitary Engineering (A.S.S.E.) was founded in Washington D.C. in 1906, eight years prior to the advent of the first U.S.PHS standards for drinking water. Although the member-

25 ship of the society for many years was small, the yearbooks indicate that active members concerned themselves with many aspects of water supply and waste disposal with primary concern for public health.

In the NBS file is a collection of three papers prepared by

30 William C. Groeniger, [16, 17, 18] who in the early thirties was for several years Chairman of the Research Committee of A.S.S.E., and earlier an Ohio State inspector of plumbing. He and the Research Committee pioneered activities toward solution of cross-connection problems. In 1932, Major Groeniger, in the capacity of Chairman of the Research 35 Committee, served as Chairman of an A.S.S.E. conference on "Cross Connections" [19] held at NBS on February 24 and 25. The conference registration list of 54 included a broad sampling of concerned persons: physicists, engineers, plumbing contractors, plumbing component manufacturers, and public health officials. Of particular interest was the

40 presence of H. H. Matthieson, Chief Sanitary Engineer of the Los Angeles Health Department because other authors have indicated that Los Angeles was early the center of activity in testing and evaluating mechanical backflow preventers -- as early as 1934.

The first national standards for devices to prevent or to control backflow (ASA A40.4 - 1942 "Air Gaps" and ASA - A40.6 - 1943 "Backflow Preventers in Plumbing Systems" were published by the American Standards Association (ASA). A.S.S.E. did not have representatives on the A40 committee of ASA but became a sponsor with the American Society of Committee on Standardization of Plumbing Material and Equipment, in 1958. 
Table 2. Results of a Survey Made by the Naval C1vil Engineering Laboratory

and Reported in Navy Technical Note N 1169

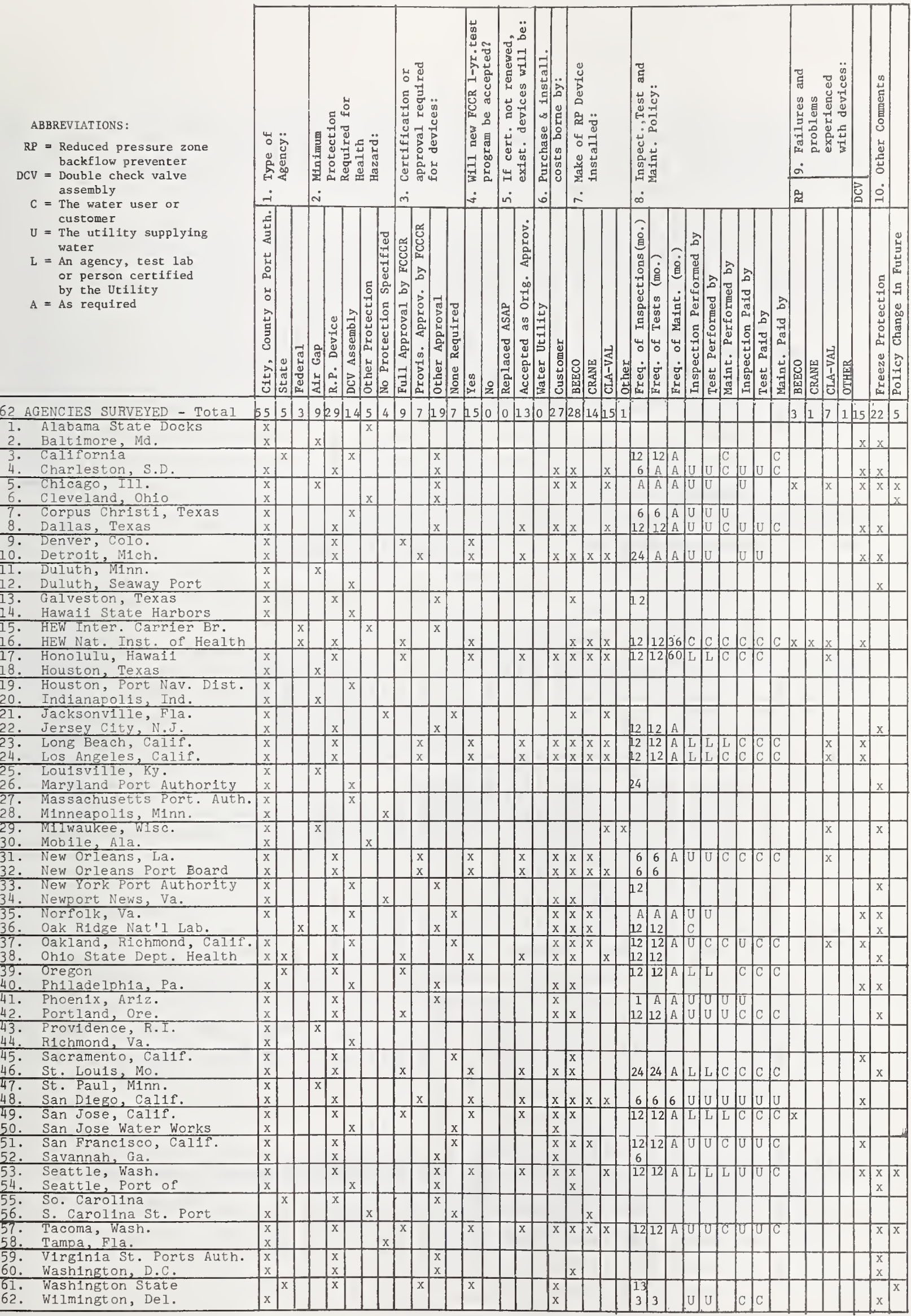


The first output of the A.S.S.E. Standards Committee on May 1966, A.S.S.E. 1001, "Pipe Applied Atmospheric Type Vacuum Breakers," received approval of the American National Standards Institute $\underline{4}$ All2 Committee to become ANSI Al12.1.1 - 1971. [20]

The A.S.S.E. 1002 covering standards and tests procedures for water closet flush tank anti-siphon ball cocks was issued in October 1964 and revised in 1968 but has not yet met the approval of ANSI.

More recently the Standards Committee has focused its attention on five additional standards for backflow preventers and has published them as A.S.S.E. 1011, 1012, 1013, 1015, and 1020 [21, 22, 23, 24, 25]. All of these are now being considered by the ANSI A112 Committee for adoption .

Backflow preventers include devices and arrangements such as the air gap, the barometric loop, double check valve assemblies, reduced pressure zone back pressure backflow preventers, and vacuum breakers. Each of these types will be described and categorized.

\subsection{Backflow Prevention Devices and Piping Arrangements}

Figure 2 shows two applications of an air gap whereby protection against back siphonage can be assured as long as there is no tampering 25 with the gap. For example it is quite possible to slip a short length of rubber tubing or rubber hose into the faucet of the lavatory, or sink without anticipating the hazards. The hose could lie in the stopped sink filled to the overflow outlet with contaminated wash water, and the faucet could be partially opened to supply water for a continuously flowing wash operation. Should a sudden vacuum occur on the water supply line contaminated wash water would back-siphon out of the sink into the potable system.

When water is needed to be under pressure for a particular ap35 plication water is delivered to a tank through an air gap as illustrated in Figure 2 and a booster pump, located between the tank and point of use, can provide the necessary pressure. However, when the booster pump fails to operate and repair or replacement is not immediately possible, maintenance men have piped across the air gap to make use of the pressure 40 in the potable supply line. Such an action could be more hazardous to human life than the act of putting a copper penny behind a blown electrical fuse. became the American Standards Association (ASA) in 1928, the United States of America Standards Institute (USASI) in 1966 and now American National Standards Institute (ANSI) since October 1969. 


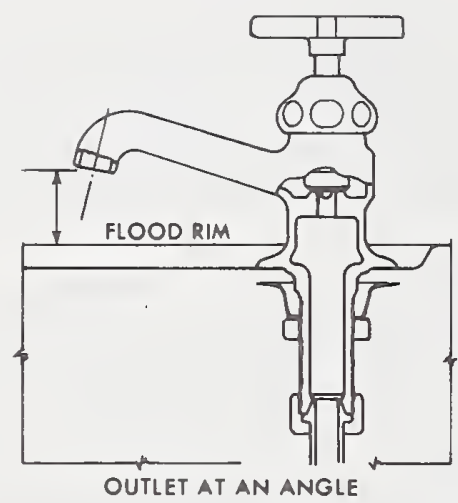

AN AIR GAP IS PROVIDED BETWEEN THE FLOOO RIM OF A FIXTURE AND THE SUPPLY FAUCET

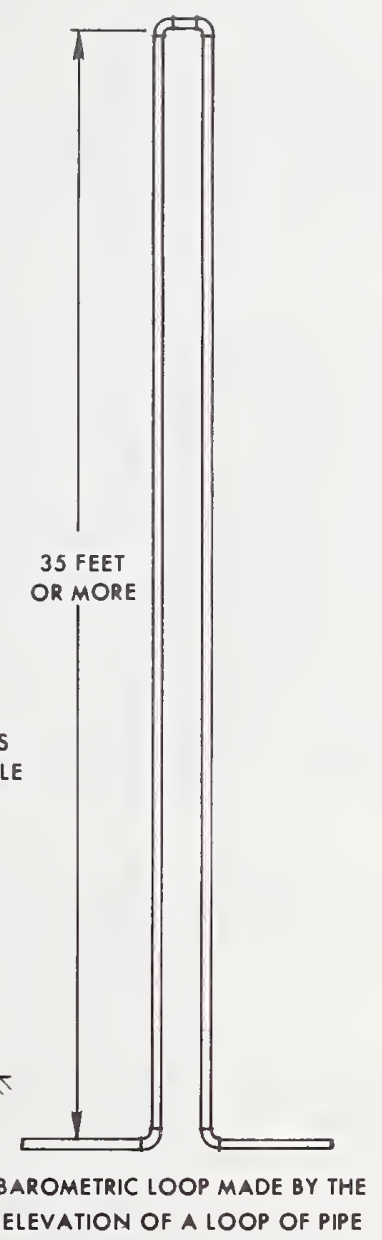

Figure 2. Showing Examples of the Air Gap and the Barometric Loop 
Work began in 1938 to develop a national standard for air gaps in water distribution piping systems suitable for all water-connected devices and fixtures. The initial American Standard ASA 40.4 1942 for air gaps was recently updated to be ANSI A112.1.2 - 1973. [26].

A sketch of a barometric loop is also shown in Figure 2. Following the principle of operation, an elongated U-bend in the water piping is extended to a height beyond which siphonic action can not occur. In practical application the top of the U-bend would be about 35 feet above the highest outlet supplied by the water piping.

De Roos and Michaelsen [27] studied the barometric loop and particularly the air-lift effect $\underline{5}$ which, should it occur in the simple loop, could make the piping arrangement ineffective at preventing back-

15 siphonage. In their experiments they installed an air-water separator in the base of the loop on the downstream side and vented the separator through 1/2-inch copper tubing to the top of the downstream leg of the 1oop. Properly designed, it appears from that research that air entering the piping downstream of the separator will be removed by the separator20 vent arrangement and will not enter the downstream leg of the loop to create the air-lift effect.

Additional matters of concern were not explored by the experiments but were noted by the authors:

1. It was not determined whether or not diffusion caused a transfer of contaminants from the downstream to the upstream side of the loop.

2. Any effect temperature gradients might have on the transfer of contaminants over the loop was not determined, and

3. Unanswered is the question of the amount of contamination transferred over the loop by air separated from water near the top of the loop.

For specific applications the barometric loop could be an inexpensive way to protect against backsiphonage. It can not be used 40 when there is any possibility of back pressure occurring on the downstream side.

5l

On the air-lift effect, air enters the downstream leg of the loop through an open outlet or leaky connection. An air bubble of sufficient size may form to rise in the pipe and lift a quantity of water over the U-bend into the potable water. 


\subsubsection{Backflow prevention devices}

A backflow preventer has been defined as any mechanical device, whether used singly or in combination with other controls, that will

5 automatically forestall the possibility of an unintentional reverse flow in a potable water distribution system. Depending upon the degree of redundancy desired, each backflow preventer is comprised of one or more check valves, atmospheric relief valves (air inlet valves) or pressure differential relief valves, together with test cocks and gate

10 valves. Among the less complicated devices are the vacuum breakers which are used primarily to protect against the hazard of back-siphonage.

Three standards for vacuum breakers have originated with the American Society of Sanitary Engineering (ASSE) to cover the pipe-

15 applied atmospheric-type [20], the hose-connection type [2] and the pressure-type [25] vacuum breakers. The International Association of Plumbing and Mechanical officials (IAPMO) has published a standard for backflow prevention devices [28] which includes design and operational specifications together with laboratory and/or field test procedures

20 for the pipe-applied atmospheric type, the single check valve pressure type and the double check valve pressure-type vacuum breakers. Also in the fifth edition of the Manual of Cross-Connection Control [2.9] published by the Foundation for Cross-Connection Control and Hydraulic Research (FCCCHR), specifications and test procedures for pressure

25 type vacuum breakers have been included for the first time.

\section{A.S.S.E. also has published a standard for Water Closet} Anti-siphon Ball Cocks [30]. In this standard the anti-siphon device may be an air gap or a vacuum breaker.

30

In Figure 3, sketches and schematic drawings are used to aid the reader in the differentiation of the several types of vacuum breakers using combinations of atmospheric relief valves, check valves, and gate valves. The pipe-applied atmospheric type and the hose-con35 nection type are designed for use downstream of the last flow control valve. With the pressure type vacuum breaker a control valve may be located downstream of the device.

Test cocks are an integral part of the device in some designs. They are required for double check valve assemblies and for reducedpressure principle backflow prevention devices.

Table 3 summarizes the sizes, working pressures, temperature services, operational features and applications for each type of

45 backflow preventer identified by an illustration and the corresponding A.S.S.E. standard number. 


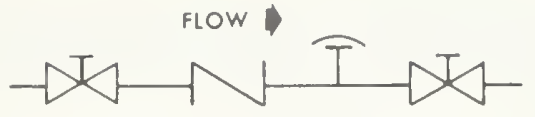

PRESSURE TYPE VACUUM BREAKER

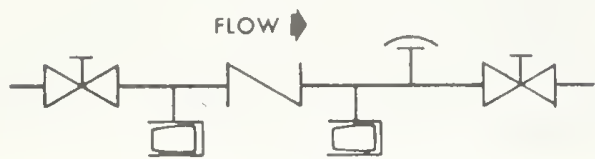

SINGLE CHECK VALVE PRESSURE VACUUM BREAKER WITH TEST COCKS

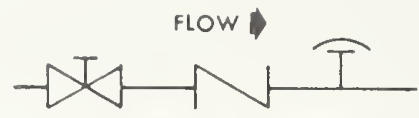

PIPE.APPLIED ATMOSPHERIC TYPE VACUUM BREAKER

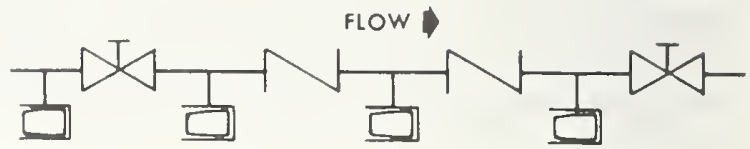

DOUBLE CHECK VALVE ASSEMBLY

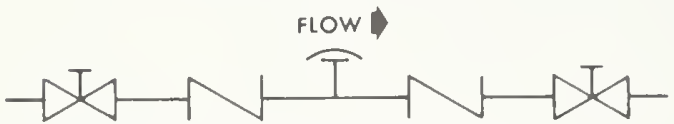

BACKFLOW PREVENTER WITH INTERMEDIATE ATMOSPHERIC VENT

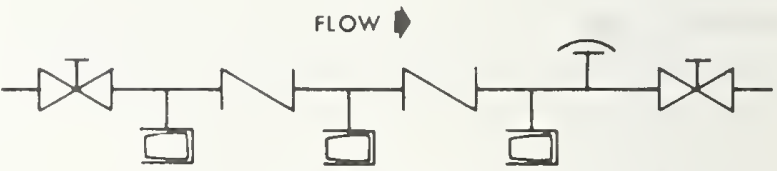

DOUBLE CHECK VALVE PRESSURE VACUUM BREAKER ASSEMBLY WITH TEST COCKS

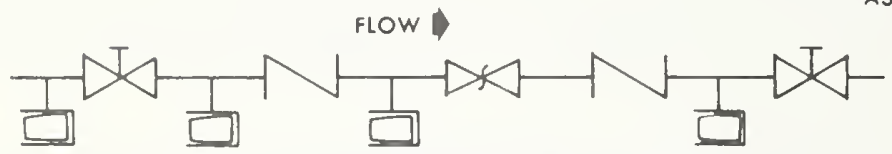

REDUCED.PRESSURE ZONE PRINCIPLE BACK PRESSURE BACKFLOW PREVENTER

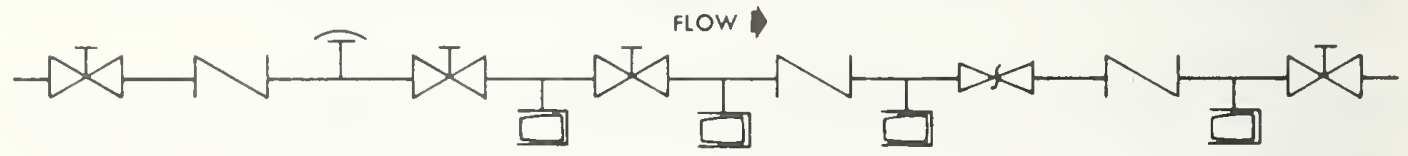

SINGLE CHECK VALVE PRESSURE VACUUM BREAKER IN TANDEM WITH A REDUCED.PRESSURE ZONE PRINCIPLE BACK PRESSURE BACKFLOW PREVENTER (SEE B.O.C.A. 1975 SECTION PI605.11.8 "CONNECTIONS SUBJECT TO BACK PRESSURE

\section{LEGEND:}

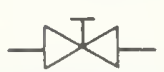

GATE VALVE

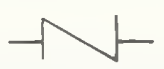

CHECK VALVE

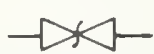

PRESSURE DIFFERENTIAL RELIEF VALVE

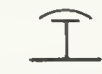

ATMOSPHERIC RELIEF VALVE

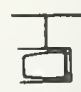

TEST COCKS

Figure 3. Schematic Drawings of Backflow Prevention Devices that Utilize Check Valves, Gate Valves, Relief Valves and Test Cocks 


\begin{tabular}{|c|c|c|c|c|c|c|c|}
\hline 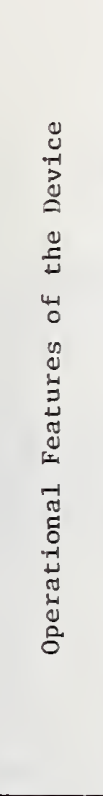 & 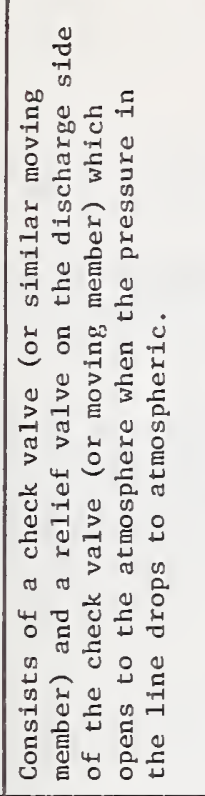 & 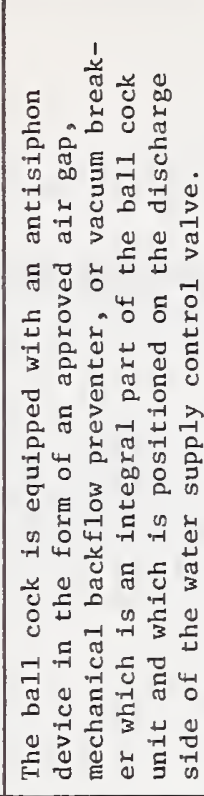 & 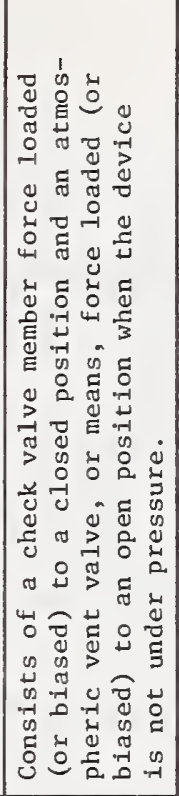 & 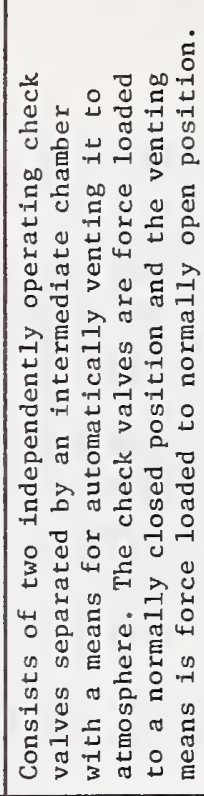 & 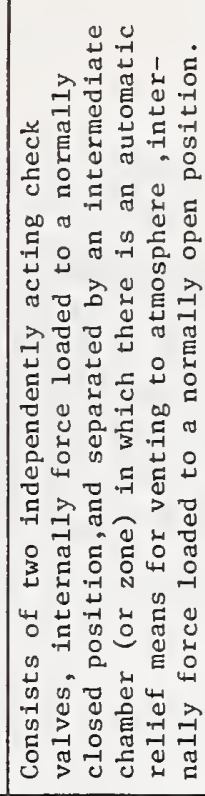 & 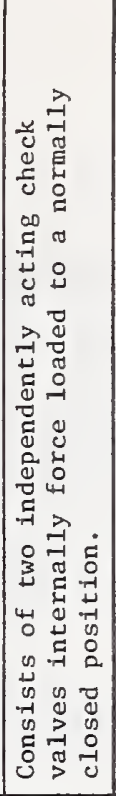 & 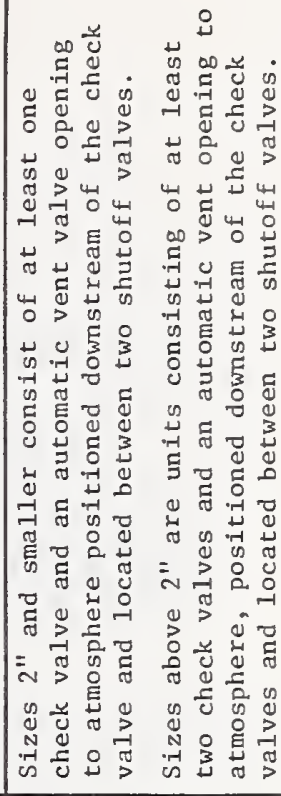 \\
\hline 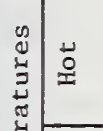 & 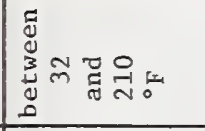 & & 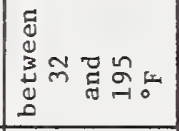 & 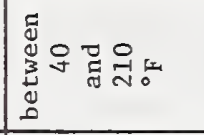 & 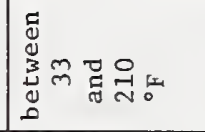 & 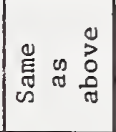 & 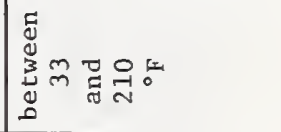 \\
\hline 递 & 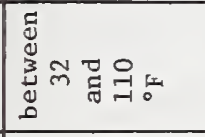 & 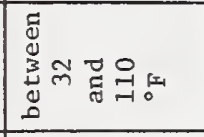 & 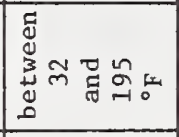 & 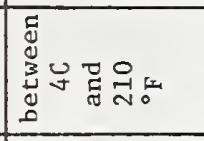 & 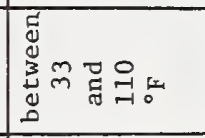 & 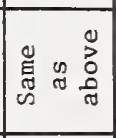 & $\begin{array}{l}\mathscr{D} \\
0 \\
0 \\
3 \\
0 \\
0\end{array}$ \\
\hline 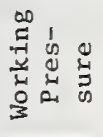 & 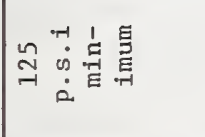 & 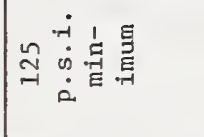 & 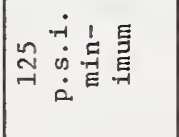 & 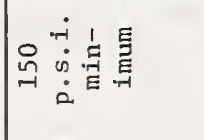 & 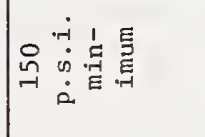 & 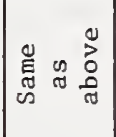 & \\
\hline$\underset{\substack{N \\
\text { in } \\
\text { is }}}{\infty}$ & $\sum_{-1}^{\infty} \rho=\frac{\dot{\varphi}}{\dot{\varphi}}$ & $=\begin{array}{l}\dot{\infty} \\
\dot{\infty} \\
m \\
\dot{n}\end{array}$ & 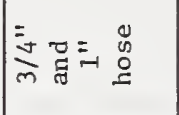 & 过该过 & 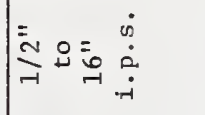 & 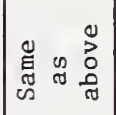 & $\stackrel{\equiv}{\sim}$ \\
\hline 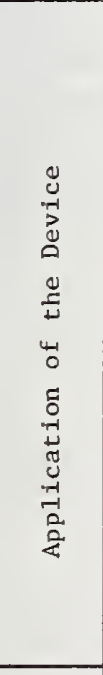 & 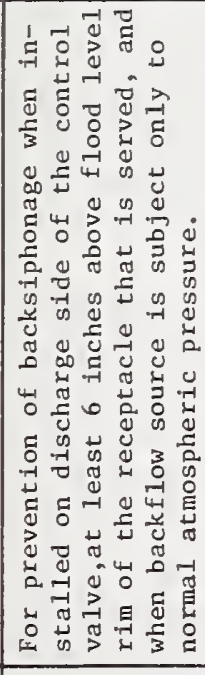 & 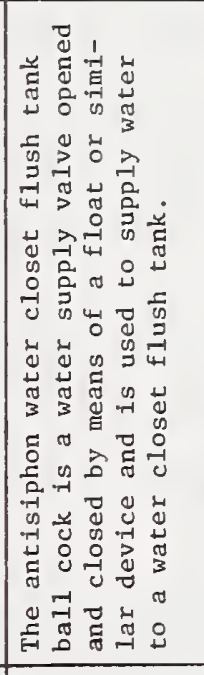 & 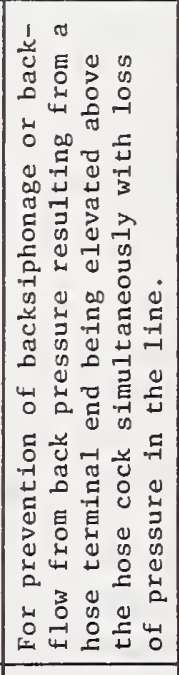 & 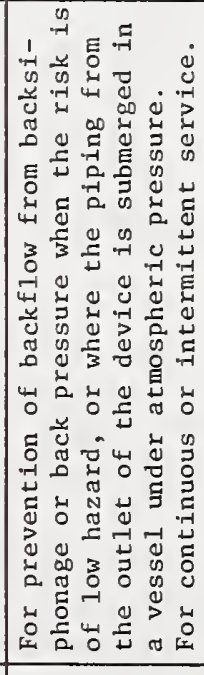 & 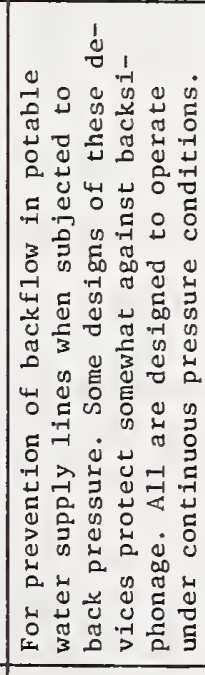 & 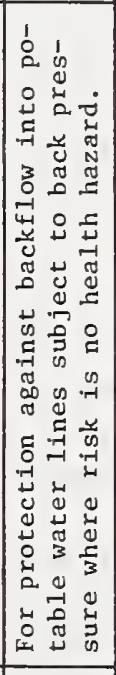 & 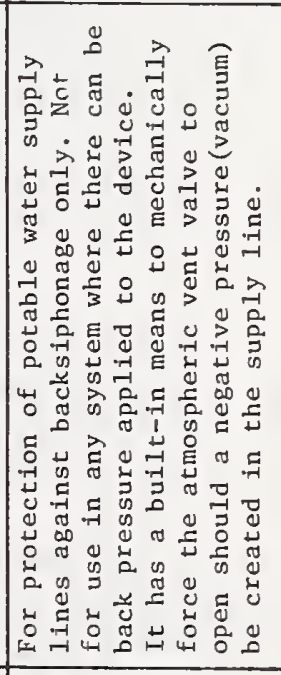 \\
\hline 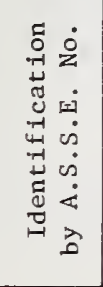 & $=\operatorname{sic}{ }_{0}$ & $\sum_{\substack{1 \\
i=1}}^{1}$ & {$\left[\begin{array}{ll}3 & -1 \\
0 & -1\end{array}\right.$} & & & & \\
\hline
\end{tabular}




\section{ELEMENTS IN THE EVALUATION OF BACKFLOW PREVENTION DEVICES}

\subsection{The Product Standards}

The first widely used standards for backflow preventers appears to be those of the Foundation for Cross-Connection Control Research at the University of Southern California. The other entries in the standards field were A.W.W.A. [31], A.S.S.E. $[20,21,22,23,24,25,30]$ and I.A.P.M.O. [28].

103.1 .1 Foundation for Cross-Connection Control and Hydraulic Research (FCCCHR)

The 5th edition, (March,1974) of the Manual of Cross-Connection Control [29] incorporated editing of Section 10 to make the original

15 intent of the formulating committee a bit clearer. Also in Sections 9 and 10, the pressure type vacuum breakers were included for the first time. The Manual is a volume of 150 pages compiled to provide for uniform cross-connection control practices as they impact upon health agencies, water purveyors, water users (consumers) and inspectors of backflow 20 prevention devices. The following subjects are included:

- A statement of policy

- Responsibilities of purveyors, consumers and officials

- Definitions of words and phrases

- Examples of cross connections

30

- Results of noncompliance
- Cross-connection control practices

- Samples of standard letters and forms

- Field testing procedures

- Specifications for devices

- Case histories

The survey made by the Navy [11] in 1968, summarized in Table 2 gives some idea of the extent of use of this particular crossconnection control manual throughout the United States.

\subsubsection{American Water Works Association (AWWA or A.W.W.A.)}

The A.W.W.A. has a standard, C 506-69, [31] for two types of devices that are designed especially for protection of water in the water mains. The work toward development of the standard appears to have started in 1959 with the first output being a manual: "AWWA M14 Recommended Practices for Backflow Prevention and Cross-Connection Contro1."

The subsequent AWWA standard C 506-69"Backflow Prevention Devices Reduced Pressure Principle and Double Check Valve Types" describes essentially the same devices as does A.S.S.E. 1013 and 1015. 


\subsubsection{American Society of Sanitary Engineering (ASSE or A.S.S.E.)}

In 1953 the Standards Committee of A.S.S.E. was appointed. The output of backflow prevention standards began in 1964 with A.S.S.E. 1001 [20] and A.S.S.E. 1002 [30], followed later in 1970 by A.S.S.E.

51011 [21], in 1971 by A.S.S.E. 1013 [23], in 1972 by A.S.S.E. 1012 [22] and A.S.S.E. 1015 [24]; and the latest A.S.S.E. 1020 [25] in 1974. The Canadian Standards Association voted to adopt these standards as the basis for their standards.

$10 \quad 3.1 .4$ International Association of Plumbing and Mechanical Officials (IAPMO or I.A.P.M.O.)

The IAPMO standards are related to the need for backflow preventer standards in the IAPMO Plumbing Code. In the development of the IAPMO

15 Specification PS 31-74 [28] many of the advisors to the FCCCHR programs, including $\mathrm{Dr}$. Springer, alded in formulating the standard. Four types of backflow preventers are 1dentified with criteria and test requirements: Reduced-pressure principle backflow prevention device, Double check valve assembly, Single check valve pressure vacuum breaker, and Double

20 check valve pressure vacuum breaker assembly.

\subsubsection{Summary of Applications of Product Standards}

Table 4 is a matrix arrangement of the information found in plumb-

25 ing codes and various other publications relating the type of backflow preventer (identified by standard when available) to the type of hazard at a cross-connection. This table illustrates how these complex relationships can be visually presented. When the environmental, engineering and economic considerations are sharply defined for each specific application,

30 the blanks and the small squares (indicating acceptable applications) and the large squares (indicating primary applications) might fit into different cells from those shown in table 4. The absence of a square, therefore, does not necessarfly mean that such application is undesirable.

$35 \quad 3.2$ The Plumbing Codes

Some regulation of cross-connection hazards is provided by the ordinances or the state laws that adopt model plumbing codes. Model plumbing codes have been developed by the following sponsors:

American Society of Plumbing Engineers (ASPE) with the National Association of Plumbing-Heating-Cooling Contractors 101620 th Street, N.W., Washington, D.C. 20036

(NAPHCC) 


\begin{tabular}{|c|c|c|c|c|c|c|c|c|c|c|c|c|c|c|c|c|c|}
\hline \multirow{7}{*}{ 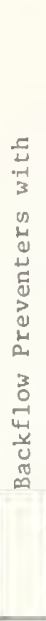 } & \multirow{3}{*}{\multicolumn{2}{|c|}{\begin{tabular}{|l} 
\\
\end{tabular}}} & $\begin{array}{ccc} & 7<6 \mathrm{~T} \\
\mathrm{IE} & \mathrm{Sd} & \mathrm{OWdVI}\end{array}$ & & & & & & & $\square$ & & & & & & & \\
\hline & & & $\begin{array}{c}696 \mathrm{I} \\
905 \mathrm{~J} \text { VMMY }\end{array}$ & & & & & & & & & & & & & & \\
\hline & & & 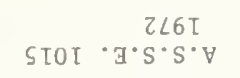 & & & & & & & & & & & & & & \\
\hline & \multirow{3}{*}{\multicolumn{2}{|c|}{ 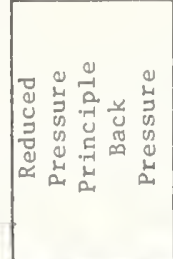 }} & 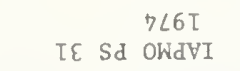 & & & & & & & & & & $\square$ & & & & $\square$ \\
\hline & & & 905 כ У & & & & & & & & & & $\square$ & & & & $\square$ \\
\hline & & & 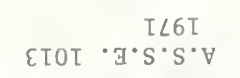 & $\square$ & & & $\square$ & & & & & & $\square$ & & & & $\square$ \\
\hline & \multicolumn{2}{|c|}{ 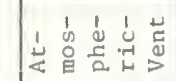 } & 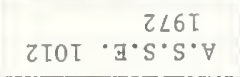 & & & & $\square$ & $\square$ & & & & & & & & & \\
\hline & \multirow{4}{*}{ 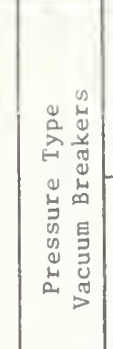 } & \multirow{2}{*}{ 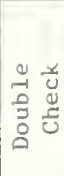 } & 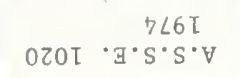 & & & & & $\square$ & $\square$ & $\square$ & & & & $\square$ & & & \\
\hline & & & 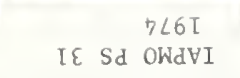 & & & & & & $\square$ & $\square$ & & & & & & & \\
\hline & & \multirow{2}{*}{ 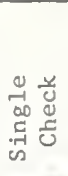 } & 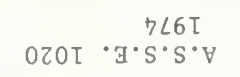 & & & & & & & & & & & & & & \\
\hline & & & 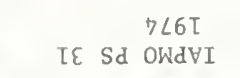 & & & & & & & & & & & $\square$ & & & \\
\hline & \multirow{3}{*}{ 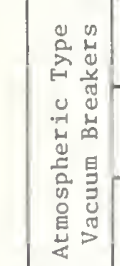 } & 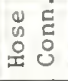 & 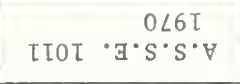 & & & & & & & $\square$. & & & & & & & \\
\hline & & $\begin{array}{l}7=0 \\
7 \overline{0} \\
\infty\end{array}$ & 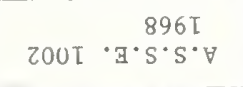 & & & & & & & & & & & & & & \\
\hline & & 竞 & $I \cdot I \cdot Z I I \quad \forall$ I ISNG & & & & & & $\square$ & & & & & & & & \\
\hline \multicolumn{3}{|c|}{ 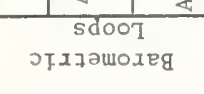 } & (prepuets oN) & & & $\square$ & & & $\square$ & $\square$ & & $\square$ & & & & & \\
\hline \multicolumn{3}{|c|}{ Sdeg } & 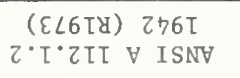 & & & & $\square$ & $\square$ & $\square$ & $\square$ & & $\square$ & & $\square$ & & & \\
\hline \multicolumn{3}{|c|}{ 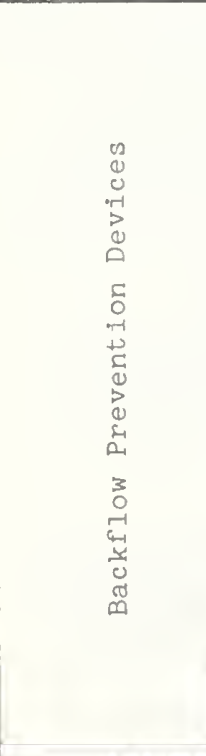 } & 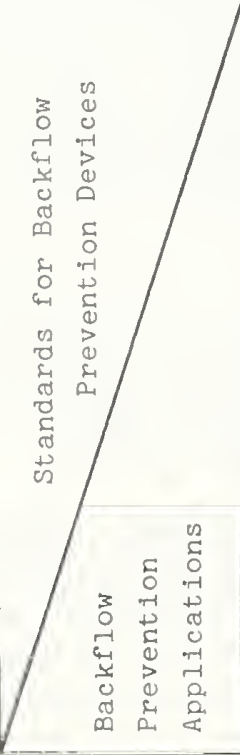 & 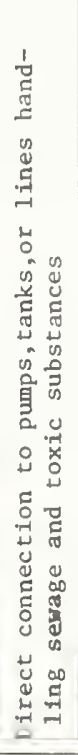 & 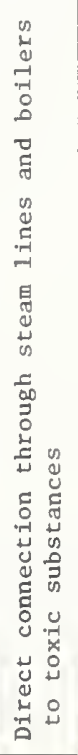 & 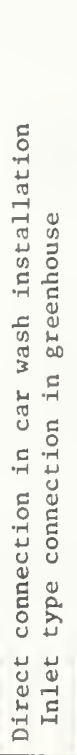 & 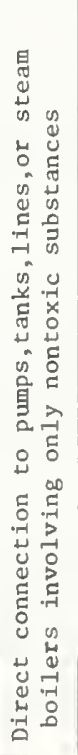 & 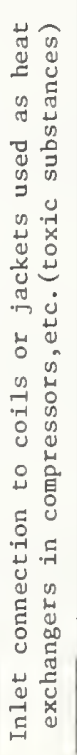 & 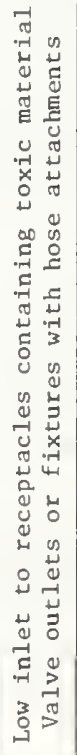 & 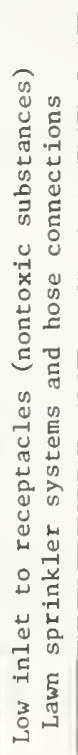 & 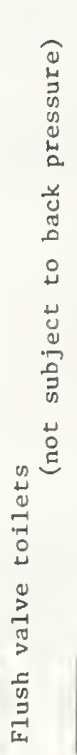 & 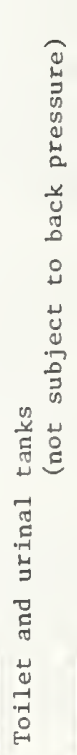 & 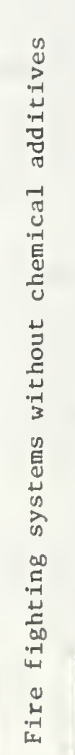 & 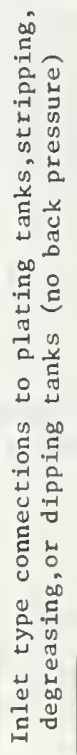 & 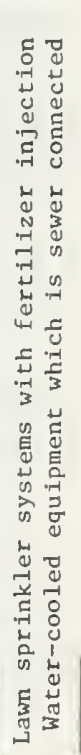 & 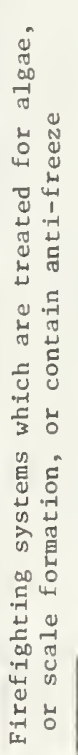 & 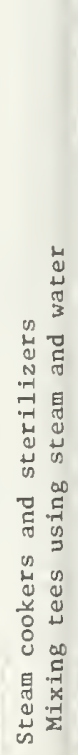 \\
\hline
\end{tabular}


Building Officials and Code Administrators International Inc. (BOCA or B.O.C.A.)

1313 East 60th Street, Chicago, Illinois 60637

International Association of Plumbing and Mechanical

officials (IAPMO or I.A.P.M.O.)

5032 Alhambra Avenue, Los Angeles, California 90032

Southern Building Code Congress International, Inc

3617 Eighth Avenue, South, Birmingham, Alabama 35222

In those localities where plumbing codes have been adopted into

10 law, plumbing inspectors are employed to effectuate the requirements of the code. As technology and economics interact, products such as backflow prevention devices are modified or new ones are introduced. In either case the compilers of plumbing codes are called upon to make changes in the codes so that acceptable innovations may be passed by the plumbing inspector. The procedures for making changes varies with each of the sponsors and is a time consuming operation.

At the Annual Meeting of the A.S.S.E. in 1974 representatives of the four model codes gave the following brief descriptions of procedures

20 for making code changes as recorded in the 1974 A.S.E.E. Yearbook:

Milton Snyder, Chairman of the Joint NAPHCC-ASPE Plumbing Code comittee stated:

'Changes and additions to the National Standard Plumbing Code can be made upon initiation by Code Committee members or can be initiated by any interested party. There are public meetings at least once a year. Chairmanship of the committee rotates between the National Association of Plumbing Contractors and the American Society of Plumbing Engineers. Actions of the committee are submitted to our Boazd of Directors and annually the actions of the Board are submitted to the entire membership. Since our membership has a broad base of Contractors, Engineers, and Inspectors -- all of whom vote -- we cannot conceive that any model code has a broader base of members with full voting privileges. And there is of course another review by any locality using our information."

\section{Clarence R. Bechtel, Managing Director of BOCA spoke to the point:}

"Code changes can be submitted by anyone on forms supplied by BOCA. The Plumbing Code is not changed by staff, only BOCA members change BOCA codes. The Plumbing Code changes are reviewed in a public hearing and followed by a vote of active members. The approved changes are then incorporated into the code.

The code is established and malntained according to National Standards and practices, that is a system or device acceptable in a distant communty should be acceptable in another community providing the performance can be proven to be identical. The local or reglonal influence is minimized. 
The responsibility for enforcement lies solely and ultimately with the local municipality.

The individuals with the duty and responsibility of enforcing the code in the local level have a voice and a vote in determining the content of the code by a democratic process.

Our technical staff provides the necessary back-up services such as code interpretations, plumbing code seminars and a plumbing code correspondence course to enhance the officials knowledge and use of the code."

R.E. Sullivan, Director of Education for Southern Building Code Congress International spoke as follows:

"We believe that a code can best be written and amended by those people who use it from day to day, utilizing the advice and assistance made available from industry and the architectural and engineering proffessions. Consequently, every member of the Southern Building Code 20 Congress is afforded the opportunity to participate in the revision process at every annual research conference, and to vote on code changes recommended by our code revision committee."

Neil A. Mac Lean, Executive Vice President of I.A.P.M.O.

"Our code changes procedure is not much different from that of any other code agency other than the fact that - and this may be true of the other agencies but it wasn't brought out - we will accept a code change from anyone in the world, anyone. When we receive a code change to the Uniform Plumbing Code, it is printed just the way it is submitted to us by the photocopier. We don't take a chance that in retyping that we may change your words. We use a photocopier to reproduce enough coples of these code changes for the code changers committee. We have a deadline of March 1st of each year, and all code changes that have come in prior to March 1st, usually by the lst of April are reviewed by a cross section of the code changing committee; still having the only voting privilege are people who have a nonvested interest, the inspectors from our jurisdiction. The code change receives a recomnendation at that point, a recommendation to either accept, reject, or hold for further study. Within 30 days prior to the annual conference - but more actually, usually within 30 days after that code changes comnittee - all of these code changes are then printed in a code changes document and mailed out to our entire membership, or to anyone else if they have an interest in the Uniform Plumbing Code - they may not be a member. These changes are then voted on at the conference, and we have remained anonymous in these code changes.': 
"We specify that a code change has to be done in a specific manner, and if a stranger to our code-changes procedure submits a code change to us, and it is incorrect, we inform him of how to do it correctly and assist him to do it correctly. We then make it anonymous.

5 3.2.2 Backflow prevention requirements in model plumbing codes

The plumbing codes determine the utilization of backflow preventers in a building at the time of the design of the structure. An effective cross-connection control program must encourage the designers to install suitable devices, where needed, at the time of construction to obviate the resistance to change later.

Table 5 presents a listing of paragraphs from four model plumbing codes pertinent to specific types of cross-connections.

\subsection{The Manufacturers of Backflow Prevention Devices}

A complete listing of manufacturers of all backflow prevention devices is beyond the scope of this document. In table 6 the names of manufacturers have been compiled from the latest listings of approved

20 devices of the American Society of Sanitary Engineering and from a similar list of the Foundation for Cross-Connection Control and Hydraulic Research. Additional names were obtained from advertisements found in recent technical publications and magazines.

25 In table 7, the matrix presentation is only as up-to-date as our source of information.

\subsection{Testing Laboratories}

There currently exist two modes for the certification of backflow prevention devices. The Foundation for Cross-Connection Control and Hydraulic Research tests for compliance of backflow prevention devices with criteria published in its Manual of Cross-Connection Control [29]. The American Society of Sanitary Engineering has working arrangements

35 with three testing laboratories to test devices and to authorize a seal of approval. Just recently. a procedure for accrediting testing laboratories was established within the Department of Commerce, effective February 25, 1976. The complete procedure, as published in the Federal Register of Wednesday, February 25, 1976 has been arranged by 40 the authors of this document to provide sidenotes and a special format as explained in Appendix Section 10.3.

Each of the above procedures will be discussed in the following paragraphs. 
Table 5. A Listing of Paragraphs from Four Model Plumbing Codes Pertinent to Specific Types of Cross Connections

\begin{tabular}{|c|c|c|c|c|}
\hline $\begin{array}{l}\text { Pcints of Contact Where a Potable Water System May Become } \\
\text { Contaninated by Backflow from a Non-potable Source }\end{array}$ & $\begin{array}{l}\text { B.O.C.A. } \\
1973 \text { Code } \\
\text { Paragraphs }\end{array}$ & $\begin{array}{l}\text { I.A.P.M.O. } \\
1973 \text { Code } \\
\text { Paragraphs }\end{array}$ & $\begin{array}{l}\text { PHCC-ASPE } \\
1973 \text { Code } \\
\text { Paragraphs }\end{array}$ & $\begin{array}{l}\text { S.B.C.C. } \\
1973 \text { Code } \\
\text { Paragraphs }\end{array}$ \\
\hline Water Closet Flushometer Valves ; Urlnal Flushometer Valves & 1605.117 & $1003(a),(c)$ & $10.5 .5 \mathrm{~A}$ & 1205.1 \\
\hline Water Closet and Urinal Tanks & 1605.117 & $1003(b)$ & $10 \cdot 5 \cdot 5 \mathrm{~A}$ & 1205.2 \\
\hline over Rim Supplies to Plumbing F1xtures & 1605.111 & $1003(d)$ & 10.5 .2 & $1205 \cdot 3$ \\
\hline $\begin{array}{l}\text { D1rect Connections Between Potable Water PIping and Sewer } \\
\text { Connected Wastes }\end{array}$ & 1605.8 & $1003(\mathrm{a})$ & $1 c \cdot 5 \cdot 3 \cdot 5 c$ & \\
\hline $\begin{array}{l}\text { Connections Between Potable Water Plping and the Inlet } \\
\text { Side of a Fixture Trap. }\end{array}$ & & $1003(\mathrm{e})$ & & \\
\hline Inlets to Tanks, Vats, Sumps and other Receptors & 1605.116 & $1003(\mathrm{~g})$ & $10.5 \cdot 3 \cdot 1$ & \\
\hline Lawn Sprinkling Systems & 1605.117 & $1003(\mathrm{~h})$ & 10.5 .9 & 1205.4 \\
\hline Fixture Inlets or Valved Outlets with Hose Attachments & 1605.117 & $1003(1)$ & $10 \cdot 5 \cdot 3 \cdot 3$ & 1205.5 \\
\hline Medical, Therapeutic, Surgical, Mortuary or Slmilar Equipment & $1403.6 ; .7$ & $1.003(j)$ & $14.27 ; .26$ & \\
\hline $\begin{array}{l}\text { Water Cooled Compressors, Degreasers or any other Water } \\
\text { Cooled Equipment }\end{array}$ & & $1003(\mathrm{k})$ & $10 \cdot 5 \cdot 3 \cdot 4$ & \\
\hline $\begin{array}{l}\text { Water Cooled Equipment Subject to Continuous Flows for } \\
\text { Periods of Twelve Hours or More }\end{array}$ & & $1003(\mathrm{k})$ & $10 \cdot 5 \cdot 3 \cdot 4$ & \\
\hline Aspirators Ccrnected to the Inlet Side of a Fixture Trap & 1403.6 & $1003(1)$ & $10 \cdot 5 \cdot 5 \mathrm{~A}$ & \\
\hline $\begin{array}{l}\text { Steam Boilers, Pumps, etc. that May Create a H1gher Pressure } \\
\text { in the Non-potable Line than Exists in the Potable System }\end{array}$ & 1605.117 & $1003(n)(0)$ & $10.5 \cdot 3 \cdot 5$ & 1205.6 \\
\hline Cup Beverage Vending Machines & 1605.117 & & $10 \cdot 5 \cdot 5 \mathrm{~A}$ & \\
\hline Dishwashing, Garbage Can Cleaning, and Laundry Machines & 1605.117 & & $10.5 \cdot 5 \mathrm{~A}$ & 1204.3 \\
\hline Hose B1bbs & 1605.117 & & 3.1 .3 & 1205.5 \\
\hline Mobile Homes in Trailer Parks & & E 25 & 18.5 .8 & c $8(c)$ \\
\hline $\begin{array}{l}\text { H1gh Pressure Untts such as Used in Car Washes to Supply } \\
\text { Water and Detergent Under High Pressure }\end{array}$ & & & & Dwg. 11 \\
\hline
\end{tabular}

NOTE:

B.o.C.A. is Building Officials and Code Administrators International. Inc.

I.A.P.M.O. is International Association of Plumbing and Mechanical officials

PHCC-ASPE is National Association of Plumbing, Heating, Cooling Contractors joined with the American Society of Plumbing Engineers.

S.B.C.C. is Southern Building Code Congress International, Inc. 
Table 6. An Alphabetical Listing of Manufacturers of Backflow Prevention Devices. (Relate to Table 7)

AMA Enterprises, Inc.

444 Hempstead Turnpike

West Hempstead, New York 11552

(516) 483-1166

Alsons Products Corp.

525 East Edna Place

Covina, Calif. 91722

(213) 966-1668

American-Standard, Inc.

P. 0. Box 2003

New Brunswick, New Jersey 08903

(201) 885-1900

Badger Meter, Inc.

4545 W. Brown Deer Road

Milwaukee, Wisconsin 53223

(414) 355-0400

Beacon Valve Company

P. O. Box 478, 2 Jackson St.

Waltham, Mass. 02154

(617) 893-0011

Belvedere Products, Inc.

725 Columbia Avenue

Belvidere, Illinois 61008

(815) 5443131

Bidoro Manufacturing Co.

229 Bellerose Avenue

East Northport, N. Y. 11731

(516) 261-5050

Buckner Sprinkler Co.

909 W. Nielson Avenue

Fresno, California 93706

(209) 269-5561

Burlington Brass Works

400 Pine Street

Burlington, Wisconsin 53105

(414) 763-3534

A. W. Cash Valve Mfg. Corp.

$666 \mathrm{E}$. Wabash Avenue

Decatur, Illinois

(217) 422-8574

Champion Brass Mfg. Co.

1460 Naud Street

Los Angeles, California 90012

(213) 221-2108

Chicago Faucet Co.

2100 S. Nuclear Dr.

Des Plains, Illinois 60018

(312) 298-1140
Chicago Speciality Mfg. Co.

7500 Linder Avenue

Skokie, Illinois 60076

(312) $674-7500$

Cla-Va1 Co. Backflow Div.

Post Office Box 1325

Newport Beach, California 92663

(714) 548-2201

Clayton Mark \& Co.

1900 Dempster Street

Evanston, Il1inois 60204

(312) $864-9100$

Consolidated Brass Co.

P. 0. Box 247

Mathews, North Carolina

(704) 847-9191

Coyne \& Delany Co.

1565 Avon Street Extended

Charlottesville, Virginia 22901

(804) 296-0166

Crane Company

300 Park Avenue

New York, N. Y. 10022

(212) 752-3600

Eastman Central D Div.

U. S. Brass Corp. P. 0. Box 37

Plano, Texas 75074

(214) 235-4531

Fluidmaster Inc.

1800 Via Burton, P. O. Box 4264

Anaheim, California, 92803

(714) $774-1444$

Frost Company

14th Ave. at 65th Street

Kenosha, Wisconsin 53140

(414) 658-4301

G. C. G. Mfg. Co. Ltd.

173 Glidden Road, BRAMPTON,

Ontario, Canada L6W 3L9

(416) 453-8120

H. L. Gee $\mathrm{Mfg}$. Co.

9292 Santa Monica Blvd. P. O. Box 5285

Beverly Hills, California 90210

(213) 275-5376

Griswold Controls

124 E. Dyer Road

Santa Ana, California 92707

(714) 546-3844 
Hamilton Industries Division American Hospital Supply Co. Two Rivers, Wisconsin 54241 (414) 793-1121

Hersey Products Inc.

250 E1m Street

Dedham, Massachusetts 02026

(617) 326-9400

ITT Grinnel1 Corp.

260 W. Exchange Street

Providence, Rhode Island 02901

(401) 831-7000

Jaco, Inc.

2945 W. Maple Road

Troy, Michigan 48084

(313) 647-0115

Johns-Manville Corp.

Greenwood Plaza

Denver, Colorado 80217

(303) 770-1000

Josam Manufacturing Co.

Corymbo Road

Michigan City, Indiana 46360

(219) 872-5531

Kirkhil1, Inc.

12021 Woodruff Avenue

Downey, California 90248

(213) 773-3492

Kohler Company

44 High Street

Kohler, Wisconsin 53044

(414) 457-4441

Lawler ITT

3500 N. Spaulding Avenue Chicago, Illinois 60618

(312) 267-1600

Lear Siegler, Inc.

6331 E. Jefferson Avenue Detroit, Michigan 48207

(313) 259-2095

Mansfield Sanitary, Inc.

P. 0. Box B

Perrysuille, Ohio 44864

(419) 938-5211

Modern Faucet Mfg. Company

1700 East 58th Place

Los Angeles, California 90001

(213) $582-6286$
Mueller Steam Specialty Company 72 Jericho Turnpike

Mineola, New York 11501

(516) 747-8300

L. R. Nelson Corporation 7719 N. Pioneer Lane

Peoria, Illinois 61614

(309) 692-2200

Nepture Water Meter Company

30 Perimeter Park

Atlanta, Georgia 30341

(404) 458-8111

Nibco, Inc.

500 Simpson Avenue

Elkhart, Indiana 46514

(219) 295-3000

Nidel Company

P. 0. Box 418

Grand Haven, Michigan 49417

(616) 842-2650

Powers Regulator Company

3400 Oakton Street

Skokie, Illinois 60076

(312) 673-6700

Rain Bird Sprinkler Mfg. Co.

7045 N. Grand Avenue

Glendora, California 91740

(213) 963-9311

Rockwel1 International Corp. P. 0. Box 487

Uniontown, Pennsylvania 15401

(412) 438-3501

Sloan Valve Company

10500 Seymour Avenue

Franklin Park, I11inois 60131

(312) $671-4300$

Surgical Mechanical Research, Inc. 960 W. 16th Street

Newport Beach, California 92663

(714) 646-4405

Taco, Inc.

1160 Cranston Street

Cranston, Rhode Island 02920

(401) 942-8000

Tempstat Corporation

Monument Road

Hinsdale, New Hampshire 03451

(603) 256-6001 
$T \& S$ Brass And Bronze Works, Inc. 119 Magnolia Avenue

Westbury, L. I., New York 11590

(516) 3345104

Toro Technology

1709 La Costa Meadows Drive

San Marcos, California 92069

(714) $744-5650$

Twentieth Century Products Corp.

3600 South Jason Street

Englewood, Colorado 80110

(303) 789-0418

Water Saver Faucet Company

701 W. Erle Street

Chicago, Illinois 60610

(312) $666-5500$
Watts Regulator Company

10 Embankment Street

Lawrence, Massachusetts 01842

(617) 688-1811

Wolverine Brass Works

648 Monroe Avenue, N. W.

Grand Rapids, Michigan 49502

(616) 45I-258I

Woodford Mfg. Company

1626 Delaware Avenue

Des Moines, Iowa 50317

(515) 262-5638

Zurn Industries, Inc. 1801 Pittsburgh Avenue Erie, Pennsylvania 16512 (814) 455-0921 
Table 7. A Matrix Presentation Relating Manufacturers with the Types of Backflow Prevention Devices that Each Manufactures.

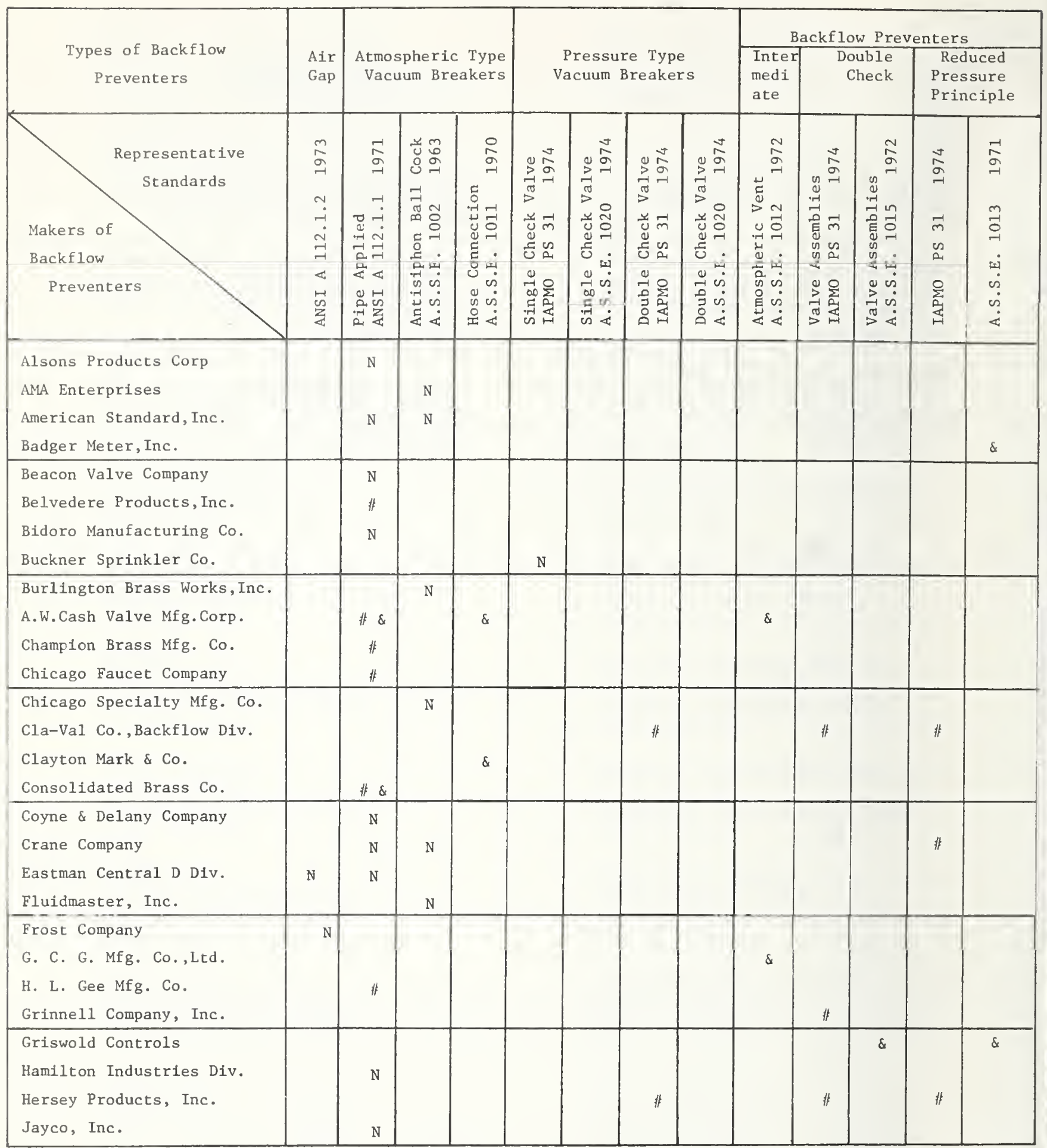




\begin{tabular}{|c|c|c|c|c|c|c|c|c|c|c|c|c|c|}
\hline \multirow{3}{*}{$\begin{array}{c}\begin{array}{c}\text { Types of Backflow } \\
\text { Preventers }\end{array} \\
\begin{array}{c}\text { Representative } \\
\text { Standards }\end{array}\end{array}$} & \multirow{3}{*}{ 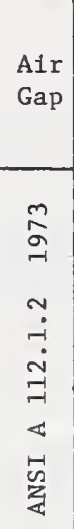 } & \multirow{2}{*}{\multicolumn{3}{|c|}{$\begin{array}{l}\text { Atmospheric Type } \\
\text { Vacuum Breakers }\end{array}$}} & \multirow{2}{*}{\multicolumn{4}{|c|}{$\begin{array}{l}\text { Pressure Type } \\
\text { Vacuum Breakers }\end{array}$}} & \multicolumn{5}{|c|}{ Backflow Preventers } \\
\hline & & & & & & & & & $\begin{array}{l}\text { Inter } \\
\text { medi } \\
\text { ate }\end{array}$ & \multicolumn{2}{|c|}{$\begin{array}{r}\text { Double } \\
\text { Check }\end{array}$} & \multicolumn{2}{|c|}{$\begin{array}{l}\text { Reduced } \\
\text { Pressure } \\
\text { Principle }\end{array}$} \\
\hline & & 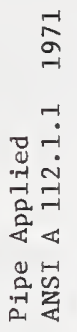 & 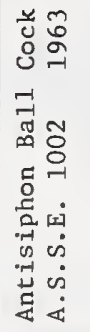 & 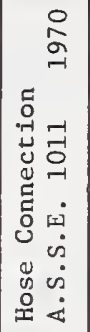 & 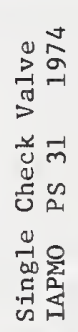 & 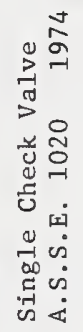 & 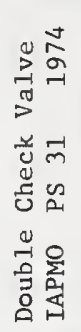 & 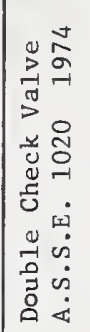 & 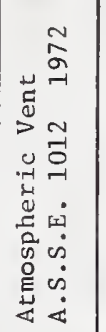 & 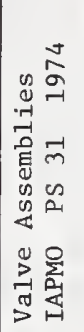 & 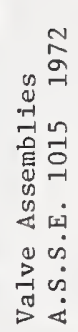 & 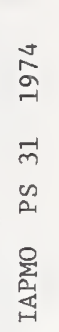 & $\begin{array}{l}\vec{a} \\
\vec{\sigma} \\
m \\
\overrightarrow{0} \\
\overrightarrow{-1} \\
\dot{4} \\
\dot{\omega} \\
\dot{\omega} \\
\dot{4}\end{array}$ \\
\hline $\begin{array}{l}\text { Johns-Manville Corp. } \\
\text { Josam Manufacturing Co. } \\
\text { Kirkhill,Inc. } \\
\text { Kohler Company }\end{array}$ & & $\mathrm{N}$ & $\begin{array}{l}\mathrm{N} \\
\mathrm{N}\end{array}$ & $\mathrm{N}$ & 非 & & \# & & & $\#$ & $\&$ & \# & $\&$ \\
\hline $\begin{array}{l}\text { Lawler ITT } \\
\text { Lear Siegler, Inc. } \\
\text { Mansfield Sanitary, Inc. } \\
\text { Modern Faucet Mfg. Co. }\end{array}$ & & 非 & $\begin{array}{l}\mathrm{N} \\
\mathrm{N}\end{array}$ & $\&$ & & & & & & & $\&$ & & $\&$ \\
\hline $\begin{array}{l}\text { Mueller Steam Specialty Co. } \\
\text { L. R. Nelson Corporation } \\
\text { Neptune Water Meter Co. } \\
\text { Nibco, Inc. }\end{array}$ & & $\&$ & & $\&$ & & & & & & & $\&$ & & $\&$ \\
\hline $\begin{array}{l}\text { Nidel Company } \\
\text { Powers Regulator Co. } \\
\text { Rain Bird Sprinkler Mfg.Co. } \\
\text { Rockwell International Corp. }\end{array}$ & & $\begin{array}{c}\# \\
\# \\
\mathrm{~N} \\
\# \&\end{array}$ & & $\&$ & & & & & $\&$ & & $\&$ & & $\&$ \\
\hline $\begin{array}{l}\text { Sloan Valve Company } \\
\text { Surgical Mech. Research, Inc. } \\
\text { Taco, Incorporated } \\
\text { Tempstat Corporation }\end{array}$ & & 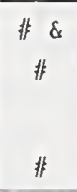 & & & \# & & 非 & & $\&$ & \# & & & \\
\hline $\begin{array}{l}\text { I \& S Brass \& Bronze Works } \\
\text { Toro Technology } \\
\text { Twentleth Century Products } \\
\text { Water Saver Faucet Company }\end{array}$ & & $\mathrm{N}$ & $\&$ & & & & & & & & $\mathrm{~N}$ & & $\mathrm{~N}$ \\
\hline $\begin{array}{l}\text { Watts Regulator Company } \\
\text { Wolverine Brass Works } \\
\text { Woodford Mfg. Company } \\
\text { Zurn Industries, Inc. }\end{array}$ & & \# \& & & $\&$ & & & & $\mathrm{~N}$ & $\&$ & & $\&$ & & $\&$ \\
\hline
\end{tabular}

Meaning of Symbols: $\#=$ FCCCHR Listed $\&=$ A.S.S.E. Listed $N=$ Advertized but not listed 
It was mentioned in Section 2.2 that the Foundation for CrossConnection Research was established as an arm of the University of Southern California in 1944. In a publication dated April, 1948 it was

5 stated that the Research Foundation for Cross-Connection Control established at the University of Southern California is properly equipped to make all the necessary studies and tests on antisiphon and backflow prevention devices and has been engaged in the work since 1944. [12]

The name of the foundation was later changed to appear in the fourth edition of the Manual of Cross-Connection Control[15] as Foundation for Cross-Connection Control Research (FCCCR). In the latest edition of the Manual the name is given as Foundation for Cross-

15 Connection Control and Hydraulic Research (FCCCHR). As reported by Bibbens [11]:

"A financial grant originally equipped the FCCCR laboratory and provided staff salaries for the first few years. Lavoratory equipment

20 and instrumentation were expanded and improved in following years through gifts from water equipment manufacturers. There is now a written agreement with the Southern California Water Utilities Association which provides financial support for the Foundation in the form of annual membership subscriptions by water utilities, cities, and

25 county, state, and federal agencies. Memberships range from $\$ 50$ to $\$ 500$ per year, depenaing on utility size. The Southern California Water Utilities Association is a non-profit organization which supports an educational institution (the FCCCR)." [11]

30 "The FCCCR laboratory was originally located on the USC campus but was removed in the mid-1960's to make way for other campus expansion. Being without laboratory facilities for a few years, the FCCCR contracted for the use of private facilities when laboratory tests were required. In, 1968, the laboratory was reestablished in an old pumping 35 station on Riverside Drive in Los Angeles. The FCCCR currently conducts backflow evaluation tests and other related research at this facility. Pressures of 45 and 150 psi are available directly from the city's water supply system. Headers up to $16^{\prime \prime}$ are installed for

40 testing the various sizes of devices. A $200 \mathrm{HP}$ diesel engine driven puxp will soon be included in the system to provide a 4600 gpm recirculating flow capacity. The Foundation's laboratory was inspected by the NCEL Project Engineer in June 1969 and was found to have facilities adequate for the testing of backflow preventers as prescribed

45 by the 4th Edition of the "Manual." During this inspection, it was observed that extensive equipment modification and improvement were underway and much new instrumentation was being installed in the laboratory. Half of the laboratory space was occupied by the Los Angeles Department of Water and Power for meter flow testing, but the remaining 
half of the laboratory had enough space for considerable future expansion by the FCCCHR for further testing or research." [11]

Summarizing from Dr. Springer's paper [32] for testing under the FCCCHR procedures, a proposer must:

5

10

15

20

25

30

35

(d) The field installed devices are tested monthly:

-- The tightness of each check valve for double check valve assemblies is determined by test to see that each check will hold a 1 psig difierential in the direction of flow.

-- The opening pressure differential of the relief valve, the pressure differential across number one check valve, and the drip tightness of number two check valve are all checked for the RPBD device."

(e) If any type of malfunction is observed during the field test, the test is terminated and such devices are returned to the manufacturer for corrective measures. 
(f) After the device has been corrected or redesigned, the device must go through the complete hydraulic laboratory evaluation again just as though it were a completely new device. Then if a successful laboratory test is again realized, the device is field tested a second time. When the device satisfies FCCCHR requirements, the manufacturer receives a "Certificate of Approval" for the particular model and size of device passing the tests.

\subsubsection{Laboratories testing in the A.S.S.E. Seal Program}

The American Society of Sanitary Engineering (A.S.S.E.) was established in 1906 with its main endeavor being in the field of Plumbing and Sanitary Research. A.S.S.E. main office is located in Cleveland, Ohio [21].

The A.S.S.E. has authorized three independent testing laboratories to test products for compliance with the A.S.S.E. Standards mentioned previously in this report. These laboratories are:

(a) The Twining Laboratories, Incorporated, Fresno, California

(b) The National Sanitation Foundation, Ann Arbor, Michigan

(c) Factory Mutual Research Corporation, Norwood, Massachusetts.

When a product is approved in one of these authorized laboratories the A.S.S.E. seal may be displayed on the product. The seal indicates that the product has been certified to be in compliance with the appropriate A.S.S.E. standard as a result of satisfactory laboratory tests. Authorization for the use of the seal is obtained from the Seal Control Board at the A.S.S.E. Central office.

The seal is issued for a period of five (5) years but must be renewed annually by the manufacturer. The manufarturer must prove to the satisfaction of the Seal Control Board that the product has not been changed or modifled in any way that would affect compliance with the requirements under which it was tested. Extension of the seal usage 40 beyond five years may be negotiated with the Seal Control Board. The manufacturer makes all arrangements for testing at an A.S.S.E. approved laboratory and defrays all costs involved. If the manufacturer changes or alters his product without notification, the Board will cancel the manufacturer's right to display the seal. 


\subsubsection{Procedures for a National Voluntary Laboratory Accreditation Program}

During the fall and winter of 1972, R.W. Beausoliel visited five laboratories in expectation that such visits would provide critical information needed to perform an evaluation of each laboratory. We know now that in the half-day alloted for each of the visits, we did not and probably could not have obtained the essential information needed for such evaluations. We know that the business of evaluating laboratories is a complex one, for we have become aware of the work being done by 10 others at NBS to define an acceptable laboratory evaluation program. The evaluation and accreditation program is now established and is presented in detail, with special formatting, in the Appendix, Section 10.3.

Concisely, the ten steps needed to develop a list of accredited laboratories to test backflow prevention devices are as follows:

(1) Some person or organization must request the Secretary of Commerce to find that there is a need for accrediting laboratories to test backflow prevention devices (Sec.7.4(a))

(2) Such request will have to show:

(a) that standards and test methods exist for the evaluation of backflow prevention devices,

(b) the number of testing laboratories believed desiring to be accredited to test backflow prevention devices,

(c) and the number of anticipated users of the testing laboratories service. (Sec. $7.4(\mathrm{~b})$ )

(3) Public hearings will be held to provide a forum for any and all opinions to be expressed. (Sec. 7.4(f))

(4) Based on the expressions that come from the hearings, the Secretary of Commerce will either decide to proceed or to withdraw. (Sec. 7.4(g)).

(5) If the Secretary proceeds he will form a National Laboratory Accreditation Criteria Committee for Backflow Prevention Devices. (Sec. 7.4(h)(3)).

(6) The Committee will be directed by the Secretary of Commerce to develop and recommend to him, general and specific criteria to accredit testing laboratories that serve backflow prevention devices. (Sec. 7.6(d)).

(7) When the specific and general criteria have been prepared for the Secretary of Commerce, he will consider them and invite comments from the public. (Sec. 7.8(a))

(8) The input from the hearings will be turned over to the Criteria Committee to evaluate and to advise the Secretary of Commerce (Sec. 7.8(c)). 
(9) Should the Secretary of Commerce accept the Criteria Committee's work, the criteria will be accepted and laboratories will be invited to apply for accreditation. (Sec. $7.10(\mathrm{~b})$ )

(10) The Secretary of Commerce will report to the public monthly, via the Federal Register, all actions which grant, revoke, terminate, or result in the withdrawal of the accreditation of a laboratory. (Sec. $7.17(\mathrm{c})$ ).

In the above procedures, the initiating action requires that

10 standards and test methods exist for the evaluation of the devices. The A.S.S.E. standards have been submitted to the American National Standards Institute (ANSI) for consideration by the A 112 Committee. For only two of these has the approval process progressed to the stage of final approval.

The correlation of A.S.S.E. standards with the ANSI numbers are:

$\begin{array}{llll}\text { A.S.S.E. } 1001 . & \text { ANSI A } 112.1 .1-1971 \\ \text { A.S.S.E. } 1011 & \text { ANSI A } 112.1 .3-1976 \\ \text { A.S.S.E. } 1012 . & \text {. ANSI A } 112.1 .4- \\ \text { A.S.S.E. } 1013{ }^{\circ} \text { ANSI A } 112.1 .5- \\ \text { A.S.S.E. } 1015 . & \text { ANSI A } 112.1 .6- \\ \text { A.S.S.E. } 1020 & \text { ANSI A } 112.1 .7-1976\end{array}$

Also required to exist for the initiating action is information on the number of testing laboratories desiring to be accredited. To explore the possibility of developing such information, reference was made to the 1976 Directory of the American Council of Independent Laboratories, Inc., 1725 K Street, N.W., Washington, D.C. 20006. (202) 659-3766.

The Directory has a classified index of its membership wherein those laboratories doing qualification testing, hydraulic testing, hydrostatic testing, and also carrying out certification programs are identified by the page number of their advertisement in the directory. All laboratories identified as being in each of the four classifications were selecting for listing here. With the names of the laboratories and three others taken from our files, table 8 was compiled. 
Table 8. A List of 24 Independent Testing Laboratories Potentially Interested in Testing Backflow Prevention Devices. (See Sec. 3.4.3)

Applied Research Laboratories of Florida,Inc. Florida Industrial Research Park SR 27 43650 S.W. 232 Avenue, Dade County,Florida P.0. Drawer 1, Homestead,Fla. (305) 245-3660

Approved Engineering Test Laboratories, Inc. 15720 Ventura Boulevard, Suite 420

Encino, California 91436

(213) 783-5985

Associated Testing Laboratories, Inc.

9 Brighton Road

Clifton, New Jersey 07012

(201) 473-6455

Bowser - Morner Testing Laboratories, Inc. 420 Davis Avenue P.O. Box 51

Dayton, Ohio 45401

(513) 253-8805

C $\mathrm{T}$ L Engineering, Inc.

2860 Fisher Road

Columbus, Ohio 43204

(614) 276-8123

Detroit Testing Laboratory, Inc.

8720 Northend Avenue

Oak Park, Michigan 48237

(313) $398-2100$

Electrical Testing Laboratories, Inc.

2 East End Avenue

New York, New York 10021

(212) 288-2600

Engineers Testing Laboratories, Inc.

3737 East Broadway

Phoenix, Arizona 85040

(602) 268-1381

Froehling and Robertson, Inc.

814 West Cary St. P.O. Box 27524 Zip 23261

Richmond, Virginia 23220

(804) 644-3025

General Environments Corp.

6840 Industrial Road

Springfield, Virginia

22151

(703) $354-2000$

Arnold Greene Testing Laboratories, Inc. East Natick Industrial Park

6 Huron Drive, Natick, Mass. 01760

(617) 235-7330

Arnold Greene Testing Laboratories of P.R., 167 Quisqueya Avenue

Hato Rey, Puerto Rico 00917

(809) 763-3910
Institute for Research, Inc.

8330 Westglen Drive

Houston, Texas 77063

(713) 783-8400

Law Engineering Testing Company

P.0.Box 98008, 2000 Century Parkway

Atlanta, Georgia 30329

(404) 325-3933

Shilstone Engineering Testing Laboratory, Inc.

1714 Memorial Drive

Houston, Texas 77007

(713) 224-2047

Skinner and Sherman, Inc.

227 California Street

Newton, Massachussetts 02195

(617) 332-8300

Smith - Emery Company

781 East Washington Boulevard

Los Angeles, California 90021

(213) 749-3411

Southwestern Laboratories,

222 Cavalcade Blvd. P.O. Box 8768

Houston, Texas 77009

(713) 692-9151

Testing Consultants, Inc.

525 East Mississippi Avenue

Denver, Colorado 80210

(303) 777-1771

Twining Laboratories of Southern California, Inc.

3310 Airport Way P.0. Box 47

Long Beach, California 90801

(213) 426-3355

United States Testing Company, Inc.

1415 Park Avenue

Hoboken, New Jersey 07030

(201) 792-2400

Value Engineering Laboratory

2550 Huntington Avenue

Alexandria, Virginia 22303

(703) $960-4600$

Wingerter Laboratories, Inc.

1820 N.E. 144th Street Drawer L

North Miami, Florida, 33161

(305) 944-3401

York Research Corporation

One Research Drive

Stamford, Connecticut 06904

(203) 325-1371 


\subsection{A Conceptual Model Cross-Connection Control Program}

In recent months a conceptual model for a realistic crossconnection control program has been evolving. The necessary elements are even now developing, with a minimum of input from the authors. The model is shown as figure 4.

I. In the model, credit is given to EPA as being the source of activity needed to bring all elements together into a workable program. The line of action indicates that EPA would provide guidelines to state or municipal authorities who would in turn develop the appropriate 10 legislation or ordinance to establish the cross-connection control program.

II. The enabling laws will require funds for the operation of the program. The funding would pay for two activities:

(a) An inspection program that:

1. Authorized installation of particular backflow prevention devices where needed.

2. Inspected the installation of the device at time of construction.

3. Carried out a regular schedule of reinspection and testing to determine that backflow protection devices were performing adequately.

(b) A contractual arrangement with an independent testing laboratory to:

1. Audit or monitor the cross-connection control program on a annual or semi-annual basis to assure that the program was being carried out under (a) above as required by law, and

2. To provide technical guidance and training to the inspection staff as needed and as contracted for.

III. To be qualified to make decisions or judgments on suitable

35 backflow protection devices the inspection staff will need technical guidance for the approval of devices. Such guidance could come from:

1. Knowledge that suitable devices are available in a competitive market to fill needs in most applications.

2. Kriowledge of existence of nationally recognized product standards that assure quality and dependability for the several types of devices.

3. Knowledge of the existence of a certification program that verifies on a continuing basis that devices claiming to meet the requirement of the standards actually do so. 


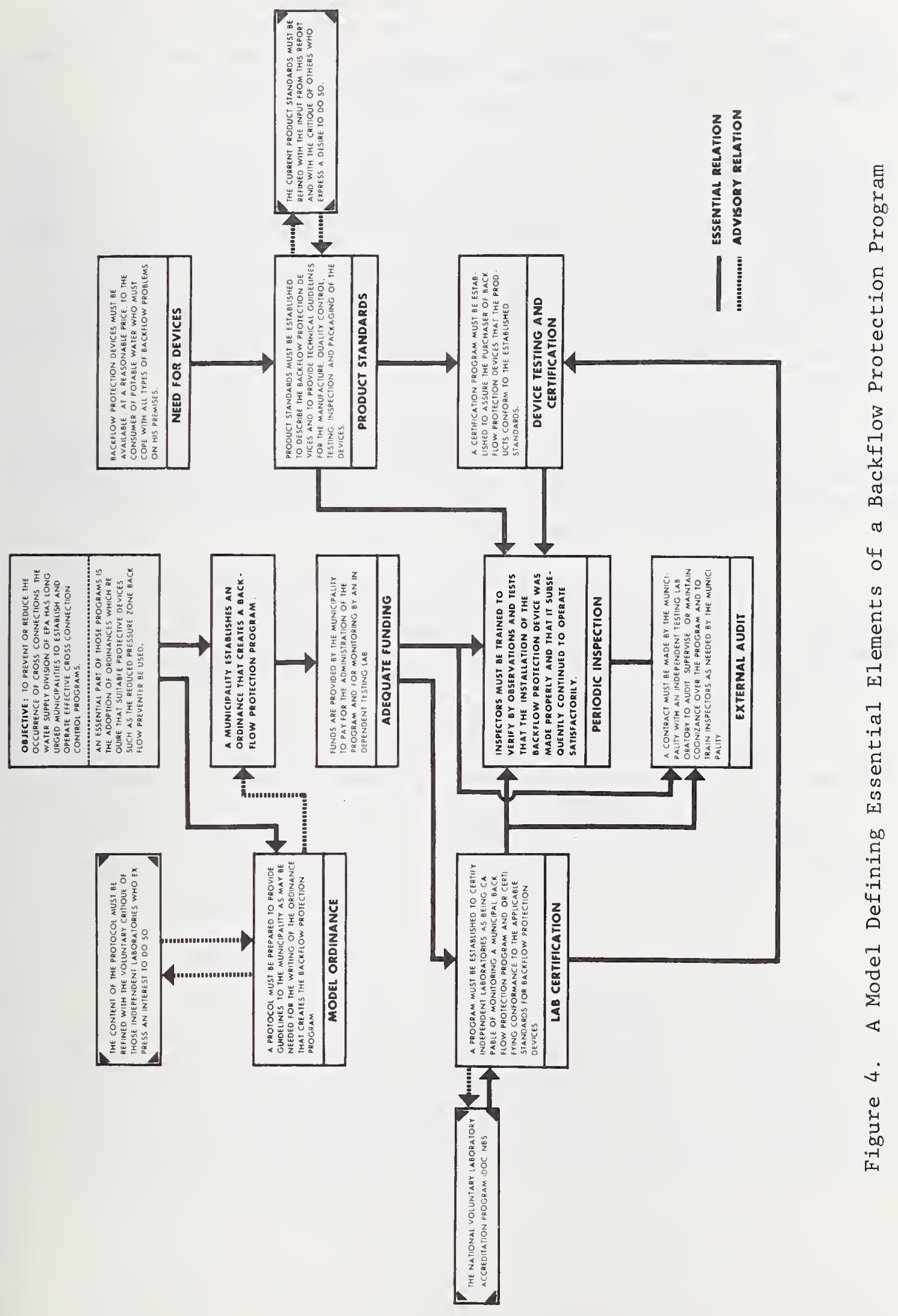


IV. The existence of a competitive market depends upon a demand for the devices. The demand may be expected to increase as the number of cross-connection control programs increase. The demand could then be expected to motivate new designs - utilizing new materials - and necessitating evaluation of the new products.

V. The product standards currently in existence need to be improved from the present stage to assure that testing and certification may be carried out uniformly by any certified independent testing laboratory. To provide for approval of suitable innovative devices, the requirements for backflow protection devices need to be stated in performance

10 language. Another document of NBS, NBSIR 76-1020 "Guide Criteria for Laboratory Evaluation of Backflow Prevention Devices for Protection of Potable Water Supplies" by Grover C. Sherlin, Robert W. Beausoliel, and Lawrence S. Galowin will aid in the develop of the performance language.

VI. Certification of the backflow protection devices would be carried out by authorized independent testing laboratories who receive compensation for such certification from the manufacturers. Authorization of the certifying laboratories could be accomplished through the U.S.

20 Department of Commerce Accreditation Program.

VII. The National Voluntary Laboratory Accreditation Program is now available to accredit testing laboratories to test backflow prevention devices. In Section 3.4.3 a concise listing is given of steps required 25 to initiate the program. The complete program is presented as Appendix Section 10.3. 


\subsection{EVALUATION OF DEVICES}

4.1 Design Considerations that Affect Reliability

\subsubsection{Air Gaps}

The design of air gaps in a potable water distribution line depends upon the size of the effective opening and the distance between the supply fitting outlet (spout or faucet) and a near-by wall. Above one-inch diameter of effective opening the length of air gap is specified to be twice the diameter; except when affected 10 by a near-by wall it is to be three times the diameter. See figure 3.

The primary function of the air gap may be defeated by attaching a hose, a pipe, or a tube between the potable water outlet and a nonpotable source. Possible means to prevent such practices are by

15 designing or modifying outlets of faucets to discourage the attachment of hoses and by initiating educational programs to apprise the public that attachment of such hoses can create potential health hazards.

\subsubsection{Barometric Loops}

20

The Environmental Services Branch, National Institutes of Health, in cooperation with the Division of Environmental Health and Safety, University of Minnesota Health Service investigated the barometric loop [27]. The investigation showed that air bubbles could transfer contaminated water through the loop when back-siphonage occurred. They developed an air-water separator that proved effective in preventing such transfer. Additional studies were recommended to determine the effect diffusion might have in the transfer of contaminants through the.loop. There are no data on how widely

30 barometric loops are used or on how many loops are used with airseparators. The use of the separators with loops does not appear in the model plumbing codes.

\subsubsection{Pipe Applied Vacuum Breakers}

35

The pressure type vacuum breakers (PVB) and the atmospheric type vacuum breakers (AVB) are vulnerable to air port blockage by rags, etc. Such blockage would render the device ineffective. Suggested countermeasures are educational efforts to explain the

40 need to keep the air ports or air inlets of the vacuum breakers open, and frequent periodic inspection, test and repair. Although PVB has means for testing the device in line, standards do not require similar test arrangement for AVB. 


\subsubsection{Hose Connection Vacuum Breakers}

There are two types of hose connection vacuum breakers (HCVB). One type has a diaphragm to seal the air inlets but does not have a check valve to seal the water inlet. This type of HCVB is essentially a special design of AVB which is not intended to be subjected to back pressure. The other type of HCVB has both a diaphragm and check valve. For such devices a nationally recognized standard ASSE 1011 specifies the following test requirements which are unique for vacuum breakers:

- The outlet of the device is subjected to a back pressure created by a ten-foot colum of water within an elevated garden hose. Backflow through the check must not take place under this pressure.

- Leakage of water from the hose through the HCVB at the rate of 1/4-pint per minute is permitted to flow through the vent ports to the ambient in order to relieve back pressure caused by the colum of water in the hose. (The check valve prevents backflow into the inlet of the device when the water is discharged from the vent ports).

The objectives of these two tests conflict with the principles set forth by two authorities concerned with vacuum breakers. For instance, the following attitudes were found concerning the first and second test methods respectively:

- HCVB exposure to back pressure is not allowed under AWWA's Pacific Northwest Sections Manual [1]. The Manual depicts this HCVB (with the check valve) as an AVB which the manual states is not effective against backflow due to back pressure.

- Dawson and Kalinske have said that the air inlets of vacuum breakers should not be used to convey water as lime deposits may cause closure of the air inlets. Also the air inlets should not be placed where they would get exposed to polluted water [3].

A third test method concerns the fouling of the check with a wire (a common test for vacuum breakers) [20] to simulate check valve leakage resulting from check material failure or a foreign substance lodged between the check and its seat. The test is summarized as follows :

- The back-81phonage test with vacuum applied at the inlet to HCVB requires the check to be fouled. 
- In the back pressure portion of the test method, the check valve is not fouled. (The standard does not say that backflow will occur if the check leaks).

It seems reasonable that if the device effectively prevents backflow under back-siphonage conditions with a fouled check, the device should also effectively prevent backflow due to combined back-siphonage and back pressure because the standard indicates that the device effectively relieves back pressure. The standard does not consider the simultaneous application of both vacuum at the inlet and back pressure at the outlet. Such likely conditions could 10 occur when filling a back yard swimming pool with an elevated garden hose. Because the standard test methods did not address this likely condition, a simple test, as explained in Appendix Section 10.4, was carried out to see how effective the device would be in relieving back pressure and preventing backflow with the simultaneous application

15 of vacuum at the inlet and back pressure at the outlet with the check fouled in the manner of the standard test method. Backflow occurred at $0.2 \mathrm{gpm}$. The test results indicate that backflow remained constant with increasing elevation of the terminal end of the hose (increasing back pressure). Such a constant backflow rate into the inlet of the 20 device does indicate that the device is effective in relieving back pressure. However, the results also indicate that a tight check valve is required to prevent backflow under these conditions. It would seem reasonable that the standard consider this limitation of the device.

25

It appears that the HCVB which includes the check valve is superior to the type that does not have a check valve. The use of garden hoses with HCVB naturally subjects HCVB to back pressure. The HCVB without a check valve can not resist back pressure. A

30 simple test by the National Bureau of Standards in accordance to ASSE 1011 [21] showed that the device would backflow when subjected to atmospheric pressure at the inlet and a three-foot head of water at the outlet. Because of this, NBS believes that HCVB without a check should not be used with garden hoses. It is possible to

35 overly criticize this relatively inexpensive device (present cost about four dollars) because obviously a garden hose installation is safer with HCVB than without it. Alternatives to present HCVB installation for garden hose applications could be the use of the pressure vacuum breaker in the hose supply or, perhaps, a redesign

40 of the water supply piping such that the terminal end of a garden hose under normal use would not be elevated above HCVB or other vacuum breaker. Such approaches would tend to increase the cost of the installation; but it must be 
remembered, however, that garden hose installation can cause deaths as shown by the example in section 2.1 of this report and the best protection must be provided. It may be that HCVB is quite adequate if the check valve does not leak. A study should be carried out to determine the following:

- Will the air ports of the HCVB become blocked with lime deposits as mentioned by Dawson and Kalinske [3]?

- Is there, in reality, a high risk of contamination at the air ports of HCVB with the check valve?6/

- How reliable is the check valve under service conditions?

- Would the HCVB give additional protection if it were installed at the nozzle end of the garden hose or at both the faucet end and nozzle end?

With any such change(s), the manufacturers and/or administrative authorities should make the general public aware of the importance and

20 function of $\mathrm{HCVB}$ and other devices (perhaps TV coverage from time to time and informative literature concerning backflow potential included with the water purveyors bills).

\subsubsection{Double Check Valve Assemblies}

The double check valve assembly (DCVA) gives no visual indication of check-valve failure. Protection depends entirely on tight check valves. Good preventive maintenance will tend to preclude check-valve leakage.

6/ It is interesting to note that if a 50-foot length of $1 / 2$-inch diameter garden hose was used to fill an elevated swimming pool such that water would backflow from the hose through the vent ports to the surrounding atmosphere at the rate allowed in the standard, 1/4pint per minute (approximately 29 cubic inches per minute), all of the water in the hose (about 118 cubic inches) would flow through the ports in about five minutes. At the end of this time, possibly non-potable swimming pool water would be flowing in the hose and vent ports. 


\subsubsection{Backflow Preventers with Intermediate Atmospheric Vent}

Since the backflow preventers with intermediate atmospheric vent are relatively new, no feedback from installation experience was found.

5

\subsubsection{Reduced-Pressure Principle Back Pressure Backflow Preventers}

Some authorities declare that a reduced-pressure principle backflow preventer (RPBD) will permit backflow when its upstream and downstream check valves both leak when there is vacuum at the inlet

10 and back pressure at the outlet. In light of such statements, and in view of the fact that existing standards for RPBD do not have tests for back-siphonage, a limited NBS laboratory test of a 3/4-inch device was conducted to determine if it would permit backflow. See Appendix 10.5 for details. With the check valves fouled with 0.042 -in

15 diameter wires in the manner normal during vacuum breaker tests [20], with a vacuum of 11 centimeters of mercury absolute (about 25 inches of mercury gage) at the inlet, and with low back pressure of 1.31 psig, and zone pressure of one inch of water column gage, an average backflow rate of $0.029 \mathrm{gpm}$ into the inlet of the device occurred. The relief valve was open under these conditions and discharged water from the zone to drain at only $1.85 \mathrm{gpm}$ indicating that the zone was not overloaded (this rate was well below the 5 gpm allowed by the standards). It was noted that the soft rubber check valve material used in the upstream check of this particular model of RPBD tended to slowly seat around the wire thus preventing backflow into the inlet.

The results above are in agreement with those for a similar test of a 3/4-inch RPBD made at NBS over 20 years ago.7/ During that test the check valves of RPBD were fouled with $0 . \overline{0} 27$-inch

30 diameter wire. The supply piping to the device was subjected to vacuum up to 18-inches of mercury gage, and at the same time a positive water pressure of 25 psig was maintained in the piping downstream of the device. The final paragraph concerning the test results stated the following: "In none of the vacuum tests described above was there any indication whatsoever of backflow. Apparently the resilient nature of the main valve seat and the force of the spring, which aids in closing the valve, are responsible, at least in part, for good results obtained. Even when the piece of wire

40

7/ National Bureau of Standards Report on Test of Backflow Preventer Requested by the Federal Security Agency, National Institutes of

Health, U. S. Public Health Service, Washington, D. C. on January 31 , 1952. Prepared by R. S. Wyly. 
was placed between the main valve and its seat, there was no apparent backflow of either air or water. Inspection of the valve showed that the wire had merely been pressed into the valve seat, and when the unit was disassembeled, the wire fell out, leaving only an insignificant mark on the valve seat." The final conclusion of the report states. "It is obvious that under extreme conditions, backflow could take place in the unit tested; for example, with the check valve and the main valve very poorly seated or held open, simultaneously with a high vacuum in the supply line. However, no backflow preventer or vacuum breaker known at this time is entirely perfect or foolproof. It is believed that in the great majority of cases serious imperfections 10 in valve seating will develop gradually; hence, in the device tested, visual evidence of this fact would be at hand long before any real danger of backflow exists."

There appear to be four reasons for backflow during the test presented in Appendix Section 10.5

( i) The fouling wires used were 0.042-inches in diameter versus 0.027 -inches in diameter for the earlier NBS test. The smaller diameter would favor check valve seating into the soft check material.

(ii) A vacuum of 11-centimeters of mercury absolute was used in this work (about 25-inches of mercury gage) which is somewhat more severe than the 18 inches of mercury gage used in the earlier NBS test.

(iii) The device used in this work was installed in a vertical line (as sanctioned by the manufacturer) with the direction of normal flow "Down". The older device was installed in a horizontal line.

( iv) There were differences in manufactures designs, i.e., internal shape and size of the zone, discharge port, etc.

It seems likely, that had the 0.042-inch diameter fouling wire been used during the earlier test, backflow probably would have occurred. It must be said also that the rate of backflow occurring during the test presented in Appendix 10.5 was very low. The likelihood of

40 such fouling of the device is probably remote because the manufacturer requires the use of a strainer upstream of the device and the upstream check valve has two seats that have to be fouled simultaneously. Considerable difficulty was experienced during initial efforts to get the wire to remain in position across both seats simultaneously. 
Additional tests should be carried out concerning RPBD of other sizes and from other manufacturers. Preliminary information obtained from such tests would be of value in the development of a back-siphonage test for a RPBD. The present standards for RPBD do not have back-siphonage test methods or requirements; however, the device is relied upon by many users to give effective protection against back-siphonage.

It was beyond the scope and resources of this project to determine the probability of the two check valves of an RPBD leaking simultaneous1y or whether any RPBD of other manufacturers would 10 allow backflow or whether the size or configuration of the device contributed to the backflow failures. An attempt was made to get information from the Los Angeles Department of Water and Power (DWP) concerning the number of times in any one year period on an average that RPBD experiences the failure of both check valves. DWP has 15 computer records of inspection, test, and performance data on over 3,000 backflow preventers [11]; however, a computer program would have to be developed to retrieve this information. The Department of Public Utilities, City of Tacoma, Washington provided data for yearly tests conducted on RPBD and double check valve assemblies

20 (DCVA) for the past $21 / 2$ years. Data collected from 114 RPBD tests showed several failures of the RPBD relief valves; however, only one RPBD was found to have both check valves leaking simultaneously. This condition occurred because of debris under the checks. Only two DCVA were found to have both checks leaking simultaneously out

25 of 59 tests of DCVA conducted during that period. Factory Mutual Fire Insurance Companies inspected 1,032 sets of DCVA and on $1 y$ four sets were found out of this number to have both checks leaking simultaneously [34]. The use of strainers ahead of RPBD may be a precaution to reduce risk of check leakage due to debris. ASSE

30 Standard 1013 for RPBD recommends the use of strainers but other standards do not. It is believed by some that strainers introduce excessive pressure drop.

The U. S. Navy has reported that on certain docks and piers

35 the relief valves of RPBD have frozen. Such failures have become an expensive and not completely solved problem [11]. Repiping for installation of a RPBD within a heated space could be a solution.

$40 \quad 4.2 \quad$ Assessment of Standard Test Methods

In this section the test methods given in standards for the backflow prevention devices will be evaluated against the following criteria: 
(a) Understandable, Usable and Fair: Can any normally equipped laboratory perform the tests as described in the standard? Can innovative devices be accepted under the test method described or would such devices be restricted from approval?

(b) Methods that test appropriate attributes (life cycle phenomena): Are the test methods realistic? Do they expose devices to water supply conditions of temperature, pressure, flow, chemistry, water borne inclusions, and actual or test contaminants that could pollute the potable water?

(c) Repeatability and Accuracy: Are the test data repeatable and how many runs of test data are taken? How accurate are the measured data?

(d) Limit testing, Failure Modes, Maintainability, and Field Testing: Are tests used to determine common modes of device failure? Is level of maintenance determined? Do laboratory tests assure satisfactory field performance?

(e) Cost/effectiveness: Are test methods periodically reviewed to determine if instrumentation techniques or other newly developed techniques might substantially reduce the cost of testing and improve data quality?

By the formulation of these criteria there has been established a "yard stick" against which the test methods may be evaluated. In tables 9,10 and 11 the tests methods are summarized with comments

40 as appropriate. In the following subsections the tests methods will be discussed in terms of the above criteria.

In Appendix 10.6 each of the ASSE Standards have been analysed in great detail to identify the test requirements, test 45 setup and preparation for testing, test procedure, observations records and computations and basis for rejection of device. The matrix format used facilitates the identification of missing elements.

50 4.2.1 Understandable, Usable, and Fair Test Methods

The ASSE Standards have test setups and test methods for a laboratory to follow which are understandable and usable. The FCCCHR and IAPMO Standards imply identical hydraulic laboratory tests but 
Table 9 Summary of Test Methods Found in Current Standards for Atmospheric Types of Backflow Preventers - with Comments

\begin{tabular}{|c|c|c|}
\hline $\begin{array}{l}\text { Devices and } \\
\text { Standards }\end{array}$ & Test Methods & Comments \\
\hline $\begin{array}{l}\text { Air Gap (AG) } \\
\text { ANS I Al12.1.2 } 1973 \text { [26] }\end{array}$ & $\begin{array}{l}\text { Measurement of the length of } \\
\text { the air gap between the flood } \\
\text { level rim of a plumbing fix- } \\
\text { ture or tank and the effective } \\
\text { (minimum) diameter of the } \\
\text { water supply outlet }\end{array}$ & Adequate test methods \\
\hline $\begin{array}{l}\begin{array}{l}\text { Atmospheric } \\
\text { Vacuum } \\
\text { Breaker } \quad(A V B)\end{array} \\
\text { A.S.S.E. } 1001,1970 \\
\text { ANSI A112.1.1 } 1971 \quad[20]\end{array}$ & $\begin{array}{l}\text { - Nontoxic certification } \\
\text { - Positive pressure test } \\
\text { - Air port shield examination } \\
\text { - Air flow test } \\
\text { - Water rise test }\end{array}$ & $\begin{array}{l}\text { Test methods are indirect, } \\
\text { that is, a tracer,yielding } \\
\text { quantitative results is } \\
\text { not used to simulate } \\
\text { contaminants. }\end{array}$ \\
\hline $\begin{array}{l}\text { Antisiphon } \\
\text { Flush Valve } \\
\text { Ball Cock (AFVBC) } \\
\text { A.S.S.E. } 1002,1968 \quad[30]\end{array}$ & $\begin{array}{l}\text { - General requirements } \\
\text { - Vacuum breaker equipped } \\
\text { - Air gap equipped ball cock }\end{array}$ & \\
\hline Barometric Loop (BL) & (No test methods) & $\begin{array}{l}\text { This device has features } \\
\text { which may be engineered } \\
\text { into the installation to } \\
\text { make it reliable and cost- } \\
\text { effective. }\end{array}$ \\
\hline $\begin{array}{l}\text { Backflow Preventers } \\
\text { with Intermediate } \\
\text { Atmospheric Vent (BPIA) } \\
\text { A.S.S.E. } 1012,1972 \text { [22] } \\
\text { ANSI A112.1.4 - } 1976\end{array}$ & $\begin{array}{l}\text { - Hoise } \\
\text { - Hydrostatic test - total } \\
\text { - Tydrostatic test - check valve } \\
\text { - Tightness of downstream check } \\
\text { - Atmospheric vent valve leakage } \\
\text { - Backflow through inlet check } \\
\text { - Atmospheric vent, opening } \\
\text { - pressure } \\
\text { - Flock-siphonage } \\
\text { - Flow with low supply pressure }\end{array}$ & $\begin{array}{l}\text { The standard does not have } \\
\text { a test method to cover the } \\
\text { likely condition of simul- } \\
\text { taneous vacuum at the in- } \\
\text { let and back pressure at } \\
\text { the outlet } \\
\text { A tracer to simulate con- } \\
\text { tamination could be used } \\
\text { to give quantitative mea- } \\
\text { surements of check valve } \\
\text { leakage. The colored water } \\
\text { tracer called for can give } \\
\text { only a qualitative value. }\end{array}$ \\
\hline $\begin{array}{l}\text { Hose Connection } \\
\text { Vacuum Breakers (HCVB) } \\
\text { A.S.S.E. } 1011,1970 \text { [21] } \\
\text { ANSI A112.1.3 - } 1976\end{array}$ & $\begin{array}{l}\text { - Resistance to hydrostatic test } \\
\text { - Noise } \\
\text { - Water flow capacity } \\
\text { - Leakage from vent ports } \\
\text { - Water hammer shock resistance } \\
\text { - Backflow due to back pressure } \\
\text { - Backflow due to back-siphonage } \\
\text { - Resistance to bending } \\
\text { - Ability to resist and relieve } \\
\text { back pressure } \\
\text { - Deterioration in hot and cold } \\
\text { water. }\end{array}$ & $\begin{array}{l}\text { Although the test method } \\
\text { for backflow, section } \\
2.1 .6 \text {, requires the use of } \\
\text { a colored water tracer, } \\
\text { this is a qualitative test } \\
\text { only which depends on } \\
\text { visual ability to detect } \\
\text { the presence of the tracer. } \\
\text { A measureable tracer is } \\
\text { not used. }\end{array}$ \\
\hline
\end{tabular}


Table 10 Summary of Test Methods Found in Current Standards for Double Check Valve Assemblies and for Pressure Type Vacuum Breakers - with Comments

\begin{tabular}{|c|c|c|}
\hline $\begin{array}{c}\text { Devices and } \\
\text { Standards }\end{array}$ & Test Methods & Comments \\
\hline $\begin{array}{l}\text { Double Check } \\
\text { Valve Assembly (DCVA) } \\
\text { A.S.S.E. } 1015,1972 \quad[24] \\
\text { ANSI All2.1.6 - } 1976\end{array}$ & $\begin{array}{l}\text { - Hydrostatic test - full } \\
\text { - Hydrostatic back pressure test } \\
\text { of check valves } \\
\text { - Tightness of check valves } \\
\text { against upstream pressure } \\
\text { of } 1 \text { psi. } \\
\text { - Rated flow and pressure loss }\end{array}$ & $\begin{array}{l}\text { Lacks realistic test for } \\
\text { performance under back- } \\
\text { siphonage conditions, 1.e., } \\
\text { vacuum is not applied to } \\
\text { the inlet of the device. }\end{array}$ \\
\hline $\begin{array}{l}\text { Double Check } \\
\text { Valve Assembly (DCVA) } \\
\text { FCCCHR - } 1974 \quad \text { [29] } \\
\text { IAPMO PS 31-74 [28] } \\
\text { AWWA C506 - } 69 \quad[31]\end{array}$ & $\begin{array}{l}\text { - Specifies similar requirements } \\
\text { as in A.S.S.E. } 1015 \\
\text { - Also spectfies but without a } \\
\text { test procedure: } \\
\text { - shock and water hammer } \\
\text { - hydrostatic test on all } \\
\text { barriers } \\
\text { - } 12 \text { months field performance } \\
\text { - no backflow under all condi- } \\
\text { tlons of pressure differ- } \\
\text { ential } \\
\text { - tolerance to sand, scale and } \\
\text { other interfering materials } \\
\text { - devices for elevated temper- } \\
\text { atures to be so tested }\end{array}$ & $\begin{array}{l}\text { The FCCCHR and IAPMO test } \\
\text { requirements are very sim- } \\
\text { ilar. The AWWA is less } \\
\text { developed. } \\
\text { Test requirments must have } \\
\text { test procedures to be } \\
\text { useful broadly } \\
\text { Periodic testing of de- } \\
\text { vices in a cross- } \\
\text { connection control program } \\
\text { may economically substi- } \\
\text { tute for field testing. }\end{array}$ \\
\hline $\begin{array}{l}\text { Antisiphon } \\
\text { Pressure Type } \\
\text { Vacuum } \\
\text { Breakers (PVB) } \\
\text { A.S.S.E. } 1020,1974 \quad \text { [25] } \\
\text { ANSI A112.1.7 - } 1976\end{array}$ & $\begin{array}{l}\text { - Hydrostatic test, internal, total } \\
\text { - Hydrostatic test, check valve } \\
\text { back pressure } \\
\text { - Check valve force loading } \\
\text { - Atmospheric vent, opening } \\
\text { pressure } \\
\text { - Air passageway areas } \\
\text { - Back-siphonage prevention } \\
\text { - Rated flow and allowable } \\
\text { pressure loss }\end{array}$ & $\begin{array}{l}\text { Test methods are indirect, } \\
\text { that is, a tracer, yielding } \\
\text { quantitative results, is } \\
\text { not used to simulate } \\
\text { contaminants. }\end{array}$ \\
\hline $\begin{array}{l}\text { Pressure Type } \\
\text { Vacuum } \\
\text { Breaker } \\
\text { Assemblies (PVB) } \\
\text { FCCCHR - } 1974 \quad \text { [29] } \\
\text { IAPMO PS } 31-74 \quad[28]\end{array}$ & $\begin{array}{l}\text { - Specifies similar requirements } \\
\text { as in A.S.S.E. } 1020 \\
\text { - Also specifies but without a } \\
\text { test procedure: } \\
\text { - shock and water hammer } \\
\text { - hydrostatic test on all } \\
\text { barriers } \\
\text { - } 12 \text { months field performance } \\
\text { - tolerance to sand, scale and } \\
\text { other interfering materials } \\
\text { - devices for elevated temper- } \\
\text { atures to be so tested }\end{array}$ & $\begin{array}{l}\text { The FCCCHR and IAPMO test } \\
\text { requirements are very } \\
\text { similar. IAPMO definitely } \\
\text { single and double check } \\
\text { valve types. FCCCHR (?) } \\
\text { Test requirements must } \\
\text { have test procedures to } \\
\text { be useful broadly. } \\
\text { Periodic testing of de- } \\
\text { vices in a cross- } \\
\text { connection control program } \\
\text { may economically substi- } \\
\text { tute for field testing. }\end{array}$ \\
\hline
\end{tabular}


Table 11 Summary of Test Methods Found in Current Standards for Reduced Pressure Principle Back Pressure Backflow Prevention Devices - with Comments

\begin{tabular}{|c|c|c|}
\hline $\begin{array}{c}\text { Devices and } \\
\text { Standards }\end{array}$ & Test Methods & Comments \\
\hline $\begin{array}{l}\text { Reduced } \\
\text { Pressure Principle } \\
\text { Backflow Prevention } \\
\text { Device (RPBD) } \\
\text { A.S.S.E. } 1013,1971 \quad \text { [23] } \\
\text { ANSI A112.1.5 - } 1976\end{array}$ & $\begin{array}{l}\text { - Hydrostatic test - full } \\
\text { - Hydrostatic test - outlet only } \\
\text { - Outlet check valve, drip } \\
\text { tightness } \\
\text { - Rated flow and ailowable } \\
\text { pressure loss } \\
\text { - Zone pressure versus inlet } \\
\text { pressure (flowing status) } \\
\text { - Zone pressure versus inlet } \\
\text { pressure (static status) } \\
\text { - Relief discharge rate } \\
\text { (backflow condition) } \\
\text { - Relief valve opening and } \\
\text { closing } \\
\text { - Relief valve discharge versus } \\
\text { inlet pressure surge }\end{array}$ & $\begin{array}{l}\text { Lacks realistic test for } \\
\text { performance under back- } \\
\text { siphonage conditions, i.e., } \\
\text { vacuum is not applied to } \\
\text { the inlet of the device. } \\
\text { Does not require a field } \\
\text { evaluation after the } \\
\text { device has passed the } \\
\text { laboratory tests. } \\
\text { Test methods are indirect, } \\
\text { that is, a tracer yielding } \\
\text { quantitative results is } \\
\text { not used to simulate } \\
\text { contaminants. }\end{array}$ \\
\hline $\begin{array}{l}\text { Reduced } \\
\text { Pressure Principle } \\
\text { Backflow Prevention } \\
\text { Device (RPBD) } \\
\text { FCCCHR - } 1974 \quad[29] \\
\text { IAPMO PS 31-74 } \\
\text { AWWA C506-69 }\end{array}$ & $\begin{array}{l}\text { - Specifles similar requirements } \\
\text { as in A.S.S.E. } 1013 \\
\text { - Also specifies but without a } \\
\text { test procedure: } \\
\text { - shock and water hammer } \\
\text { - hydrostatic test on all } \\
\text { barriers } \\
\text { - } 12 \text { months field performance } \\
\text { - no backflow under all condi- } \\
\text { tions of pressure differ- } \\
\text { ential } \\
\text { - tolerance to sand, scale and } \\
\text { other interfering materials } \\
\text { - devices for elevated temper- } \\
\text { atures to be so tested }\end{array}$ & $\begin{array}{l}\text { The FCCCHR and IAPMO test } \\
\text { requirements are very sim- } \\
\text { ilar. The AWWA is less } \\
\text { developed. } \\
\text { Test requirements must } \\
\text { have test procedures to } \\
\text { be useful broadly. } \\
\text { Periodic testing of de- } \\
\text { vices in a cross- } \\
\text { connection control program } \\
\text { may economically substi- } \\
\text { tute for field testing. }\end{array}$ \\
\hline
\end{tabular}


they do not give test methods. Field test setups and field test methods are given by FCCCHR and IAPMO, but these are not clear concerning test site selection. ASSE Standards do not require a field test but do invite the manufacturers to furnish recommendations for field testing upon request. The field test appears to be a major difference between requirements of some standards. The field test is an aspect of backflow preventer testing that requires further study.

The standards are for particular product types and are generally prescriptive concerning functional parts. The standards do not have a mechanism that would allow test of an innovative device that may be entirely different than the particular products covered which makes those standards difficult if not impossible to apply to innovative devices.

\subsubsection{Methods that Test Appropriate Attributes}

\subsubsection{Backflow Prevention}

Although authorities claim the RPBD and DCVA prevent back-siphonage, the standards for RPBD and DCVA do not have backsiphonage requirements or back-siphonage test methods. No standard test requires that vacuum be applied to the inlet of RPBD and DCVA. The standards do not give emphasis to the ability of RPBD to prevent backflow due to back-siphonage. In fact, the opposite impression is given. The foreword to ASSE 1013 for RPBD states the following: "This standard covers only the type of device which is identified as a Reduced-Pressure Principle Backflow Preventer which is designed primarily for the prevention of backflow due to back pressure." (Underline added for emphasis).

ASSE 1012, Backflow Preventers with Intermediate Atmospheric Vent, requires a back-siphonage test for the very inexpensive device, about $\$ 17.00$, as compared to RPBD which would cost several hundred dollars. This device has two independently operating check valves separated by an intermediate chamber with provision for automatically venting it to the atmosphere. Therefore, although it does not incorporate a relief valve, it is similar to RPBD in configuration. ASSE standard 1012 has a test method to determine that no back-siphonage will occur if both check valves leak when vacuum is applied to the inlet of BPIA and the downstream pressure is atmospheric. (A basic purpose of this device is to protect the potable water supply against backflow where contaminants located within the outlet piping are under pressure from such equipment as a low pressure residential heating boiler). In light of the fact 
that back pressure will exist continuously during normal operation of the device, it would seem that the above mentioned back-siphonage test method would be more realistic if it were performed with back pressure on the downstream side in lieu of atmospheric pressure.

The test method concerning HCVB was discussed in section 4.1.4. The basic conclusion concerning HCVB (without check valves) is that it would not pass the backflow test of HCVB (with check valves); consequently, it would not be approved under ASSE 1011 test methods. The device is a special AVB that should as a minimum be tested under the procedures of ASSE 1001. The test methods for 10 HCVB (with check valve) concerning backflow due to back-siphonage and back pressure appear adequate. However, the tests would be more realistic if a quantitative tracer could be used that relates to insecticides, herbicides, car wash soap, swimming pool water and perhaps other substances that are associated with garden hose 15 application.

The water rise test for $A V B$ and $P V B$ appears to be generally effective but could be improved upon if a quantitative tracer could be used that relates to sewage and other commonplace contaminants.

20 The ASSE Standards do not apply the water rise test to AVB, HCVB or BPIA when the devices are at operating temperatures. IAPMO has no such test for PVB. It seems reasonable that moving parts of devices might bind due to material expansion or contraction which could cause device malfunction.

Additional backflow test improvements concerning all devices would encompass tests that show the device to meet all of the operating requirements. These are as follows:

- Functional operation under dynamic conditions.

- Functional operation at design pressure temperature combinations.

- Functional operation would, of course, be under exposure to vacuum at the inlet, pressure at the outlet and combinations of vacuum and back pressure.

Generally standards for devices do not test the devices for failure modes. RPBD failure is generally indicated by water flowing from the zone. However, the device does not have a means to warn of failure unless someone actually sees the water discharging from the zone. A remote-indicating device for RPBD located in hazardous areas such as sewage treatment plants would be an improvement. 45 No standard for other devices considers failure detection. 


\subsubsection{Nontoxic Materials}

Devices should be constructed of nontoxic materials. ASSE Standards are the only standard that consider nontoxic materials. However, ASSE looks for a statement from the manufacturers that all materials in contact with the potable water are nontoxic. No criteria such as that given in the U. S. Public Health Service Drinking Water Standards $8 /$ is mentioned. No standard cites a test method for this important parameter. FCCCHR, IAPMO, and AWWA Standards do not have requirements concerning toxicity of materials. The standards should address this aspect of devices definitively because one of the most important attribute of devices is nontoxicity.

\subsubsection{Design Temperature}

The standards are not consistent concerning test methods at design temperatures. For instance, ASSE has design temperature tests for AVB but no design temperature tests for RPBD and DCVA. on the other hand, FCCCHR and IAPMO have tests for RPBD and DCVA if the design temperature exceeds $110^{\circ} \mathrm{F}$. Such tests are important for all devices because of possible binding of moving parts at elevated operating temperatures. It seems reasonable that standards should not be inconsistent concerning temperature tests.

\subsubsection{Rated Flow and Allowable Pressure Loss and Hydrostatic Pressure Resistance}

The standards (ASSE, AWWA, FCCCHR and IAPMO) agree on the acceptable flow rates for RPBD and DCVA. ASSE test methods for pressure drop versus flow rate are defined and appear adequate. AWWA does not have test methods, FCCCHR and IAPMO have implied tests but their methods are not defined. ASSE has acceptable flow rate and allowable pressure loss test methods for all devices except AVB. It would seem reasonable that acceptable flow rates and an acceptable test method be given for AVB.

8/ Under the Safe Drinking Water Act, Public Law 93-523, National Interim Primary Drinking Water Regulations were promulgated December 24,1975 to become effective 18 months later. 
ASSE, FCCCHR, and IAPMO have hydrostatic pressure tests for devices. However, there is some inconsistency in the duration of the time that internal pressure of two times working pressure (2 $\times 150$ psig) is applied. FCCCHR and IAPMO require at least two minutes. ASSE requires a ten minute application. The basic purpose of this test is to observe any leaks in valve bodies and check valves or distortion of parts. The test time should be standardized. ASSE requires that $A V B$ be subjected to a hydrostatic test at design temperature extremes $\left(32^{\circ} \mathrm{F}\right.$ and $212^{\circ} \mathrm{F}$ for hot water devices and $32^{\circ} \mathrm{F}$ and $110^{\circ} \mathrm{F}$ for cold water devices) but other devices such as RPBD

10 which has identical operating requirements is not tested at a design temperature.

\subsubsection{Water Hammer}

The standards are inconsistent concerning test methods for water hammer. ASSE has water hammer tests for HCVB but no tests for RPBD and DCVA. FCCCHR and IAPMO indicate water hamer tests but do not give the methods for $\mathrm{RPBD}$ and DCVA.

Water hammer results in overpressure that could occur periodically. In light of this, devices should be exposed to a certain number of cycles of water hammer to determine possible failure of parts. A similar test method is used on shock absorbers that prevent water hammer. This test method is detailed in the standard for water hammer arresters [35].

\section{2 .2 .6 Noise}

ASSE has a noise test method for HCVB and BPIA but does not mention a test for RPBD and DCVA. The method basically depends on the hearing ability of the test personnel. FCCCHR considers that RPBD and DCVA should not "chatter" which implies noise but no test method is given. It is important that these devices not be noisy. Users may defeat them or have them removed from service. Study would be required to develop quantitative techniques to detect noisy devices.

\subsubsection{Resistance to Actual Contaminants or Simulated Contaminants Under Laboratory Conditions}

No standard test method requires that contaminants such as sewage or other toxic substance or an appropriate nontoxic tracer be used to demonstrate quantitatively the ability of the devices to prevent backflow of contaminants under realistic conditions. For example, such performance standard should include a tracer test for functional performance under various steady state normal flow, and dynamic flow conditions (water hammer, etc.). 
Although the standards for devices do not consider these realistic conditions, such tests have been performed on one model of RPBD by the Oak Ridge National Laboratory (ORNL) using the procedures of activation analysis [36]. The RPBD passed this test which had a sensitivity of about 0.2 parts per billion of manganese. The nonradioactive test was generally as follows:

(a) The water supply at the test setup was first sampled to determine the threshold level of manganese, if any.

(b) The manganese tracer was introduced down stream of the device and the device subjected to pressure differentials, fluctations water hammer, etc.

(c) The upstream side of the device was next sampled to determine if manganese had backflowed. The samples were irradiated in a nuclear reactor in order to determine the amount of manganese present. The upstream samples did not indicate backflow. That is, the manganese concentration upstream did not increase over the threshold value.

No correlation was made between manganese tracer and other hazardous substances. Further work is needed to validate and develop the practical application of this promising test method.

\subsubsection{Repeatability and Accuracy}

With the exception of ASSE 1001 and ANSI Al12.1.1.1971 (pipe Applied Atmospheric Type Vacuum Breakers), no other standards require data repeatability (the average of three test runs are required) or measure accuracy. However, an acceptable value of data repeatability is not mentioned (departure from the average).

\subsubsection{Limit Testing, Failure Modes, Maintainability and Field Testing}

The standards do not require that devices be cycled to failure over operating conditions of temperature, pressure, and flow in order to detect failure nodes. The standards do not require that devices fail safe or that devices indicate when they have failed (except for RPBD). RPBD discharges water from its ports on failure

40 of check valves or relief valve but this does not necessarily mean such failure would be observed or detected. As noted earlier, no test methods determine whether a device can prevent backflow of a pollutant when subjected to conditions of backflow under operating conditions of temperature, pressure, and flow. Guidelines and tests 
for mean time between failure, mean time to maintain, mean time to repair, level of spare parts required, availability of repair parts are not considered.

FCCCHR and IAPMO Standards require a twelve-month field test of RPBD and DCVA. Although the standards do not go into detail concerning the tests, the following is the general procedure as given in an unpublished FCCCHR paper [32]: See Section 3.4.1.

(a) One or more units of each size and model are submitted from the manufacturer's stock. These devices shall pass the laboratory test prior to the field evaluation.

(b) The manufacturer arranges for the placement of at least three devices, of each size and model tested in the laboratory in the field installation. FCCCHR approves of the selected field location. The location must not be on a fire service where normally a no-flow condition exists almost continuously. The devices must not be placed where the flow is maximum all of the time. Also, an RPBD under test must not be placed in a pipeline where there is potential for hazardous backflow if the RPBD should fail during the field test. The devices must be located in pipelines where the water supply can be turned off for short periods of time as required by test procedures.

(c) The field evaluation consists of a monthly test of all of the devices on the field test program.

The field test purpose is to assure that a device will function under actual operating conditions. ASSE Standards do not require a field test and as a result their standards do not give assurance of satisfactory performance under operation conditions. Field testing is presently performed only for RPBD, DCVA and PVB. AVB is not field tested. It appears that this aspect of testing requires additional study. Certainly, assurance should be given that all devices will perform in the field. 


\section{SUMMARY OF FINDINGS}

The following is a summary of findings concerning backflow protection devices, test methods, and laboratories.

\subsection{Air Gap (AG)}

An air gap provides positive protection against backflow of liquid and solid contaminants. However, authorities zecognize that an air gap may be defeated through attachment of by-passes[1]. This attribute of $A G$ is no different than that of other devices such as the electric fuse which can be defeated in households by use of coins or other means that result in burned wiring and houses.

\subsection{The Reduced Pressure Backflow Device (RPBD)}

The RPBD provides good protection against backflow in high risk situations. This device is in its weakest mode of operation when subjected to both back pressure and back-siphonage conditions simultaneously. NBS tests have demonstrated that one RPBD would backflow when the check valves leaked under such conditions. The standards for RPBD do not have requirements or test methods for back-siphonage. However, one manufacturer's literature states that the RPBD is absolute protection against back-siphonage conditions. Administrative authorities use RPBD for protection against both back-siphonage and back pressure within the water service lines to hazardous locations such as sewage treatment plants. The probability of simultaneous back pressure and back-siphonage conditions is unknown but is presumed to be much smaller than the likelihood of either event singly. Thus, RPBD's clearly do provide protection. The RPBD's only means of protection under simultaneous conditions of both back-siphonage and back pressure is the tightness of the check valve on the upstream side of the zone. For this reason, a periodic test and maintenance program is essential for RPBD (some authorities test RPBD at least annually) [1]. The use of strainers is considered helpful by some, but others feel that strainers can cause excessive pressure drop (ASSE's standards require strainers ahead of both RPBD and DCVA but FCCCHR does not).

\subsection{Fail Safe Devices}

No device currently used to prevent backflow provides a positive indication of the device function or malfunction in the way that a fuse or circuit-breaker protects an electrical circuit. An RPBD can be observed to discharge fluid as an indicator only if an informed person happens to be near the device at the time the backflow condition exists. 
The ASSE standard 1001 does not consider means to test AVB for malfunction in the field [20].

Although Barometric Loops are used in large laboratory complexes to protect against backflow of potentially hazardous substances, there are questions concerning its adequacy to protect against transfer of contaminants by air bubbles if an air water separator is not used. Additional studies concerning transfer of pollutants by diffusion and by air have been recommended by the National Institutes of Health [27].

HCVB with a check valve is in its weakest mode of operation when subjected to back pressure which occurs when the terminal end of the garden hose is elevated above the HCVB. In this situation the device does give protection as long as the check valve does not leak. More protection could occur if the devices were located above the terminal end of the hose, though such an arrangement may not be practical in many cases. The HCVB without the check valve should not be used on garden hoses because this type of HCVB does not prevent backflow caused by back pressure. This type HCVB (without a check valve) is merely a special $A V B$ and should be tested under ASSE type 1001 methods.

\subsection{Realistic and Usable Test Methods}

The AWWA standard for RPBD and DCVA does not contain test methods or implied tests. FCCCHR and IAPMO indicate the type of tests that are to be performed but do not give details of the test methods or test setups for hydraulic laboratory tests. ASSE standards specify test methods and test setups.

In the case of RPBD, the current standards do not consider back-siphonage conditions and yet the device is used for this condition in actual practice. Similarly RPBD tests do not involve actual demonstration of functional performance i.e., prevent backflow of actual contaminants under simulated use conditions.

The RPBD standards are not consistent concerning the necessity for field test. ASSE does not require a field test and FCCCHR and IAPMC require a twelve month field test. Further, FCCCHR and IAPMO standards do not provide definitive detail concerning how to perform the tests. Although PVB is field tested, AVB is not field tested.

The standard for HCVB (check valve type) tests the device with water discharging from its air inlet ports. This is reasonable in light of the fact that the device is designed to relieve back pressure through its ports. However, some authorities, Dawson and Kalinske, [3] have said that one of the main requirements to good vacuum breaker 
design and installation is to prevent the discharge of water from the air inlet ports. Such discharge is alleged to cause blockage of the ports by a build up of lime deposits. Further study is required to determine if this condition will occur with HCVB. Port pollution possibilities should also be studied.

No standard requires the use of actual or simulated contaminants or an appropriate tracer to demonstrate quantitatively or qualitatively the ability of the devices to prevent backflow. All present tests are indirect in that they show that valves do not leak or that relief valves function. The water-rise test for AVB is the most realistic test, but it is not concerned with upstream measurements to determine if a contaminant (air, aerosol, etc.) has passed into the inlet of the device.

With the exception of the ASSE/ANSI Standard for AVB, no other standard specifies data repeatability or measurement accuracy.

Limit testing to determine failure modes or other tests to determine mean-time-to-maintain or to-repair, and level of spares required or availability of spares are not considered by standards. Many of these devices are very expensive, costing thousands of dollars.

The standards do not explicitly require periodic review of test methods/equipment.

\section{6, CONCLUSIONS AND RECOMMENDATIONS}

\subsection{Conclusions}

1. Existing backflow prevention devices do provide protection against backflow. However, insufficient data appears to exist to evaluate quantitatively the effectiveness of these devices, the risks associated with various types of system designs, or the relative advantages of various devices in particular installations.

2. None of the existing devices is fool proof. Most do not provide positive indication of failure, when it occurs, or device usage when backflow conditions arise; nor are any of the devices used fail-safe. There is some apparent misconception of the test methods regarding the capabilities of the RPBD and HCVB (with check valves) in particualr concerning functional performance under all normal service conditions (i.e., combined back pressure and back-siphonage conditions and possible lime deposits blocking HCVB air ports). HCVB (without a check) should not be used with garden hoses. 
3. A.S.S.E. Standards are the only standards that have detailed test methods, i.e., definitive test procedures and test setups. However, the standards are inconsistent concerning the application of realistic tests. For instance (other examples are in section 4.2 ), if a device is designed to operate in water that is $32^{\circ} \mathrm{F}$, the device should be tested to demonstrate the ability to prevent backflow at that temperature. AVB's are tested at their operating temperatures for leaks and distortion of parts but not back-siphonage. RPBD's do not have test methods that show the device will operate at design temperatures. Although both AVB's and RPBD's are used to protect against backsiphonage, AVB's are tested with vacuum and RPBD's are not. In fact no standard of FCCCHR, IAPMO, or AWWA specifies performance for RPBD under vacuum conditions simulating back-siphonage. FCCCHR and IAPMO require a twelve month field test, but ASSE does not. Some standards do not explicity spell out test methods or equipment. Others are prescriptive and provide no means for testing of innovative devices. No existing standards test devices for functional performance under full actual or simulated service life conditions. The test methods, however, do show that devices provide protection. These test methods could be much improved by the use of realistic service condition simulation.

4. In fairness to the backflow prevention device industry and the standards to which they adhere it is appropriate to note:

(a) The backflow prevention device industry provides an extremely valuable National service in the manufacture and sales of devices which adhere to recognized standards. The purpose of this work was not to discredit any party concerned, but to present constructive criticism when required.

(b) Although the devices of a particular manufacturer may be recognized in this report, tests presented and discussed here do not in any way discredit specific products.

\subsection{Recommendations}

\subsubsection{First Order Priority}

(a) It is recommended that a study be carried out concerning the reliability of devices that have been field tested versus the reliability of devices that have not been field tested in order to resolve the apparent controversy concerning whether to require field test or not. 
(b) It is recommended that a functional performance test and performance standard based on using a quantitative tracer (pollutant) be developed that would be applicable for testing all classes of devices including innovative devices under simulated life cycle conditions. During the test, the devices would be subjected to a program of various water supply operating conditions including backsiphonage to determine the ability of the device to prevent the backflow of the tracer or simulated contaminant. See Section 4.2.2.7.

(c) It is recommended that a program be undertaken to develop a positive fail-safe means of indicating or calling operator attention to any backflow condition particularly in high-hazard locations. Ideally a device corresponding to an electrical fuse or circuit breaker would be desirable.

\subsubsection{Second Order Priority}

(a) It is recommended that means be developed that would allow the homeowner or plumbing inspectors a ready means to determine whether or not an AVB or HCVB or similar device is functioning properly and has not failed.

(b) It is recommended that manufacturers provide definitive data concerning reliability, maintainability, mean-timeto-maintain, and mean-time-to-failure on their devices for various locations and water type, etc.

(c) It is recommended that a study be conducted to determine the level of barometric loop usage and whether or not the barometric loops in use are using air-water separators [19].

(d) It is recommended that a study be carried out concerning the use of strainers ahead of RPBD, DCVA, PVB, and AVB. Such strainers would tend to prevent the passage of particles that could foul the checks of devices.

(e) It is recommended that a back-siphonage detection monitoring system be developed. This should include sampling at statistically selected high-hazard locations such as sewage treatment plants, hospitals, and hazardous industrial and commercial locations. Such information would define the magnitude of the problem and pinpoint recurring low pressure conditions in the water 
supply system that must be corrected. Better data on backflow incidents is needed to provide a basis for developing and evaluating alternative program options in this field.

(f) It is recommended that a rational approach be developed to determine the order of magnitude of the risk presented by any particular type of hazard on a premise as related to other premises and the water utility itself. For instance, hazardous condition on a premise of a given type located in the middle of a highly populated metropolitan area would present a greater risk in terms of population density alone than the same condition on a premise located outside the metropolitan area where the population density is very much lower. This method would provide a means of establishing priorities for the installation of devices of various types. This approach would be based on information on adverse water pressure fluctuations and backflow incidents reported in paragraph (e) above.

(g) It is recommended that the HCVB's be studied to obtain answers to the following questions:

(i) Will the air ports become blocked with lime deposits to make them ineffective.

(ii) Is there a high risk of contamination at the air ports?

(iii) Would the device give greater protection installed at the nozzle end of the hose instead of the sillcock end? 


\section{ABBREVIATIONS AND DEFINITIONS}

The following Abbreviations have been used in this report. The source of definitions are identified at the end of the section.

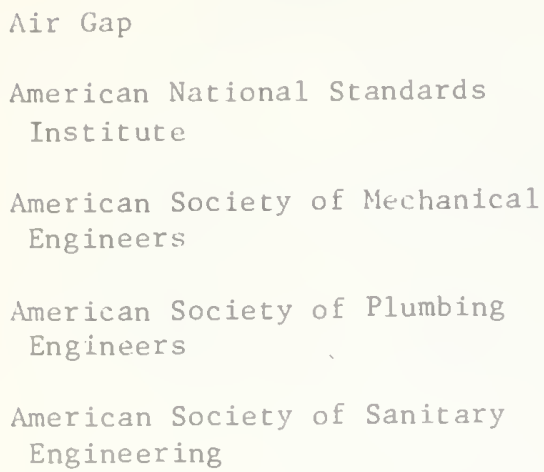

Antisiphon flush valve ball cock AFVBC

Atmospheric Type Vacuum Breaker AVB
AG

ANS I

ASME

$\mathrm{A}, \mathrm{PE}$

A. S.S.E. or ASSE

A.S.A. or ASA

A.W.W.A

or AWWA

BPIA

$B C$

BL

B. O.C.A. or BOCA

C- I- L

DCVA

EPA

ft

FCCCHR

FCCCR
Gallons per minute

g.p.m.

nr $\mathrm{gnm}$

Hose Connection Vacuum

HCVB

Breaker

Inch or inches

in

International Association

I.A.P.M.O

of Plumbing and

or IAPMO

Mechanical Officials

Iron pipe size

i. P.s. or ips

Library of Congress "Science Policy, a working Glossary"

Los Angeles Department of Water and Power

LCSPWG

Mililiters

$\mathrm{ml}$

Minute

min

National Association of Plumbing-HeatingCooling Contractors

National Bureau of Standards

NBS

National Sanitation Foundation

National Standard

NSPC

Plumbing Code

Oak Ridge National

ONRL Laboratory

Pounds per square inch P.s.i. or psi

Pounds per square inch, gage psig

Pressure type vacuum PVB breaker

Product Standard PS

P.educed Pressure Principle Backflow Prevention Device
RPBD or or RP 


\subsection{Definitions}

Administrative Authority: The individual official, board, department, or agency established and authorized by a state, county, city or other political subdivision created by law to administer and enforce the provisions of the plumbing code or of a cross-connection control program. (NSPC \& NBS)

Air Gap: An air gap in a potable water distribution system is the unobstructed vertical distance through the free atmosphere between the lowest opening from any pipe or faucet supplying water to a tank, plumbing fixture or other device and the flood level rim of the receptacle. (NSPC)

Air Gap Separation: The physical separation between the free-flowing discharge end of a potable water supply pipeline and an open or non-pressure receiving vessel. The width of separation shall be at least that specified in ANSI Al12.1.2 - 1973 (FCCCHR \& NBS)

Air Inlet: The opening or series of openings through the body of a vacuum breaker connecting the free atmosphere with the liquid passageway of the device (ASSE 1001)

Ambience (noun): The surroundings or environment of a place or thing used in experimental research to indicate, e.g. the temperature, humidity pressure, gases, and radiation in the space surrounding the object of an experiment. (LCSPWG)

Analysis: The action of taking something apart and examining its components. (The very extent of the use of the term may seem to deprive the word of much of its meaning. It is employed in a great many different senses, and in many combinations. The meaning seems to depend somewhat on the discipline connected with its use.)

The notion that analysis is an identifiable and describable process independent of the discipline involved or the item being analyzed is suggested by the large number of compound words hyphenated with it, for example: value-, failure-, costeffectiveness-, operations-, systems-, stress-, reliability-, maintainability-, etc. (LCSPWG \& NBS)

Atmospheric Air: Air of the surrounding atmosphere and at its existing pressure. (ASSE 1013)

Backflow: The unintentional reversal of flow in a potable water distribution system which may result in the transport of harmful materials or substances into the other branches of the distribution system. (NBS)

Backflow Connection: The point of joining of potable water piping with equipment, fixtures, or other piping that may be contaminated. (NBS). 
Backflow Preventer: Any mechanical device, whether used singly or in combination with other controls, that may automatically forestall the possibility of an unintentional reverse flow in a potable water distribution system. (ASSE 1001)

Backflow Preventers with Intermediate Atmospheric Vent: These devices have two independently operating check valves separated by an intermediate chamber with a means for automatically venting the chamber to the atmosphere. The check valves are force loaded to a normally closed position and the venting means is force loaded to a normally open position. These devices can operate under continuous or intermittent pressure conditions. (ASSE 1012)

Backflow Preventers, Reduced Pressure Principle, Back Pressure: These devices consist of two independently acting check valves, internally force loaded to a normally closed position, and separated by an intermediate chamber (or zone) in which there is an automatic relief means for venting to atmosphere, internally force loaded to a normally open position. These devices are designed to operate under continuous pressure conditions. (ASSE 1013)

Backflow Preventers, Double Check Valve Type, Back Pressure: These devices consist of two independently acting check valves internally force loaded to a normally closed position and designed and constructed to operate under intermittent or continuous pressure conditions: (ASSE 1015)

Back Pressure: Pressure created by any means in the water distribution system on the premises, which by being in excess of the pressure in the water supply main could cause backflow. (NBS)

Back-Siphonage: The backflow of possibly contaminated water into the potable water supply system as a result of the pressure in the potable water system becoming unintentionally less than the atmospheric pressure in the plumbing fixtures, pools, tanks or vats that may be connected to the potable water distribution piping. (NBS)

Ball Cock: A water supply valve opened or closed by means of a float or a similar device and used to supply water to a tank. (ASSE 1001)

Ball Cock, Antisiphon: A ball cock that contains an antisiphon device in the form of an approved air gap or a vacuum breaker which is an integral part of the ball cock unit and which is positioned on the discharge side of the water supply control valve. (ASSE 1001)

Check Valve Assembly: A combination of spring and weight loaded check valves with resilient discs for the intended purpose of preventing back pressure backflow in a water supply line. Assembly is usually furnished with test cocks for field testing the tightness of the check valves. Some assemblies include a vacuum breaker to admit atmospheric air downstream of the assembly. (ASSE 1013) 
Community Water System: A public water system which serves at least 15 service connections used by year-round residents or regularly serves at least 25 year-round residents. "Non-community water system" means a public water system that is not a community water system (EPA 141.2.(e)) (see public water system).

The purpose of defining "Community water system" is to allow appropriate regulatory distinction between public water systems which serve residents on a year-round basis and public water systems which principally serve transients or intermittent users. The possible health effects of a contaminant in drinking water in many cases are quite different for a person drinking the water for a long period of time than for a person drinking the water only briefly or intermittently. Different monitoring requirements are appropriate for the two types of systems. (EPA 141.2(e))

Constraint: A limiting condition to be satisfied in the design or operation of a system. For example: the total cost may be a constraint, or the percentage of system life consumed in downtime, or the compatability of a system with other systems. (LCSPWG)

Contamination: The admission of contaminants into a potable water supply (ASSE 1013)

Contaminants (as applicable to standards for backflow prevention devices): Materials (solids or liquids or gases) which may be added unintentionally (or intentionally) to the potable water supply and cause it to be unfit for human or animal consumption. (ASSE 1013)

Contaminants (as applicable to the Safe Drinking Water Act): Any physical, chemical, biological, or radiological substance or matter in water. (EPA 141.1(6))

This definition, in the review of Section 141.2 of the National Interim Primary Drinking Water Regulations of December 24, 1975, was critized for its breadth. The term as defined includes virtually any constituent in water, including constituents considered to be harmless or even beneficial. The definition was taken directly from Section $1401(6)$ of the Safe Drinking Water Act. It is not intended to suggest that all constituents of water are undesirable, but rather is intended to permit the regulation of any constituent which may be harmful. (see definition of maximum contaminant level) 
Control Valve: A valve that is operated each time water is supplied to or shut off from a receptacle or plumbing fixture. Familiar examples are faucets and sill cocks. (ASSE 1001)

Cost/Benefit Analysis: The relation between social benefits and social costs associated with the operations of a technical system under study. The benefits and the costs include direct and indirect effects. Monetary equivalents are sometimes assigned to the nonmaterialistic values for the purpose of comparison and to clarify the relationships between benefits and costs. (LCSPWG)

Cost/Effectiveness: This is a term widely used in systems analysis, and has been carried over into budgeting analysis. It signifies the ratio, over an explicit and finite time-span, of cost in dollars and other tangible values to effectiveness. In the military area, in which cost/effectiveness analysis originated, the payoff was defined in terms of the effectiveness of the military system. In the civilian area, "effectiveness" is replaced by "benefit." Admittedly, benefits in soclal systems are even more difficult to define than effectiveness in military systems. (LCSPWG)

Criterion (plural Criteria): A standard or an explicit measure by which to evaluate any activity or thing. Criteria may be quantitative or qualitative and objective or subjective. In effectiveness analysis, criteria are the elements to be measured to determine costs and benefits. (LCSPWG)

Critical Installation Level: A designated operational 11mitation prescribing a safe helght on installed vacuum breaker above the floodlevel rim of the fixture or receptacle served. In the absence of a physical mark on the device, indicating a helght measurement reference point, the extreme bottom of the device shall be considered the height reference point. (ASSE 1001)

Cross Connection: Any physical connection or arrangement between two otherwise separate piping systems, one of which contains potable water and the other elther water of unknown or questionable safety or steam, gas, chemicals or other substances whereby there may be a flow from one system to the other, the direction of flow depending on the pressure differential between the two systems. By-pass arrangements, jumper connections, removable sections, swivel or changeover devices and other temporary or permanent devices through which or because of which backflow can or may occur are considered to be cross-connections. (FCCCHR)

Cross Connection, Point of: The specific point or location in a potable water distribution where a cross connection exists. (FCCCHR) 
Effectiveness: In system analysis, the term effectiveness is an aggregative expression intended to encompass all performance qualities of a system that is likely to be judged as relevant. The term describes a condition in which a system or program possessing it has been designed to satisfy at some pre-determined level all criteria selected as relevant. The term does not imply perfection but essential adequacy in all significant categories of performance. An effective design will result from the total of design decisions among options, selecting the optimal trade-off at each decision point, to satisfy all conceivably relevant internal and external criteria, quantitative and qualitative, tangible and intangible of performance and environmental compatibility. The concept includes such obvious criteria as cost, efficiency, and reliability. It also involves total life cost, maintainability, maintenance of the state-of-the-art modernity, compatibility with expected operating environment, recycle or scrap value, and such other criteria as the design engineer and the customer (or sponsor) consider relevant. (LCSPWG)

Flood Level Rim: That level from which liquid in plumbing fixtures, appliances or vats could overflow to the floor when all drain and overflow openings built into the equipment are obstructed. (NBS)

Hazard: A possible source of danger or peril; also a condition that tends to create or increase the possibility of loss or harm.

Hazard, Health: An actual or potential threat, of contamination or pollution of a physical or toxic nature to the potable water system to such a degree that there would be a danger to health. (FCCCHR)

Hazard, Minimal: A connection made to the potable water system whereby the risk from backflow occurring would entail the contamination of the potable water with objectionable but non-toxic substances such as steam, air, food, beverage etc. (NBS)

Hazard, Plumbing: A plumbing type cross-connection in a consumer's potable water system that has not been properly protected by a vacuum breaker, air gap separation, or other suitable device. (FCCCHR)

Health Agency: The organization established by law to have jurisdiction over the water supply quality. (FCCCHR)

In the National Interim Primary Drinking water Regulations, "State" means the agency of the state government which has jurisdiction over public water systems. During any period when a state does not have primary enforcement responsibility pursuant to section 1413 of the Safe Drinking Water Act, the term "State" means the Regional Administrator, U. S. Environmental Protection Agency. (EPA $141.2(\mathrm{~h})$ ) 
Maximum Contaminant Level: The maximum permissible level of a contaminant in water which is delivered to the free flowing outlet of the ultimate user of a public water system, except in the case of turbidity where the maximum permissible level is measured at the point of entry to the distribution system. Contaminants added to the water under circumstance controlled by the user, except those resulting from corrosion of piping and plumbing caused by water quality, are excluded from this definition. (EPA $141.2(\mathrm{c})$ )

Model: A simplified description of a process or system, or the interaction of either with its environment. (LCSPWG)

Potable water: Water from any source which has been approved for human consumption by the health agency having jurisdiction. (FCCCHR)

Potable Water: Water that meets the maximum contaminant level requirements of the National Interim Primary Drinking Water Regulations and which has been approved for human consumption by the health agency having jurisdiction. (EPA)

Pollution: As used in this report the word is equivalent to contamination in the sense that substances in the water are either undesirable or harmful. FCCCHR credits the California State Health and Safety Code with differentiating the two words: contamination of water creates health hazards (q.v.) and pollution of water creates minimal hazards (q.v.). (NBS)

In view of the EPA definition of a contaminant, the word "pollutant" may provide the means of defining or designating the "contaminants" that are undesirable or harmful.

Pressure, Absolute: Pressure measured on a scale having a zero value approximately $14.7 \mathrm{lb} / \mathrm{in}^{2}$ below normal atmospheric pressure.

Pressure, Atmospheric: The pressure exerted in every direction at any given point by the weight of the atmosphere.

Pressure, Hydrostatic: Pressure exerted by or existing within a liquid at rest with respect to adjacent bodies.

Public Water System: A system for the provision to the public of piped water for human consumption, if such system has at least fifteen service connections or regularly serves an average of at least twenty-five individuals daily at least 60 days out of the year. Such term includes (1) any collection, treatment, storage, and distribution facilities under control of the operator of such system and used primarily in connection with 
such system and (2) any collection or pre-treatment storage facilities not under such control which are used primarily in connection with such system. A public water system is either a "Community water System" or a "Non-Comunity Water System". (EPA $141.2(\mathrm{e})$ )

Service Connection: The point at or near the water main where the water purveyor delivers potable water to the consumer's water system. Usually the water purveyor loses jurisdiction and sanitary control over the water at the service connection.

Trade-off: The foregoing of some portion of one benefit in order to achieve some unused portion of another benefit: (or) foregoing some portion of a benefit in order to achieve a reduction in some portion of a cost: (or) accepting an increased portion of one cost in order to receive a decrease in the portion of another cost. Other more complicated permutations of this concept can be suggested. The term is in wide usage. (LCSPWG)

Toxic: Poisonous [see Code of Federal Regulations, Title 21, Food and Drugs Parts 170 to 299, 21 CFR 170.1, Section 191.1, Hazardous Substances. Definitions.] (ASSE 1011)

Vacuum: Any space in a water-supply system from which water has been displaced by water vapor, air, or other gases, and in which the pressure is less than the prevailing atmospheric pressure. (RP 1086)

Vacuum Breaker, Atmospheric Type: A back-siphonage prevention device which is designed to operate under pressure only when water is flowing through the system and not under static, standing conditions. Must be installed upstream of any shut-off or control valve or means. (ASSE 1011)

Vacuum Breaker, Pressure Type: A back-siphonage prevention device which can be subjected to continuous pressure, flowing, static, or both. (ASSE 1011)

Vacuum Breaker, Hose Connection Type: A backflow prevention device designed to be attached to an outlet having a hose connection thread. It may be either atmospheric or pressure type. (ASSE 1011)

Water Hammer: The term used to identify the hammering noises and severe shocks that may occur in a pressurized water system when flow is halted abruptly by the rapid closure of a valve or faucet. (NBS)

Water Purveyor: The owner or operator of the public potable water system supplying an approved water supply to the public. The 
purveyor operates under a valid permit from the state Department of Public Health or the local health agency having jurisdiction. (FCCCHR)

Water Supply Approved: Any public potable water supply which has been investigated and approved by the state Department of Public Health or the local health agency having jurisdiction. The system must be operating under a valid health permit. (FCCCHR)

Sources of definitions are identified by code as follows:

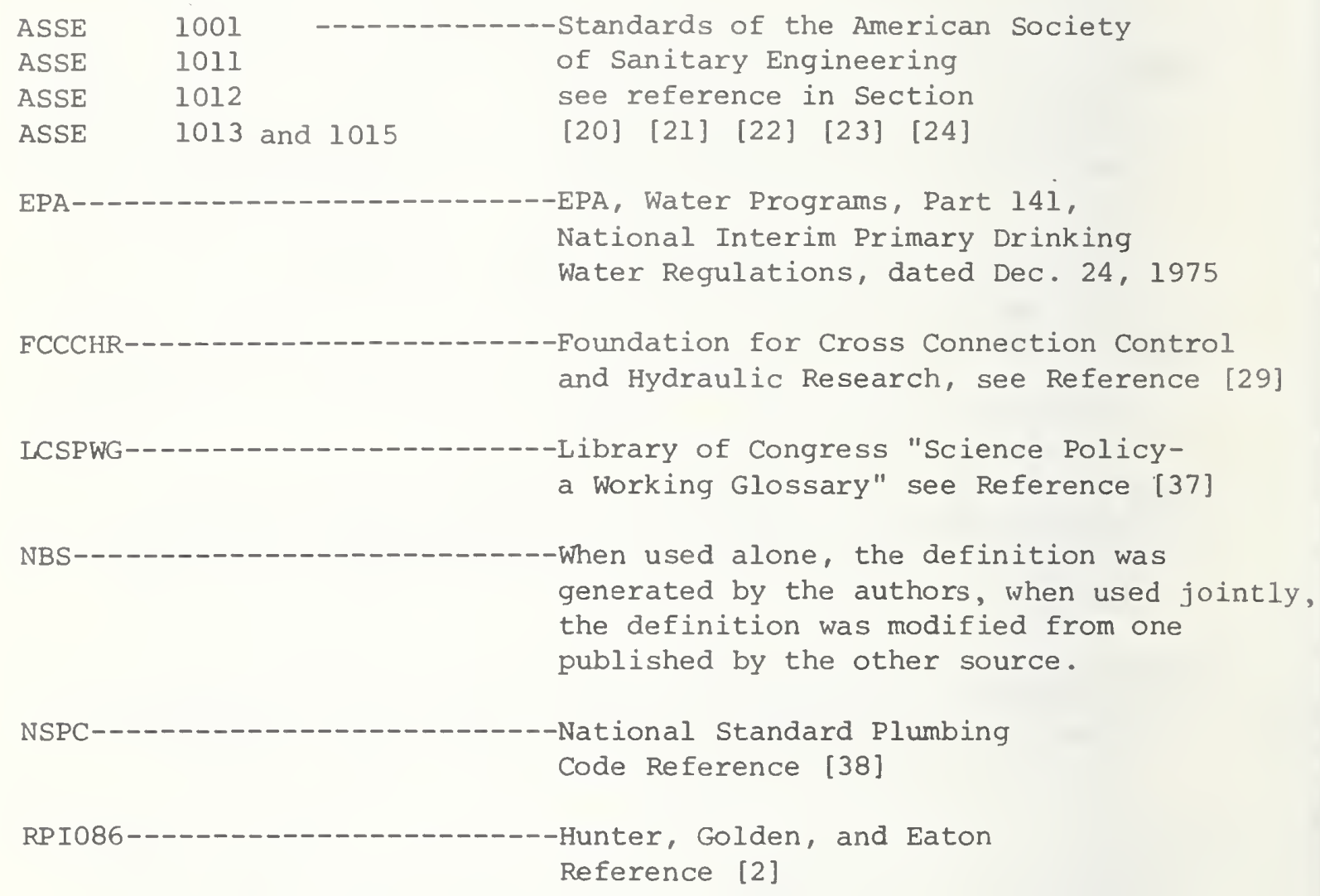




\section{REFERENCES}

[ 1] "Accepted Procedure and Practice in Cross Connection Control Manual," Prepared and edited by the cross Connection Control Committee of Pacific Northwest Section, American Water Works Association, Published by Pacific Northwest Section, AWWA, October 1971 .

[ 2] Hunter, R. B., Golden, G. E., and Eaton, H. N. "Cross-Connections in Plumbing Systems" National Bureau of Standards (U. S.) Research Paper RP 1086, Vol. 20, April 1938.

[ 3] Dawson, F. M. and Kalinske, A. A. "Report on Plumbing CrossConnections and Back-Siphonage Research" State University of Iowa, National Association of Master Plumbers of the United States, Inc., (now NAPACC) Washington, D. C., Tech. Bulletin No. 1,1938 .

[ 4] Nielsen, L. S. Standard Plumbing Engineering Design, (McGraw-Hill Book Company, Inc., New York, N. Y., 1963.)

[ 5] Craun, G. F., and McCabe, L. J., "Review of the Causes of Waterborne Disease Outbreaks." Journal American Water Works Association, Vol. 65, 74 (1973).

[ 6] Craun, G. F. "Microbiology - Waterbourne Outbreaks" Journal Water Pollution Control Federation, Vol. 46, No. 6, June 1974.

[ 7] "Cross-Connection Control Manual," U. S. Environmental Protection Agency, Office of Water Programs, Water Supply Division, 1973, EPA $-430 / 9-73-002$.

[ 8] Hutchinson, Gary D. "The Problem of Cross-Connections," Presented at AWWA Cross-Connections Control Seminar, Atlanta, Ga., March 28,1972 .

[ 9] Hutchinson, G. D. "Cross-Connection Control Policy and Recommendations" American Society of Sanitary Engineers, 1970 Yearbook, Vol. 48, pp 96-98.

[10] Stockton, E. L. "Cross-Connection in Calhoun County, Michigan," The University of Missouri Bulletin, Engineering Series, Engineering Experiment Station Bulletin No. 32, 1943.

[11] Bibbens, R. N. "Backflow Prevention Devices for Potable Water Systems at Naval Shore Facilities, Investigation through January 1971," Naval Civil Engineering Laboratory, Port Hueneme, Calif., Technical Note N-1169, May 1971. 
[12] Vivian, R. E. and Reynolds, K. C. "Objectives, General Testing Procedure, Specifications, Results of Tests," The Research Foundation for Cross-Connection Control, University of Southern California, Los Angeles, Calif., Paper No. 5, April 1948.

[13] Springer, E. K. and Reynolds, K. C. "Definitions and Specifications of Double Check Valve Assemblies and Reduced Pressure Principle Backflow Prevention Devices," University of Southern California, School of Engineering, Report 48-101, January 30, 1959.

[14] Reynolds, K. C. "Manual of Cross-Connection Control Recommended Practice," Research Foundation for Cross-Connection Control, University of Southern California, Los Angeles, California, August 1960 .

[15] Springer, E. K. "Manual of Cross-Connection Control" Foundation for Cross-Connection Control Research, University of Southern California, Los Angeles, Calif., March 1969.

[16] Groeniger, W. C., "Insurance Against Water-Born Diseases Through Plumbing Fixtures," Plumbers and Heating Contractors Trade Journal, September 1, 1927.

[17] Groeniger, W. C. "The Contamination of Water Supply Through Cross Connections," Plumbers and Heating Contractors Trade Journal, January 1, 1929.

[18] Groeniger, W. C. "Cross Connections," Read at Twenty-Fourth Annual Convention of the American Society of Sanitary Engineering, Detroit, Michigan, September 3, 1929.

[19] "Cross Connections" The American Society of Sanitary Engineering, Minutes of the Conference held at the Bureau of Standards at Washington, D. C. on February 24 and 25, 1932. Reported and Prepared by Henry B. Weaver, Washington, D. C.

[20] ANSI - Al12.1.1 - 1971 "Performance Requirements for Pipe-Applied Atmospheric Type Vacuum Breakers," (A.S.S.E. 1001), American Society of Sanitary Engineering, 228 Standard Building, Cleveland, Ohio.

[21] A.S.S.E. 1011, "Hose Connection Vacuum Breakers," American Society of Sanitary Engineering, 228 Standard Building, Cleveland, Ohio, June 1970 .

[22] A.S.S.E. 1012, "Backflow Preventers with Intermediate Atmospheric Vent," American Society of Sanitary Engineering, 228 Standard Building, Cleveland, Ohio, May 1972. 
[23] A.S.S.E. 1013, "Performance Requirements for Reduced Pressure Principle Back Pressure Backflow Preventers," American Society of Sanitary Engineering, 228 Standard Building, Cleveland, Ohio, June 1971.

[24] A.S.S.E. 1015, "Double Check Valve Type Back Pressure Backflow Preventers," American Society of Sanitary Engineering, 228 Standard Building, Cleveland, Ohio, May 1972.

[25] A.S.S.E. 1020, "Performance Standard for Vacuum Breakers, Antisiphon, Pressure Type," American Society of Sanitary Engineering, 228 Standard Building, Cleveland, Ohio, November 1974.

[26] ANSI - Al12.1.2 "Air Gaps in Plumbing Systems," American Society of Mechanical Engineers, 345 East 47 th St., New York, N. Y., January 1973.

[27] DeRoos, R. L. and Michaelsen, G. S. "Use of Barometric Loop for Protection of Potable Water Systems," Air Conditioning, Heating and Ventilating, pp 99-103, June 1969.

[28] PS 31-74, "Specification for Backflow Prevention Devices" International Association of Plumbing and Mechanical Officials, Los Angeles, California, 1974.

[29] Springer, E. K. "Manual of Cross-Connection Control," Foundation for Cross Connection Control and Hydraulic Research, University of Southern California, Los Angeles, California, 1974.

[30] A.S.S.E. 1002 "Standards and Test Procedures for Water Closet Flush Tank Ball Cocks" American Society of Sanitary Engineering 228 Standard Building, Cleveland Ohio, Oct. 1964 (Rev Oct. 1968).

[31] AWWA C506-69 "Backflow Prevention Devices - Reduced Pressure Principle and Double Check Valve Types," American Water Works Association, New York, 1969.

[32] Springer, E. Kent "The Protection of Potable Water Systems from Contamination or Pollution by Backflow" A paper presented to the Medford Water Commission, Medford, Oregon, Nov. 16, 1971. FCCCHR, University of Southern California, Los Angeles, Calif.

[33] "Oxygen Pressure Method for Accelerated Aging Tests of Rubber Compounds" Bulletin of Research No. 16 June 1940. Underwriters Laboratories, Chicago, IIl. 
[34] Angle, G. J. "Cross-Connections and Backflow Prevention" AWWA Supplementary Reading Library Series, No. S106, American waterworks Association New York, N. Y. Dec 31, 1970.

[35] ANSI Al12.26.1 "Water Hammer Arresters" American Society of Mechanical Engineers, New York, N. Y. 1969.

[36] Baird, J. N.; Sanford, W. R. and Cristy, G. A.; "Reduced Pressure Principle Backflow Preventer Evaluation and Use at Oak Ridge National Laboratory" "Health Physics" Pergamon Press, 1965 Vol. 11, pp. 743-757.

[37] Huddle, F. P.; Boesman, W. C., and Rothberg, P. F. "Science Policy: A Working Glossary", Science Policy Research Division, Library of Congress July 1973.

[38] National Standard Plumbing Code - 1975 Co-sponsored by National Association of Plumbing-Heating-Cooling Contractors and the American Society of Plumbing Engineers, (National Association of Plumbing Heating - Heating-Cooling Contractor, Washington, D. C., June 1975). 


\subsection{ACKNOWLEDGMENT}

The authors acknowledge the critical reviews of Roger D. Lee, James A. Warren and Thomas $\mathrm{N}$. Hushower in the Water Supply Division of the Environmental Protection Agency and the equally valuable work of William G. Street in the NBS Center for Building Technology. Also the informal contribution of Thomas P. Kruzic with Naval Facilities Engineering Command was appreciated.

The list of other individuals who contributed material for the updating of this paper is long, including many sales engineers, plumbing officials, laboratory personnel and code writers. The authors are grateful for the cooperation of each person. 


\section{APPENDIX}

\subsection{Vacuum Dissipation Calculations}

Dawson and Kalinske present the following useful equations in their report on "Plumbing Cross-Connections and Back-Siphonage Research," pages 28 and 29 [3]. The introductory paragraph concerning these equations is as follows:

"In order that some idea may be had of the time required to dissipate vacuums in different-size volumes, an analysis will be made of this particular problem. It is to be remembered that the rate of air flow in pounds per second through any given opening remains constant for any vacuum greater than 14 inches of mercury. Therefore, the time required for a vacuum in a volume $V$ to be reduced to the critical pressure of 14 inches of mercury vacuum, can be obtained from the following expression :

$$
t_{1}=\frac{V\left(W_{c}-W_{i}\right)}{Q_{a}}
$$

Equation (11)

Where: $t_{1}=$ seconds of time required.

$\begin{aligned} W_{C}= & \text { weight of air per cubic foot at critical } \\ & \text { pressure } P_{C} \cdot\left(1 \mathrm{bs} / \mathrm{ft}^{3}\right)\end{aligned}$

$P_{c}=0.53 P_{a}=14$ inches of mercury vacuum. $W$ is to be determined by considering adiabatic expansion from $\mathrm{P}_{a}$ to $\mathrm{P}_{c} \cdot \mathrm{P}_{\mathrm{a}}$ = atmospheric pressure ( $1 \mathrm{bs} / \mathrm{ft}^{2}$ )

$\mathrm{W}_{1}=$ Unit weight of air at initial pressure and temperature in the volume into which air is flowing. (1bs/ft $\mathrm{ft}^{3}$ "

$\mathrm{Q}_{\mathrm{a}}=$ pounds per second of air flow into the vacuum for vacuums exceeding 14 inches of mercury. $\mathrm{Q}_{2}=50 \mathrm{CA}$, where $\mathrm{C}=$ the discharge coefficient of the opening through which air enters the vacuum. $A=$ the area of the opening in square feet. 
The unit weight of air after adiabatic expansion from atmospheric pressure to any pressure, $P$, can be determined from the following formula:

$$
\mathrm{W}=\mathrm{W}_{\mathrm{a}}\left(\frac{\mathrm{P}}{\mathrm{P}_{\mathrm{a}}}\right)^{1 / \mathrm{k}}
$$

Where: $\mathrm{W}_{\mathrm{a}}=$ unit weight of atmospheric air $\left(1 \mathrm{bs} / \mathrm{ft}^{3}\right.$ )

$$
\mathrm{k}=1.4 \text { for air }
$$

The time to dissipate vacuums less than 14 inches mercury is given by Dawson and Kalinske as follows:

$$
\mathrm{t}_{1}=\frac{0.00086 \mathrm{~V}}{\mathrm{CA}}
$$

Equation (15)

They give the following example:
"Taking an example where $V$ is 10 gallons or 1 and $1 / 3$ cubic feet, find the time required to dissipate the vacuum from 29 inches of mercury to atmospheric pressure if air flows in through a $3 / 4-i n c h$ circular opening having a flow co- efficient of $1 / 2$. From equation (11), the time required to reduce the vacuum from 29 inches to 14 inches is 0.8 seconds. To reduce the vacuum from 14 inches of mercury to atmospheric pressure required about another 0.8 seconds. Therefore, the total time for dissipation of the vacuum is 1.6 seconds. The persistence of a vacuum for such a short time would obviously prevent the maximum back-siphonage effect. A 10 gallon volume is equivalent to about $100 \mathrm{feet}$ of 1 1/2-inch pipe. The time required for vacuum dis- sipation in other volumes would be in proportion."

From Dawson and Kalinske's equation above,(11) and (15), a simplified equation for the dissipation of vacuum to atmospheric pressure can be developed as follows for the total time $t_{t}$.

$$
\begin{aligned}
& t_{t}=t_{1}+t_{2} \\
& t_{t}=\frac{\left.w_{c}-w_{1}\right) V}{Q_{a}}+\frac{0.00086 V}{C A}
\end{aligned}
$$

By substitution of the parameters of the above example into equation 11 , it can be shown that $\left(W_{C}-W_{i}\right)=0.0460$ for Dawson and Kalinske assumed conditions. SubstiEuting this value into the above equation gives: 


$$
\begin{aligned}
& t_{t}=\frac{0.0460 \mathrm{~V}}{50 \times 1 / 2 \times 0.785 \mathrm{D}^{2}+\frac{0.00086 \mathrm{~V}}{1 / 2 \times 0.785 \mathrm{D}^{2}}} \\
& t_{t}=\frac{0.00234 \mathrm{~V}}{\mathrm{D}^{2}}+\frac{0.00219 \mathrm{~V}}{\mathrm{D}^{2}}=\frac{0.00453 \mathrm{~V}}{\mathrm{D}^{2}} \\
& \text { Where } \mathrm{D}=\text { diameter in feet. } \\
& \text { For a diameter d in inches } \\
& t_{t}=\frac{0.00453 \mathrm{~V}}{\mathrm{~d}^{2}} \times 144=\frac{0.65232 \mathrm{~V}}{\mathrm{~d}^{2}}
\end{aligned}
$$

For example in section 2.1 of this report, where $\mathrm{V}=$ seven and one third gallons $=0.98 \mathrm{ft}^{3}$ and $\mathrm{d}=0.375$ inches, the total time is as follows:

$$
t_{t}=\frac{0.65232 \times 0.98}{0.1406}=4.547 \text { seconds }
$$


10.2 The Navy Survey Form

The Navy survey form is reproduced here to aid in the interpretation of the data gathered for table 2 on page 11.

\section{BACKFLOW PREVENTION POLICY \\ SURVEY IFORM}

MAVAL CIVIL ENGINEERING LABORATORY

Port Huencme, California 93043

Mechanical and Electrical Engincering Department

Work Unit: YF38.534.006.01.007, Backflow Prevention Devices

\section{BACKFLOW PREVENTION SURVEY}

The following questions concern policies and regulations governing the protection of a potable water source which supplies a customer having a known or potential cross-connection to a health hazard. Or spacific interest are the requirements for backflow preventers at vessel watering points at piers and wharves.

\section{Responding Agency}

Name:

Address :

Phone:

Respondent: Name/Titlc

Please complete this questionnaire by checking ( $/$ ) the appropriate answer to each question that applics to your backflow prevention policies.

1.a. What is the minimum backflow prevention you require where a health hazard cxists?

( ) Air gap separation required (reduced pressure dev1ces and double check valve devices not allowed).

( ) Reduced pressure principal backflow preventer required.

( ) Doulle chcck valve assembly required.

() Other protection.

() No protection specified. 
1.b. What minimum protection do you require at vessel watering polnts at piers and wharves?

2. If reduced pressure principal devices are used, what certification or approval of the device do you require prior to Its installation?

( ) Full approval by the Foundation for Cross-Connection Control Research at the University of Southern California.

( ) Provisional approval by the above foundation.

( ) Laboratory test only by the above Foundation.

( ) other certification or approval. (Please specify and 11st devices approved.)

( ) No certification or approval required.

3. The Foundation for Cross-Connection Control Research has recently changed the field test requirement, before granting full approval, from a three-year test to a one-year test with more frequent inspection. If you currently require full or provisional approval will you:

( ) accept all devices approved under the new one year test prográm.

( ) accept only those devices previously approved under the three-year test program.

( ) provide an alternate policy. (Please specify)

4. If devices now in service were previously approved by a certifying authority, and if they do not have their certification renewed, or if it is rescinded by that authorfty, what will your policy be?

( ) Replace these devices at the earliest possibility with an approved device.

( ) Replace these devices at the first sign of malfunction with an approved device.

( ) Accept the device as originally approved.

( ) Other policy. (Please specify)

5. The cost of purchasing and installing a backflow prevention device is borne by the:

( ) water utility.

( ) customer. 
6. Please list the manufacturer, model, and slze of reduced pressure principal hackflow preventers which have been installed in your water system. Reduced pressure devices have been used for how many years?

Manufacturer Mlodel S1ze No. Installed

7. Pleasc indicate your mai..tenance and inspection policy regarding reduced pressure principal devices.

3. Frequency of inspection

b. Frequency of scheduled testing

c. Frequency of scheduled maintenance

d. Work required during scheduled maintenance

e. Who performs inspection

testing

maintenance

f. Who pays for inspection

testing

maintenance

8. Please describe any malfunctions, fallures, or problems encountered with reduced pressure preventers, including the make, model, and size of unsatisfactory units, the date of installation, and length of operation before malfunction. 
9. Repeat question 8 for double-check valve assemblies.

10. Is freezing a problem in your area?

How are these units protected from freezing?

What are the effects from freezing on reduced-pressure devices and double-check valve assemblies?

11. Do you foresee any changes in your existing backflow preventicn policy in the near future?

12. Other comments. (Please attach a copy of any regulations applicable to this survey.) 
10.3 Procedures for a National Voluntary Laboratory Accreditation Program.

The National Voluntary Laboratory Accreditation Program was promulgated by the publication of procedures in the Federal Register on February 25, 1976. It was stated that the goal of this program is to provide in cooperation with the private sector a national voluntary system to examine upon request the professional and technical competence of private and public testing laboratories that serve regulatory and nonregulatory product and certification needs. The program is also intended to accredit those laboratories that meet the qualifications which will be established under these procedures.

The program has been set up as Part 7 of Title 15 in Commerce and Foreign Trade. For this reason the document is divided into eighteen sections numbered from 7.1 through 7.18. Because some of the sections are quite lengthly and tedious to read, a format with sidenotes has been chosen for the presentation of Part 7 in this paper. Also the format incorporated the following arrangements:

1. The first line of the first sentence in a paragraph is indented.

2. Subsequent sentences in the same paragraph are not indented but, after a line space, begin at the margin.

3. A small circle marks the location of each sentence and a dash through a circle represents supporting statements or phrases for a previous sentence.

4. Where sentences are long, the ideas are separated by breaking the line and continuing after a single line space. 


\subsection{Purpose}

o

The purpose of this part is to establish procedures under which a National Voluntary Laboratory Accreditation Program will function.

\subsection{Description and goal of program}

7. 2 (a)

This system would examine competence of testing laboratories

Laboratories that meet qualifications would be accredited

Periodic checks and examinations will be required

\section{2 (b)}

Program will make maximum use of all existing activities

Would avoid

duplication of

other programs

Secretary will insure close coordination and consultation

\section{2 (c)}

To serve needs of industry, consumers and the Government

To promote technical competence

To establish a background of experience would examine the professional and technical competence of testing laboratories that serve regulatory and non-regulatory product evaluation and certification needs.

- Laboratories that meet the qualifications established pursuant to the procedures set out below would be accredited.

- This program will also require those laboratories that are accredited to maintain their qualification status through periodic checks and examinations.

The program will seek through coordination and consultation, to maximize benefits derived from other laboratory examination and accreditation activities.

$\$$ In this way, it is intended that the program will avoid duplication of other laboratory examination or accreditation programs conducted by the public and private sectors.

$\emptyset$ To this end, the Secretary will insure that close and continuing coordination and consultation is undertaken and maintained with interested representatives of Federal, State and local governments and of the private sector, including those from professional and trade associations and societies.

The intended goal of this program is to serve, on a timely basis, the needs of industry, consumers, the Government, and others by accrediting this nation's testing laboratories.

$\$$ The achievement of this goal would be sought by fostering and promoting a uniformly acceptable base of professional and technical competence in testing laboratories

$\phi$ and by establishing a background of experience necessary to the orderly evolution of a laboratory accreditation system designed to serve national needs as they develop.

\subsection{Definitions}

$7.3(\mathrm{a})$

Secretary

$7.3(\mathrm{~b})$

Product o his designee.

$\circ$
The term "Product" includes the plural thereof and means a type or a category of manufactured goods, constructions, installations and natural and processed materials or those associated services whose characterization, classification or functional performance determination is specified by standards. 
$7.3(\mathrm{c})$

Criteria

Committee

7.3 (d)

Person

$7.3(e)$

Testing

Laboratory

$7.3(f)$

General

Criteria

$7.3(\mathrm{~g})$

Specific

Criteria

$7.4(\mathrm{a})$

Any person may

initiate request

for finding of

need.

7.4 (b)

Request must include specific

information on product standards, test methods.

Also basis of need will include 1 tems set out in Sec.7.5

and the

Number of labs

to be accredited

Number of users

of testing labs
The term "Criteria Committee" means a National Laboratory Accreditation Criteria Comittee appointed by the Secretary under these procedures.

o

The term "person" means associations, companies, corporations, educational institutions, firms, government agencies at the Federal. State and local level, partnerships and societies, as well as divisions thereof, and individuals.

$\circ$

The term "testing laboratory" means any "person," as defined above, whose functions include testing, analyzing or inspecting "products," as defined above, and/or evaluating the designs or specifications of such "products" according to the requirements of applicable standards.

$\circ$

The term "general criteria" means those characteristics of a testing laboratory commonly found in, and generally expected of, such a laboratory serving the product under consideration. See in this connection Sec. 7.7(a).

The term "specific criteria" means those detailed requirements deemed essential to assuring an acceptable examination and evaluation of the testing function performed by a testing laboratory in performing specific tests related to identified standards for the product under consideration. See in this connection Sec. 7.7(a).

\subsection{Finding of need to accredit testing}

laboratories.

o

Any person may request the Secretary to find that there is a need to accredit testing laboratories which render services regarding a specific product so that it may be ascertained whether such product meets the requirements of applicable standards.

- Such a request shall be in writing and will include the following:

$\phi$ (1) Identification of the product;

$\emptyset$ (2) Text of an applicable standard;

6 (3) Text of a test method, if not included in the applicable standard identified in paragraph (b) (2) of this section; and

6 (4) Basis of need for accrediting testing laboratories that serve the product identified in paragraph (b) (1) of this section.

ф The basis will provide information relative to the items set out in Sec. 7.5 and will include, where appropriate, documentary evidence on such items as:

(i) the number of testing laboratories that is believed will want to be accredited to serve the product identified in paragraph (b)(1) of this section; and

(ii) the number of users of testing laboratories that is believed will desire services of testing laboratories accredited to serve the product identified in paragraph (b) (1) of this section. 


\section{$7.4(\mathrm{c})$}

Secretary may ask

for more information

Secretary may

decline to act

upon the request

Secretary must

respond in 10

working days

7.4 (d)

Should a request be made that may affect accreditation program of a Federal agency, Secretary shall seek views of such agency.

Should the affected agency object in writing within 30 days, the Secretary shall cease further actions

And the Secretary shall notify the requester of such actions

\section{$7.4(\mathrm{e})$}

Should Secretary find that a need exists he will publicize in the Federal Register

and provide at least 30 days for written coments

Should a public hearing be held, time for written comments shall be extended to hearing date

\section{4 (f)}

Persons desiring to be heard shall notify the Secretary in 15 days

If requested, informal hearings will be held for oral presentations
The Secretary may ask for more information to support a request made under paragraph (a) of this section if he feels it is necessary to do so.

- If on the basis of the information provided or because of the lack of resources, the Secretary is unable to justify the making of a preliminary finding of need, he will decline to act further on the request.

- The Secretary shall in that event notify the requester in writing within ten (10) working days after making a decision and shall state the reasons for so declining.

If a request received under this section is believed to affect an existing or developing testing laboratory examination or accreditation program of a Federal regulatory agency, the Secretary shall seek from the head of such agency its views relative to the Secretary's making a preliminary finding of need.

- If within thirty (30) days after receipt of the Secretary's solicitation of views, or such extension of time as may be agreed to by the Secretary, the head of the affected Federal regulatory agency explains, in writing, his objections to the Secretary's making a preliminary finding of need, the Secretary shall cease to act further on the making of such finding.

In that event, the Secretary shall notify the requestor of such objections and of his declination to act on the request pursuant to paragraph (c) of this section.

If, on the basis of the information provided to him, the Secretary finds that a need exists to accredit testing laboratories that serve a specific product, he shall publish a notice in the Federal Register indicating that such finding is a preliminary finding.

The notice shall include a statement as called for in Sec.7.5 as to the basis for the Secretary's finding and shall provide at least a thirty (30) day period for the submission of written comments thereon.

- In the event that a public hearing or hearings are held on this preliminary finding as authorized under paragraph (f) of this section, the period allowed for the submission of written comments shall be extended to the date on which such hearing or hearings are held.

Interested persons wanting to express their views in an informal hearing shall notify the Secretary of that desire within fifteen (15) days after the notice is published in the Federal Register.

- Upon receipt by the Secretary of such request, informal public hearings shall be held so as to give all interested persons an opportunity for the oral presentation of data, views, or arguments, in addition to the opportunity to make written submissions. 
If appropriate

hearings may be

held at two places

with notice published

in Federal Register

Al1 comments will

be on file in the

Commerce Building

\section{$7.4(\mathrm{~g})$}

By a notice in the Federal Register the Secretary shall make a final finding of need or shall withdraw hts preliminary finding

And shall state the basis for such finding

\section{$7.4(\mathrm{~h})$}

If notice sets out the final finding of need, it will include:

(1) identification of product

(2) identification of standards and test methods

(3) statement that separate notice in Federal Register will advise that a NLACC will be formed or else an existing criteria comittee will be used

Such separate notice will state duties of Committee, its size and basis for selection of committee members.
- If deemed appropriate by the Secretary, such hearings may be held at two locations, one of which shall be east of the Mississippi River and the other west thereof.

- Notice of such hearings shall be published in the Federal Register at least twenty (20) days in advance thereof.

- A transcript shall be kept of any oral presentation.

$\oint$ (1) All written and oral comments will be filed in the Central Reference and Records Inspection Facility, Room 7068, Commerce Building, 14th Street between E Street and Constitution Avenue, N.W., Washington, D.C. 20230, and will be available for public inspection at that location.

After evaluating the comments received, the Secretary shall publish a notice in the Federal Register making a final finding of need or withdrawing his preliminary finding of need to accredit testing laboratories that serve a specific product.

- The notice shall state the basis for the Secretary's final finding of need or for the withdrawal of his preliminary finding.

The notice published under paragraph $(\mathrm{g})$ of this section, if it sets out the Secretary's final finding of need, will also include:

\$ (1) Identification of the product for which testing laboratories will be accredited to serve;

$\emptyset$ (2) The identification of applicable standards, including the test methods involved; and

\$ (3) A statement that the Secretary is publishing simultaneously with this notice,

a separate notice in the Federal Register advising that pursuant to the provisions of the Federal Advisory Committee Act (Pub. L. 92-463, dated October 6, 1972) the Secretary will form a National Laboratory Accreditation Criteria Comittee pursuant to Sec. 7.6

or will utilize an existing Criteria Committee previously established under that section.

\$ Except where the Secretary utilizes an existing Criteria Committee such separate notice will outline the functions and duties of the Committee, its size, and the basis for selection of the members thereof. 
7.5 Statement of the basis for a preliminary finding of need.

Basis for preliminary finding of need are:

\section{$7.5(\mathrm{a})$}

The establishment of criteria must benefit public interest

\section{5 (b)}

A National need extends beyond that served by any existing program

\section{$7.5(\mathrm{c})$}

An existing product standard is deemed suitable by the Secretary

\section{5 (d)}

Existing testing methodology is determined by the Secretary to be valid

\section{$7.5(\mathrm{e})$}

Secretary determines that accreditation is feasible and practical

\section{$7.6(a)$}

When the Secretary establishes a Criteria Committee he wil1:

(1) publish a notice in the Federal Register according to Sec. $7.4(\mathrm{~h})(3)$

(2) and file a charter setting forth purpose and nature

\section{$7.6(\mathrm{~b})$}

Membership of Criteria Comittee is chosen broadly from interested groups
- The statement setting forth the basis for the preliminary finding of need referred to in Sec. $7.4(\mathrm{e})$ shall as a minimum address the following items:

Whether the establishment of general or specific criteria and other conditions for accrediting testing laboratories that serve a specific product would benefit the public interest;

Whether there is a national need to accredit testing laboratories for the specific product involved beyond that served by any existing laboratory accreditation programs in the public or private sector;

Whether for the specific product involved, there is in existence a standard that is deemed by the Secretary as being of importance to commerce, consumer well-being, or the public health and safety; o as determined by the Secretary for ascertaining conformity to to the standard of the specific product involved; and
Whether it is feasible and practical to accredit testing laboratories that serve the specific product involved.
7.6 Establishment and functions of a National

Laboratory Accreditation Criteria Committee.

The Secretary will establish a Criteria Committee and appoint the Chairman and members thereto following:

$\phi$ (1) Publication of the separate Federal Register notice referred to in Sec. $7.4(\mathrm{~h})(3)$ that announces the Secretary's intention to form a Criteria Committee, as distinguished from an announcement of intent to utilize an existing committee; and

(2) The filing of a charter setting forth the purpose and nature of the Criteria Committee.

The membership of the Criteria Committee will be composed of employees of the Department of Commerce, other Federal agencies, and qualified representatives chosen from among producers, distributors, users, consumers, testing laboratories, academia, and general interest groups, including state and local governmental bodies and agencies affected by the Secretary's finding of need to accredit testing laboratories serving a specific product. 
Equitable balance of members that represent all interested groups

\section{$7.6(\mathrm{c})$}

Criteria Committee shall be governed by the Federal Advisory Committee Act

Committee members may be paid per diem and travel expenses

\section{$7.6(d)$}

Criteria Committee will develop and recommend criteria to the Secretary

Secretary will define a time period for development of criteria

\section{$7.6(\mathrm{e})$}

Criteria Committee may consult with other public and private parties to develop criteria

and evidence of such consultation will be made a matter of public record.

\section{7 (a)}

Secretary and Criteria Comittee will be guided in Criteria development by factors such as these:

for general criteria
- The membership of each Criteria Committee shall be selected so as to provide an equitable balance that represents the interests affected by the Secretary's finding of need.

○ Committee formed and utilized by the Secretary under these procedures shall be governed by the applicable provisions of the Federal Advisory Committee Act, cited earlier herein.

- Persons selected to serve on a Criteria Committee may be paid travel expenses and per diem, provided authorized travel is involved.

Upon formation of the Criteria Committee, the Secretary will request it to develop and recommend to him general and specific criteria to accredit testing laboratories that serve a specific product.

- The Secretary, in a written communication to the Chairman of the Comittee, shall designate a time period for the development of general and specific criteria.

When developing general or specific criteria, the Criteria Committee may, where it deems such action to be appropriate, consult with other interested public and private parties, including Federal, State and local agencies and private standards bodies.

- Exchanges of correspondence, memorandums and other evidence of such consultation will be made a matter of public record.

\subsection{Development and recommendation of} criteria for accrediting testing laboratories.

- The Secretary, and the Criteria Committee acting at the request of the Secretary, in developing general and specific criteria to accredit testing laboratories that serve a specific product shall consider factors such as:

6 (1) For general criteria pertaining to testing laboratories:

(i) Organization;

(1i) Staff:

(iii) Physical plant;

(iv) Operational processes;

(v) Control procedures;

(vi) Quality assurance; and

(vii) Professional and ethical business practices, as appropriate.

6 (2) For specific criterla pertaining to testing laboratories:

and for specific criteria (i) Personnel and equipment qualifications required of the testing laboratory function;

(i1) Requirements applicable to proficiency sample prograns; 


\section{7 (b)}

Criteria in existing standards will be used when appropriate, but where none are found

Criteria Committee will undertake development of criteria

\section{7 (c)}

Instructions for making application shall be included in criteria together with conditions to be followed in the program:

(1) examination and audit

(2) payment of fees

(3) Iimitation on advertising

\section{7 (d)}

Accreditation by this program does not relieve laboratories from observing any existing statutes, or regulations

\section{$7.7(\mathrm{e})$}

This section does not:

(1) prohibit accreditation solely on basis of organizational association or for being a foreign firm

(2) provide for development of product standards or test methods

(iii) Application requirements;

(iv) Initial and periodic examination and audit procedures; and

(v) Professional and technical qualifications of personnel who examine testing laboratories.

Where appropriate existing criteria cannot be found, the Criteria Comittee will, at the request of the Secretary, undertake to develop and recommend to him such appropriate general and specific criteria as may be needed.

The criteria shall contain instructions for making application by testing laboratories serving the product involved and

shall require that each testing laboratory that desires to participate in this program must agree to conditions that include but are not limited to the following:

$\phi \quad$ (1) Be examined and audited, initially and on a continuing basis;

$\oint$ (2) Pay accreditation fees and charges; and

\$ (3) Avoid reference by itself and forbid others utilizing the services of an accredited testing laboratory from referencing its accredited status in consumer media and in product advertising or on product labels, containers and packaging or the contents therein.

The criteria shall contain a statement that compliance by testing laboratories with the general and specific criteria and other conditions established by the Secretary and which are accredited by him under these procedures

shall in no way relieve such laboratories from the necessity of also observing and being in compliance with any existing Federal, State and local statutes, ordinances, and regulations that may be applicable to the operation of such laboratories, including consumer protection and anti-trust laws. section:

In carrying out the activities authorized by this

6 (1) No action will be taken or criteria developed that would prohibit the accreditation of a testing laboratory solely on the basis of that laboratory's association or nonassociation with manufacturing, distributing or vending organizations, testing laboratory is a foreign firm; or because the

(2) No action will be taken under this program to develop a product standard or test method standard; 
(3) establish procedures to modify a product standard or a test method standard

(4) propose to promulgate criteria considered to be impractical or contrary to the public interest

(5) want or accept business data, trade secrets, etc.

$7.8(a)$

Criteria Comittee shall forward its recommendations to the Secretary

Secretary will publish it in Federal Register

inviting written comments within forty-five (45)days

$7.8(\mathrm{~b})$

Request for a hearing can be made by interested persons within 15 days

If requested, informal hearings will be held for oral presentation

If appropriate, hearings may be held at two places

with notice published in Federal Register

written and oral comments will be filed and available for inspection

(3) No action will be taken under this program to modify a product standard or a test method standard where such a standard is in existence;

(4) No general or specific criteria will be promulgated unless compliance with such criteria and its implementation has been determined by the Secretary to be feasible and practical and not contrary to the public interest; and

f (5) The Secretary, under this program, will not ask for or accept confidential business data, trade secrets or other proprietary information.

\subsection{Publication of proposed criteria.}

$\circ$ criteria for accrediting testing laboratories under Sec. 7.7, the Criteria Committee shall forward its recommendations for such criteria to the Secretary for his consideration.

Secretary, after consideration of such criteria will publish in the Federal Register a notice giving the complete text of the proposed general and specific criteria,

- and inviting any interested persons to submit written comments on such proposed criteria within forty-five (45) days after its publication in the Federal Register, unless another time limit is provided by the Secretary.

Interested persons wanting to express their views in an informal hearing shall notify the Secretary of that desire within fifteen (15) days after such proposed criteria are published in the Federal Register.

- Upon receipt by the Secretary of such request, informal public hearings shall be held so as to give all interested persons an opportunity for the oral presentation of data, views, or arguments, in addition to the opportunity to make written submissions.

- If deemed appropriate by the Secretary, such hearings be held at two locations, one of which shall be east of the Mississippi River and the other west thereof.

- Notice of such hearings shall be published in the Federal Register at least twenty (20) days in advance thereof.

- A transcript will be kept of any oral presentation.

ф (1) All written and oral comments will be filed in the Central Reference and Records Inspection Facility, Room 7068, Commerce Building, 14th Street between E Street and Constitution Avenue NW., Washington, D.C. 20230,

and will be avallable for public inspection at that location. 


\section{$7.8(\mathrm{c})$}

Criteria Committee w111 evaluate comments and make recommendations to the Secretary

Secretary w111 act upon the Criteria Committee's recommen-

dations in one of

three alternatives:

(1) to announce the

final general and specific criteria

(2) to postpone action for further development

(3) to withdraw the criteria from consideration

\section{9}

Secretary w11l consult with interested Federal agencles for meaningful cooperation

Opportunities for Federal agency representatives to serve on Criteria Committees

\section{7. $10(a)$}

Secretary shall establish fees and charges for examining, accrediting and auditing

Fees shall be calculated to maximize the self-sufficiency of the accrediting program

Notice in the Federal Register w111 give criteria of Sec. $7.8(\mathrm{a})$
The Secretary upon recelpt of all written and oral comments will request the Criterla Committee to conduct and return to him in writing, within a time period specified by the Secretary, its evaluation and recommendations with respect to such comments.

After considering the Criteria committee's evaluation and recommendations, the Secretary w1ll prepare his evaluation and publish in the Federal Register a notice;

6 (1) Announcing the final general and specific criteria that testing laboratories must meet in order to be accredited and the date when such final criterla shall go into effect which shall not be less than thirty (30) days after the date of publication of such notice;

\$ (2) Stating that the proposed general and specific criteria w1ll be further developed before final publication; or

ф (3) Withdrawing the proposed general and specific criteria from further consideration.

\subsection{Coordination with Federal agencies.}

As a means of assuring effective and meaningful cooperation, Input, and participation by those Federal agencles that have an interest in and may be impacted by the laboratory accreditation program carried out under these procedures,

the Secretary shall undertake to communicate and consult with appropriate officials at policy making levels within those agencies.

- These coordination efforts w111 include opportunities for representatives designated by those agencles to serve on each Criteria Committee established by the Secretary in which those agencies have an interest.

\subsection{Establishment of fees and charges.}

The Secretary in conjunction with the use of the Working Capital Fund of the National Bureau of Standards, as authorlzed by section 12 of the Act of March 3, 1901 , as amended (15 U.S.C. 278b),

for this program shall establish fees and charges for examining, accrediting, and auditing testing laboratories.

o The fees and charges established by the Secretary, which may be revised by him when he deems it approprlate to do so, shall be in amounts calculated to maximize the selfsufficlency of this program.

- A separate notice w111 be published in the Federal Register simultaneously with the notice of proposed general and specific criteria referred to in Sec. $7.8(a)$. 
and a tentative schedule of fees and charges

so that public may evaluate criteria against fees charged

7.10 (b)

Upon the announcement of final general and specific criteria a separate notice in Federal Register will list final schedule of fees

to become effective on date criteria becomes effective

\section{$7.10(\mathrm{c})$}

Subsequent revisions to be published in Federal Register to gecome effective in not less than thirty (30) days

\section{$7.11(a)$}

Each laboratory may initiate an application for accreditation

$7.11(\mathrm{~b})$

Secretary w1ll notify applicant and NBS of requirements and fees

Rejected applicant may reapply after he has corrected deficiences

Rejected applicant may request a hearing
- Such notice will set out a schedule of estimated fees and charges the Secretary proposes to establish.

- The notice would be furnished for informational and guidance purposes only in order that the public may evaluate the proposed criteria in light of the expected fees to be charged.

- At such time as the Secretary publishes the notice announcing the final general and specific criteria referred to in Sec. $7.8(c)(1)$,

he shall simultaneously publish a separate notice in the Federal Register setting forth the final schedule of fees that will be charged testing laboratories that serve a specific product.

- The effective date of such final schedule of fees shall be the same as the date on which the final general and specific criteria are to take effect.

Revisions, if any, to the fees and charges established by the Secretary under paragraph (b) of this section shall be published in subsequent Federal Register notices and shall take effect not less than thirty (30) days after the date of publication of such notice.

- Mention of such revisions shall also be published in the appropriate quarterly reports referred to in Sec. 7.17(a).

\subsection{Participation of testing laboratories.}

Each testing laboratory serving a product for which final general and specific criteria have been promulgated under Sec. $7.8(\mathrm{c})(1)$,

and desiring to be accredited under this program, will notify the Secretary of its desire pursuant to the provisions of such criteria.

After receipt and evaluation of the testing laboratory's application and information contained therein, the Secretary sha11, upon the acceptance thereof, notify the applicant testing laboratory

and the National Bureau of Standards in writing of the specific applicable examination requirements for accreditation and examination and accreditation.

the fees and charges for such

- If the application is not accepted, the Secretary shall notify the applicant testing laboratory of the reasons for rejection of its application,

and such testing laboratory

may reapply under Sec. 7.13 (d) after correcting the deficiencies set out in the Secretary's notification of rejection.

- Alternatively, the applicant testing laboratory shall have thirty (30) days to request a hearing pursuant to 5 U.S.C. 556 . 
Secretary's rejection would be stayed until the hearing

7.11 (c)

Applicant laboratories must meet general and specific criteria

\subsection{1 (d)}

National Bureau of Standards, on behalf of Secretary, will arrange for examination of applicant laboratory

National Bureau of Standards will assure that examiners possess qualification of Sec. 7.8 (c) (1)

If NBS conducts examination, the resulting report will be sent to the Secretary

If testing is prepared by contractor, NBS will review it before sending to Secretary

\section{$7.11(\mathrm{e})$}

Secretary will grant or propose to deny accreditation within 20 working days after receiving report.

or will notify applicant in writing with reason for delay

Secretary's determination of status will be given in writing

and if he proposes to deny the accreditation he will state reasons

- In the event, however, that the applicant testing laboratory requests a hearing within that thirty (30) day period the Secretary's rejection shall be stayed until the hearing held pursuant to 5 U.S.C. 556.

○ this program to serve the product identified by the Secretary in his final finding of need under Sec. $7.4(\mathrm{~g})$ in accordance with the standards and test methods identified by the Secretary in that finding must meet the general and specific criteria promulgated by him.

o

Upon receipt by the National Bureau of Standards of the applicant testing laboratory's written request for examination and of the fees and charges specified in paragraph (h) of this section,

the National Bureau of Standards on behalf of the Secretary, will arrange for by contract or will itself conduct, the examination requirements of the Secretary.

- In all cases where testing laboratories are examined, the National Bureau of Standards will assure that the personnel used by the contractor

or by the National Bureau of Standards possess the professional and technical qualifications set out in the specific criteria promulgated under Sec. 7.8 (c)(1).

- If the National Bureau of Standards conducts the examination, the resultant examination report will be forwarded to the Secretary.

- In cases where the examination report was prepared by a contractor, the National Bureau of Standards, before making payment thereunder

or forwarding the report to the Secretary, will review the report to assure that the contract terms have been fulfilled.

The Secretary, after reviewing the examination report furnished under paragraph (d) of this section, will make a determination granting or

proposing to deny accreditation to the applicant testing laboratory, not later than twenty (20) working days following the date on which the report is received by him.

- If the determination is not made within such time limit, the Secretary shall notify the applicant testing laboratory in writing of the reasons for the delay.

- Upon making his determination, the Secretary will notify the testing laboratory in writing of its accreditation status.

- If the Secretary proposes to deny accreditation to an applicant testing laboratory, the notification will state the reasons for such proposed dental. 
7.11 (f)

and the applicant

shall have thirty

(30) days from

receipt of notice

to request a hearing

If appeal is not

made in required

period the Secretary's

proposed denial will be

made final in a written

notification

However, if hearing is requested, proposed denial shall be stayed until hearing

\subsection{2}

Advertising by the accredited laboratory is limited in scope

$7.13(\mathrm{a})$

Secretary may find cause to revoke the accreditation of a laboratory

$7.13(\mathrm{~b})$

If so notified by the Secretary such laboratory may request a hearing

Revocation would become final should hearing not be requested in 30 days

Should a hearing be properly requested the proposed revocation shall be stayed Secretary that he proposes to deny accreditation, the testing laboratory shall have thirty (30) days from the date of receipt of such notification to request a hearing under the provisions of 5 U.S.C. 556.

- The Secretary's proposed denial shall become final through the issuance of a written decision to the applicant in the event that the applicant does not appeal such notification by the end of that thirty (30) day period.

- In the event, however, that the applicant testing laboratory requests a hearing within that thirty (30) day period, the Secretary's proposed denial shall be stayed until the hearing held pursuant to 5 U.S.C. 556.

\subsection{Reference to accredited status.}

Except as limited under Sec. 7.7(c)(3), a testing laboratory accredited under this program may use the following statement on its letterheads and in professional, technical and trade publications:

$\oint \quad$ "Accredited by the Department of Commerce, National Laboratory Accreditation Program for (appropriate wording as authorized by the Secretary's notification under Sec. 7.11(e))."

7.13 Revocation or termination of accreditation of a testing laboratory.

If the Secretary finds that a testing laboratory which he has previously accredited has violated the terms of its accreditation

or the provisions of these procedures, he may, after consultation with such testing laboratory, notify that testing laboratory that he proposes to revoke its accreditation.

Upon receipt of a notice from the Secretary of the proposed revocation, which notice shall set forth the reasons for such proposed revocation,

the accredited testing

laboratory shall have thirty (30) days from the date of receipt of such notification to request a hearing under the provisions of 5 U.S.C. 556.

- The Secretary's proposed revocation shall become final through the issuance of a written decision to the testing laboratory in the event that such testing laboratory does not appeal the proposed revocation within that thirty (30) day period.

o In the event, however, that the accredited testing laboratory requests a hearing within that thirty (30) day period, the Secretary's proposed revocation sha11 be stayed until the hearing held pursuant to 5 U.S.C. 556. 
$7.13(c)$

A laboratory may end participation with a written notice to

the Secretary

Receipt of notice would terminate processing of application

or terminate

the accreditation

when acknowledged by the Secretary

\section{$7.13(d)$}

A laboratory may reapply should accreditation be denied, revoked or terminated

\section{$7.14(a)$}

Secretary may cease laboratory accreditation for a specific product

Notice of preliminary finding in Federal Register

Shall address those items of Sec. 7.5 covered by original finding.

\subsection{4 (b)}

Minimum period of 60 days to submit written comments

Should public hearings be held written comments accepted up to hearing date

\subsection{4 (c)}

Twenty (20) days allowed for the request for hearing
A testing laboratory may at any time terminate its participation and responsibilities under this program or withdraw its application for accreditation by giving written notice to the Secretary.

- Upon recelpt by the Secretary of such notice, he shall terminate further processing of the testing laboratory's application for accreditation.

- If such testing laboratory has been accredited, the Secretary shall terminate that testing laboratory's accreditation.

o The Secretary shall notify the testing laboratory that its accreditation has been terminated pursuant to its request.

A testing laboratory whose application has been rejected or whose accreditation has been denied, revoked or terminated or which has withdravm its application prior to being accredited may reapply for and be accredited if it meets the applicable general and specific criteria promulgated by the Secretary under Sec. 7.8 (c)(1) and

agrees also to meet the conditions set out under Sec. 7.7 (c) and the provisions of Sec. 7.12.

\subsection{Cessation of accreditations.}

The Secretary may cease the accreditation of testing laboratories that serve a specific product if he finds that there is no longer a need to accredit such laboratories.

- An action to cease such accreditations shall commence with the issuance of a preliminary finding which shall be published in the Federal Register.

- Such notice shall set forth the Secretary's reasons for his preliminary finding and shall,

as a minimum, address those relevant items listed in Sec. 7.5 which formed the basis for his original finding of need to accredit testing laboratories serving a specific product.

The notice published under paragraph (a) of this section shall provide at least a sixty (60) day period for the submission of written comments on the Secretary's preliminary finding.

- In the event that a public hearing or hearings are held on this preliminary finding as authorized under paragraph (c) of this section,

the period allowed for the submission of written comments shall be extended to the date on which such hearing or hearings are held.

Interested persons wanting to express their views in an informal hearing shall notify the secretary of that desire within twenty (20) days after the notice is published in the Federal Reglster. 
Public hearings may be heid to get views of all concerned

Hearings may be held east and west of the Mississippi

Twenty (20) days advance notice in Federal Register

all records of hearings will be available at Commerce Building

7.14 (d)

Notice of Secretary's decision shall be in Federal Register

together with basis for his decision

Cessation date shall be not less than 60 days after publication of notice

\subsection{4 (e)}

Cessation of accreditation affects al1 those previously accredited for a product.

Such accredited laboratory may seek to serve another product

and may be accredited by meeting provisions of Secs. 7.7 (c), $7.8(\mathrm{c}) 1$ and 7.12

7.14 (f)

Accreditation may be reinstituted by procedures of Sec. 7.4
- Upon receipt by the Secretary of such request, informal public hearings shall be held so as to give all interested persons an opportunity for the oral presentation of data, views, or arguments, in addition to the opportunity to make written submissions.

- If deemed appropriate by the Secretary, such hearings may be held at two locations, one of which shall be east of the Mississippi River and the other west thereof.

- Notice of such hearings shall be published in the Federal Register at least twenty (20) days in advance thereof.

- A transcript shall be kept of any oral presentation.

\$ (1) All written and oral comments will be filed in the Central Reference and Records Inspection Facility, Room 7068, Commerce Bullding, 14th Street between E Street and Constitution Avenue N.W., Washington, D.C. 20230 ,

and will be avallable for public inspection at that location.

- After evaluating the comments received, the Secretary shall publish a notice in the Federal Register making a final finding,

or withdrawing his preliminary finding, that there is no longer a need to accredit testing laboratorles that serve a specific product.

o The notice sha11 state the basis for the Secretary's final finding or for the withdrawal of his preliminary finding.

- If the notice sets forth the Secretary's final finding that there is no longer a need to accredit testing laboratories that serve a specific product,

such notice shall also state the effective date of such final finding which shall not be less that sixty $(60)$ days after the publication of the notice.

If the Secretary ceases the accreditation of testing laboratories that serve a specific product as provided for in this section,

he shall withdraw the accreditation previously issued to all those testing laboratories serving the same specific product.

- Any testing laboratory whose accreditation to serve a specific product has been withdrawn by the Secretary under this subsection may seek to be accredited to serve a different specific product under these procedures,

- and may be so accredited if it meets the general and specific criteria promulgated by the Secretary under Sec. 7.8 (c) (1) that are applicable to that different specific product

and if it agrees also to meet the conditions set out under Sec. 7.7 (c) and the provisions of Sec. 7.12 .

The Secretary may reinstitute the accreditation of testing laboratories that serve a specific product which he previously ceased accrediting under this section. 
- In that event he shall follow the same procedures set out under Sec. 7.4 relative to the finding of need to accredit testing laboratories that serve a specific product.

\subsection{Refund of fees and charges.}

\section{$7.15(\mathrm{a})$}

Some fees w111 be refunded should the laboratory withdraw its application for accreditation

\subsection{5 (b)}

No refunds made when laboratory terminates participation

\subsection{5 (c)}

No refunds made when accreditation is revoked under

Sec. 7.13

\section{$7.15(d)$}

Some fees will be refunded when the accreditation ceases as in Sec. 7.14 accreditation after it has submitted the required examination

fees and provides written notice to the Secretary of such withdrawal prior to the issuance of an accreditation or the denial thereof,

the testing laboratory will be refunded such fees except for the application fee, if any, and for any other costs that have been incurred relative to its application. responsibilities under this program at any time after it has been accredited or

after it has been notified by the Secretary that it is not being accredited, no part of the fees and charges paid by the testing laboratory will be refunded.

If the accreditation of a testing laboratory 18 revoked by the Secretary under Sec. 7.13, no part of the fees and charges paid by the testing laboratory will be refunded.

If the Secretary ceases the accreditation of testing laboratories that serve a specific product under Sec. 7.14 and withdraws the accreditation of a testing laboratory to test a specific product under that section,

such testing

laboratory will be refunded the unexpended part of the examination fees or charges paid by such testing laboratory to maintain its accredited status under this program:

PROVIDED, HOWEVER, That no such testing laboratory w111 be refunded 1ts original application fee, if any, to be accredited to serve a specific product.

\subsection{Amendment or revision of criteria.}

○

7.16

Provisions are made for amendments or revisions to previously promulgated criteria
The Secretary, or a Criteria Committee acting at the request of the Secretary, may undertake the development of amendments or revisions of any applicable general or specific criterla previously promulgated by the Secretary by following the same procedures pertaining to the original development of such criteria. 


\subsection{7 (a)}

Secretary will publish a quarterly report of actions involving each specific product

Such report to state clearly that accreditation does not relieve the laboratories from any legal responsibilities

\section{$7.17(\mathrm{~b})$}

Secretary's annual report shall list all laboratories accredited during the year

\subsection{7 (c)}

Secretary shall report monthly in the Federal Register

\section{all actions involving} status change

with name and address of laboratories concerned

\section{Secretary shall} provide necessary support

\subsection{User education and reports.}

o

made a final finding under these procedures that a need exists to accredit testing laboratories that serve such product,

will publish a quarterly report noting all action taken by hit regarding such matters as accreditations, revocations, the establishment of fees and charges, the promulgation of general and specific criteria and any amendments or revisions to such criteria.

- Such publications shall clearly state that testing laboratories accredited by the Secretary under these procedures are in no manner immune from the necessity of being in compliance

with all legal obligations and responsibilities imposed by existing Federal, State, and local laws, ordinances, and regulations, including those related to consumer protection and antitrust prohibitions.

The Secretary will also prepare an annual report summarizing all activities carried out under these procedures which shall include a listing of all testing laboratories accredited by the Secretary during the year to which the annual report relates.

$\circ$ accreditation actions taken by the Secretary, he shall, in addition to the reports called for under this section, publish in the Federal Register all actions taken by him during the preceding month which grant, revoke, terminate or result in the withdrawal of the accreditation of a testing laboratory.

- Such notice shall include the name and address of the testing laboratory concerned, and a brief explanation of the action taken by the Secretary with respect to that laboratory.

\subsection{Support function.}

- The Secretary shall make provisions for administrative and technical support and staff services as may be needed to carry out this program. 


\subsection{Hose Connection Vacuum Breaker Tests at NBS}

A test was conductod to soo how the HCV would fospond to simultaneous back-siphonage and back pressure (due to garden hose elevation) when the check valve was fouled with a wire in the manner presented in ASSE standard No. 1011 for the back-siphonage test method.

\subsubsection{Test Procedure and Results}

figure 5:

The basic test procedure was as follows and as depicted in

(a) Fill pail "A" to some level (measured from the floor) as shown in setup \#1, figure 5. (Pail "A" simulates a contaminated source - swimming pool).

(b) Weigh Pail "B" (tare weight) on weighing platform shown in figure 6, Appendix 10.5 (Water flows out of the vent ports down the outside of the hose and into Pail "B").

(c) Open spring loaded hose nozzle submerged to bottom of Pail "A".

(d) Open vacuum valve " $C$ " (make sure Pail " $B$ " is dry). The purpose of Pail " $\mathrm{B}$ " is to collect vent port discharge.

(e) Simultaneously open quick-closing valve "D" and start time interval recorder.

(f) Read vacuum manometer and record vacuum (absolute value).

(g) When the sight glass is half full with water, shut valve "D" and simultaneously stop time interval recorder. (Water collected in the sight glass is backflow).

(h) Weigh Pail "B" to get weight of water plus weight of bucket.

(i) Remove the hose from HCVB and blow water (compressed air) from sight glass through HCVB into a graduated cylinder (milliliters). Record the volume of water as milliliters of back-siphonage.

For each setup shown in figure 5, make triplicate runs. 


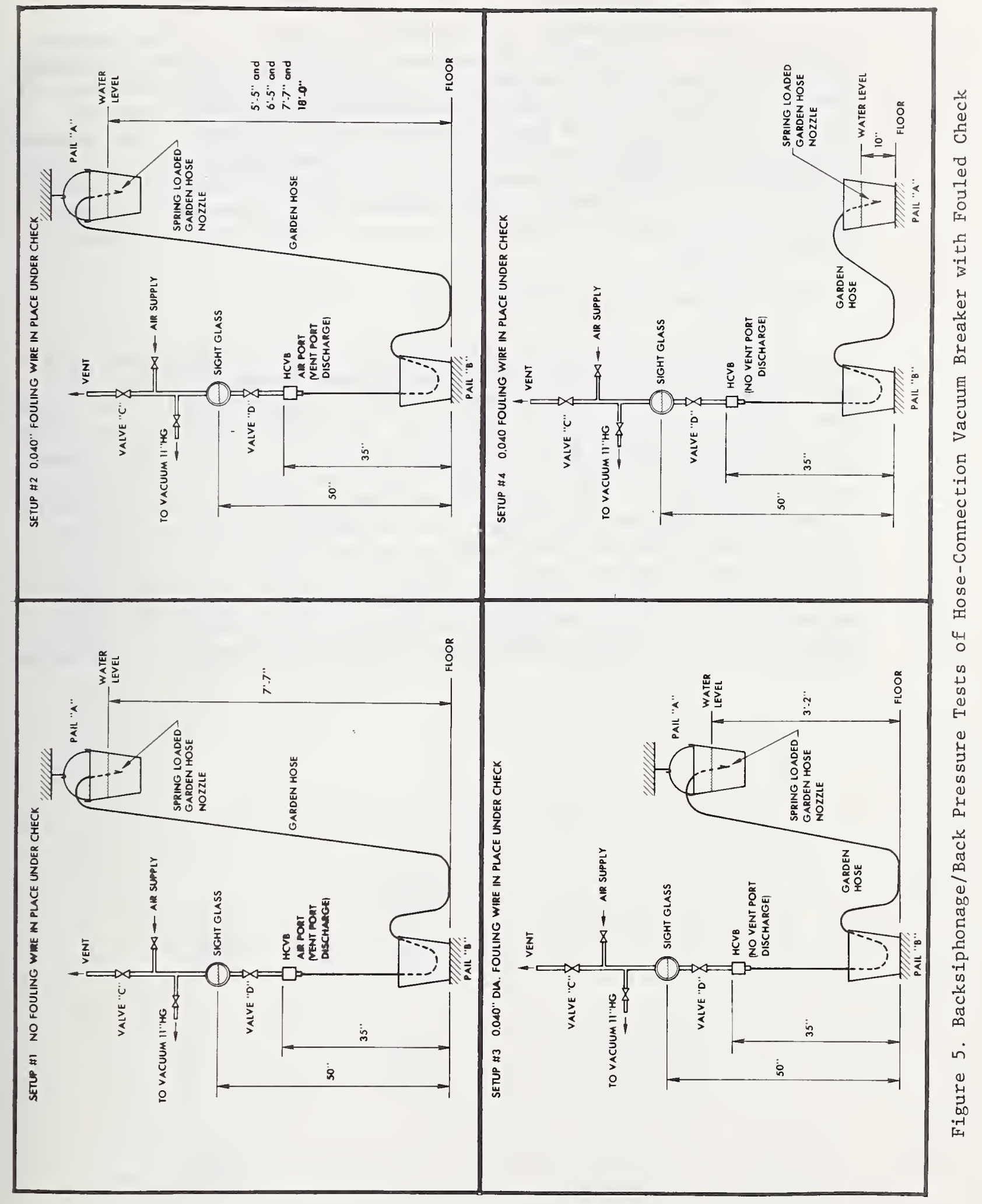


The average results are presented in Table 12 . The average vacuum was 11.7 centimeters of mercury, absolute. The above average rate results were quite repeatable even though vacuum fluctuations of about $\pm 2 \mathrm{~cm}$ of mercury occurred sporadically throughout each run. The last observed vacuum reading before closing valve " $D$ " was recorded as the running vacuum and these values were averaged. This variation is judged to be normally caused by water movement through the atmospheric vents of the HCVB. Water movement being somewhat variable since air is attempting to enter the vents simultaneously as water tends to escape.

\subsubsection{Discussion of Results}

Even though vacuum varied somewhat, the back-siphonage rate tended to remain quite constant. The volumes collected generally were several hundred milliliters and these volumes tended to be repeatable within $+20 \mathrm{milliliters}$ during any set of three runs for a given setup. Out of fifteen runs only one run was off by +50 milliliters. The back-siphonage rate did not vary appreciably with increasing back pressure condition. The device is designed to relieve back-pressure through the ports and data shows that it does this quite effectively. Although back-siphonage rate remained relatively constant with increasing back pressure, the vent discharge increased considerably as back pressure head was increased. A constant back-siphonage rate indicated that back pressure at the HCVB must be relatively constant regardless of the back pressure head potential imposed by the elevated hose. 


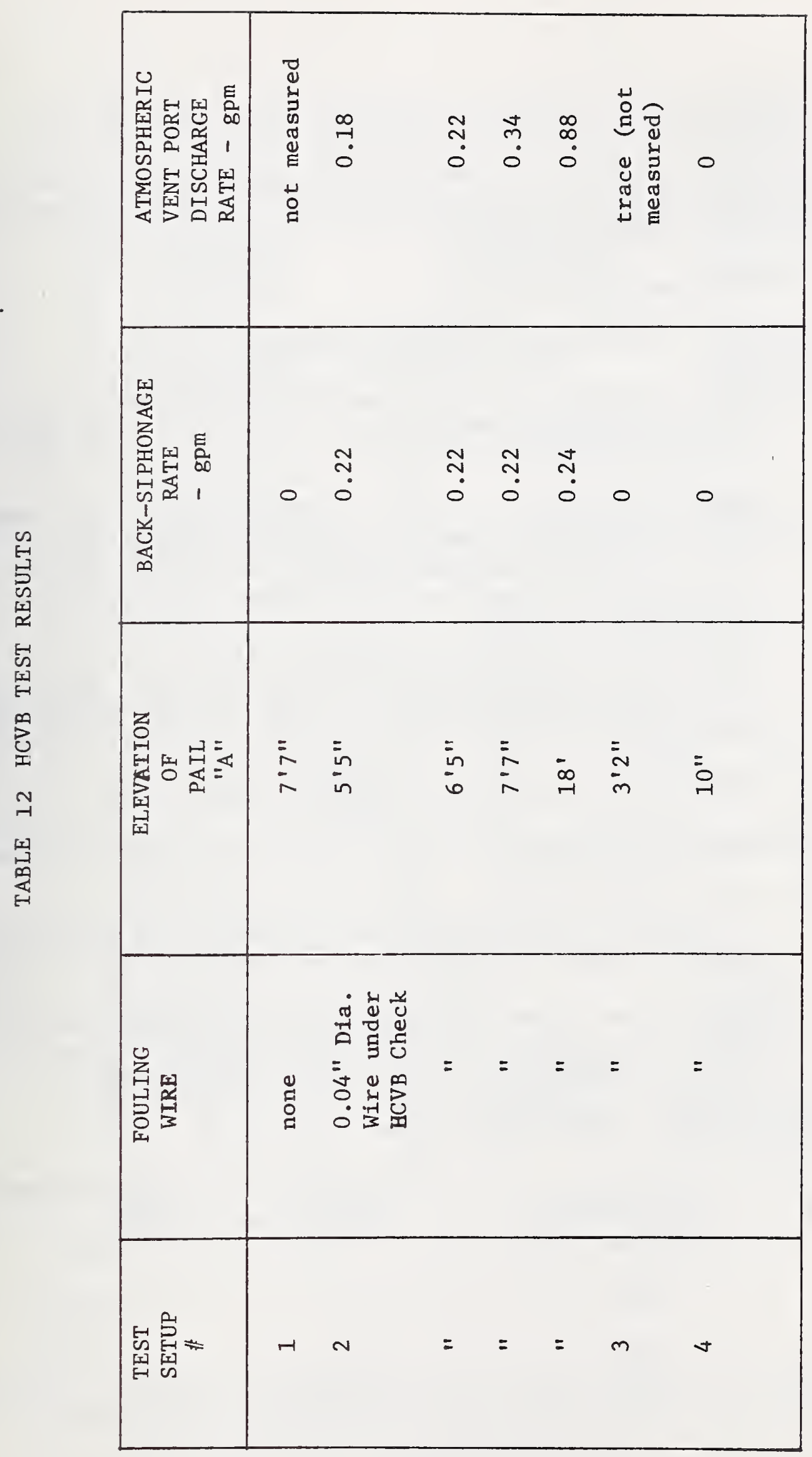


10.5 Reduced-Pressure Backflow Prevention Device Tests at NBS

A test was conducted to determine if the RPBD would allow backsiphonage, when checks were fouled with wires in the manner used for testing vacuum breakers.

\subsubsection{Test Procedure and Results}

The basic test procedure was as follows:

(a) Mount the device in its normal operating position as recommended by the manufacturer, using test setup shown in Figure 6 .

(b) Apply water pressure to the device and conduct the three tests described in AWWA publication No. S106, pages 21 and 22 [34] to determine that the checks are tight and that the relief valve is functioning according to specifications.

(c) With check valve seats fouled with 0.042 inch diameter wire, apply vacuum to the inlet and back-pressure to the outlet of the device simultaneously. (Down stream check appears to be open more than 0.042 inches because of its design).

(d) Measure zone pressure in inches of water column and record.

(e) Read back pressure at pressure gage $P$ and record reading.

(f) With start of the run referenced to the initial application of vacuum, time the run for an interval of 60 to 70 seconds and close inlet and outlet valves simultaneously.

(g) Measure the volume of backflow (back-siphonage) collected during the time interval and also the weight of water in the zone discharge. Calculate flow rates in gpm.

(h) Tabulate results as follows:

\begin{tabular}{|c|c|c|c|}
\hline \multirow{3}{*}{$\begin{array}{c}\text { RUN } \\
\# \equiv\end{array}$} & VOLUME OF & TIME TO & BACK-SIPHC \\
\hline & BACK-SIPHONAGE & COLLECT & RATE \\
\hline & COLLECTED - ml & - Sec. & $-g p m$ \\
\hline 1 & 130 & 60 & 0.034 \\
\hline 2 & 125 & 70 & 0.028 \\
\hline 3 & 110 & 70 & 0.025 \\
\hline
\end{tabular}




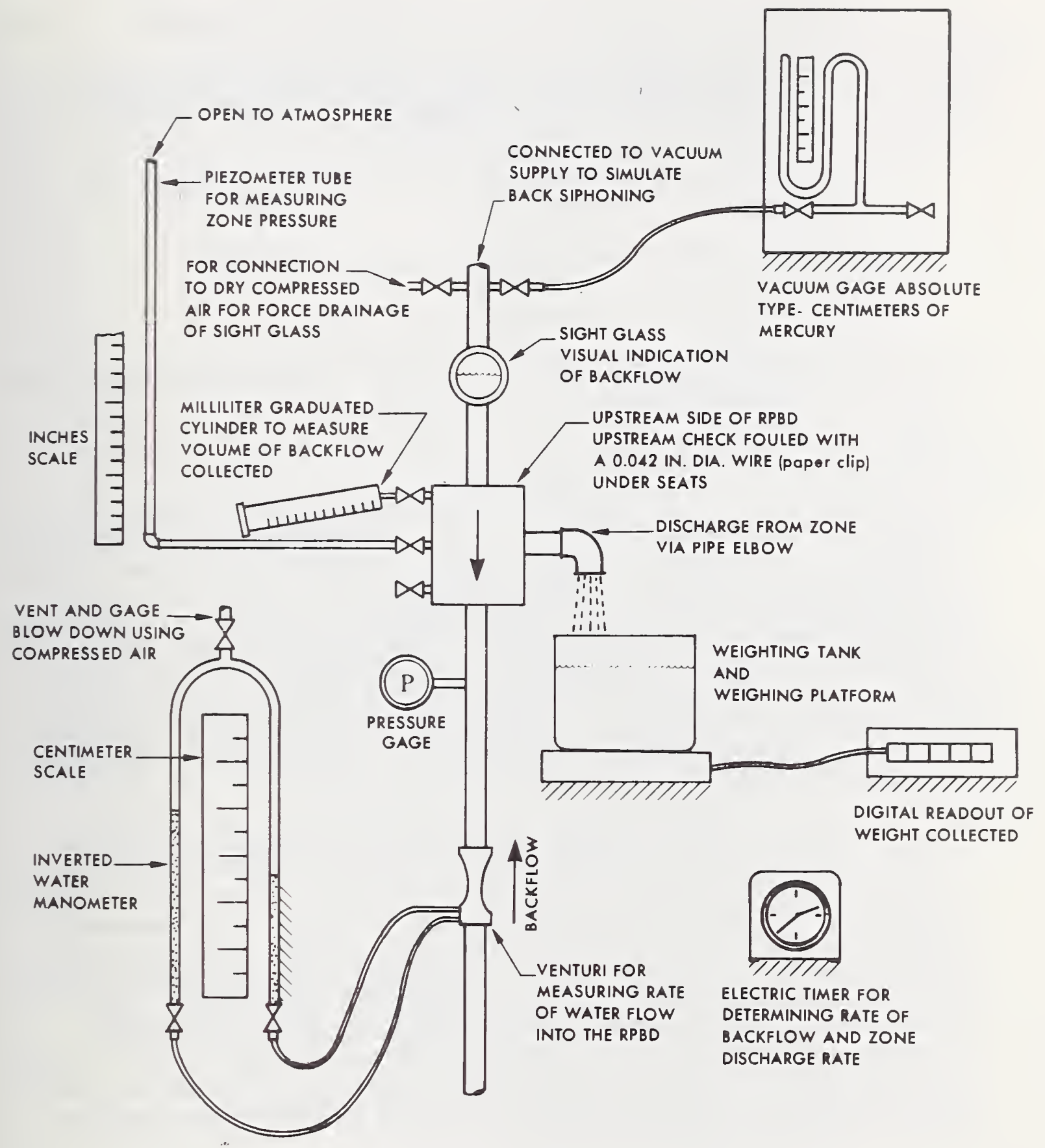

Figure 6. A Diagram of Apparatus Used in the Testing of the ReducedPressure Backflow Prevention Device. 
The average of three (3) runs of data are as follows:

(a) $1.85 \mathrm{gpm}$ backflow rate (also zone discharge rate for all practical purposes). Well below the rate specifled in the standards for a $3 / 4^{\prime \prime}$ safe RPBD.

(b) $0.029 \mathrm{gpm}$ back-siphonage rate (rate into inlet of the device).

(c) Zone pressure one (1) inch of water column.

(d) Backpressure 1.31 psig (36 1/4" head).

(e) Vacuum, 11 centimeters of mercury absolute (at inlet during back-siphonage).

\subsubsection{Discussion of Results}

The relatively low backflow rate appeared close to the cutoff condition when backflow would not occur (not exactly defined since such information would serve no useful purpose at this time because the purpose was merely to test at some reasonable condition). The rubber check material tended to seal itself around the fouling wire and backsiphonage rate decreased with time. Unfortunately, it was beyond the scope of this effort to investigate this phenomenon. It was noticed that backflow rate tended to fall off with time after initial installation of the fouling wires. The preceding backflow data 1llustrates a slight change and trend during the runs. The three runs were taken in about one hour (approximately $20 \mathrm{~min} . / \mathrm{run}$ ).

After the device had been idle for several weeks with fouling wires in place, it was noticed that only about $10 \mathrm{ml}$ was collected during a one minute period. The short term effect (one hour) appears to be the seating of the soft rubber upstream check valve material around the wire (self repairing, sealing tendency). The long term effect (several weeks) appears to be the self repairing tendency plus the effect of wire diameter reduction caused by corrosion. After several weeks the wire diameter was reduced to about 0.020 inch diameter in that portion under the seat of the upstream check. It was not determined if complete sealing would result in time due to the seating effect. Some reduction in backflow rate must have occurred due to reduction in wire diameter. 
The flow rates imposed on the zone were well below the value set in the RPBD standards (five gPm). Zone pressure with or without backsiphonage were well below the 1.5 psig maximum allowed by the RPBD standards (appeared to be the same with or without vacuum at inlet to the $\mathrm{RPBD})$. Zone pressures and flow rates were checked as follows:

\section{ZONE FLOW RATE}

$1.85 \mathrm{gpm}$

4.27

4.88
BACK PRESSURE

1.3 psig

2. 5

5.0
ZONE PRESSURE

$1^{\prime \prime}$ of water

$2.5^{\prime \prime}$ of water

$4.0^{\prime \prime}$ of water

At the end of the test, the fouling wires were removed and the device tested in the usual field test manner using a differential gage . $8 /$ The test was conducted with 60 psig of water pressure. The opening differential pressure of the relief valve was 6.5 psig which was the same as that obtained at the beginning of the test. This test and zone pressure tests demonstrated that the device was operating in a satisfactory manner.

The reason why backflow took place is simply that the zone was full of water at a pressure superior to that at the inlet, and the inlet was separated from the zone by the leaking check which allowed water to flow from the high pressure zone into the low pressure inlet. One of the basic problems is that water flowing from the relief valve port blocks air that tends to enter the zone to vent the vacuum in the inlet. In other words, this RPBD acts like a submerged vacuum breaker. If it had adequate zone shape and configuration with independent zone venting and drainage such that the air inlet was not submerged and the upstream check were exposed only to the entering air during backsiphonage, backflow of the liquid would be prevented.

\section{8/}

The differential gage was a special manufactured kit especially designed and sold for use with RPBD. 
While seeking a means of evaluating the tests methods that apply to existing standards for backflow protection devices, it was noted that the recent ASSE Standards could be analyzed into:

(a) Test requirement

(b) Test Setup and Preparation for Testing

(c) Test Procedure

(d) Observations, Records, and Computations

(e) Basis for Rejection of Device

The results of such analyses to the ASSE Standarajs 1001, 1002, 1011, 1012, 1013, 1015 and 1020 are documented herewith on tables 13 through 19. A uniformity of style has become established with the more recent output. The uniformity of style or format is sharply defined in table 20 wherein the numerical sequence of paragraph of ASSE 1013 were matched with comparable subject mattex (where possible) to be found in ASSE 1001, 1011, 1012, and 1015. Such analysis is expected to be helpful in the development of criteria. 


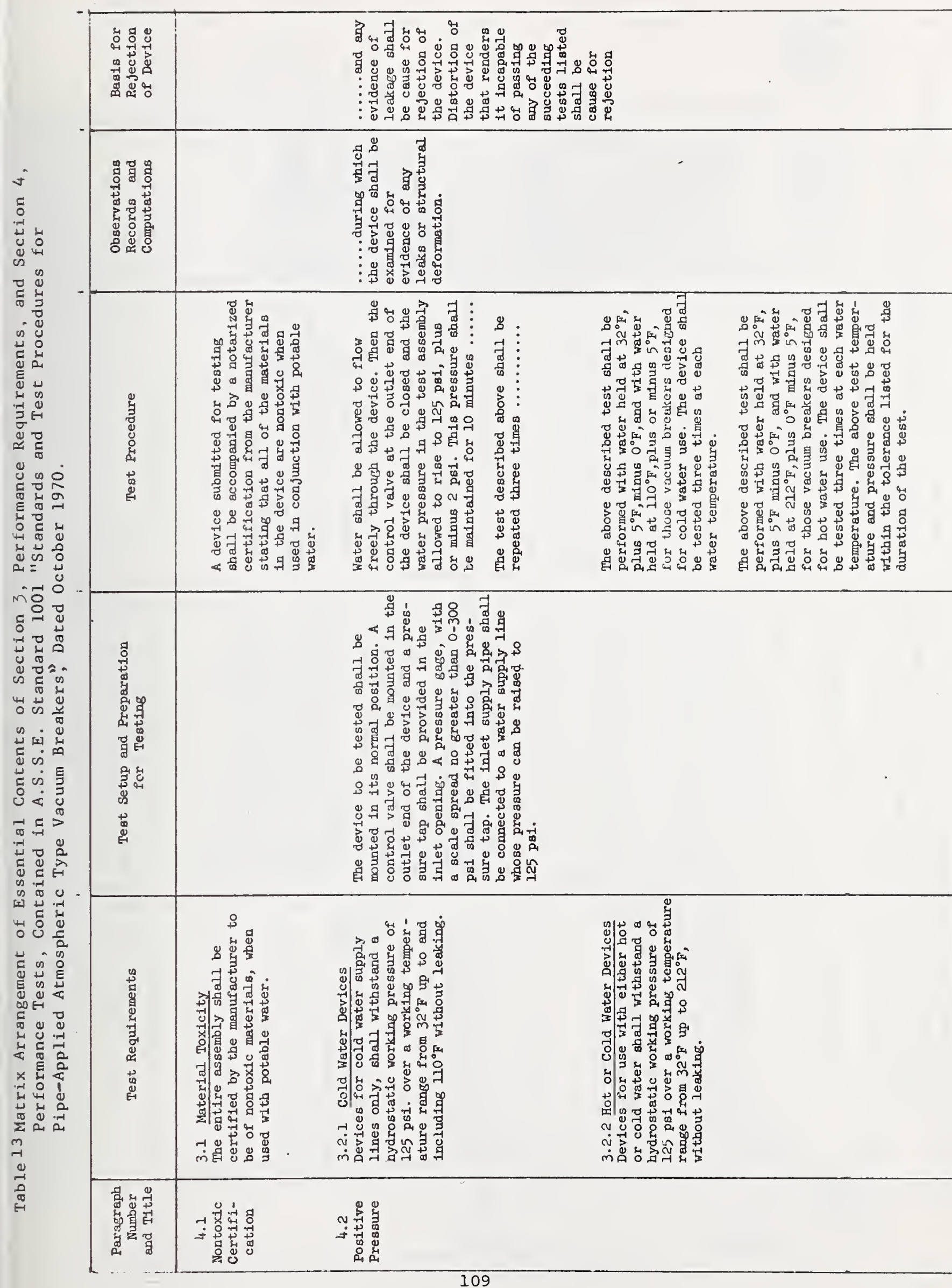




\begin{tabular}{|c|c|c|c|}
\hline 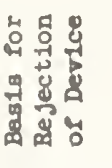 & & & \\
\hline 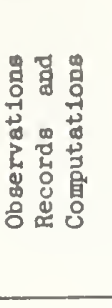 & 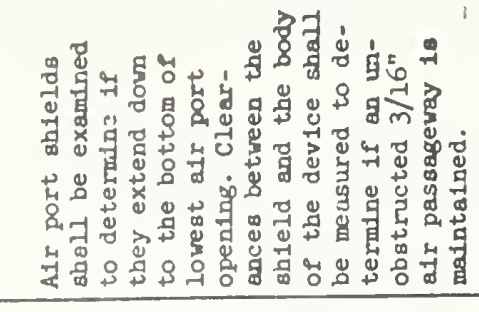 & 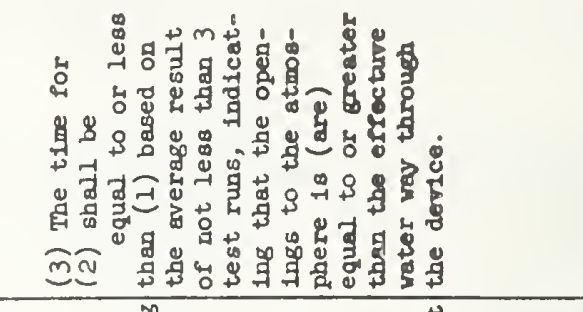 & \\
\hline 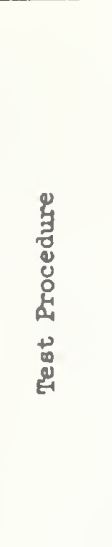 & & 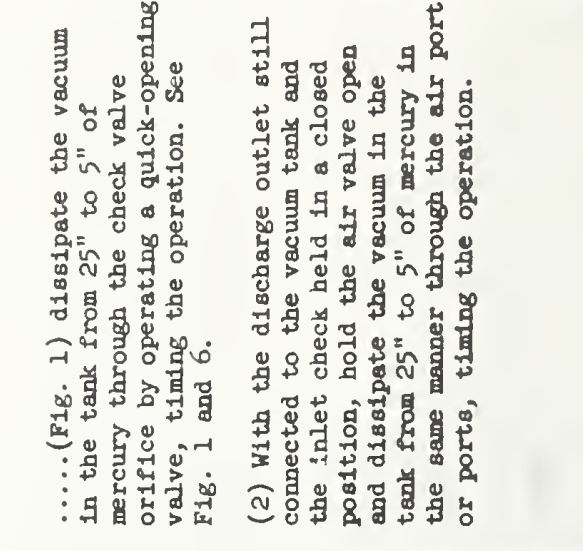 & \\
\hline 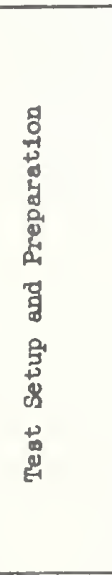 & & 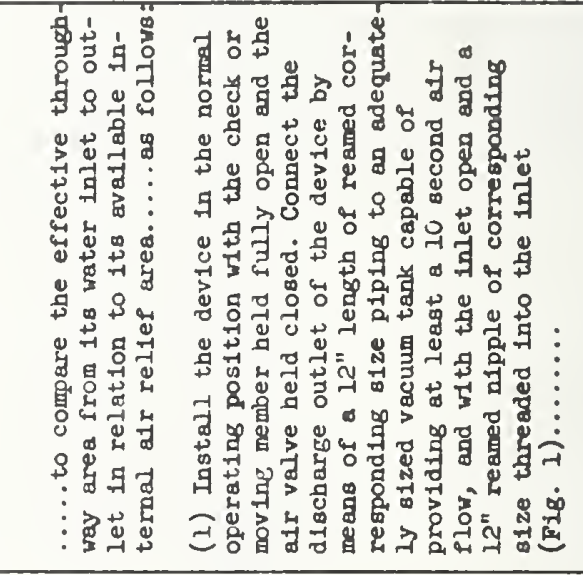 & 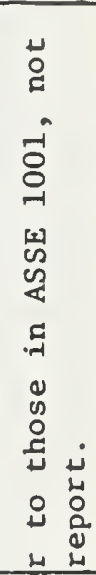 \\
\hline 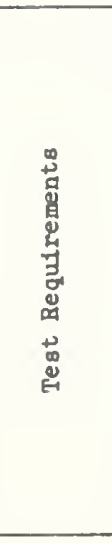 & 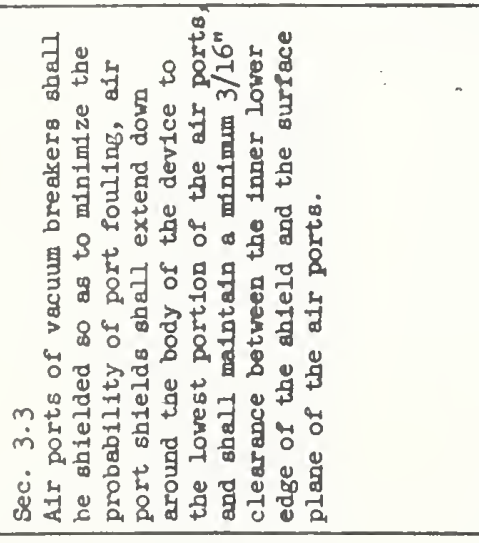 & 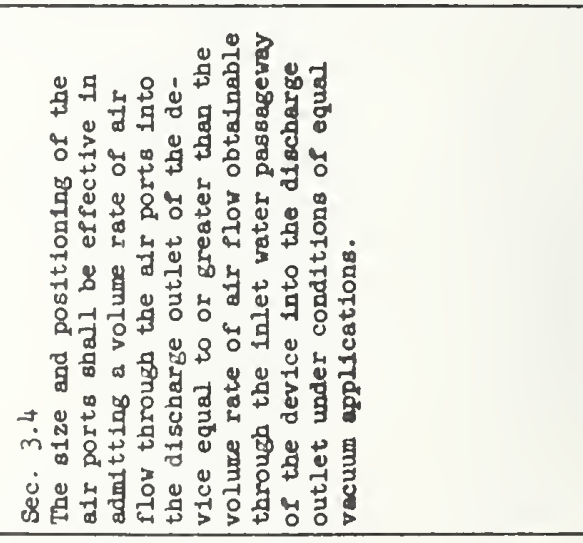 & 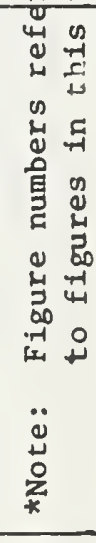 \\
\hline 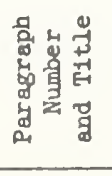 & 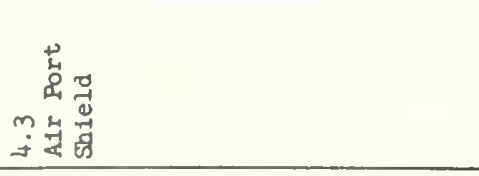 & 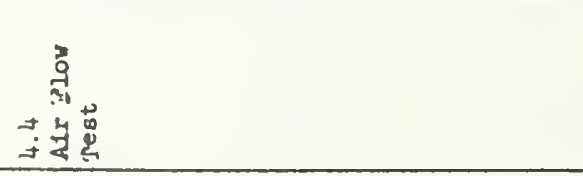 & \\
\hline
\end{tabular}




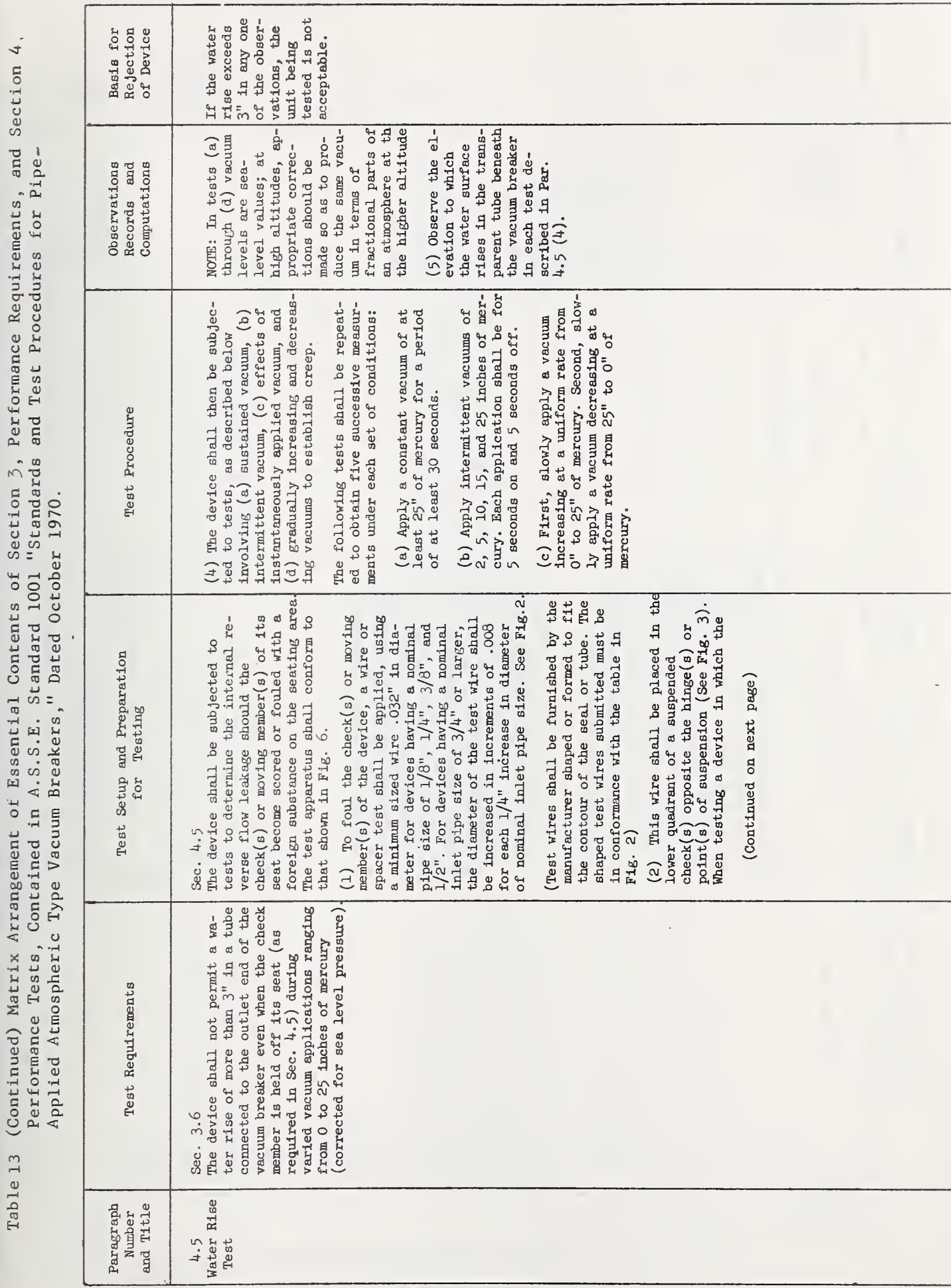




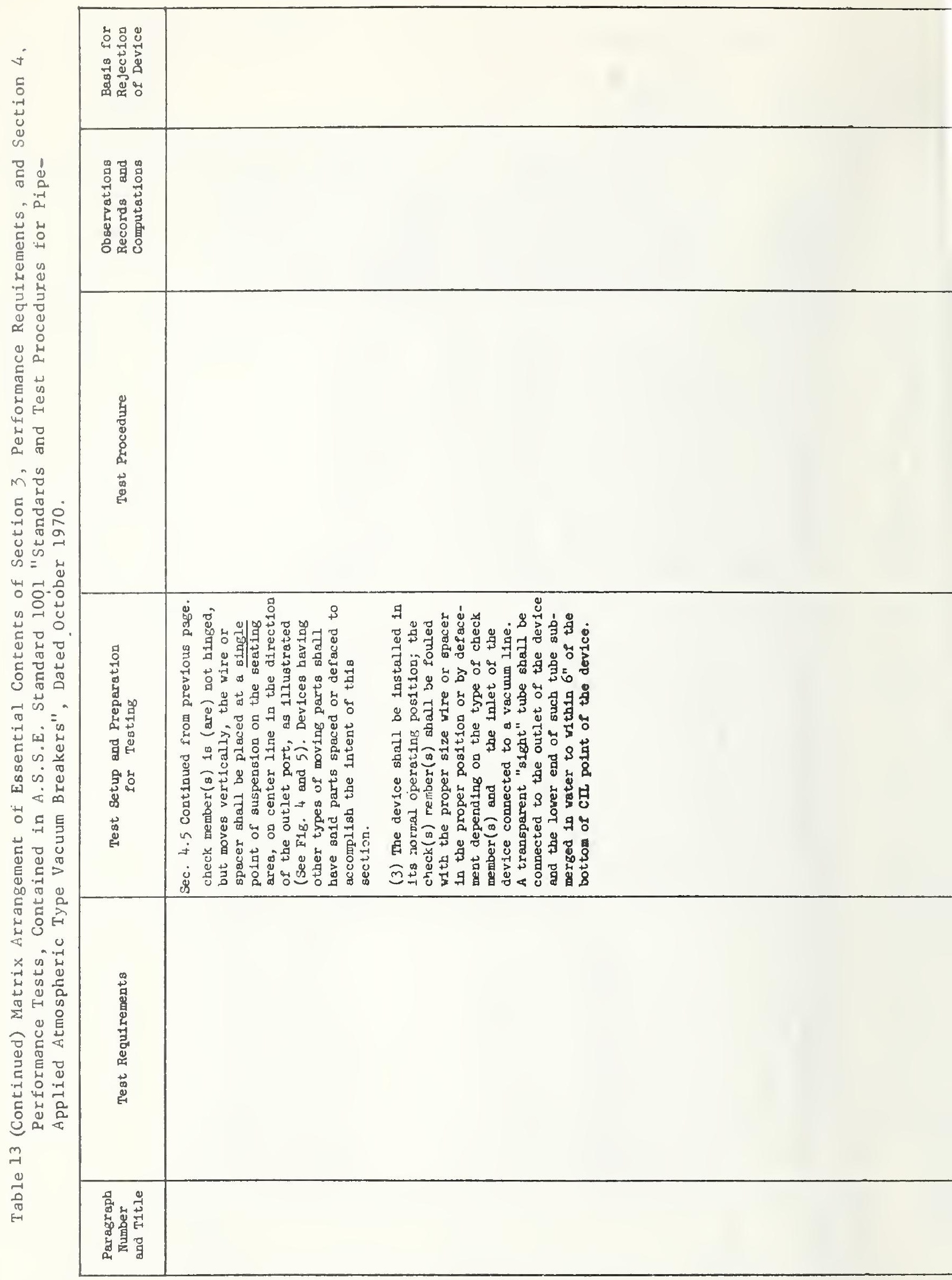




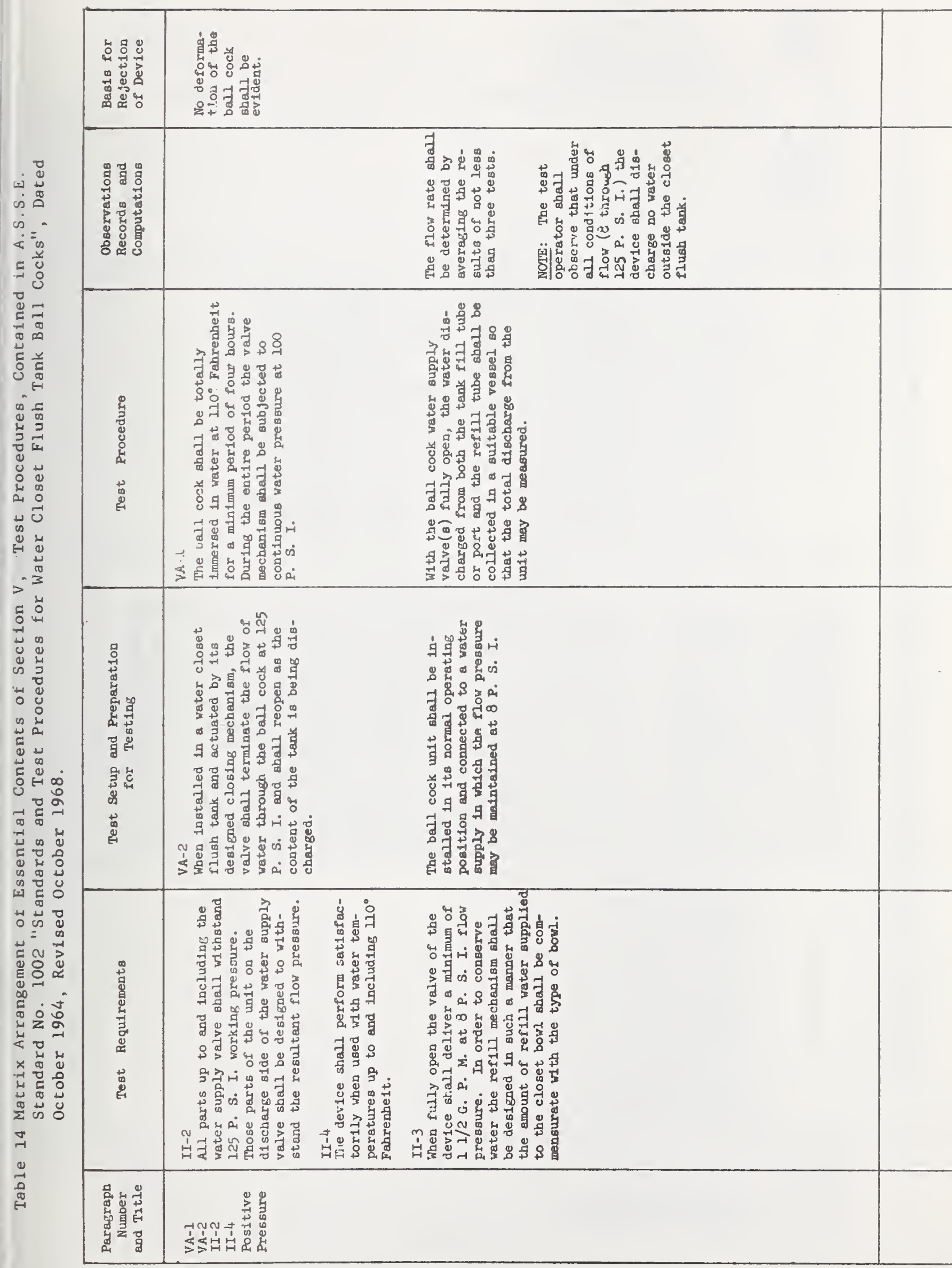




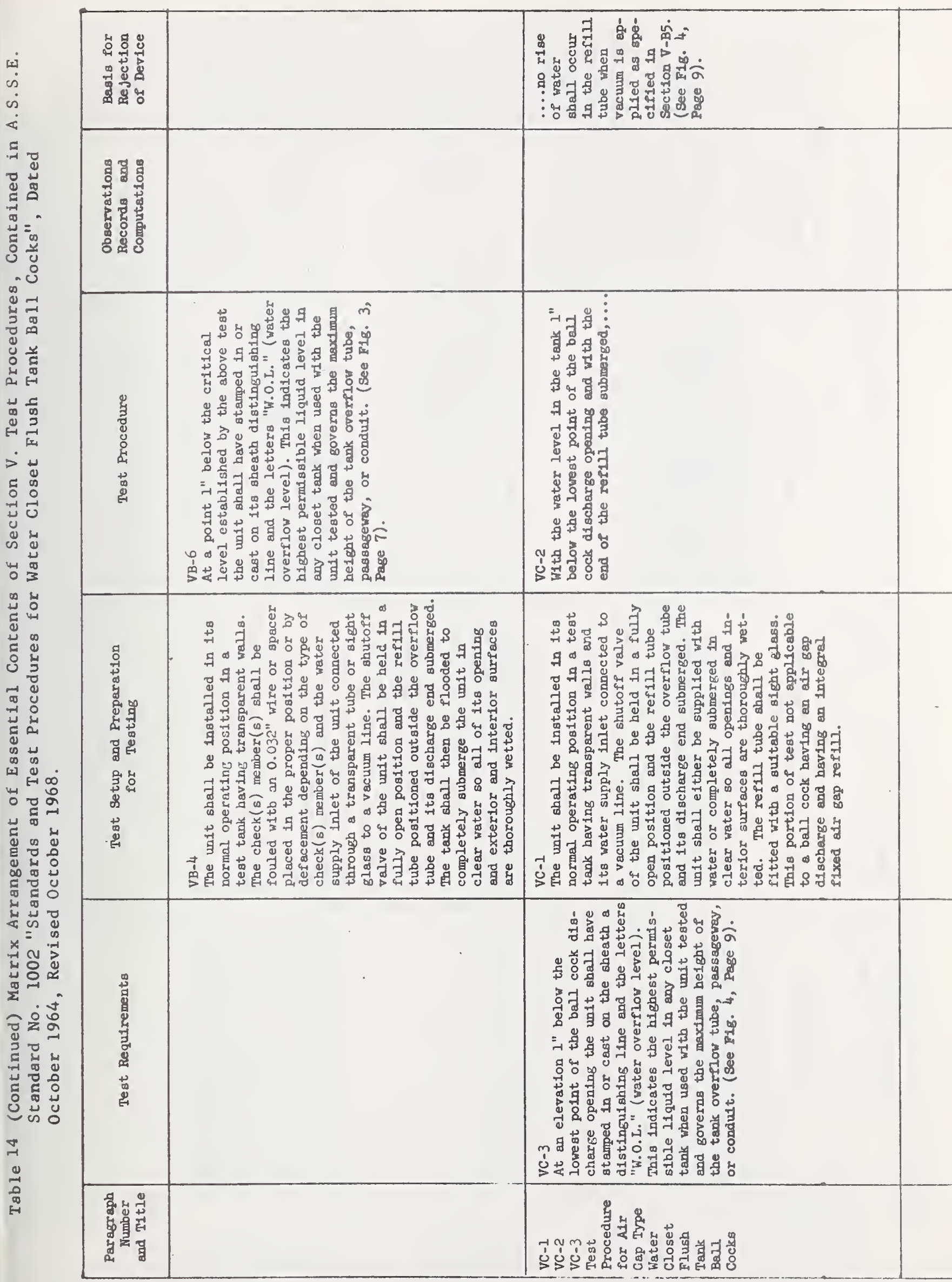




\begin{tabular}{|c|c|c|c|c|c|}
\hline 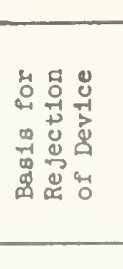 & 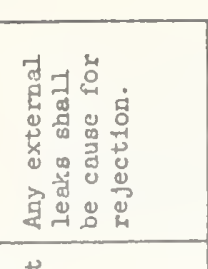 & 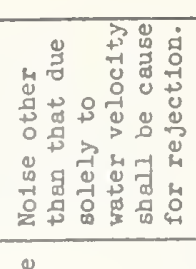 & 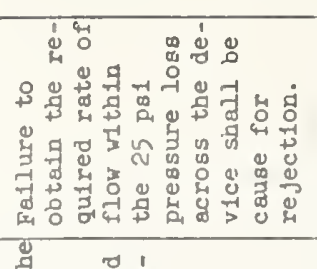 & 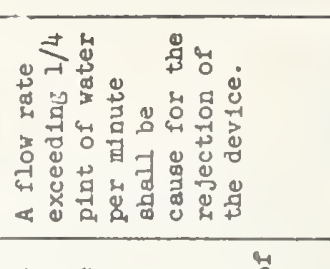 & 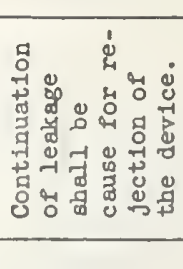 \\
\hline 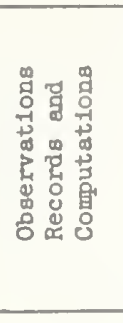 & 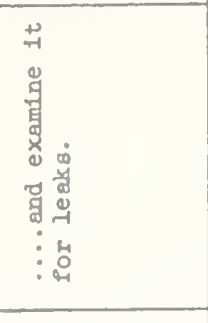 & 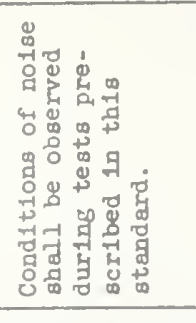 & 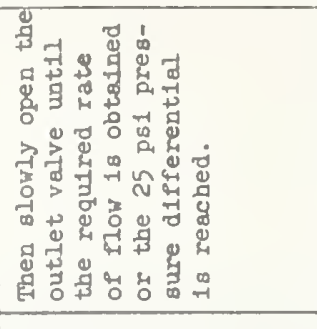 & $\begin{array}{l}\dot{8} \\
8 \\
8\end{array}$ & 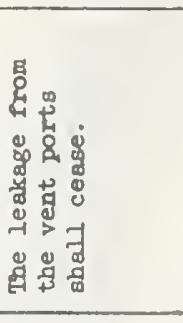 \\
\hline 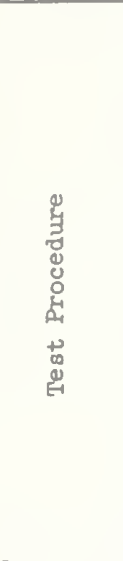 & 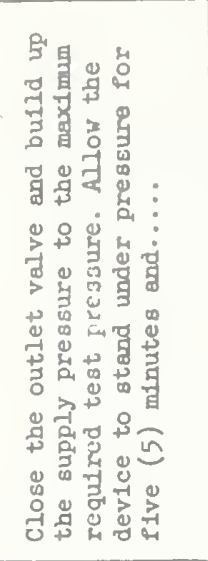 & & 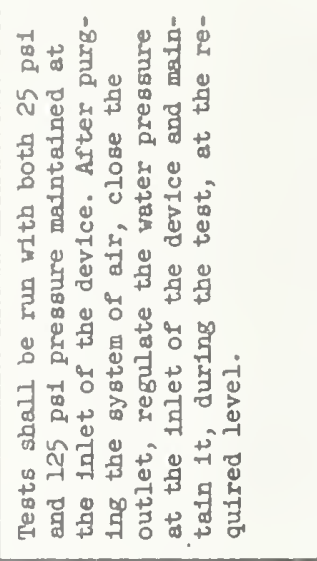 & 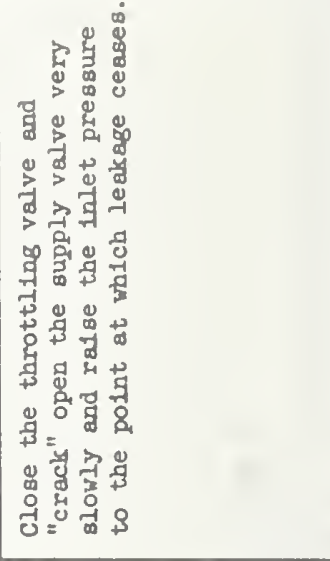 & 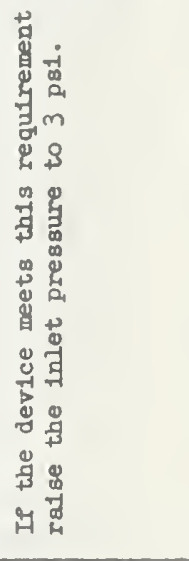 \\
\hline 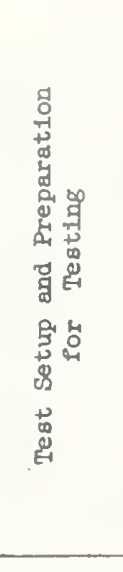 & 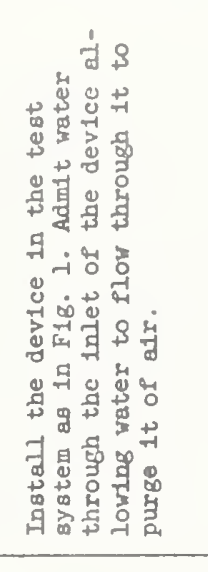 & & 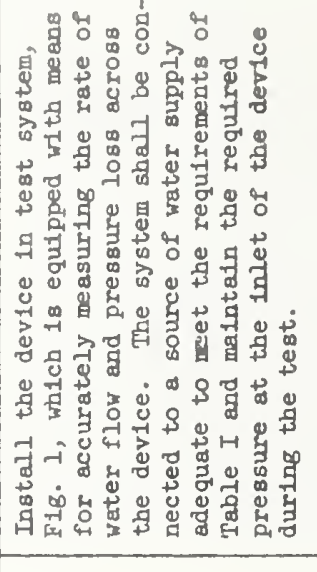 & 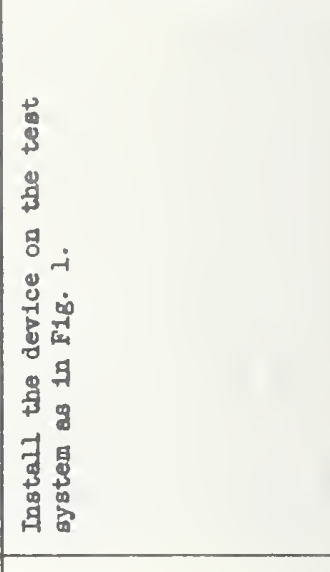 & \\
\hline 常 & 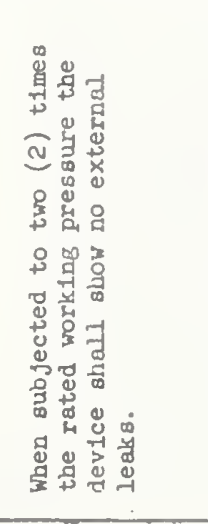 & 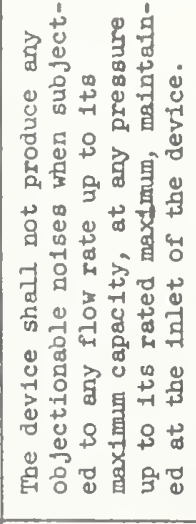 & 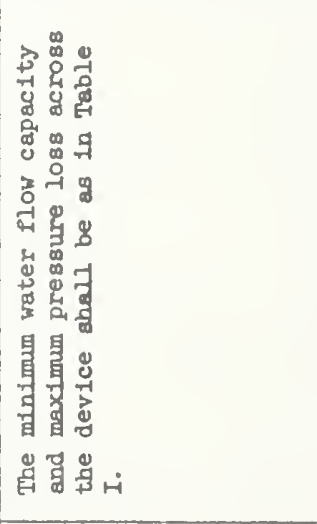 & 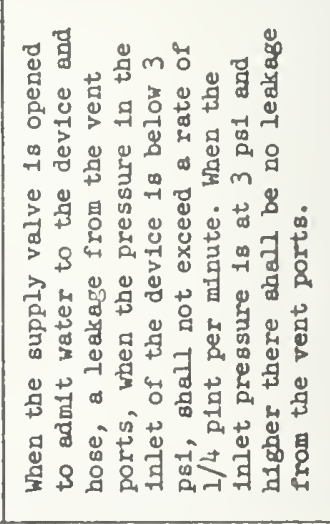 & \\
\hline 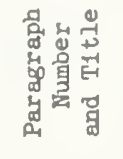 & 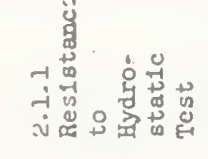 & 㲾 & 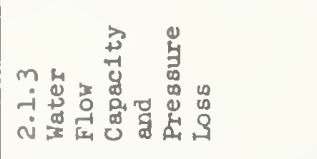 & 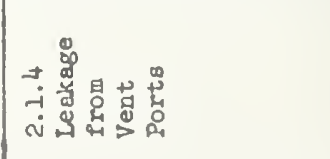 & \\
\hline
\end{tabular}




\begin{tabular}{|c|c|c|}
\hline 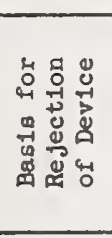 & 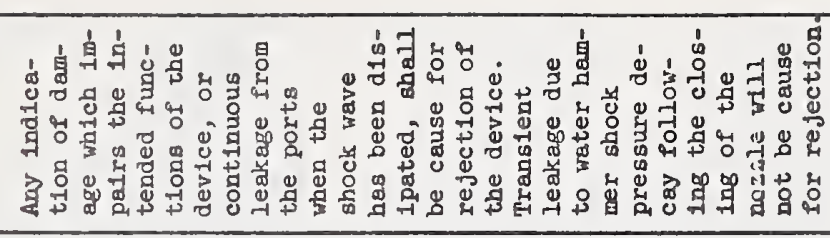 & 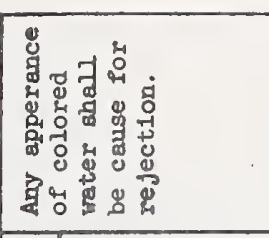 \\
\hline 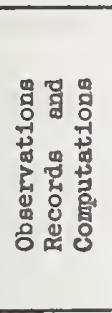 & & 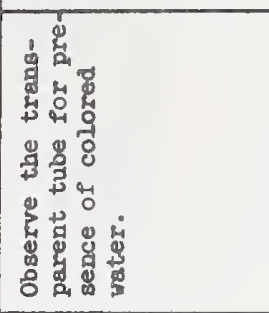 \\
\hline 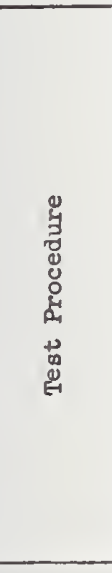 & 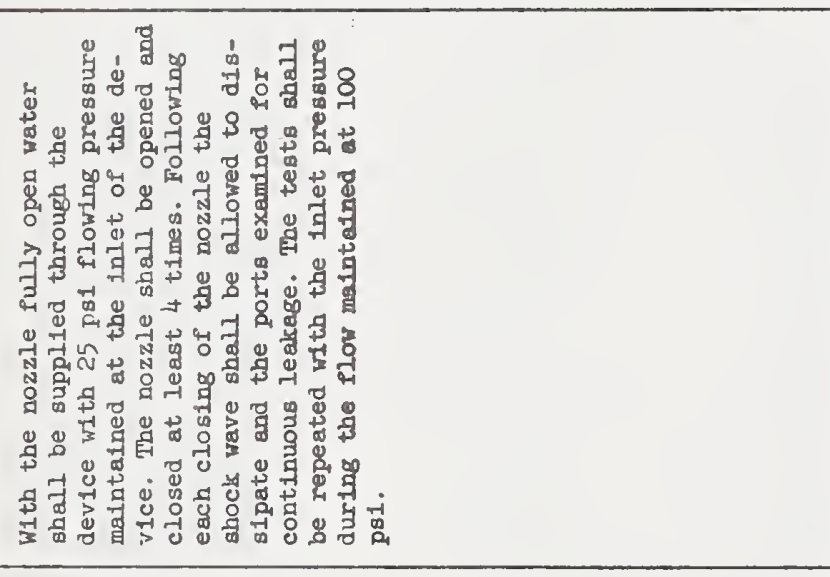 & 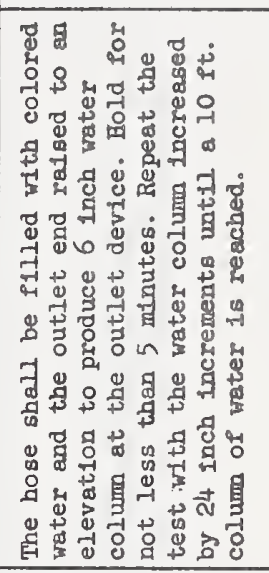 \\
\hline 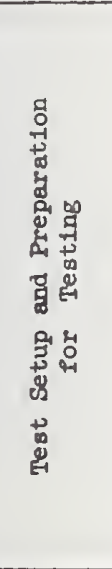 & 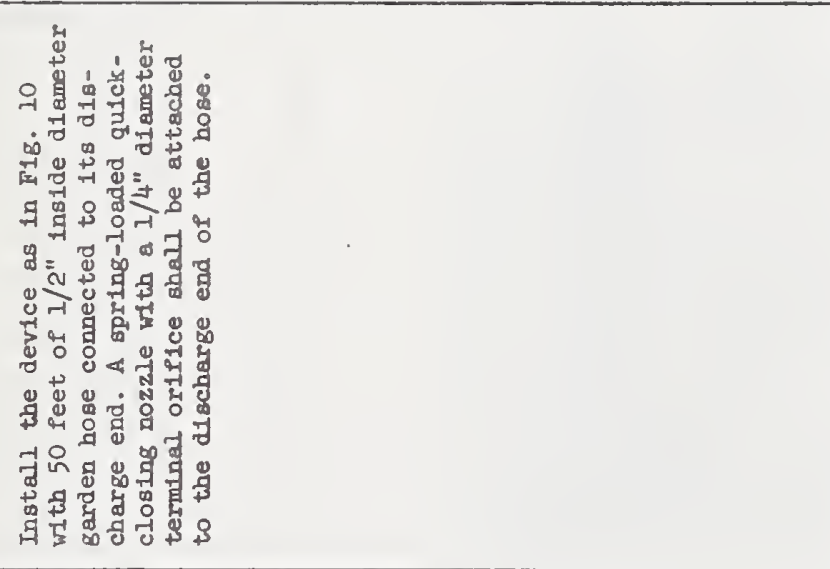 & 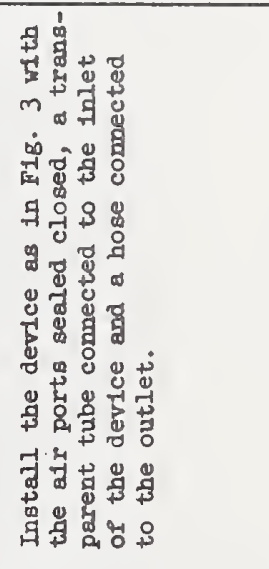 \\
\hline 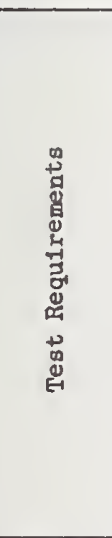 & 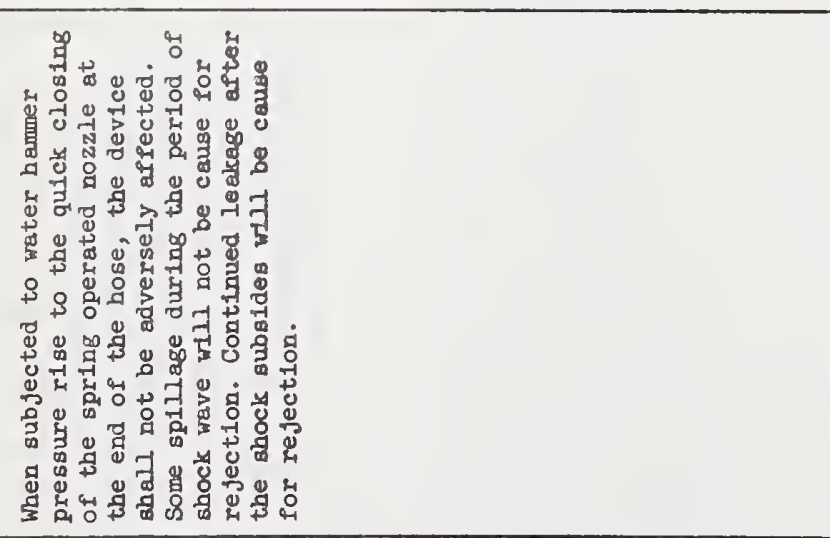 & 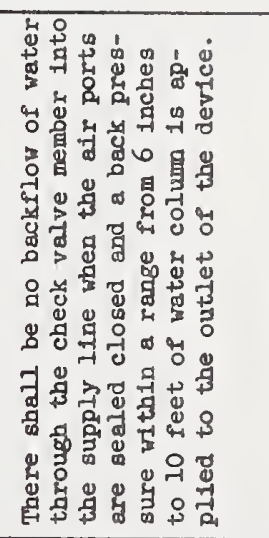 \\
\hline 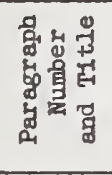 & 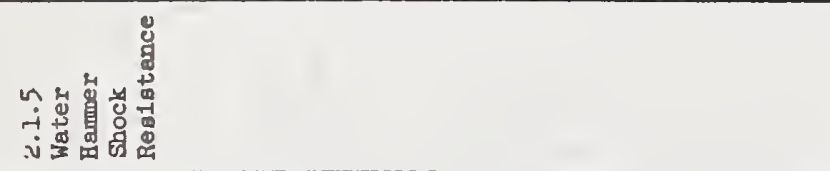 & 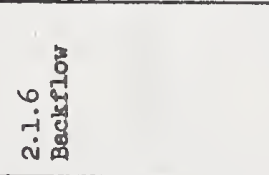 \\
\hline
\end{tabular}




$$
\begin{aligned}
& \text { 물 } \\
& \text { 등 } \\
& \text { Ф } \\
& \text { ¿ } \\
& ن \text { 오 } \\
& \text { 过 } \\
& \text { 눙 } \\
& \text { (1) E } \\
& \text { - } \\
& \text { 듕 } \\
& \text { U } \\
& 4 \text { 4 } \\
& \text { ㄴ. } \\
& \rightarrow \frac{0}{2} \\
& \text { 点 } \\
& \text { 我苗 }
\end{aligned}
$$$$
\text { 吕 }
$$$$
\text { 공 }
$$$$
\text { 出 }
$$$$
\text { Uै }
$$$$
\text { E }
$$$$
\text { प्र }
$$$$
\text { ค. }
$$$$
\text { तi }
$$$$
\text { I }
$$$$
\text { क : }
$$$$
\text { 吕 }
$$$$
\text { 嵅 }
$$$$
\text { 간 }
$$$$
\text { 舟 }
$$

त

is

密

\begin{tabular}{|c|c|c|}
\hline 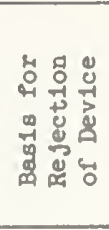 & 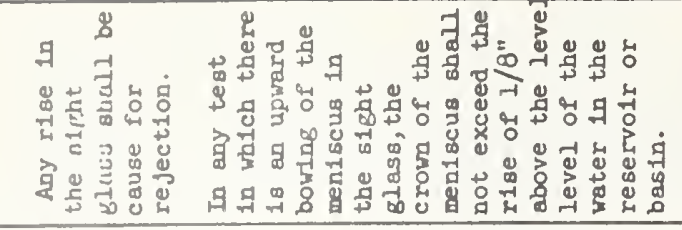 & 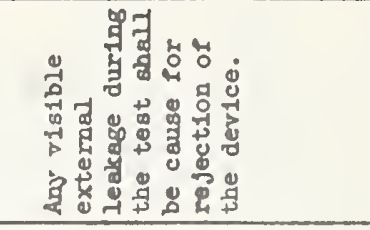 \\
\hline 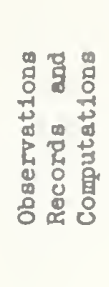 & 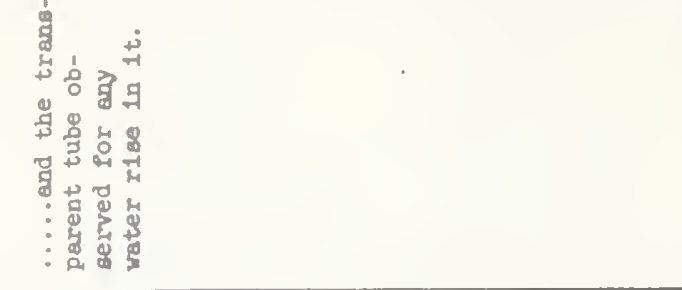 & \\
\hline 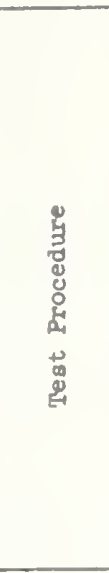 & 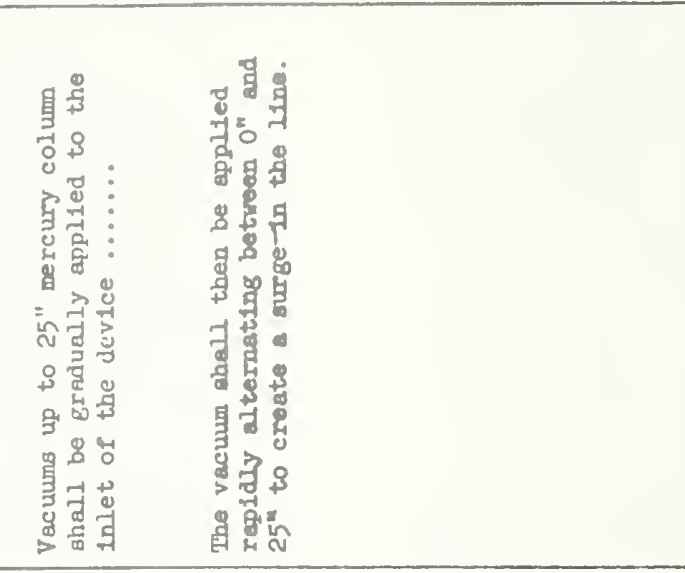 & 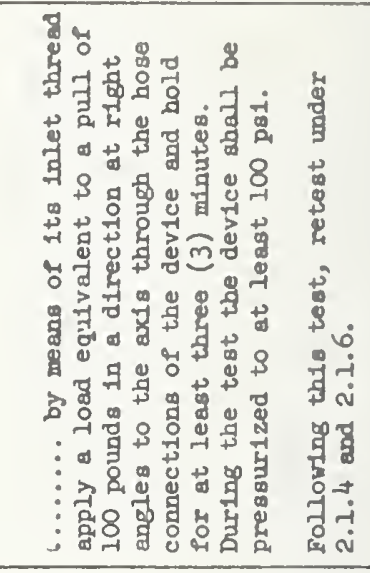 \\
\hline 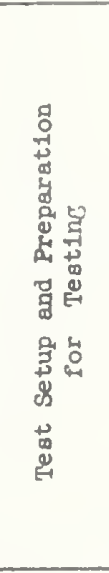 & 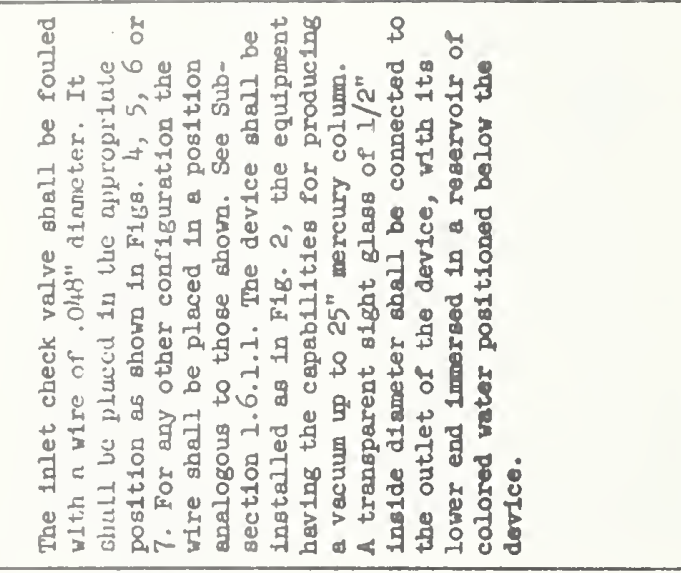 & 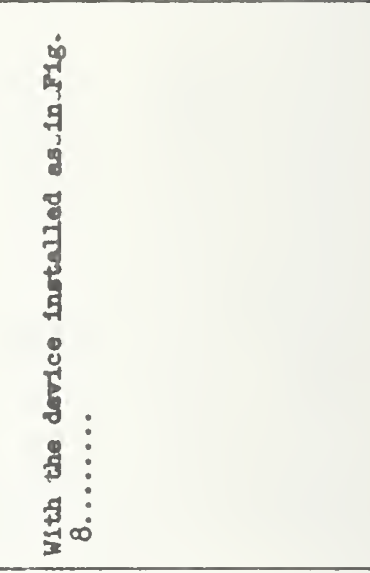 \\
\hline 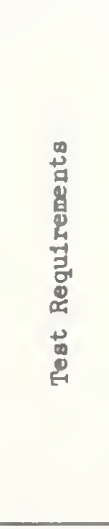 & 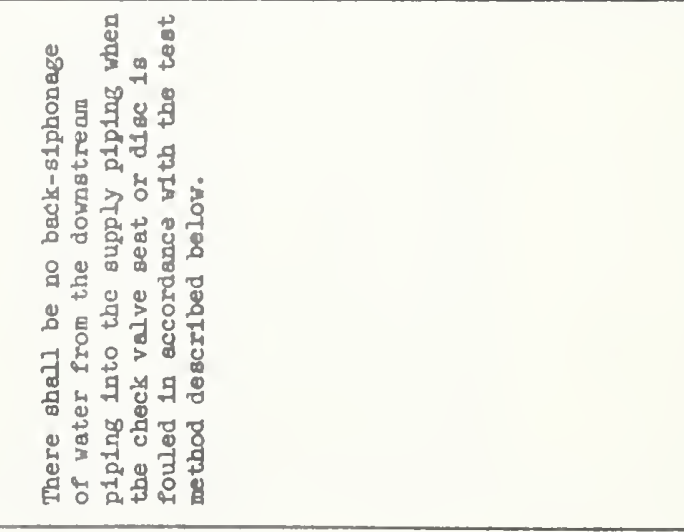 & 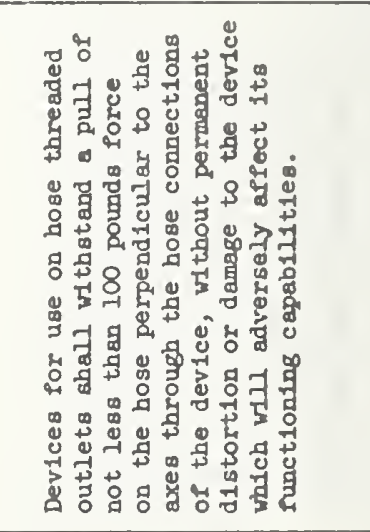 \\
\hline 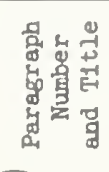 & 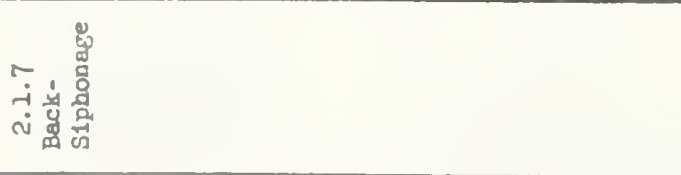 & 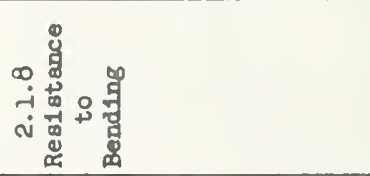 \\
\hline
\end{tabular}

$\stackrel{0}{0}$

医

岃

$\times \quad 0$

글

出

远弯

ช 8

\%

崩

此

당

U $0>$

넘

$\underset{1}{1}$ 


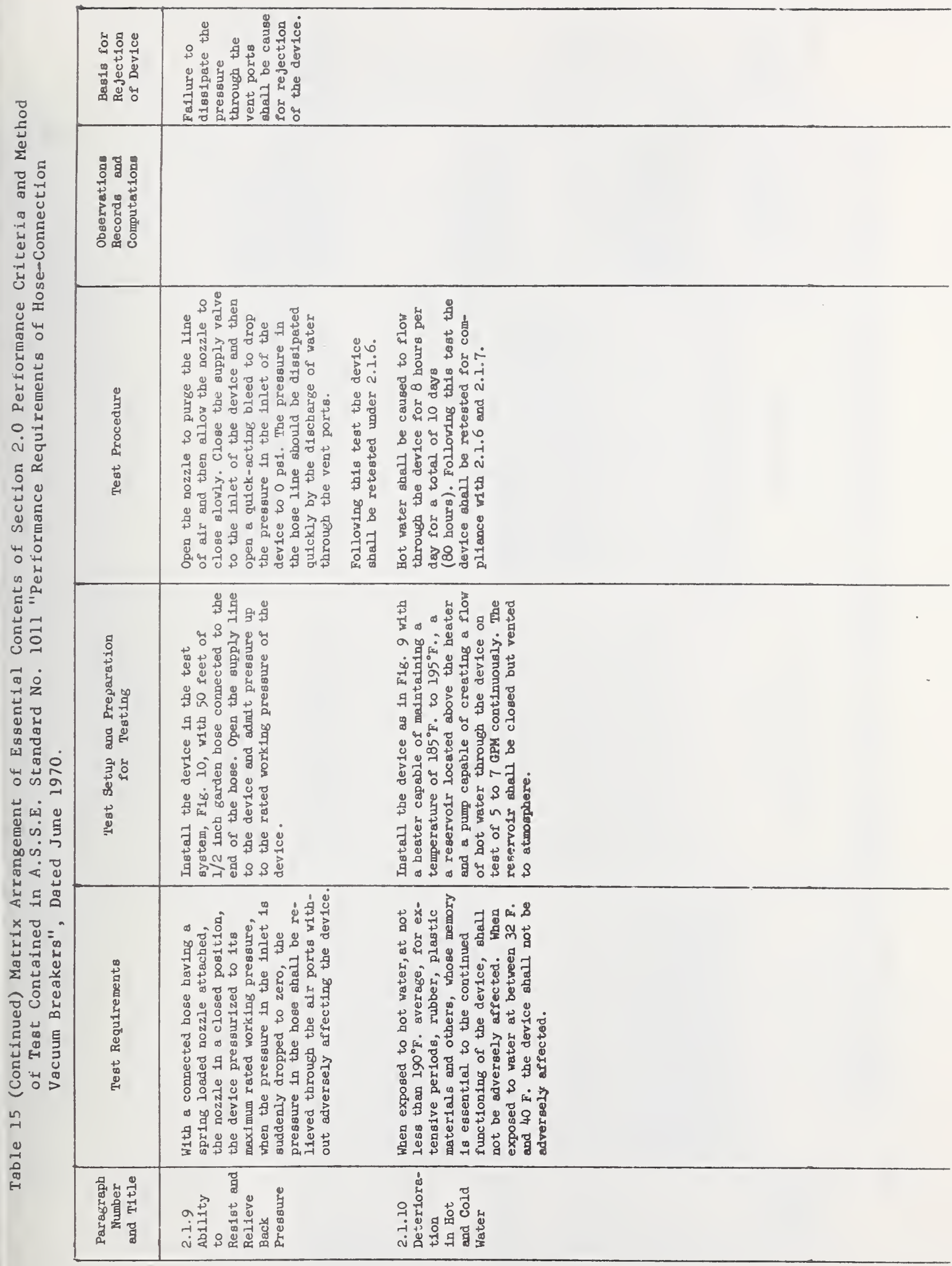




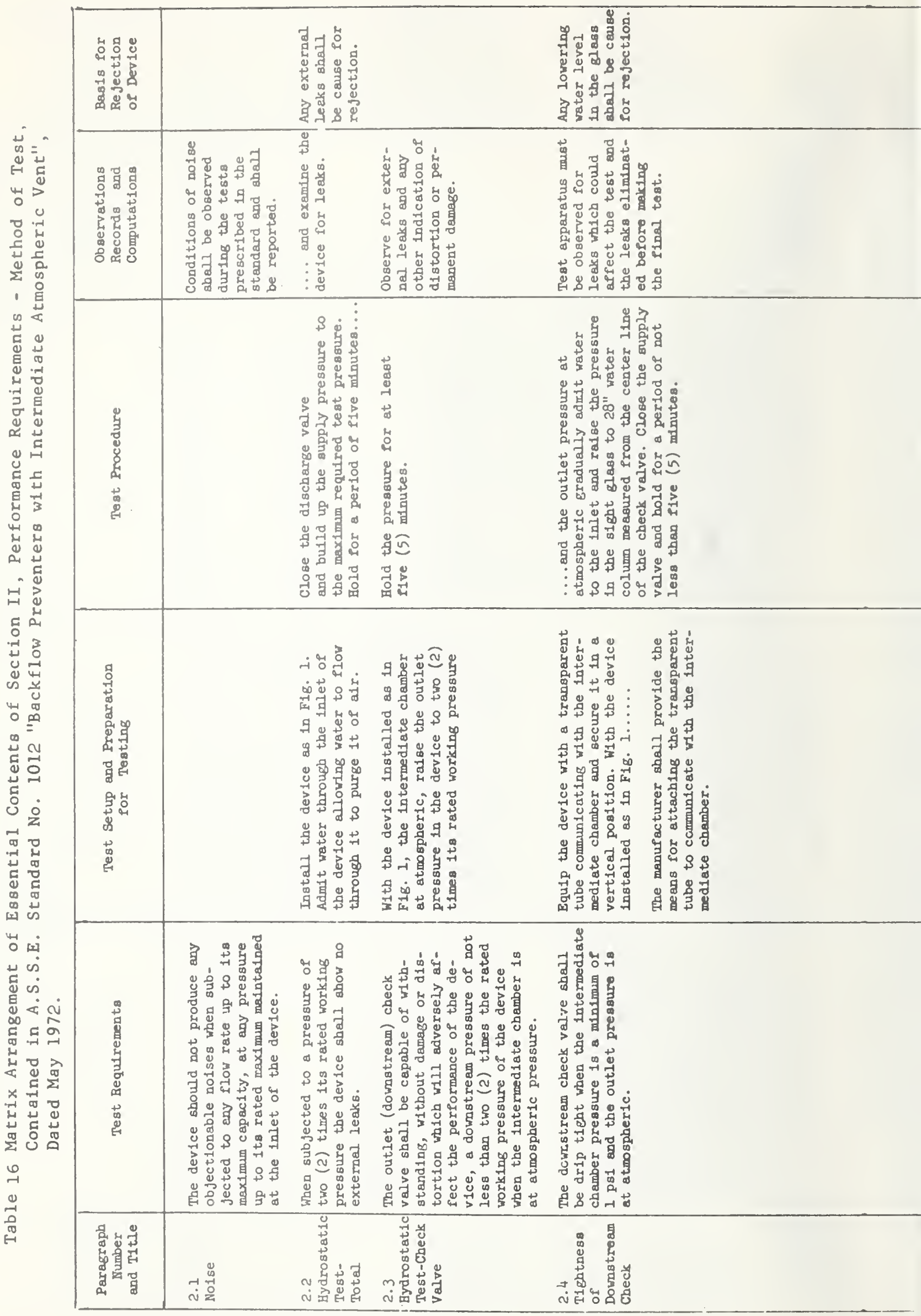




\begin{tabular}{|c|c|c|c|}
\hline 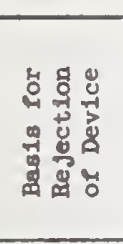 & 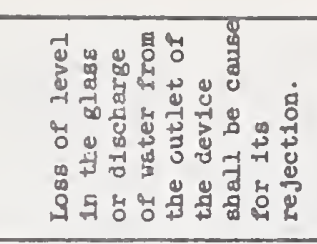 & 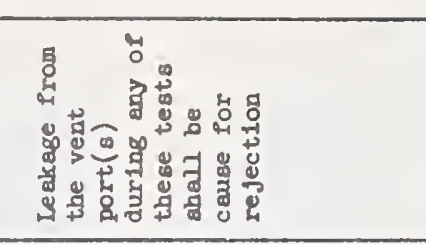 & 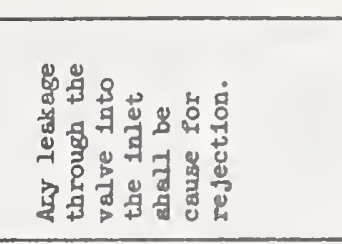 \\
\hline 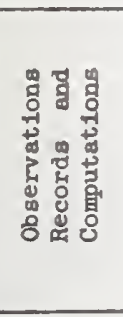 & 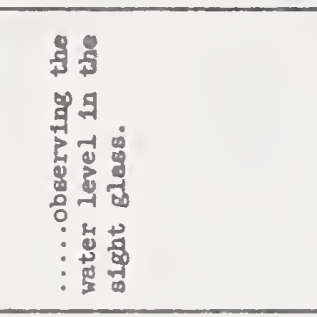 & & 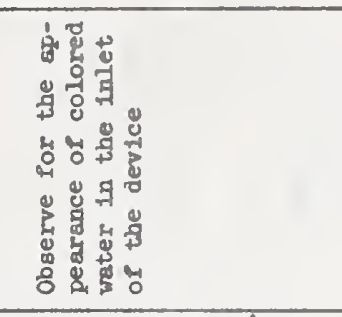 \\
\hline 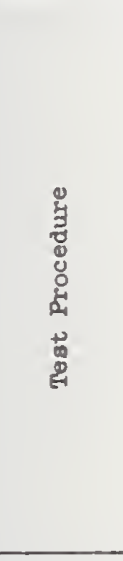 & 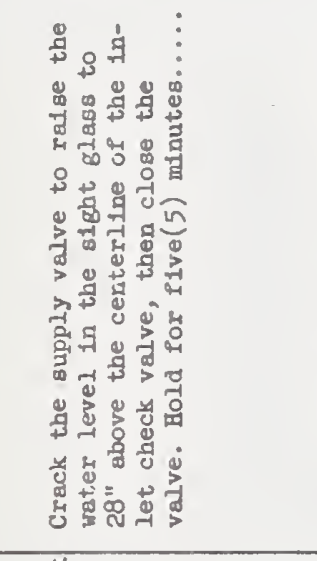 & 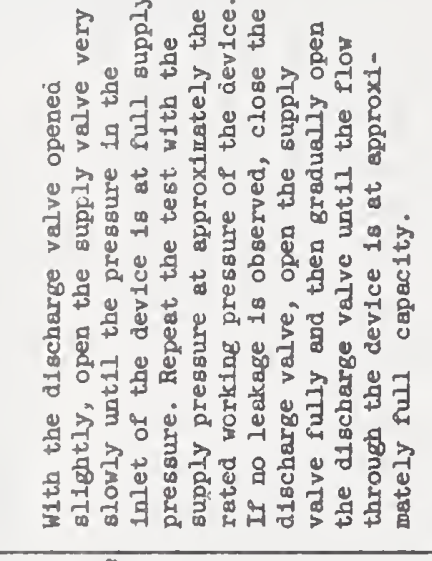 & 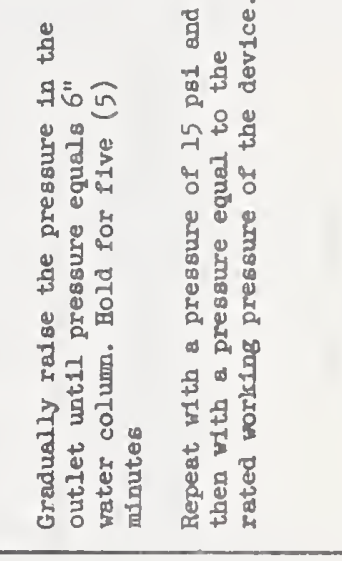 \\
\hline 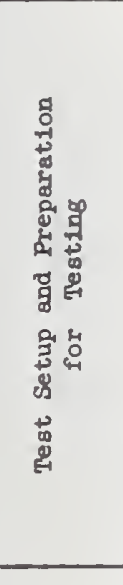 & 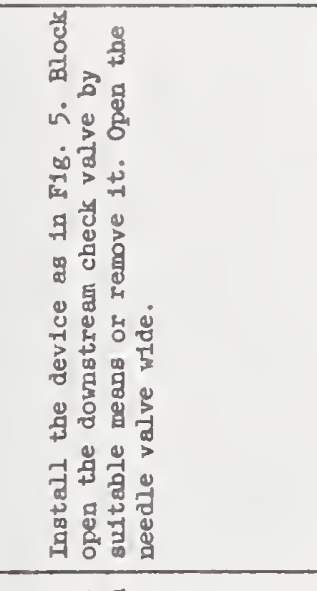 & 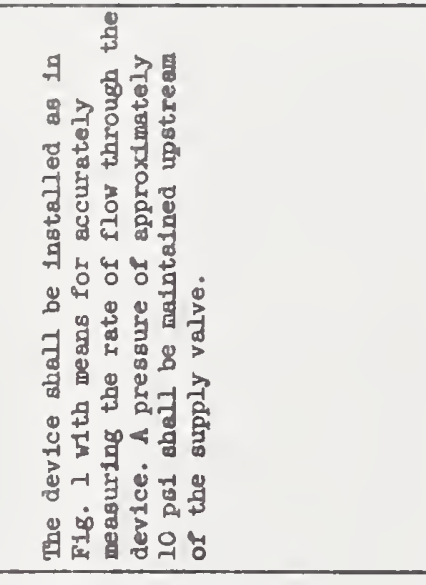 & 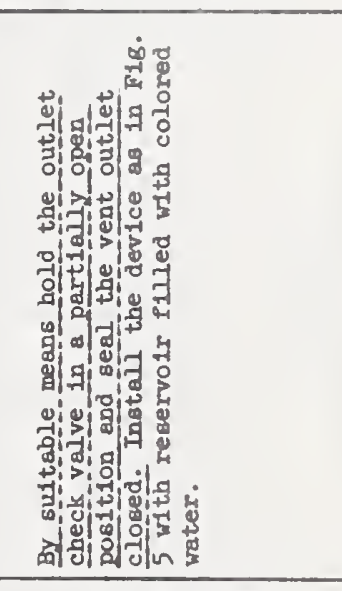 \\
\hline 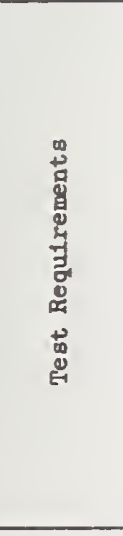 & 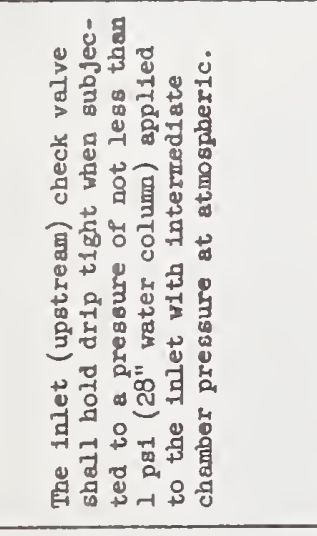 & 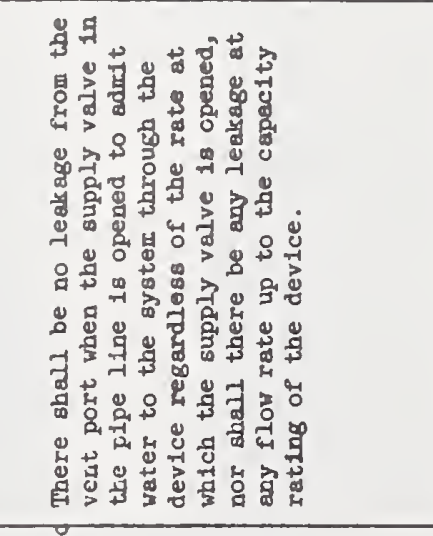 & 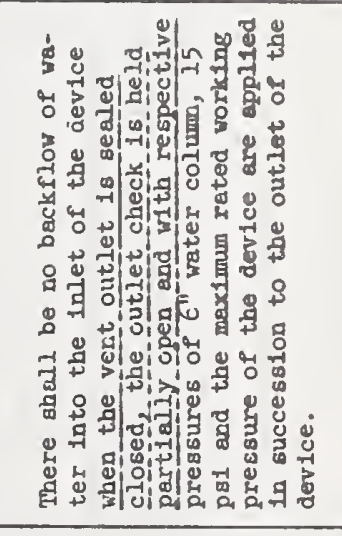 \\
\hline 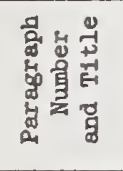 & 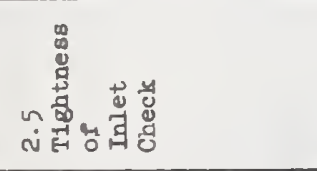 & 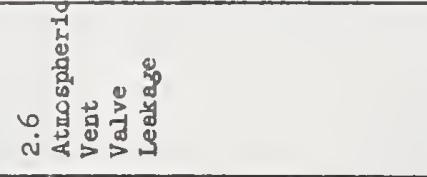 & 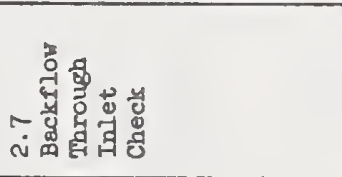 \\
\hline
\end{tabular}




\begin{tabular}{|c|c|c|c|c|}
\hline \multirow{3}{*}{ 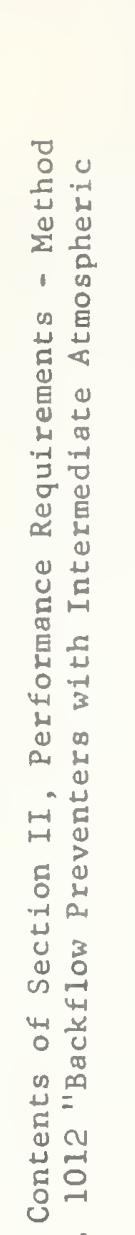 } & 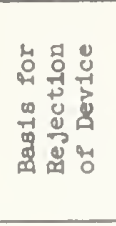 & \multicolumn{3}{|c|}{ 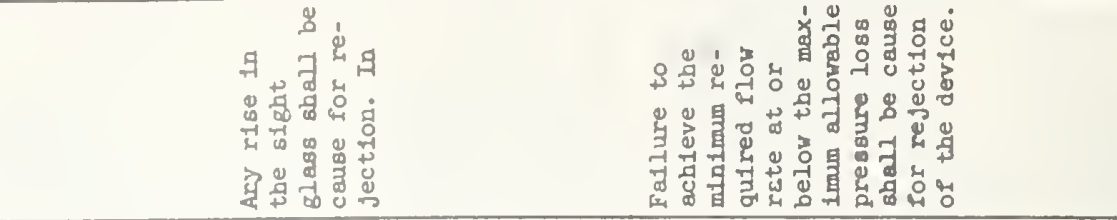 } \\
\hline & 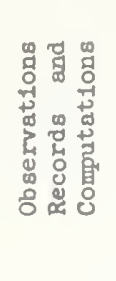 & 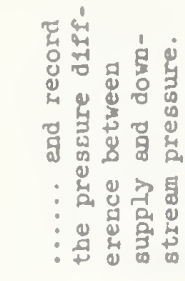 & 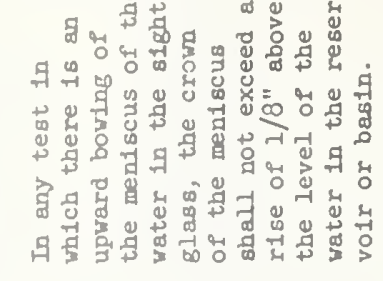 & 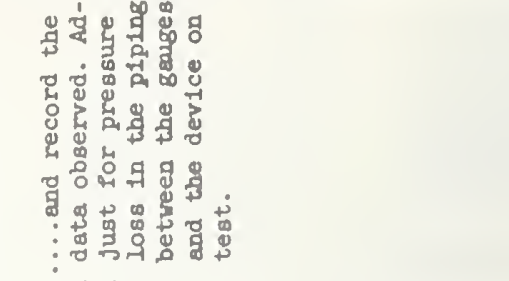 \\
\hline & 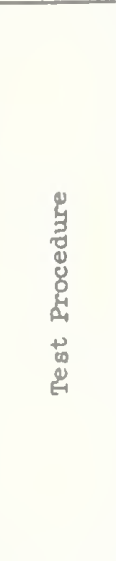 & 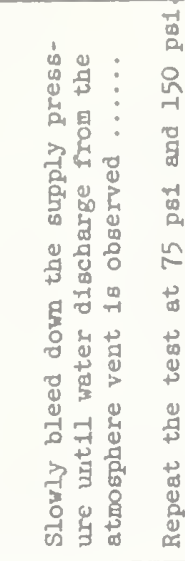 & 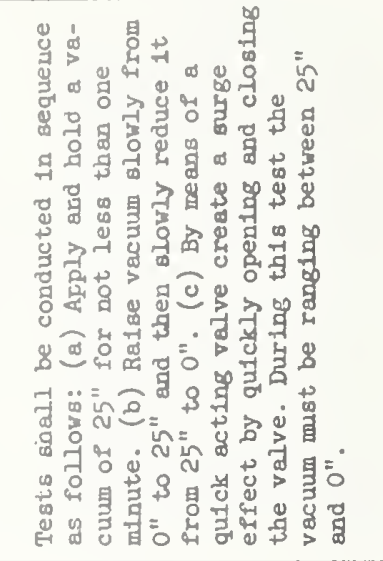 & 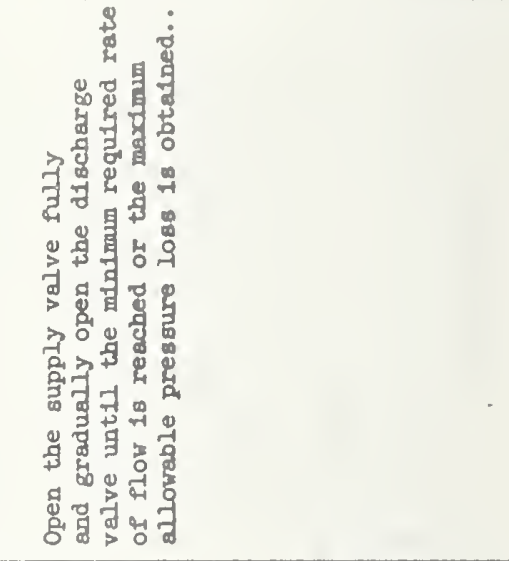 \\
\hline 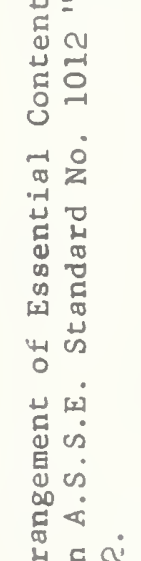 & 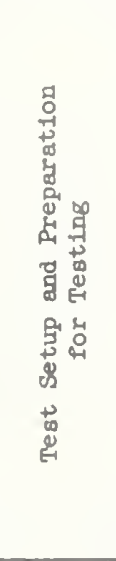 & 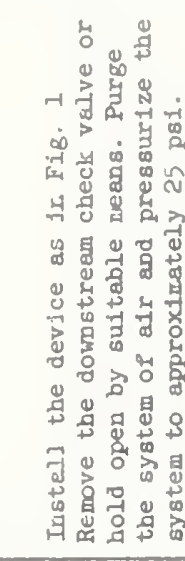 & 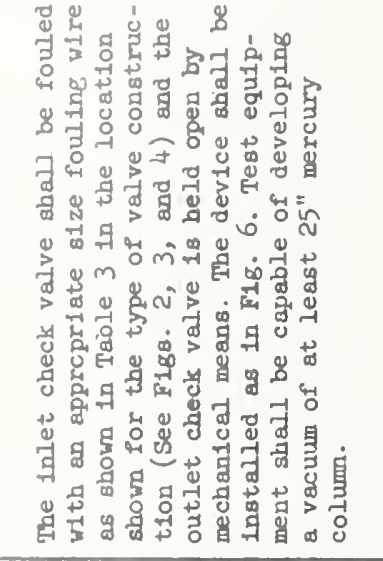 & 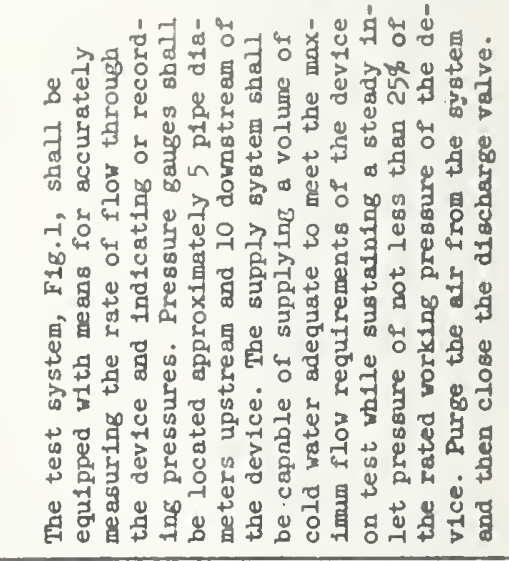 \\
\hline 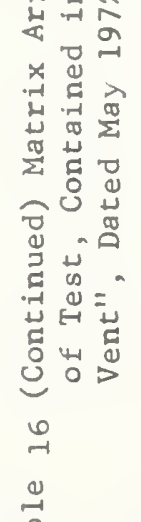 & 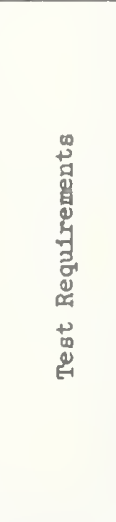 & 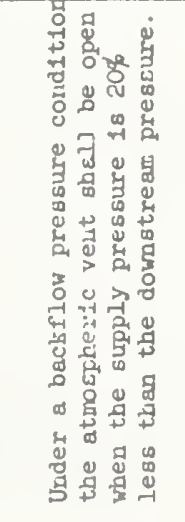 & 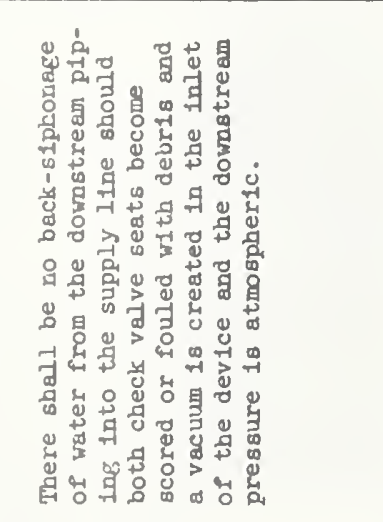 & 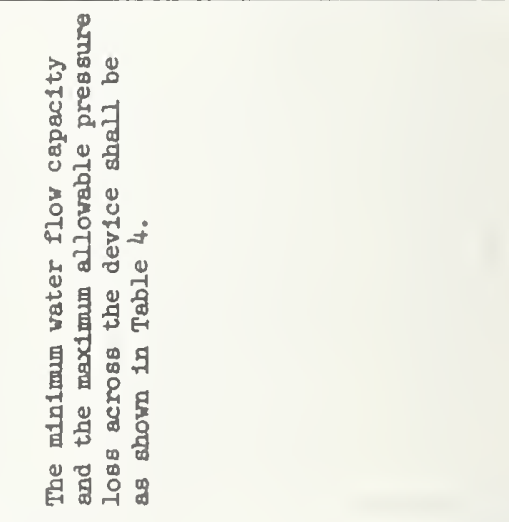 \\
\hline 画 & 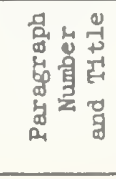 & 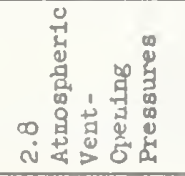 & 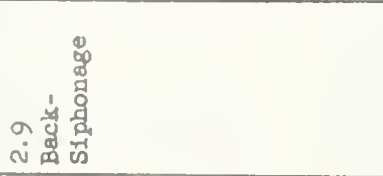 & 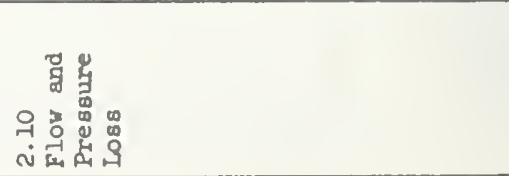 \\
\hline
\end{tabular}




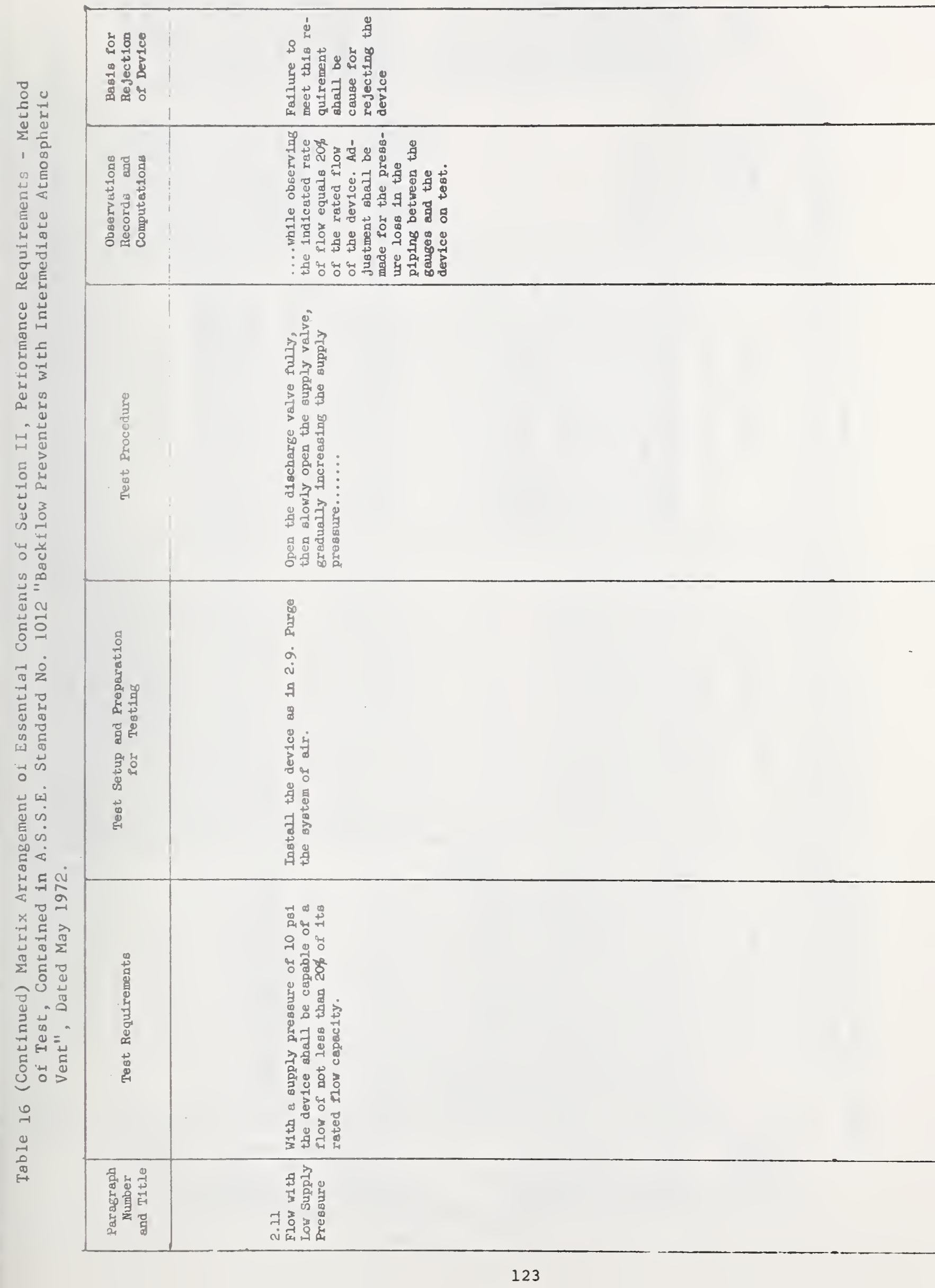




\begin{tabular}{|c|c|c|c|c|c|}
\hline \multirow{2}{*}{\multicolumn{2}{|c|}{ 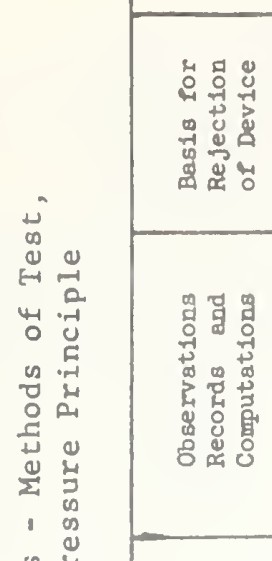 }} & \multicolumn{2}{|c|}{ 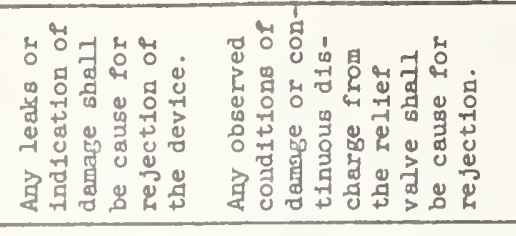 } & 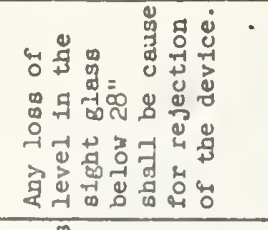 & 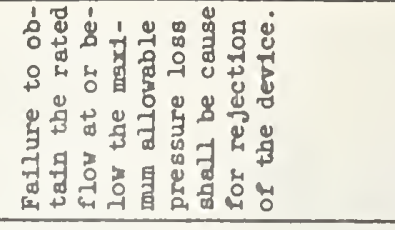 \\
\hline & & 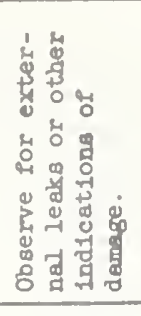 & & \multicolumn{2}{|c|}{ 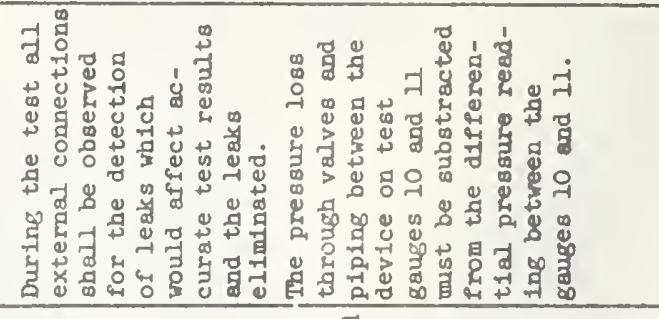 } \\
\hline 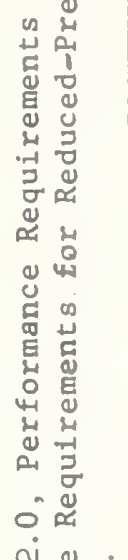 & 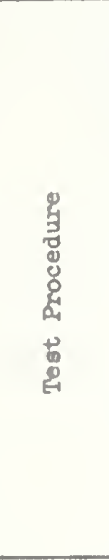 & 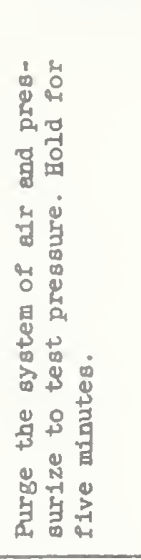 & 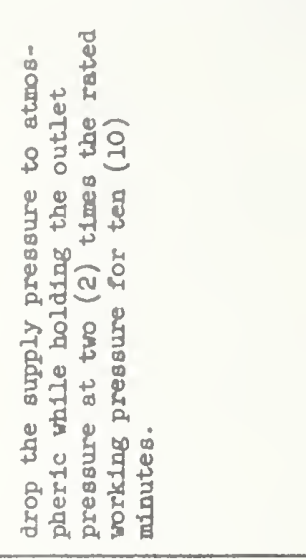 & 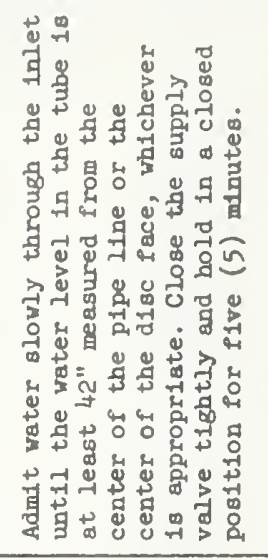 & 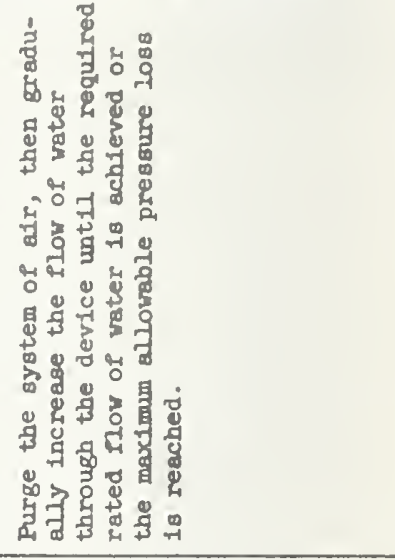 \\
\hline 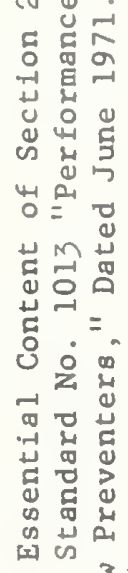 & 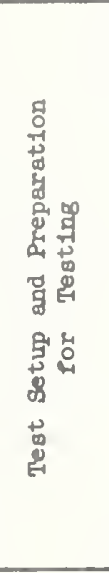 & 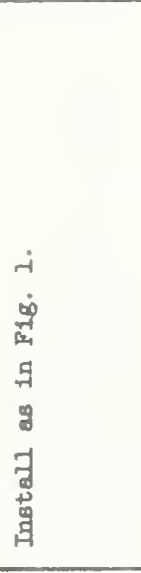 & 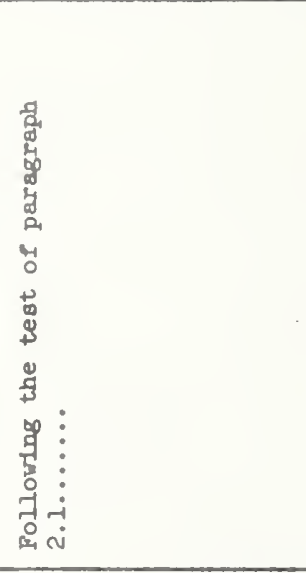 & 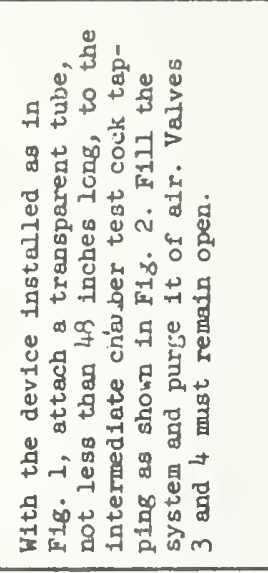 & 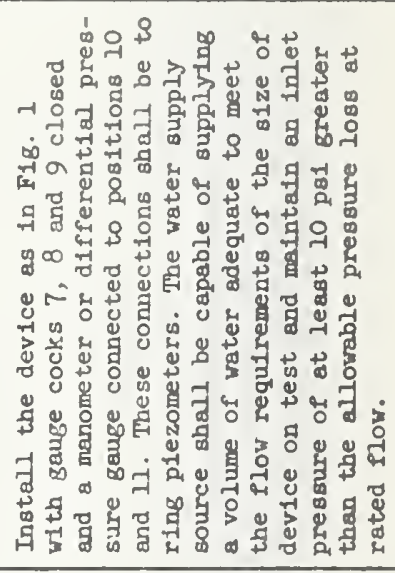 \\
\hline 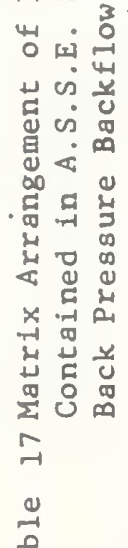 & 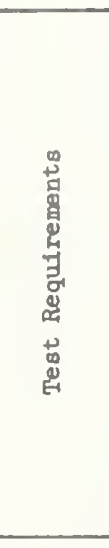 & 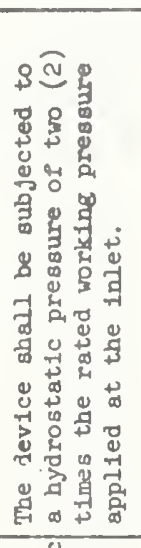 & 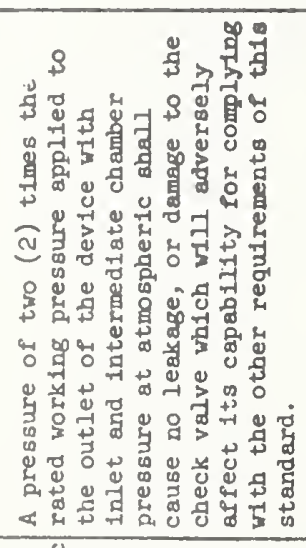 & 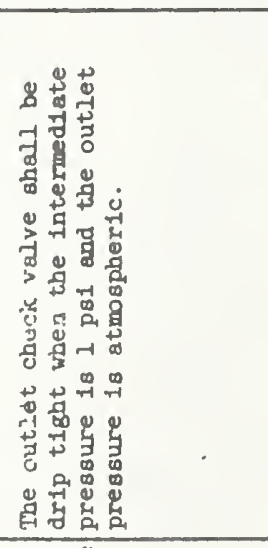 & 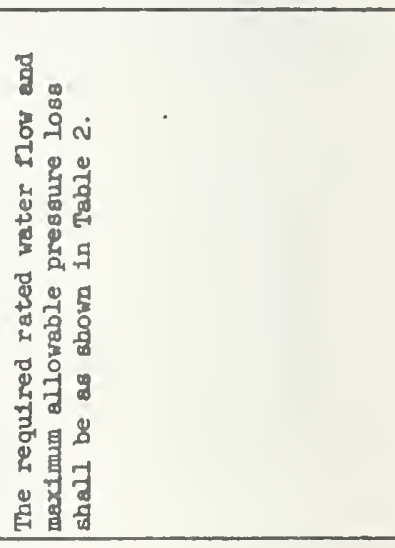 \\
\hline 吕 & 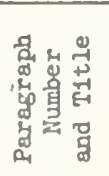 & 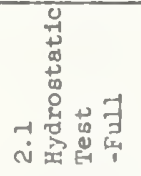 & 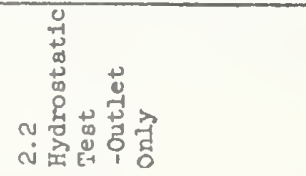 & 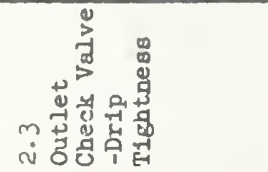 & 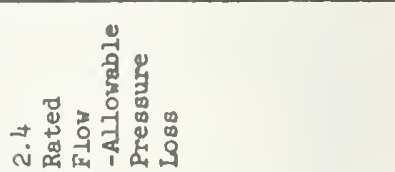 \\
\hline
\end{tabular}




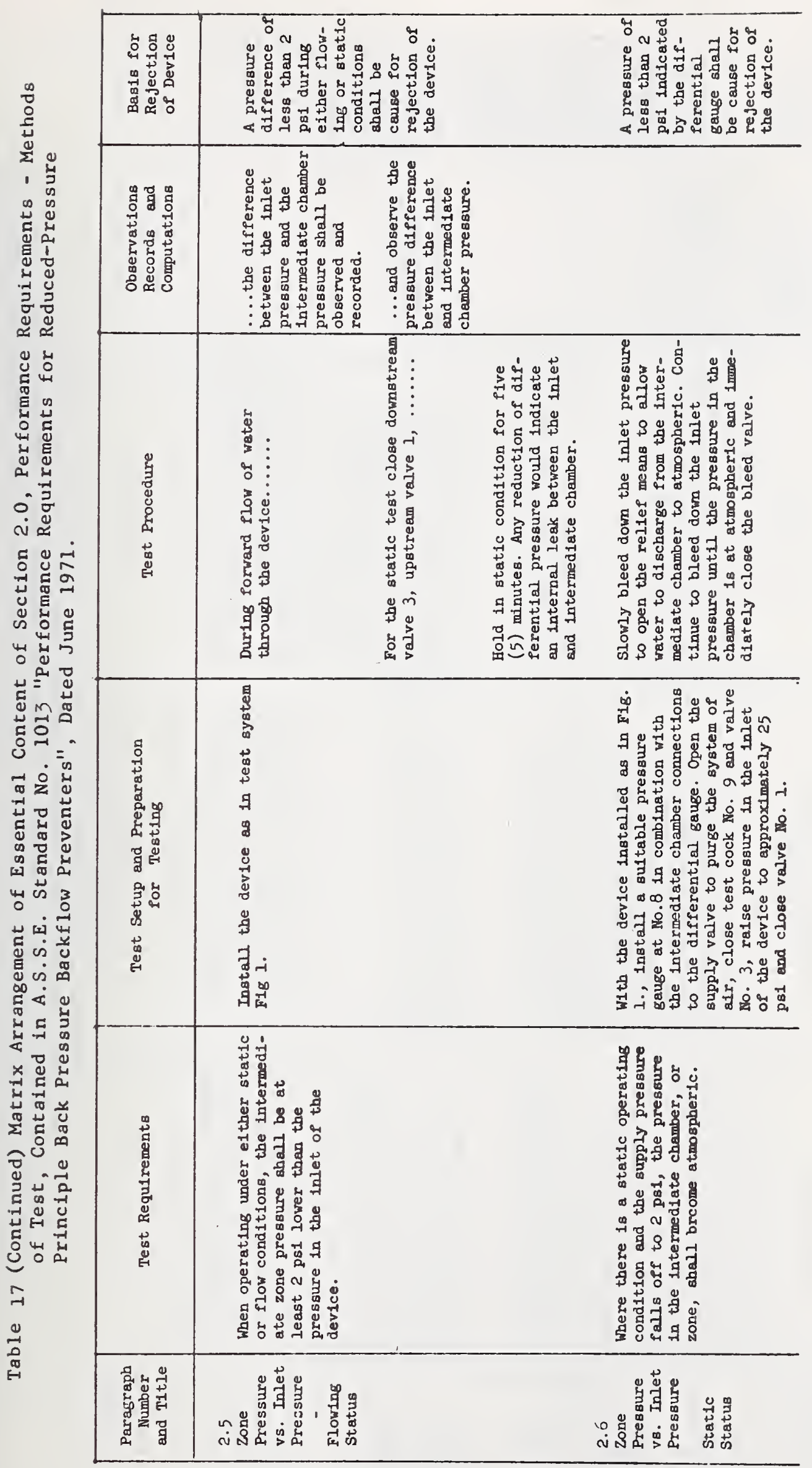




\begin{tabular}{|c|c|c|c|}
\hline 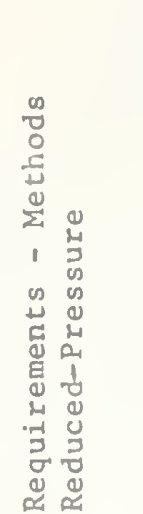 & 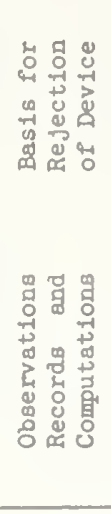 & 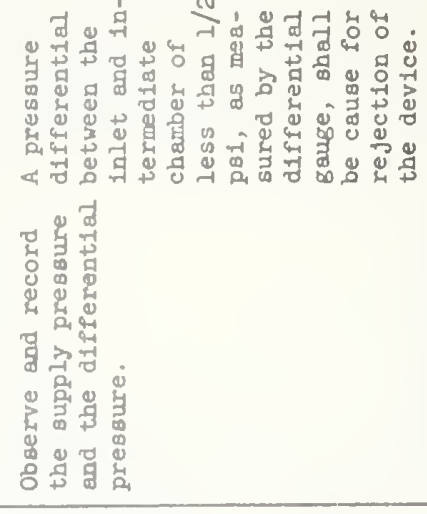 & 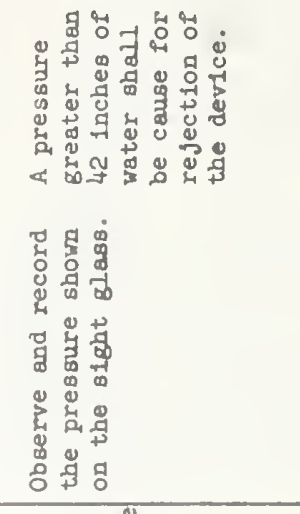 \\
\hline 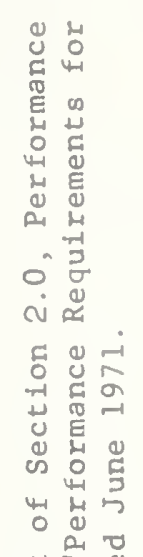 & 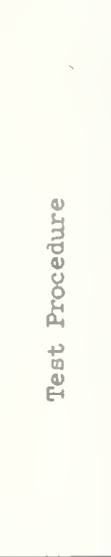 & 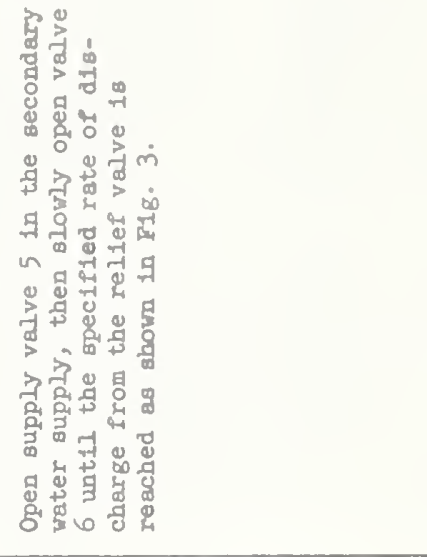 & 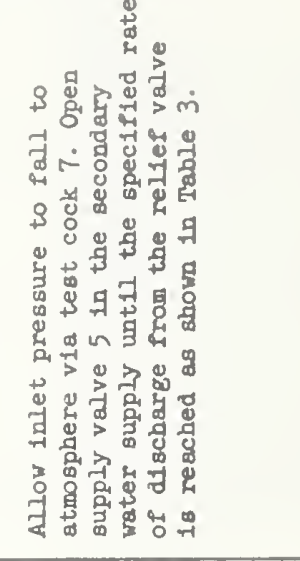 \\
\hline 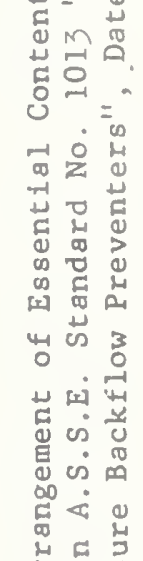 & 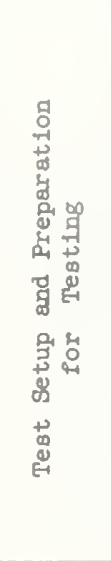 & 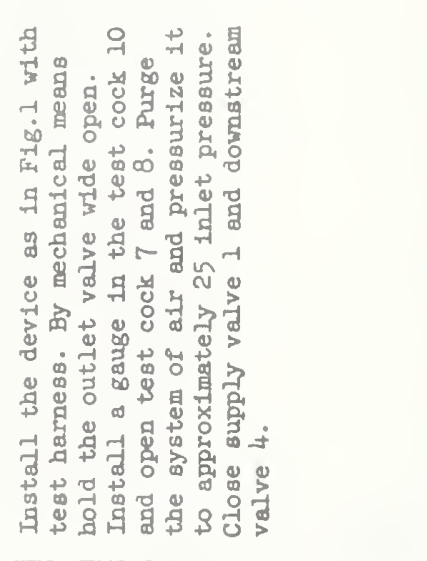 & 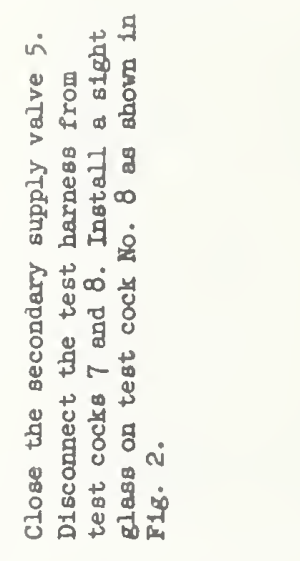 \\
\hline 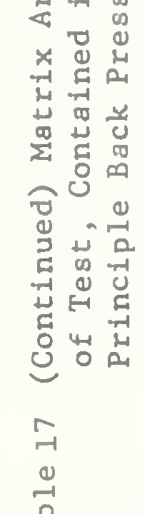 & 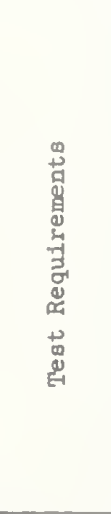 & 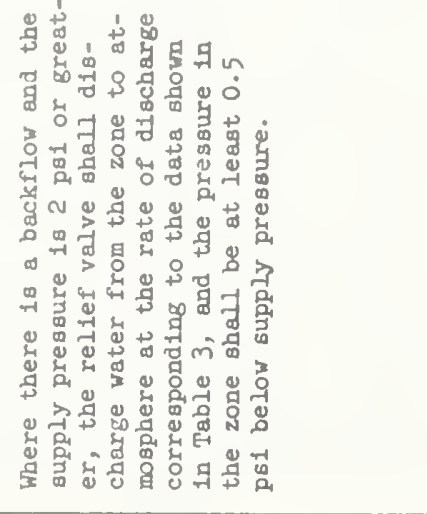 & 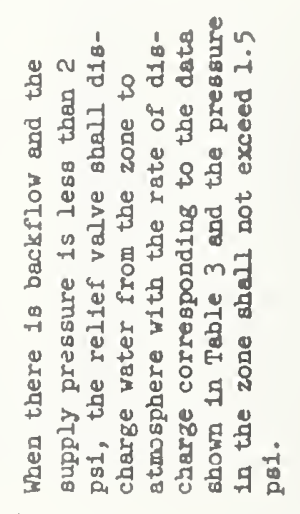 \\
\hline & 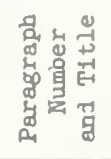 & 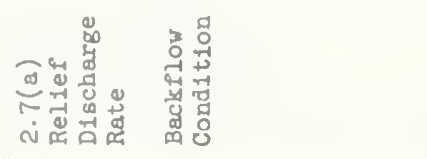 & 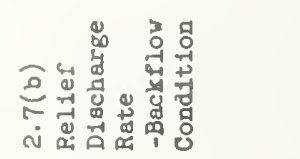 \\
\hline
\end{tabular}




\begin{tabular}{|c|c|c|}
\hline 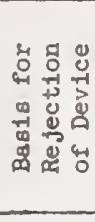 & 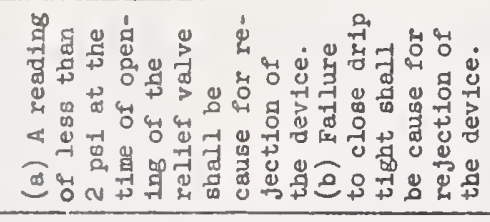 & 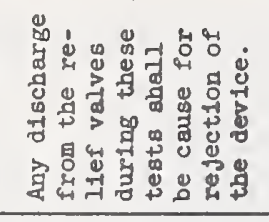 \\
\hline 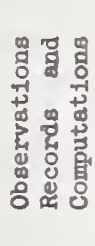 & & \\
\hline 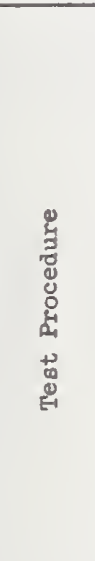 & 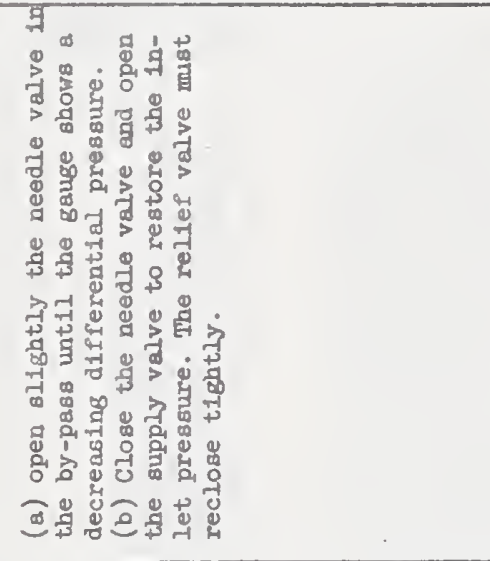 & 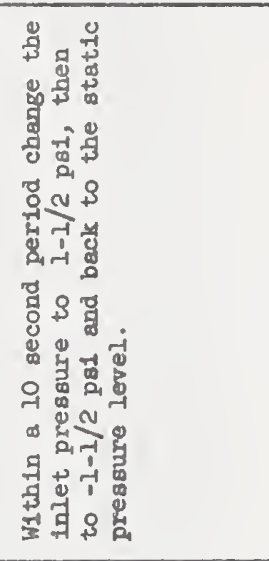 \\
\hline 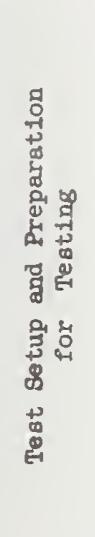 & 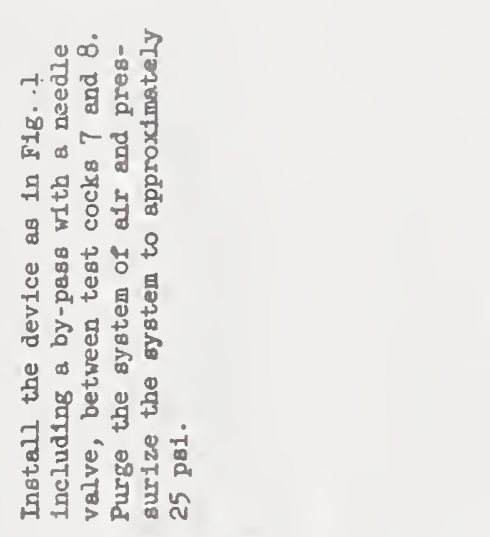 & 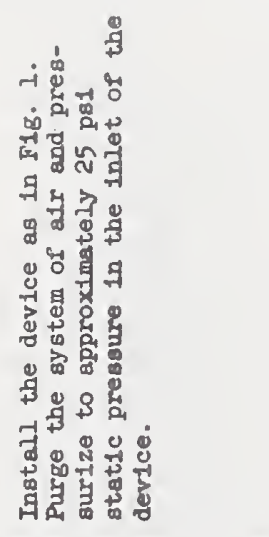 \\
\hline 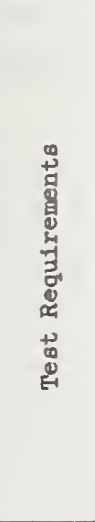 & 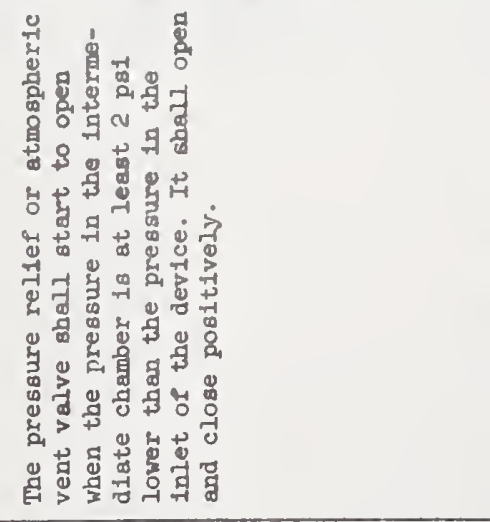 & 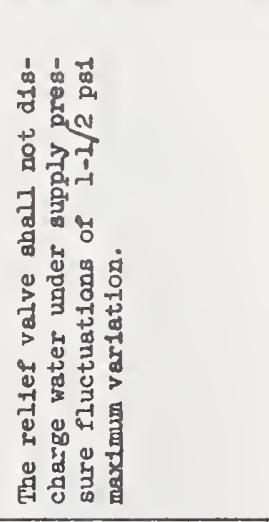 \\
\hline 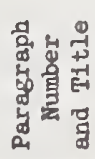 & 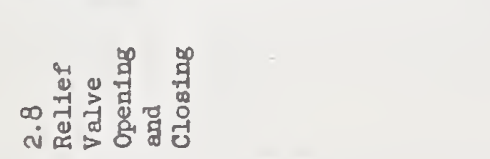 & 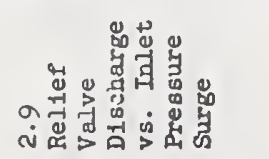 \\
\hline
\end{tabular}




\begin{tabular}{|c|c|c|c|c|}
\hline 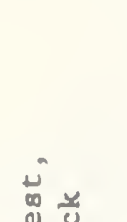 & 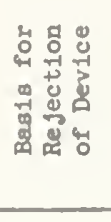 & 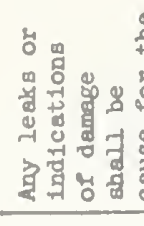 & & 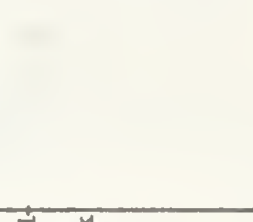 \\
\hline 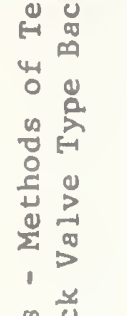 & 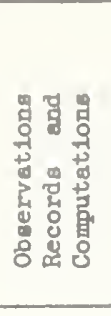 & 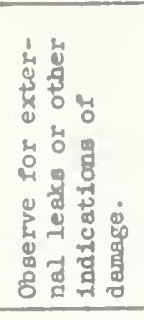 & 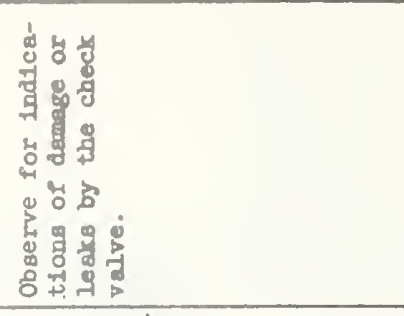 & 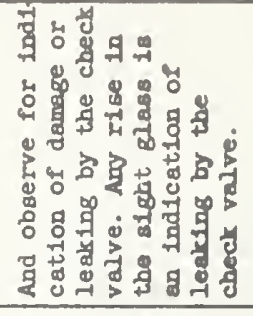 \\
\hline 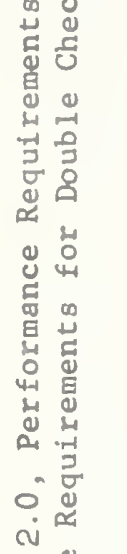 & 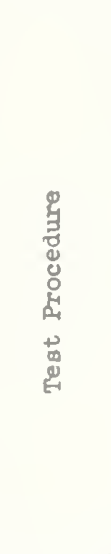 & 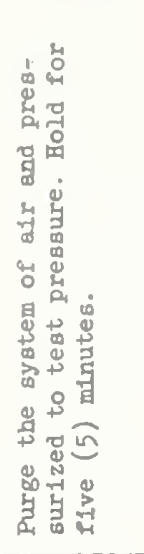 & 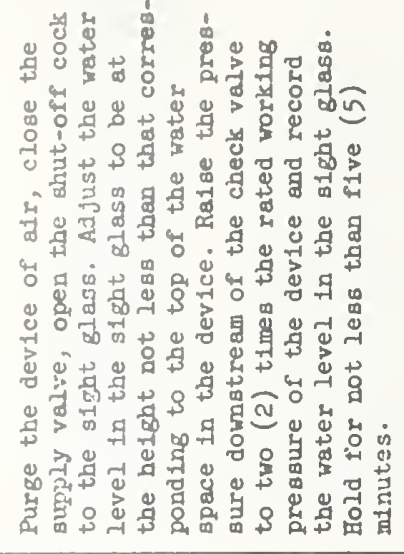 & 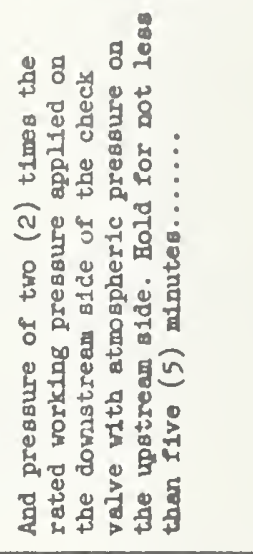 \\
\hline 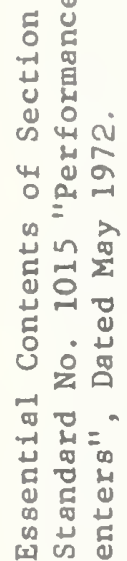 & 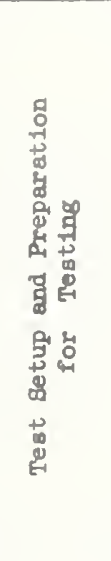 & 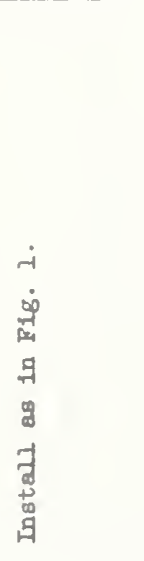 & 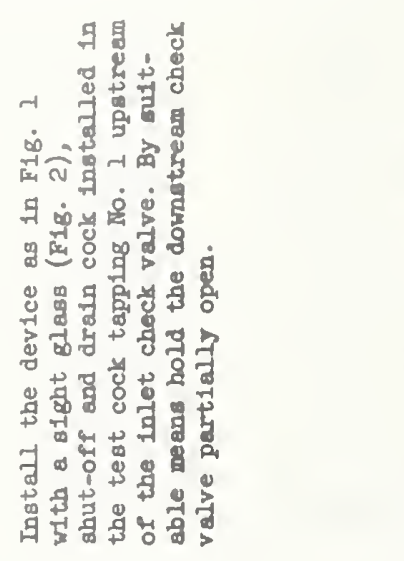 & 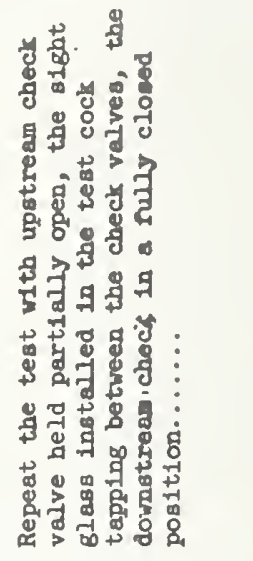 \\
\hline 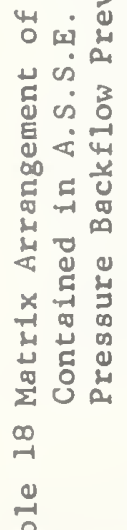 & 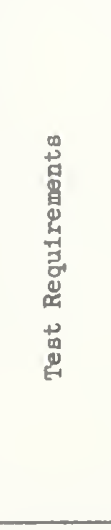 & 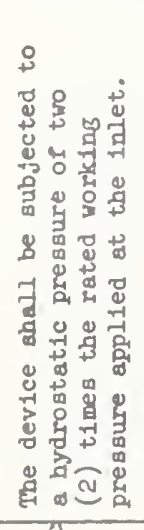 & 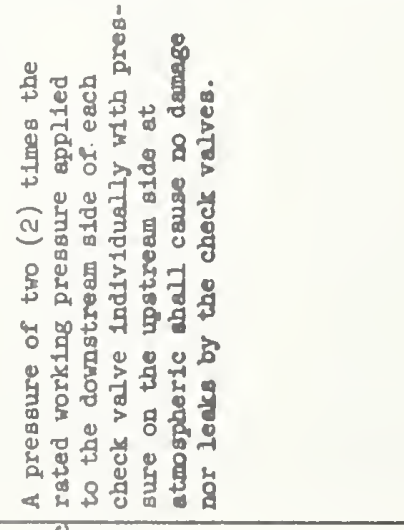 & \\
\hline ⿷匚 & 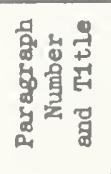 & 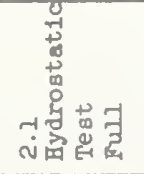 & 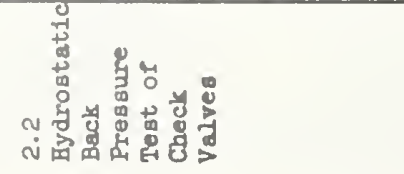 & \\
\hline
\end{tabular}




\begin{tabular}{|c|c|c|c|}
\hline 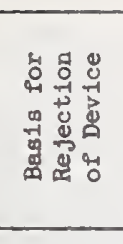 & 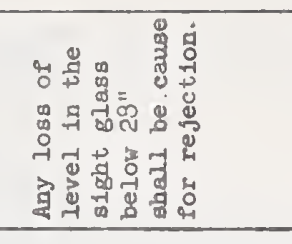 & 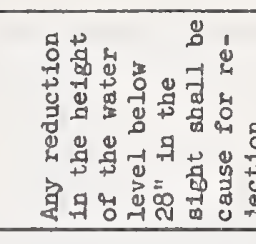 & 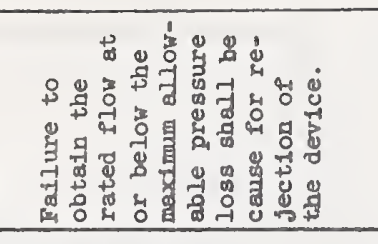 \\
\hline 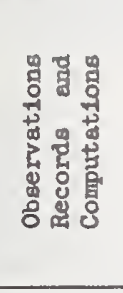 & & & 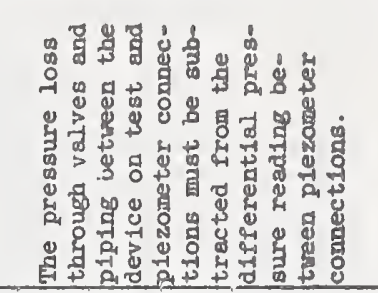 \\
\hline 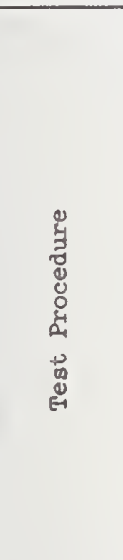 & 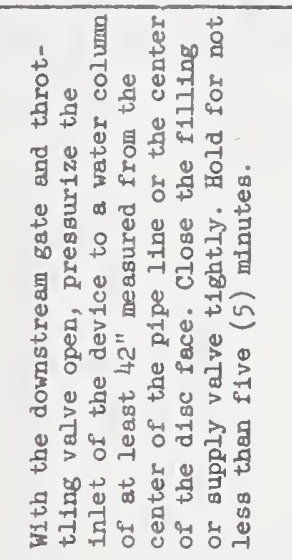 & 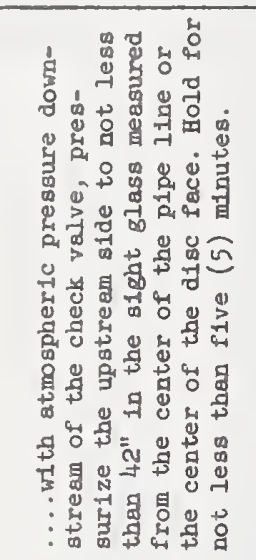 & 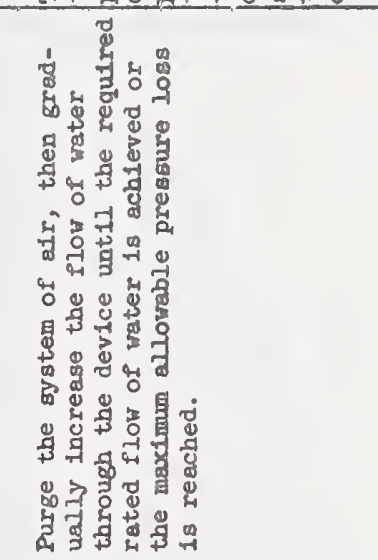 \\
\hline 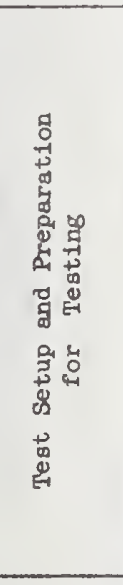 & 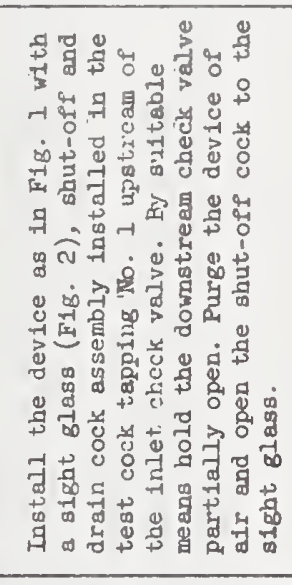 & 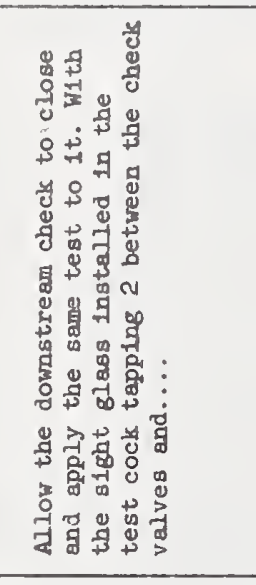 & 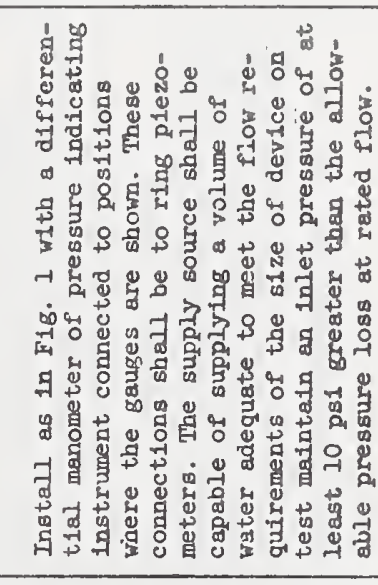 \\
\hline 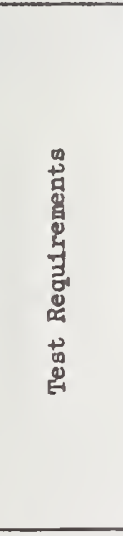 & 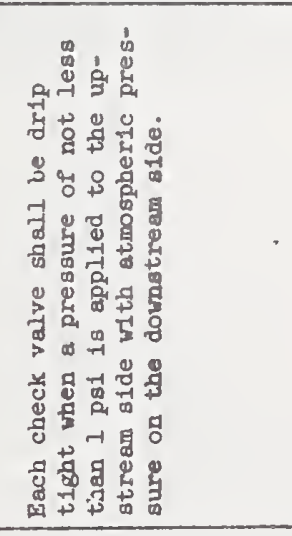 & & 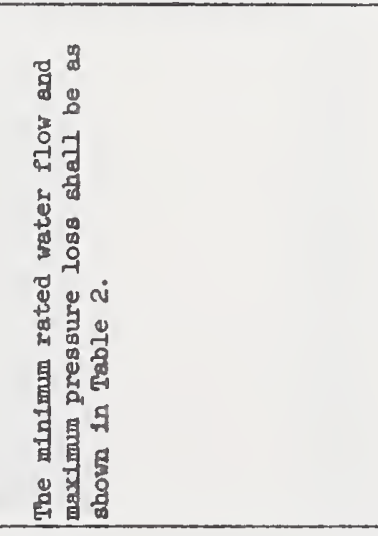 \\
\hline 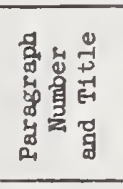 & 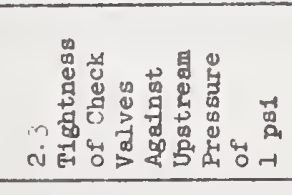 & & 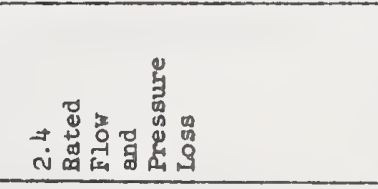 \\
\hline
\end{tabular}


票

(1)

บै

要

造

क्षे

ค.

०

$\dot{\alpha}^{5}$

도 웡

$-1$

U

4

虫

幽

동

ह

0 品

का

거농

造 8

๓

되 검

出这

븡

क

更

品

ट

म्र थ

य

$x$ 되 z

H

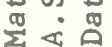

a

$\frac{0}{9}$

\begin{tabular}{|c|c|c|c|c|c|}
\hline 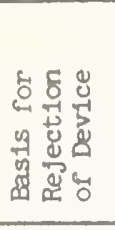 & 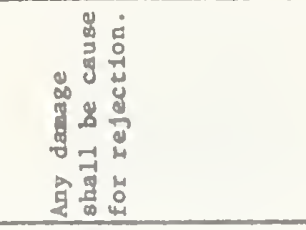 & & & & 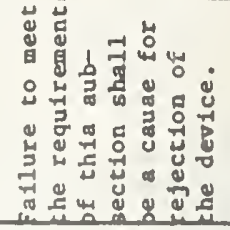 \\
\hline 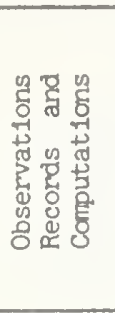 & 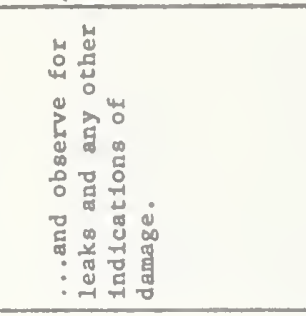 & 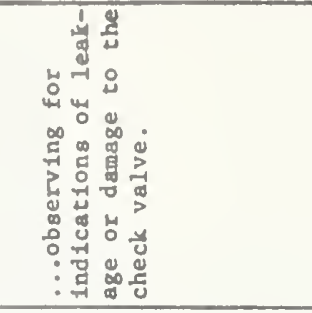 & 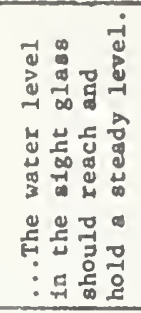 & & \\
\hline 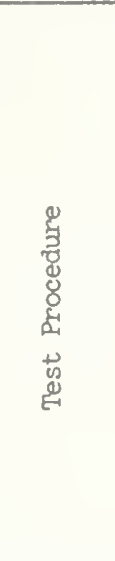 & 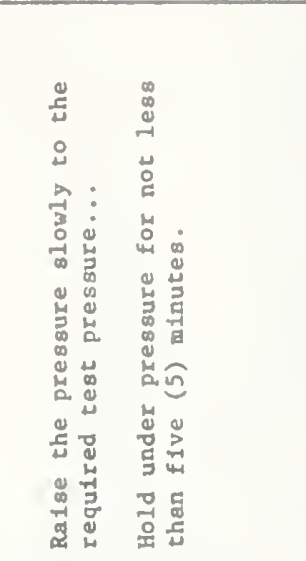 & 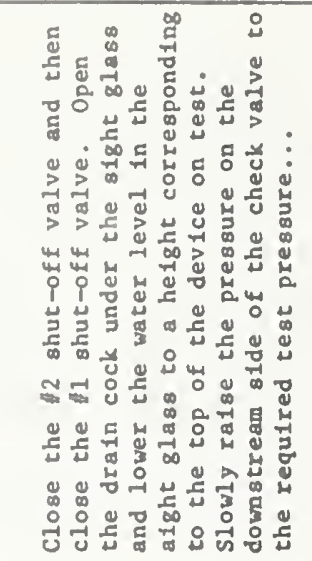 & 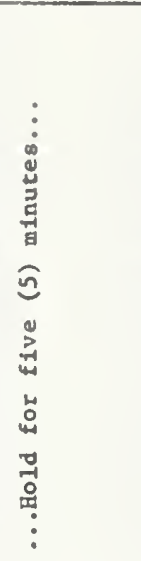 & 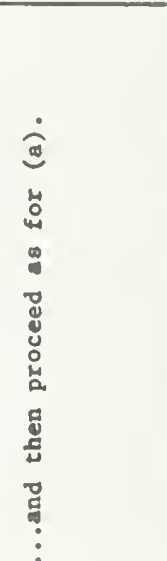 & 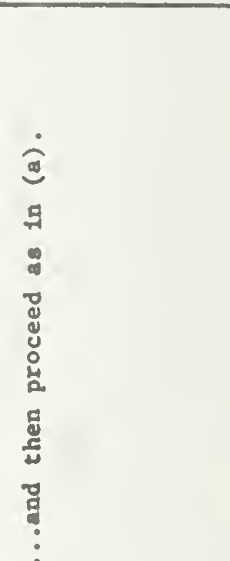 \\
\hline 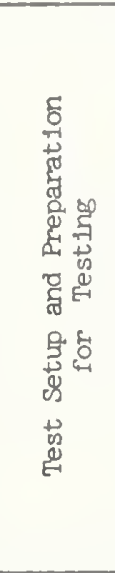 & 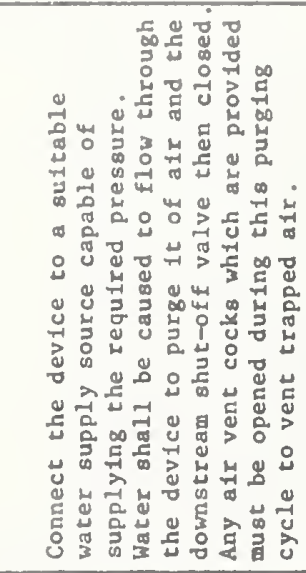 & 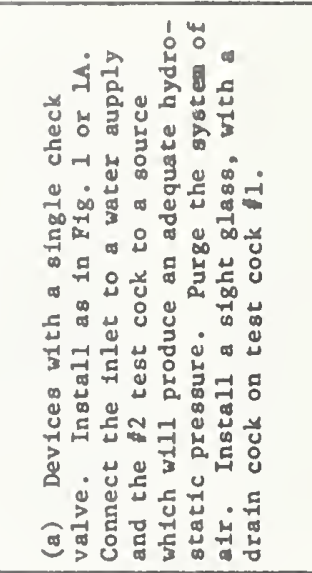 & & 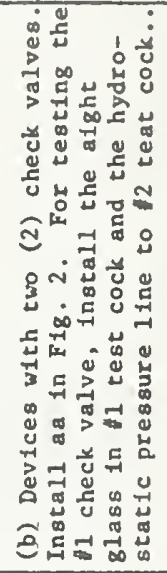 & 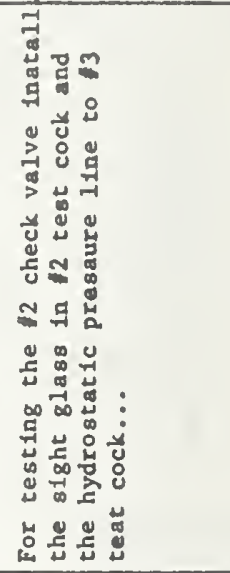 \\
\hline 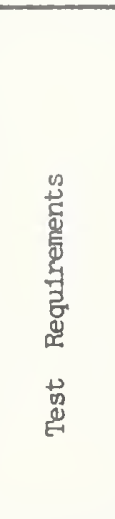 & 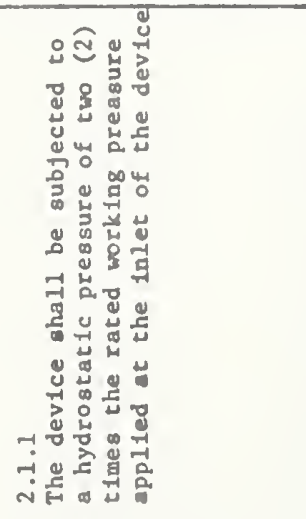 & 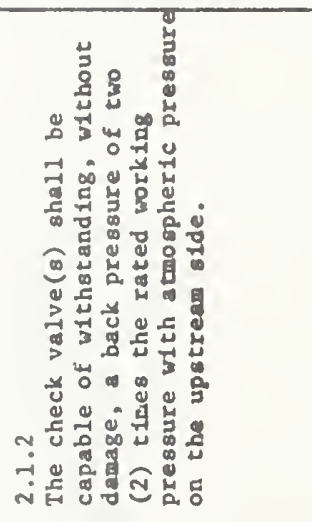 & & & \\
\hline 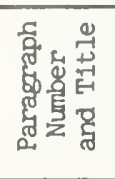 & 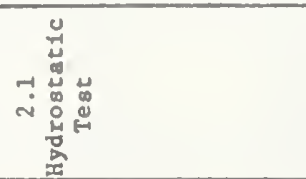 & & & & \\
\hline
\end{tabular}




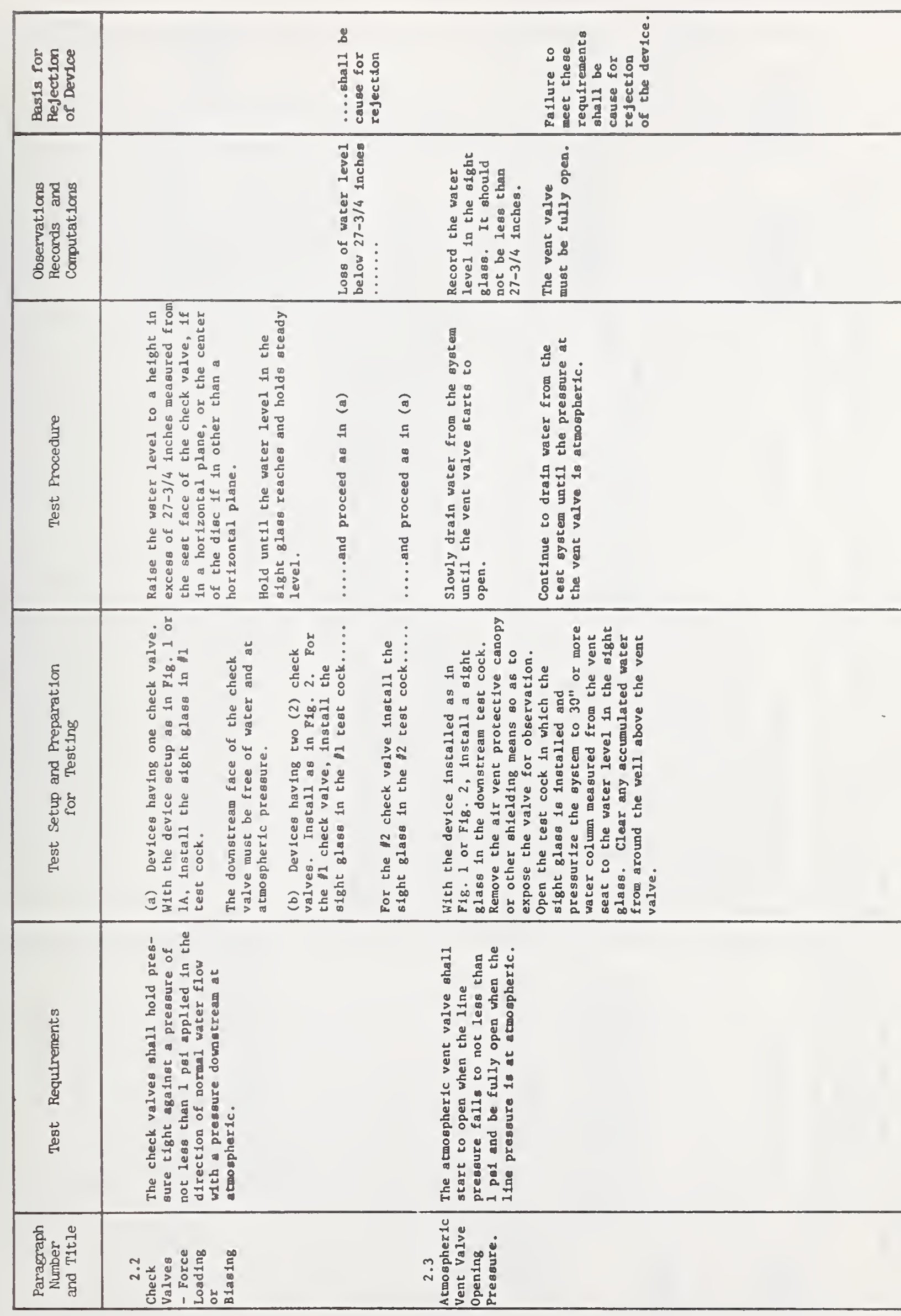




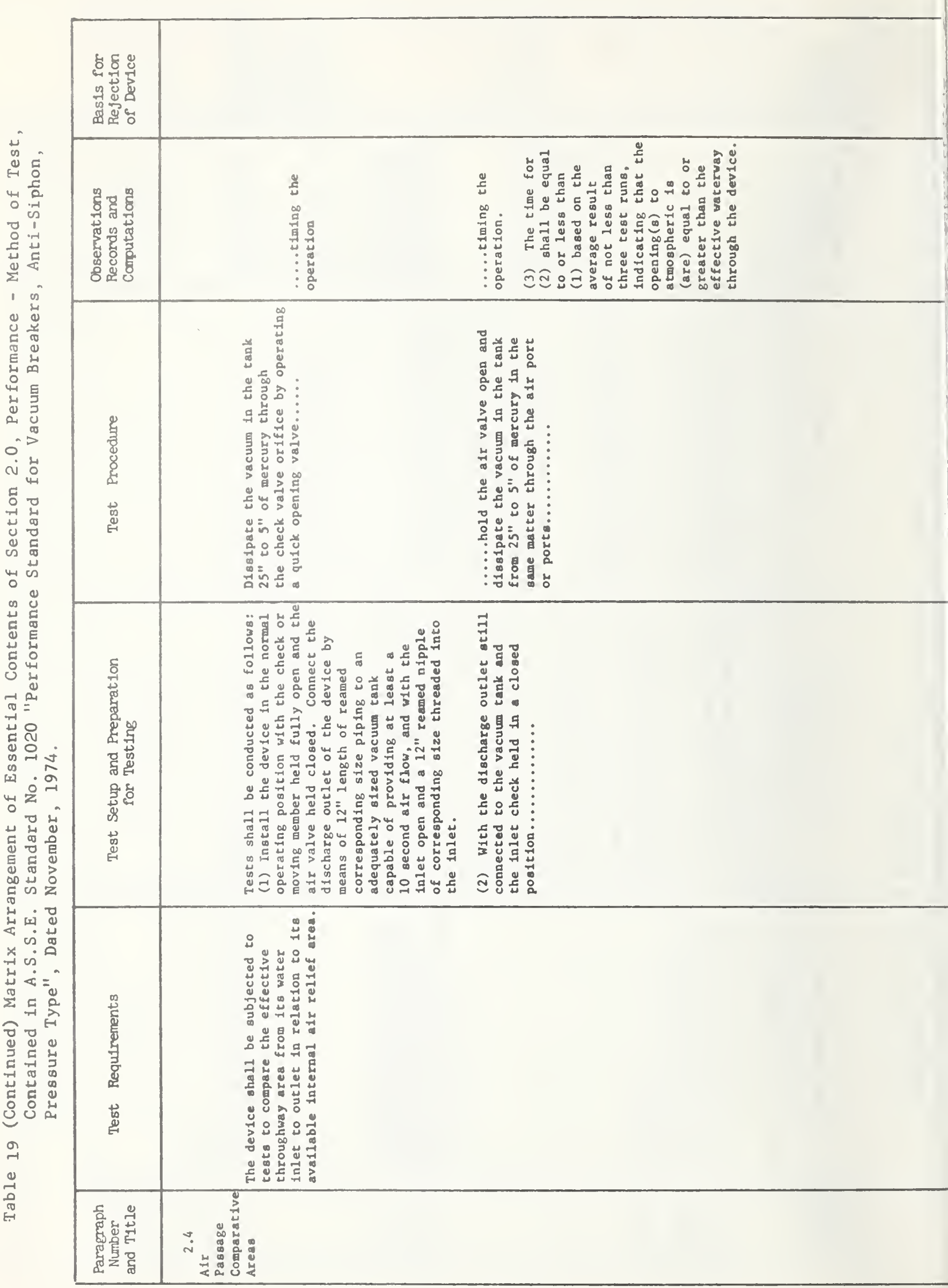




\begin{tabular}{|c|c|c|c|c|}
\hline 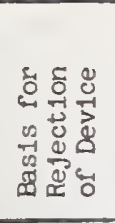 & 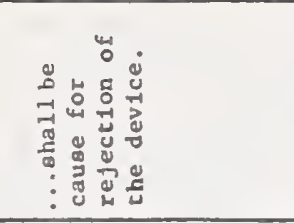 & & 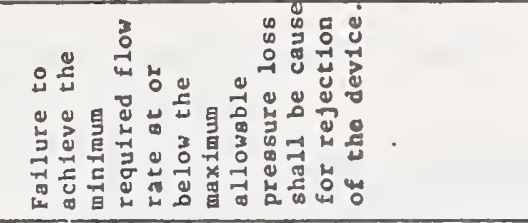 & \\
\hline 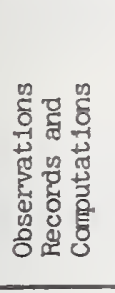 & 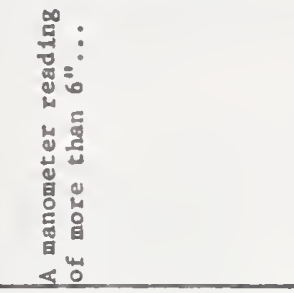 & & 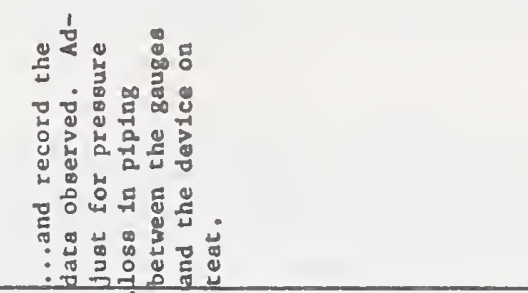 & \\
\hline 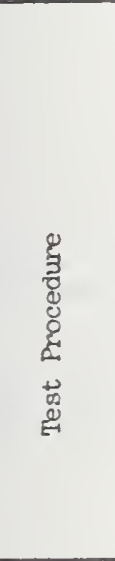 & 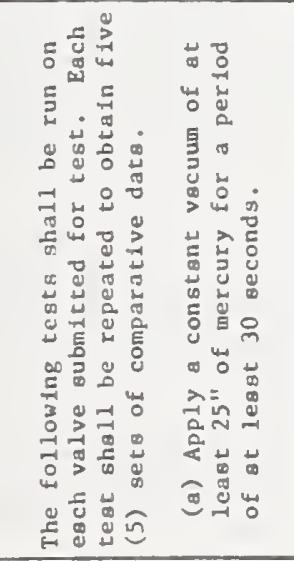 & 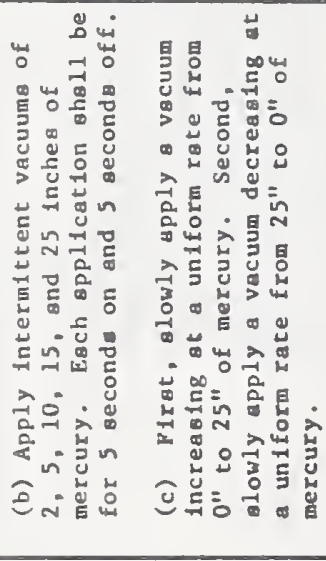 & 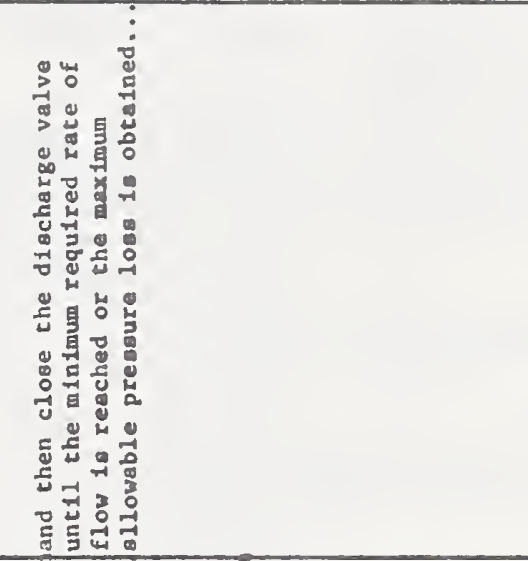 & \\
\hline 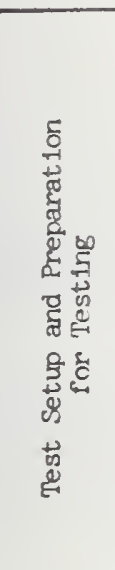 & 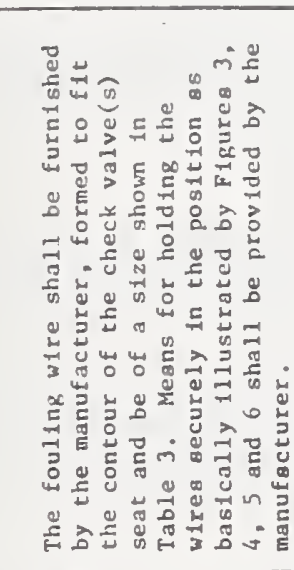 & 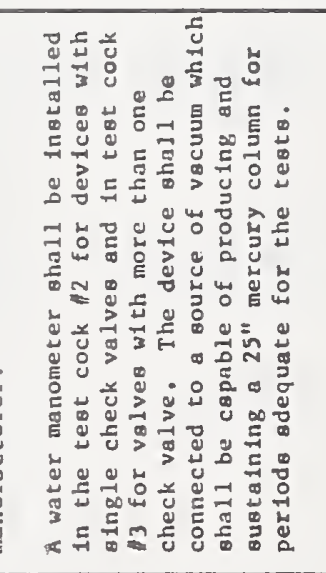 & 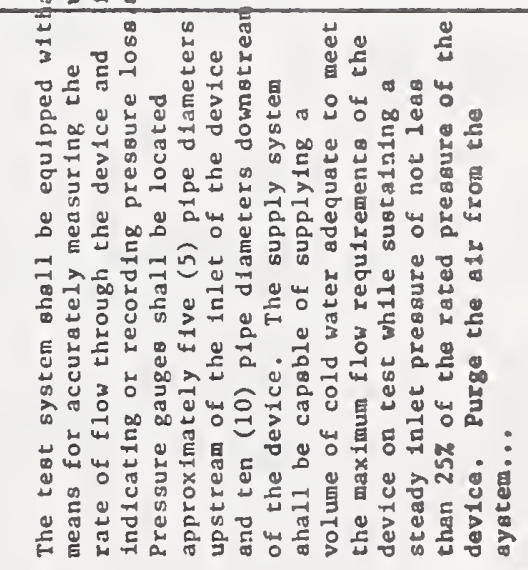 & \\
\hline 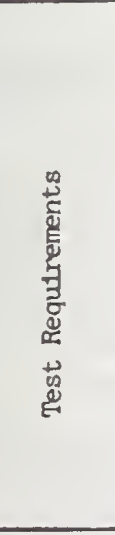 & 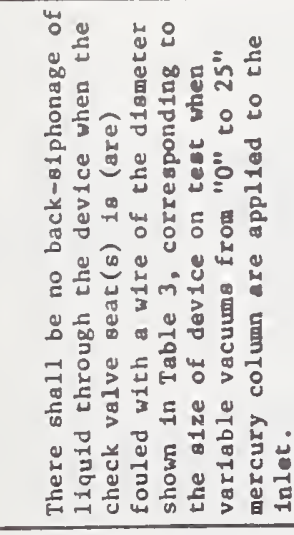 & & 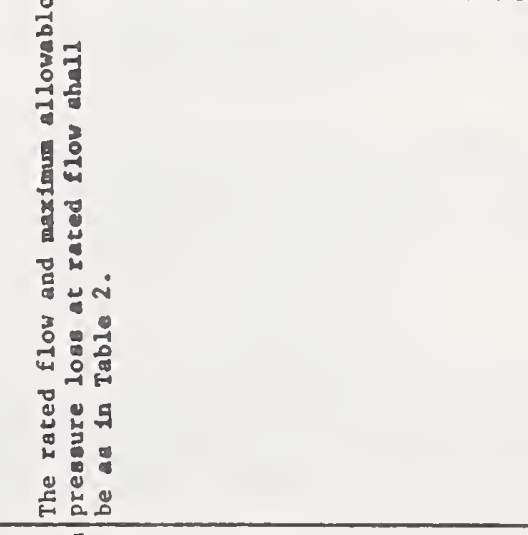 & \\
\hline 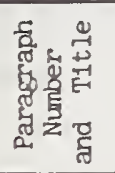 & 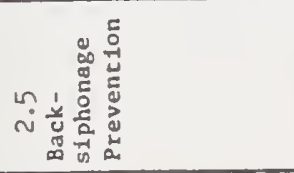 & & 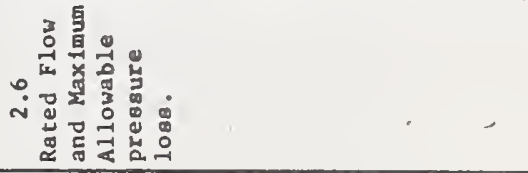 & \\
\hline
\end{tabular}


Table 20 Descriptive Cataloging of Five Backflow Prevention Devices Indexed to Comparable Paragraphs of the Respective A.S.S.E. Standards

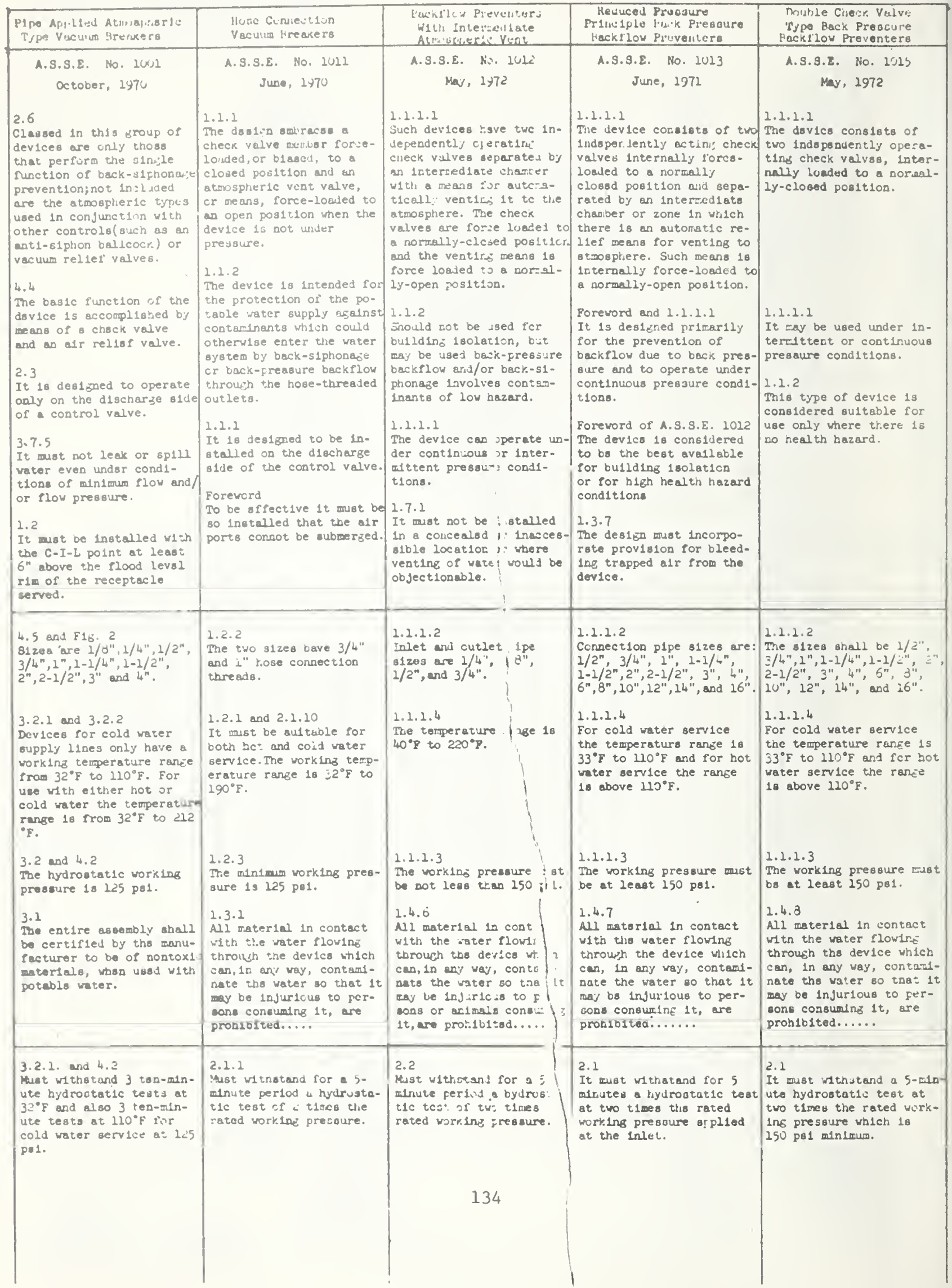


Table 20 Descriptive Cataloging of Five Backflow Prevention Devices Indexed to Comparable Paragraphs of the Respective A.S.S.E. Standards

\begin{tabular}{|c|c|c|c|c|}
\hline $\begin{array}{l}\text { Pije Applicil Atmicspheric } \\
\text { Tyje Vactum lienkcri }\end{array}$ & $\begin{array}{l}\text { llose Connection } \\
\text { Vucuum Bucotirs }\end{array}$ & 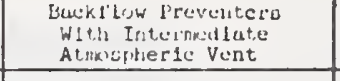 & 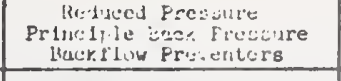 & 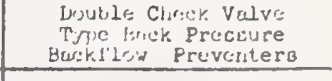 \\
\hline 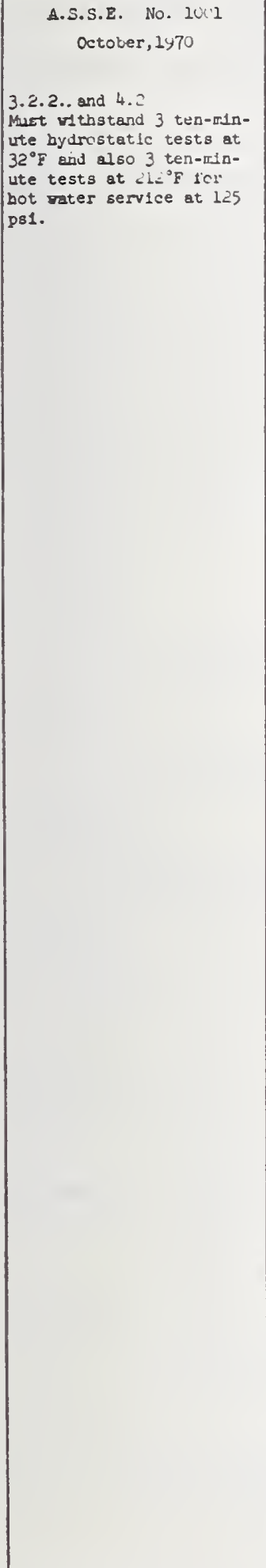 & 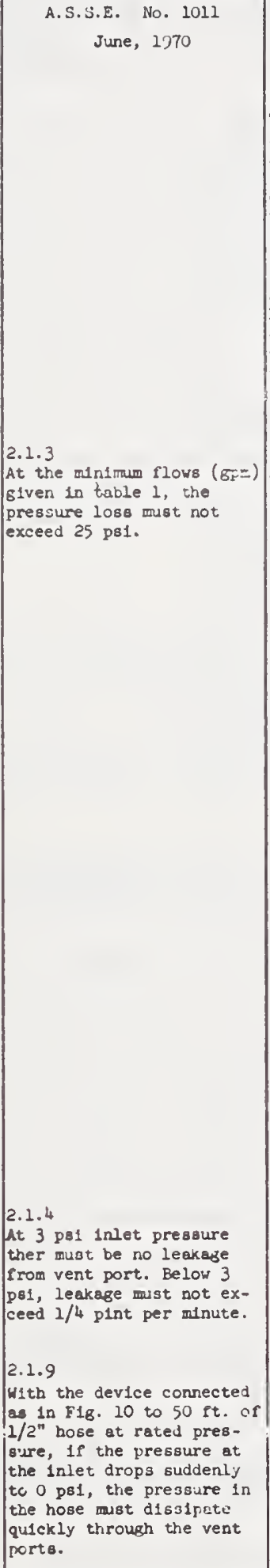 & 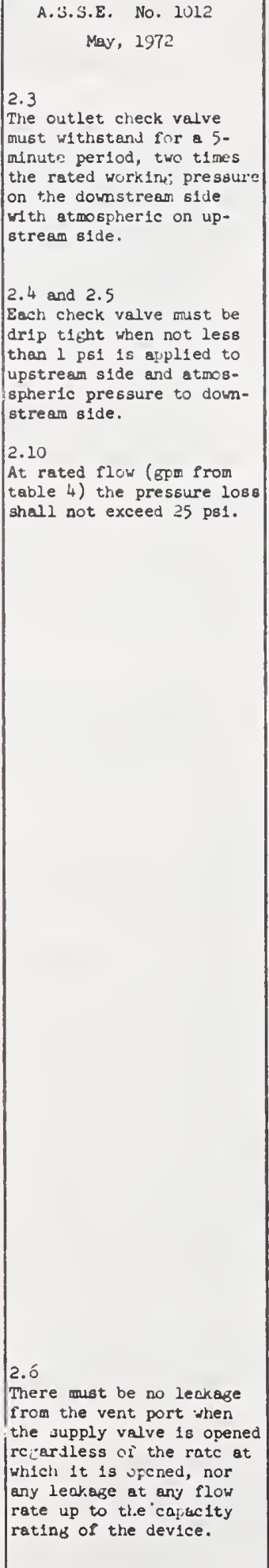 & 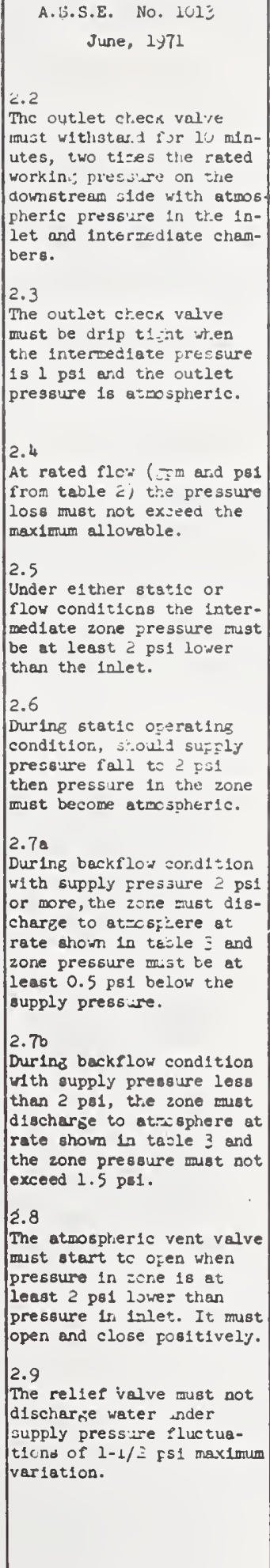 & 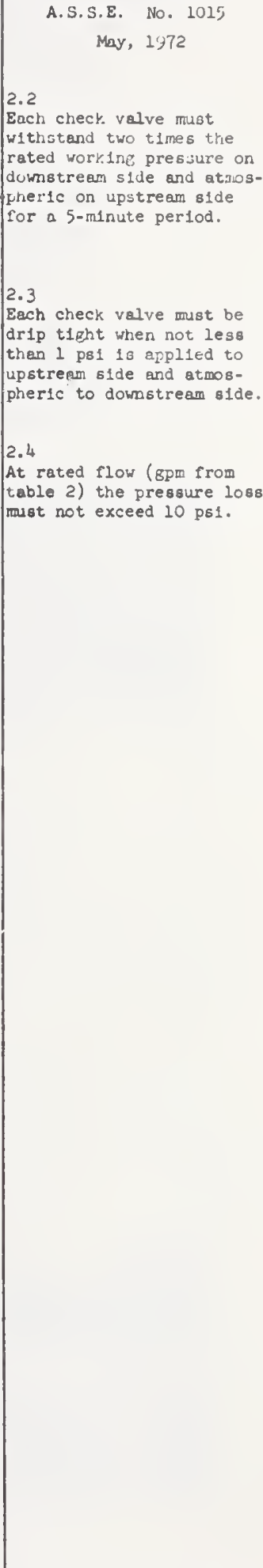 \\
\hline
\end{tabular}


Table 20 Descriptive Cataloging of Five Backflow Prevention Devices Indexed to Comparable Paragraphs of the Respective A.S.S.E. Standards

\begin{tabular}{|c|c|c|c|c|}
\hline $\begin{array}{l}\text { P1pe Applied Atmospheric } \\
\text { Type Vacisum brew.er:3 }\end{array}$ & $\begin{array}{l}\text { Hose Connection } \\
\text { Vusuum Breakers }\end{array}$ & $\begin{array}{l}\text { Buckilut Preventers } \\
\text { With Iftermediale } \\
\text { Atmosptiaric vent }\end{array}$ & 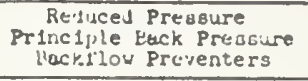 & $\begin{array}{l}\text { Doutle Check Valve } \\
\text { Type Esck. Preijure } \\
\text { Rackflow Preventero }\end{array}$ \\
\hline 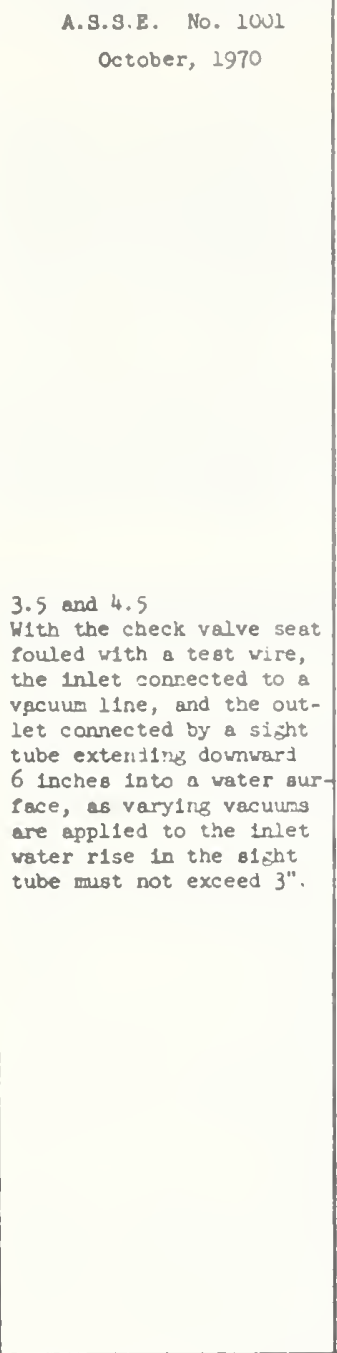 & 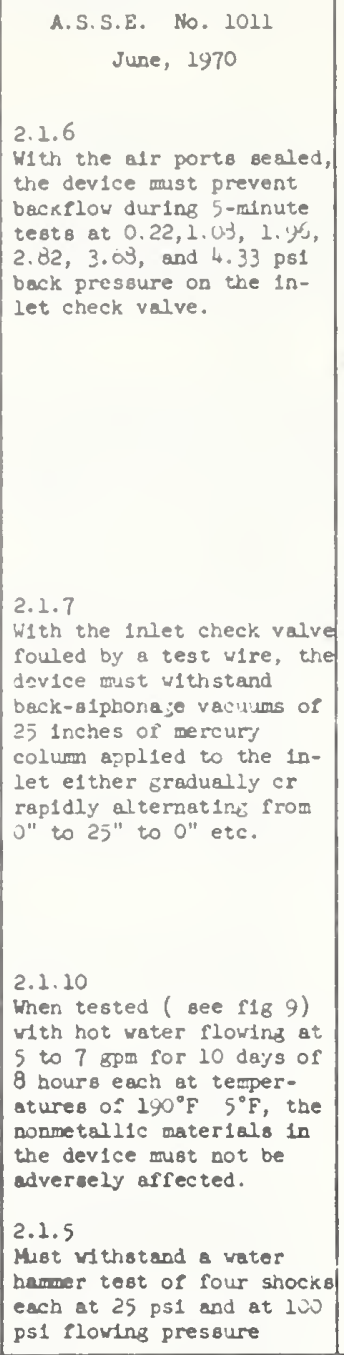 & 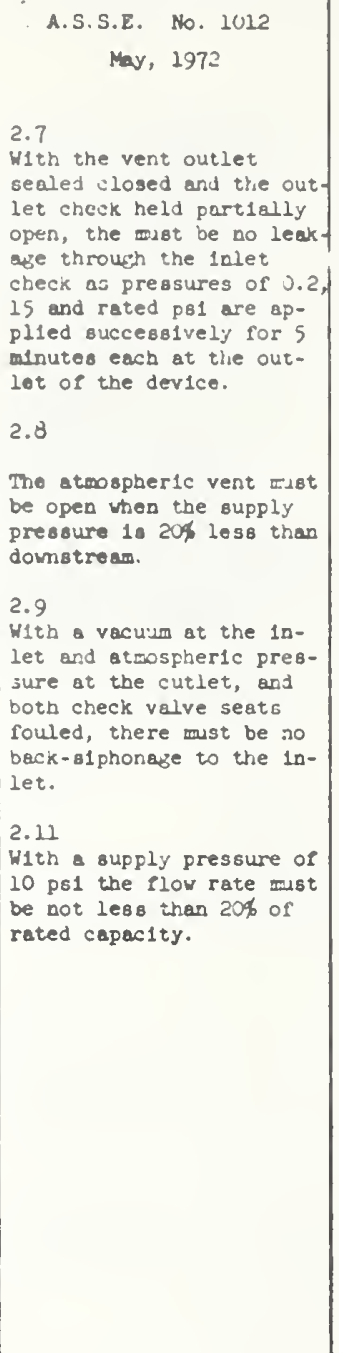 & $\begin{array}{l}\text { A.S.S.E. No. } 1013 \\
\text { June, } 1971\end{array}$ & $\begin{array}{c}\text { A.S.E.E. No. LU15 } \\
\text { May, } 1972\end{array}$ \\
\hline 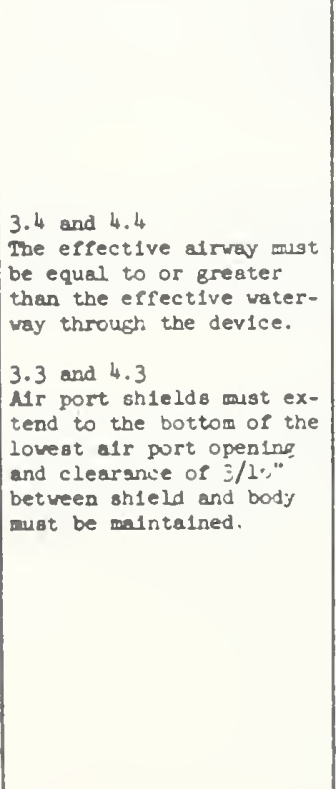 & 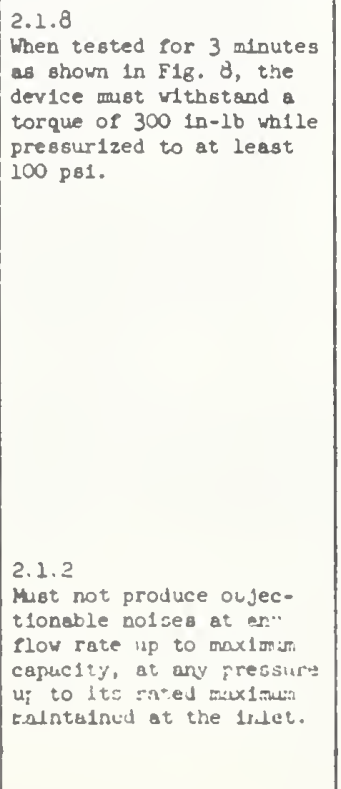 & 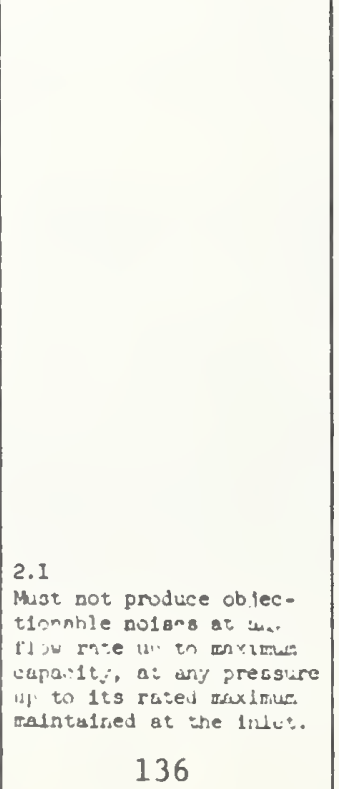 & & \\
\hline
\end{tabular}


10.7 Units of Measure and S. I. Conversion Factors

In NBS Document LC 1056, revised August 1975, guidelines were established to reaffirm and strengthen the commitment of NBS to the greatest practicable use of the International System of Units (S. I.) in all of its publications and also in all of its dealings with the science and engineering communities and with the public. In this report the measurements are those of the U.S. Customary units as they appear in the referenced standards, in order that the readers may give full attention to discussions and the compilation of data in this state-of-the-art report on backflow preventers. Notwithstanding the immediate objectives of this report, subsequent actions leading to the updating of backflow preventer standards should establish the metric system to the fullest extent possible.

The following conversion factors are appropriate for the units of measure that appear in this report:

Length -

1 inch (in) $=0.0254$ meter (m)

1 foot (ft) $=0.3048$ meter (m)

Mass -

1 pound-mass $(1 \mathrm{bm})=.4535924$ kilogram

Temperature -

1 Degree Fahrenheit $\left({ }^{\circ} \mathrm{F}\right)=(1.8)^{-1} \operatorname{kelvin}(\mathrm{K})$ or $\left({ }^{\circ} \mathrm{K}\right)$

Temperature Fahrenheit $\left({ }^{\circ} \mathrm{F}\right)=\left(459.67+\right.$ temp. $\left.{ }^{\circ} \mathrm{F}\right) / 1.8$ kelvins $(\mathrm{K})$

Time -

1 hour $(h)=60$ minutes $($ min $)=3600$ seconds $(s)$

Velocity -

1 foot per second $(\mathrm{fps})=0.3048$ meter per second $(\mathrm{m} / \mathrm{s})$

Force -

1 pound-force $(1 \mathrm{bf})=4.448222$ newtons $(\mathrm{N})$

Pressure -

1 pound-force per square inch $(p s i)=6894.757$ pascals $(\mathrm{Pa})$ 6.894757 kilopascals ( $\mathrm{kPa}$ )

1 inch of water column at $60^{\circ} \mathrm{F}=248.84$ pascals $(\mathrm{Pa})$

Volume - 1 U.S. liquid gallon (ga1) $=0.003785412$ meter $^{3}\left(\mathrm{~m}^{3}\right)$

$=3.785412$ liters ( 1 )

Flow Rate -

1 U.S. gallon per minute $(\mathrm{gpm})=0.0000630902$ meters $3 /$ second

$=63.0902$ centimeters $3 /$ second $\left(\mathrm{cm}^{3} / \mathrm{s}\right)$

$=0.0630902$ liters $/$ second $(1 / \mathrm{s})$ 


\begin{tabular}{|c|c|c|c|}
\hline $\begin{array}{l}\text { U.S. DEPT. OF COMM. } \\
\text { BIBLIOGRAPHIC DATA } \\
\text { SHEET }\end{array}$ & $\begin{array}{l}\text { 1. PUBLICATION OR REPORT NO. } \\
\text { NBSIR } 76-1070\end{array}$ & $\begin{array}{l}\text { 2. Gov't Accession } \\
\text { No. }\end{array}$ & 3. Recipient's Accession No. \\
\hline \multirow{2}{*}{\multicolumn{3}{|c|}{$\begin{array}{l}\text { 4. TITLE AND SUBTITLE } \\
\qquad \begin{array}{l}\text { Evaluation of Backflow Prevention Devices: } \\
\text { A State-of-the-Art Report }\end{array}\end{array}$}} & $\begin{array}{l}\text { 5. Publication Date } \\
\text { November } 1976\end{array}$ \\
\hline & & & 6. Performing Organization Code \\
\hline \multicolumn{3}{|c|}{$\begin{array}{l}\text { 7. AUTHOR(S) } \\
\text { Grover C. Sherlin and Robert W. Beausollel }\end{array}$} & 8. Performing Otgan. Report No. \\
\hline \multicolumn{3}{|c|}{$\begin{array}{l}\text { 9. PERFORMING ORGANIZATION NAME AND ADDRESS } \\
\text { NATIONAL BUREAU OF STANDARDS } \\
\text { DEPARTMENT OF COMMERCE } \\
\text { WASHINGTON, D.C. } 20234\end{array}$} & $\begin{array}{l}\text { 10. Project/Task/Work Unit No. } \\
4624190 \\
\text { 11. Contract/Grant No. } \\
\text { EPA-IAG-0170 } \\
\text { (D)A }\end{array}$ \\
\hline \multirow{2}{*}{\multicolumn{3}{|c|}{$\begin{array}{l}\text { 12. Sponsoring Otganization Name and Complete Address (Street, City, State, ZIP) } \\
\text { Environmental Protection Agency } \\
\text { Water Supply Division } \\
\text { Washington, D.C. } 20460\end{array}$}} & $\begin{array}{l}\text { 13. Type of Report \& Period } \\
\text { Covered } \\
\text { Final }\end{array}$ \\
\hline & & & 14. Sponsoring Agency Code \\
\hline
\end{tabular}

\section{SUPPLEMENTARY NOTES}

16. ABSTRACT (A 200 word or less factual summary of most significant infomation. If document includes a significant bibliography or literature survey, mention it here.)

A significant potential for potable water supply contamination exists within all water supply systems due to backflow and cross connections. Survelllance of the water supplies to protect from such hazards requires continuing vigilance by the administrators of cross-connection control programs, and continuing upgrading of technical criteria and methods of evaluation.

The Environmental Protection Agency assists local (usually municipal) authorities, through the State water supply agency, in establishing and operating cross-connection control programs. Essential to these programs are (1) information on the suitability of commercially available devices for use in potentially high-hazard locations, and (2) practical and effective standardized test methods for evaluation of devices. The National Bureau of Standards investigation reported herein addresses the two needs identified.

This study includes a systematic review of the 11terature, together with consultations and visits with water purveyors, plumbing officlals, laboratory officlals and researchers in this field. Emphasis has been placed on those devices, test methods, and laboratory practices considered most essent1al to an effective assessment of the stateof-the-art. Also, test development needs were identified in a few areas of greatest concern.

17. KEY WORDS (six to twelve entries; alphabetical order; capitalize only the first letter of the first key word unless a proper name; separated by semicolons)

Backflow; backflow preventers; back pressure; back-siphonage; cross connections; health hazard; potable water; vacuum breaker; water supply.

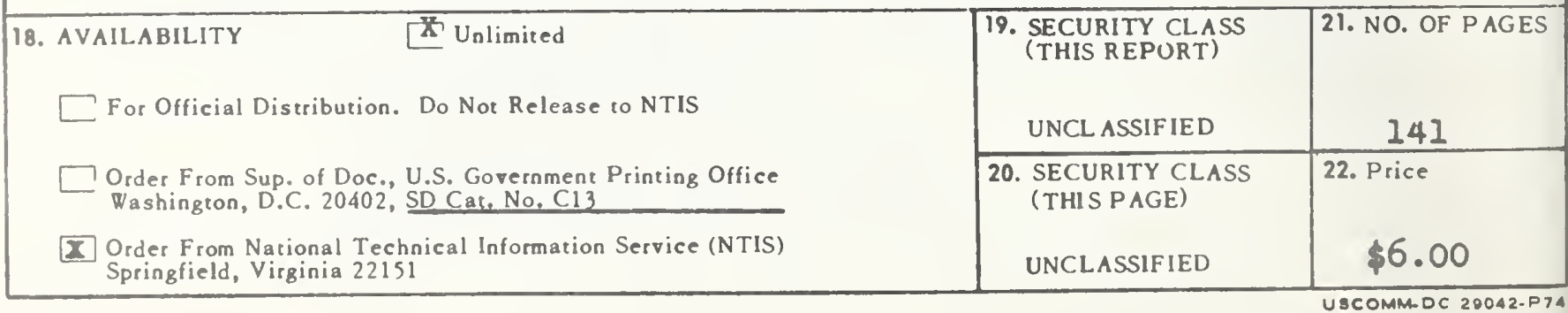


